\title{
Onkologie für die Palliativmedizin
}

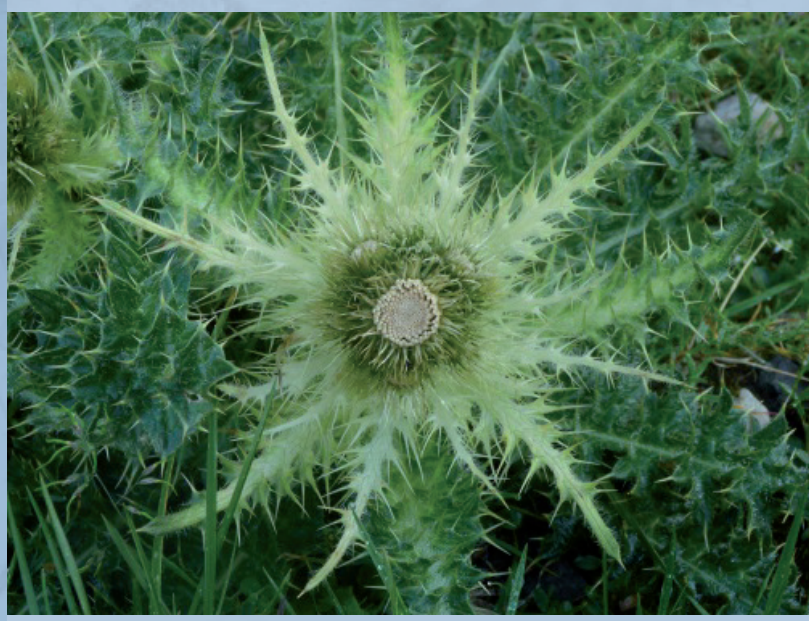

herausgegeben von

Bernd Alt-Epping Stefan Fuxius Ulrich Wedding

AG Interdisziplinäre Onkologie der Deutschen Gesellschaft für Palliativmedizin DEUTSCHE GESELLSCHAFT FÜR PALLIATIVMEDIZIN 

Bernd Alt-Epping, Stefan Fuxius, Ulrich Wedding (Hg.)

Onkologie für die Palliativmedizin

Dieses Werk ist lizenziert unter einer

Creative Commons

Namensnennung - Weitergabe unter gleichen Bedingungen

4.0 International Lizenz.

(c) (1) (2) 
erschienen im Universitätsverlag Göttingen 2015 


\section{Onkologie für die Palliativmedizin}

Herausgegeben von

Bernd Alt-Epping

Stefan Fuxius

Ulrich Wedding

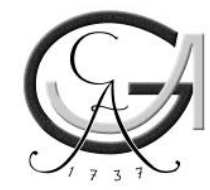

Universitätsverlag Göttingen 2015 
Bibliographische Information der Deutschen Nationalbibliothek

Die Deutsche Nationalbibliothek verzeichnet diese Publikation in der Deutschen Nationalbibliographie; detaillierte bibliographische Daten sind im Internet über $<$ http://dnb.dnb.de> abrufbar.

\author{
Anschriften der Herausgeber \\ PD Dr. med. Bernd Alt-Epping \\ E-Mail: bernd.alt-epping@med.uni-goettingen.de \\ Dr. med Stefan Fuxius \\ E-Mail: stefanfuxius@gmx.de \\ PD Dr. med. Ulrich Wedding \\ E-Mail: ulrich.wedding@med.uni-jena.de
}

Ein Projekt der

AG Interdisziplinäre Onkologie der

Deutschen Gesellschaft für Palliativmedizin

Dieses Buch ist auch als freie Onlineversion über die Homepage des Verlags sowie über den Göttinger Universitätskatalog (GUK) bei der Niedersächsischen Staats- und Universitätsbibliothek Göttingen (http://www.sub.uni-goettingen.de) erreichbar. Es gelten die Lizenzbestimmungen der Onlineversion.

Satz und Layout: Jutta Pabst Umschlaggestaltung: Margo Bargheer Titelabbildung: Bernd Alt-Epping

(C) 2015 Universitätsverlag Göttingen http://univerlag.uni-goettingen.de ISBN: 978-3-86395-229-7 


\section{Inhaltsverzeichnis}

Inhaltsverzeichnis $\quad 5$

Vorwort: Onkologie für die Palliativmedizin 15

PD Dr. med. Bernd Alt-Epping, Dr. med. Stefan Fuxius,

PD Dr. med. Ulrich Wedding

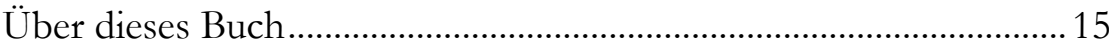

1. Was ist Krebs? Tumorbiologie für Nichtonkologen 17

Prof. Dr. med. Norbert Frickhofen

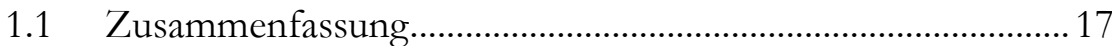

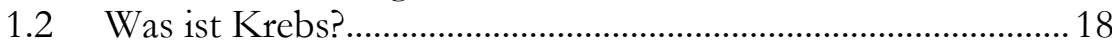

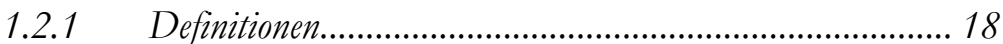

1.2.2 Klassifikation und Stadieneinteilung ................................ 19

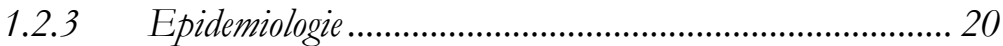

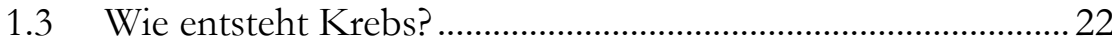

1.3.1 Eine Erkerankung der genetischen Maschinerie................. 22

1.3.2 Außerordentliche Fäbigkeiten ........................................ 25

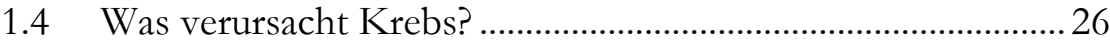

1.4.1 Unterschiedliche Ursachen in unterschiedlichen

Populationen................................................................. 26

1.4.2 Vererbung, Umwelt oder einfach nur Pech........................ 26

1.4.3 Bedeutung für Prophylaxe und Früberkennung von

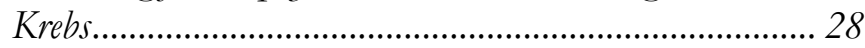

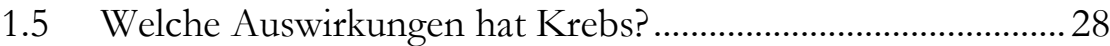

1.5.1 Effekte am Ort des Krebswachstums ................................ 28

1.5.2 Effekte auf den gesamten Organismus................................ 28

1.5.3 Bedeutung für Diagnostik und Therapie........................... 29

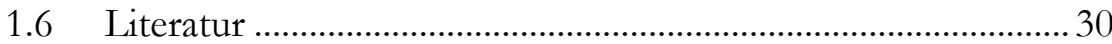

2. Grundlagen der Tumortherapie 33

PD Dr. med. Ulrich Wedding

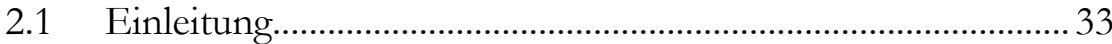

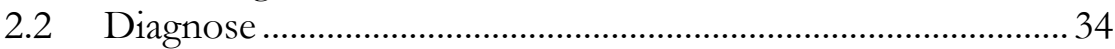

2.3 Stadium und Prognose................................................................... 35 


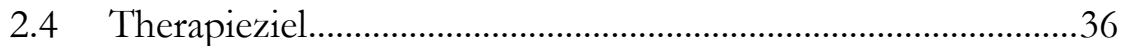

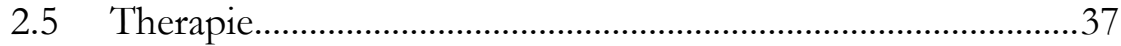

2.5.1 Zusammenwirken tumorspesifischer

Therapiemaßnahmen ………………………………........39

2.5.2 Festlegung des therapeutischen Vorgehens...........................39

2.5.3 Beurteilung des Ansprechens auf eine medikamentöse Tumortherapie ................................................................ 40

2.5.4 Wertung des Ansprechens als Therapieerfolg......................42

2.6 Betreuung im Team ..................................................................42

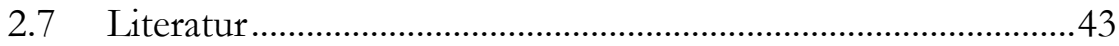

3. Grundlagen der onkologischen Diagnostik 45

Dr. med. Mathias Kleiß, Prof. Dr. med. Stefan Delorme,

Dr. med. Stefan Fuxius

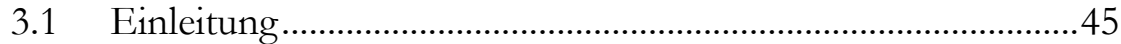

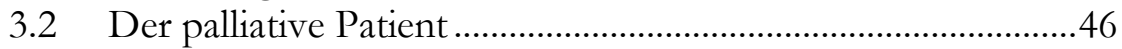

3.3 Therapeutische Konsequenz ……………...................................4

3.4 Onkologische Diagnostik - allgemein .....................................48

3.5 Diagnostische Massnahmen in der Onkologie - speziell........49

3.5.1 Untersuchung von Blut und Knochenmark ........................ 49

3.5.2 Mikeroskopie ................................................................. 50

3.5.3 Immunphänotypisierung..................................................5 50

3.5.4 Zytogenetische Untersuchung............................................50

3.5.5 Molekulare Diagnostik...................................................5 50

3.5.6 Punktion von Körperböblen ...................................................

3.5.7 Endoskopie...................................................................51

3.5.8 Ösophago-Gastro-Duodenoskopie …………………..........51

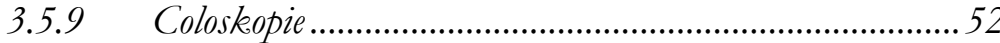

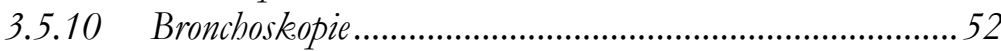

3.6 Perkutane Punktion von Tumoren ...........................................53

3.7 Chirurgische/Invasive Verfahren ............................................54

3.8 Bildgebende Diagnostik in der Palliativmedizin.........................55

3.8.1 Schmerz.....................................................................56

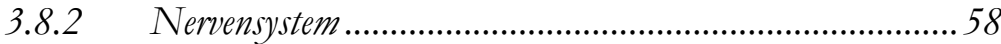

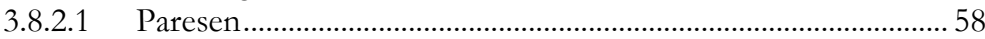

3.8.2.2 Zentralnervöse Symptome ……………………………………..... 61 
3.8.3 Gastrointestinale Symptome ........................................ 61

3.8.4 Niere und Harnwege .................................................... 64

3.8.5 Haut und Weichteile.................................................... 65

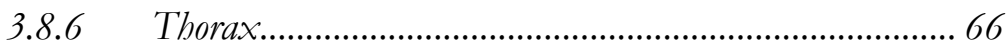

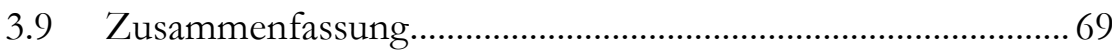

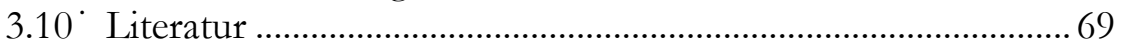

4. Tumorchirurgische Verfahren - für Nichtchirurgen 71

Prof. Dr. med. habil. Konrad Klaus Richter

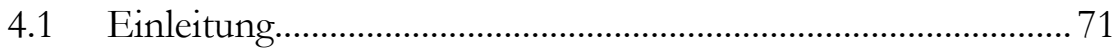

4.2 Nomenklatur, Grading, Staging, Epidemiologie...................... 72

4.3 Tumorchirurgische Prinzipien................................................ 73

4.4 Chirurgische Tumoren............................................................ 74

4.4.1 Ösophaguskarzinome................................................. 74

4.4.2 Magenkarqinome......................................................... 75

4.4.3 Kolorektale Karzinome ................................................ 77

4.4.4 Hepatobiliäre und Pankereastumoren ............................... 80

4.4.5 Lungentumoren........................................................ 81

4.5 Chirurgische Notfälle bei Tumorpatienten............................. 83

4.6 Kurative, nicht-kurative und palliative Chirurgie.................... 84

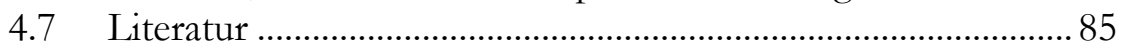

$\begin{array}{ll}\text { 5. Palliative Strahlentherapie } & \mathbf{8 7}\end{array}$

PD Dr. med. Birgitt van Oorschot, Prof. Dr. med. Franz-Josef Prott, Prof. Dr. rer. medic. Uwe Haverkamp

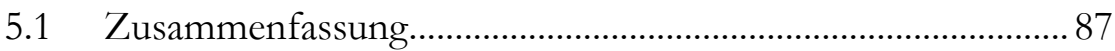

5.2 Basiswissen ........................................................................... 88

5.2.1 Unterscheidung qwischen befund-und symptomorientierter palliativer Strablentherapie, Therapieziele und Bewertung des Therapienutzens.................................................... 88

5.2.2 Formen der Strablentherapie ........................................ 88

5.2.3 Grundlagen der Fraktionierung und Bedeutung der Prognose............................................................. 89

5.2.4 Prognosebezogene Fraktionierungsschemata und Ansprechraten .............................................................. 91

5.2.5 Patientenpräferenzen.................................................. 93 
5.3 Knochen- und Hirnmetastasen...................................................94

5.3.1 Knochenmetastasen ...........................................................94

5.3.1.1 Re-Bestrahlung bei unkomplizierten Knochenmetastasen...... 95

5.3.1.2 Strahlentherapie komplizierter Knochenmetastasen ................. 95

5.3.1.3 Metastatisch bedingte Rückenmarkskompression ..................... 95

5.3.2 Hirnmetastasen ......................................................... 96

5.3.2.1 Therapieoptionen............................................................................ 96

5.3.2.2 Fraktionierungsschemata (Einzeit/Mehrzeit) .......................... 100

5.3.2.3 Lebensqualität mit Hirnmetastasen ............................................. 101

$5.4 \quad$ Symptomlinderung exemplarisch ............................................101

5.4.1 Obstruktions- und Kompressionssyndrome ....................... 101

5.4.1.1 Strahlentherapie zur Linderung von Dyspnoe........................... 102

5.4.1.2 Blutungen, Exulceration und Schwellungen ............................. 103

5.5 Haut- und Schleimhautpflege.................................................104

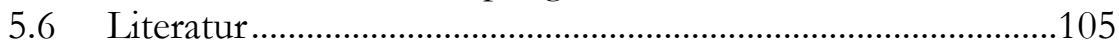

6. Nuklearmedizin - Endoradiotherapie mit spezifischen und unspezifischen Verfahren 111

Prof. Dr. med. Uwe Haberkorn

6.1 Einleitung.....

6.2 Unspezifische Therapie - Selektive interne Radiotherapie (SIRT)

6.2.1 Tracer mit Anreicherung in Zonen des

Knochenumbaus ....................................................... 113

6.3 Spezifische Verfahren...........................................................114

6.3.1 Peptid Rezeptor Radionuklidtherapie (PRRT)................114

6.3.2 Somatostatin-Rezeptoren .................................................115

6.3.3 Liganden für das Prostata Sperifische Membranantigen (PSMA) zur Therapie des metastasierten

Prostatakarzinoms........................................................117

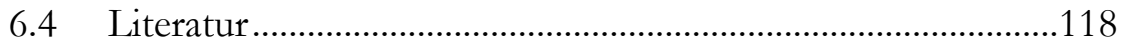

7. Systemische/medikamentöse Tumortherapie 123

Dr. med. Stefan Fuxius

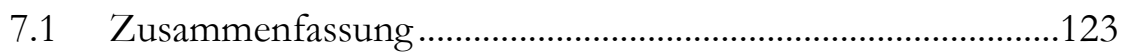

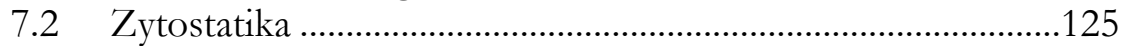

7.3 Hormone bzw. Antihormone .................................................131

7.4 Antikörper, Signaltransduktionshemmer und andere molekulare Therapien 


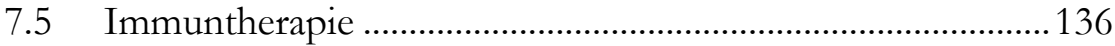

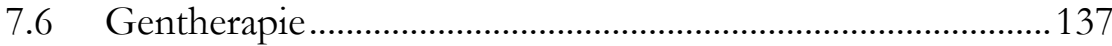

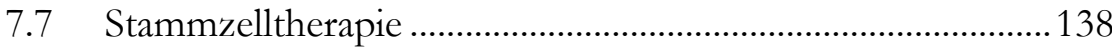

7.7.1 Autologe Stammzelltransplantation ………………….... 138

7.7.2 Allogene Stammzelltransplantation.................................. 139

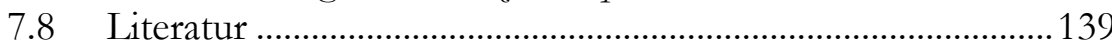

8. Lebensqualität unter (und durch) Tumortherapie 141

PD Dr. med. Bernd Alt-Epping

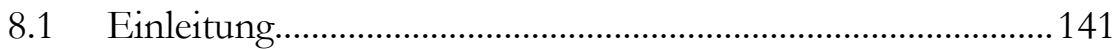

8.2 Erfassung von „Lebensqualität“ ................................................142

8.3 Studienendpunkte in der Onkologie.........................................143

8.4 Lebensqualität als klinische Outcome-Parameter in onkologischen Studien................................................................. 144

8.5 Symptomlinderung - Toxizitätsvermeidung - Lebenszeit:

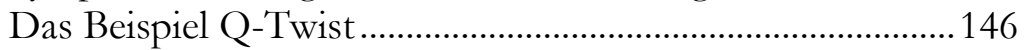

8.6 Zusammenfassung und Ausblick ...........................................147

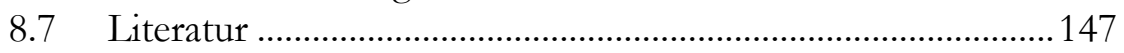

9. Zuerst einmal nicht schaden, dann aber Fürsorge und Selbstbestimmung gewichten

PD Dr. med. Dr. phil. Eva C. Winkler,

Dr. med. Bernd Oliver Maier.............................................................151

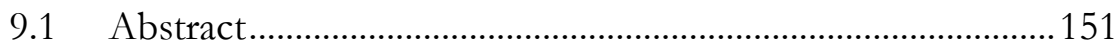

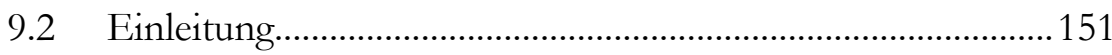

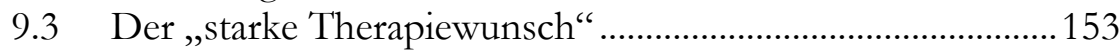

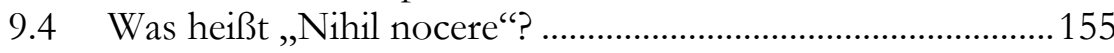

9.5 Kein palliativer „Fatalismus“ “...................................................156

9.6 Das Spannungsfeld von Fürsorge und Selbstbestimmung des Patienten .............................................................................157

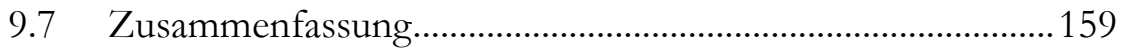

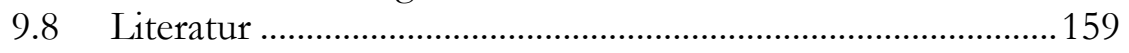

10. Spezielle Supportivtherapie 163

Dr. med. Sabine Mousset, PD Dr. med. habil. Christoph Kabl

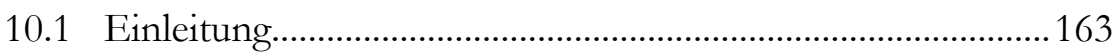

10.2 Therapie von Infektionen ....................................................... 164 


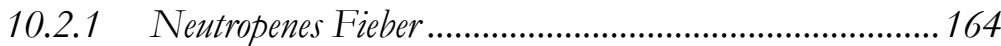

10.2.2 Schimmelpil rinfektionen...................................................166

10.2.3 Infektionen mit Hefepilzen .................................................166

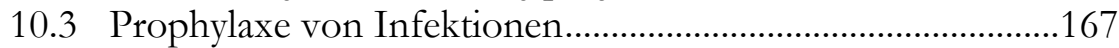

10.3.1 Hygienemaßnahmen ......................................................167

10.3.2 Medikamentöse Prophylaxe.............................................167

10.3.3 Gabe von Myeloischen Wachstumsfaktoren zur Prophylaxe von Neutropenem Fieber ................................168

10.3.4 Impfungen bei Krebspatienten .........................................168

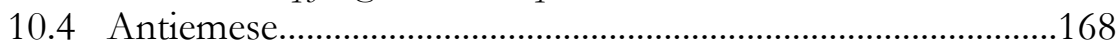

10.4.1 Allgemeines................................................................168

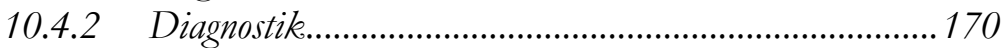

10.4.3 Therapie ……………………………........................170

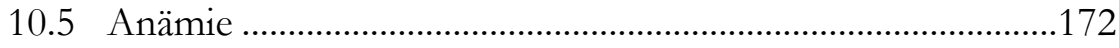

10.5.1 Allgemeines................................................................ 172

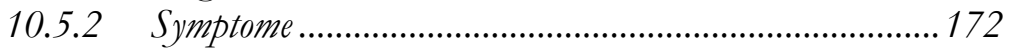

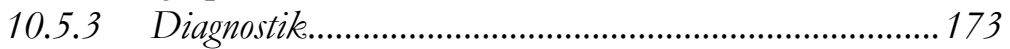

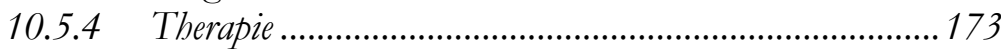

10.6 Prophylaktische Transfusion von Thrombozyten ..................174

10.7 Medikamentöse Behandlung von Knochenmetastasen .........174

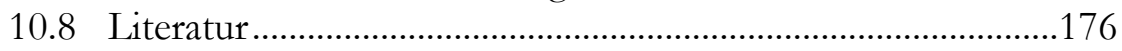

11. Die Rolle der onkologischen Fachkrankenpflege 179

Bärbel Heise

11.1 Einführung in das Berufsbild ...................................................179

11.2 Pflegerische Handlungsmöglichkeiten am Beispiel

häufiger Nebenwirkungen .........................................................180

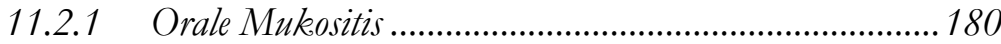

11.2.2 Übelkeit und Erbrechen...............................................182

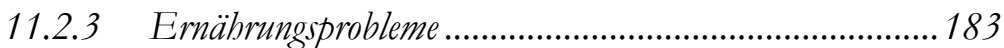

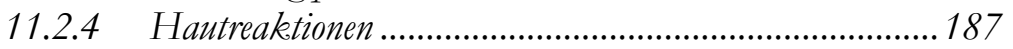

11.2.4.1 Hautreaktionen durch Chemotherapie ........................................187

11.2.4.2 Hautreaktionen bei „targeted therapies“..................................... 188

11.2.4.3 Allgemeine Maßnahmen zur Prävention kutaner

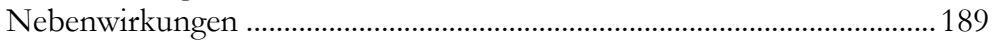

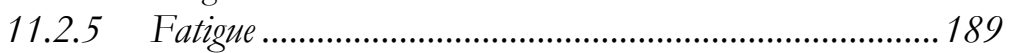

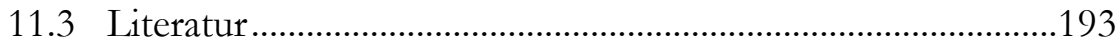


12. Psychoonkologie

Dipl.-Psych. Dipl.-Biol. Stefan Zettl

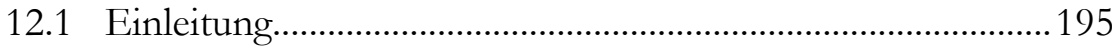

12.2 Der Sturz aus der Wirklichkeit ...................................................196

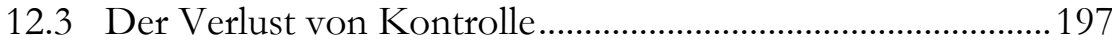

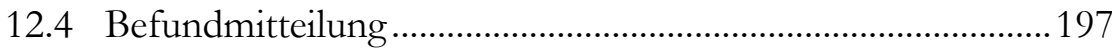

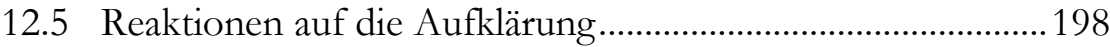

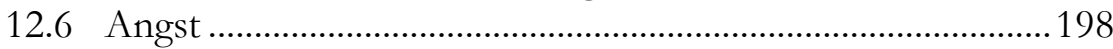

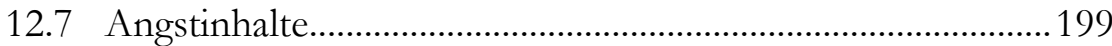

12.8 „Angst essen Seele auf“................................................................200

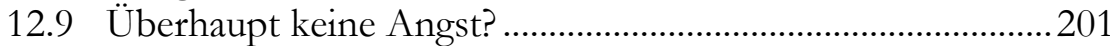

12.10 Diagnostik und Behandlung der Angst .................................202

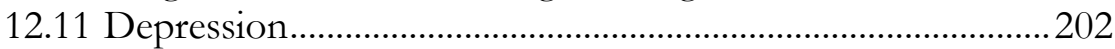

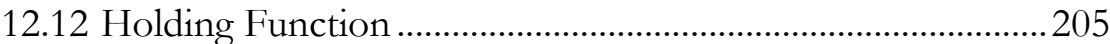

12.13 Auseinandersetzung mit Sterben und Tod ..............................206

12.14 Spiritualität und Sinnsuche.....................................................207

12.15 Nicht an Krebs erkrankt, aber betroffen:

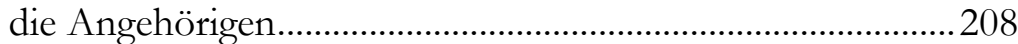

12.16 Supportives dyadisches Coping ...........................................209

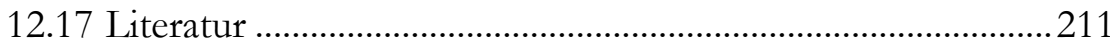

\section{Das Schnittstellenproblem 215}

Dr. med. Marianne Kloke, Dr. med Manuela Sauren

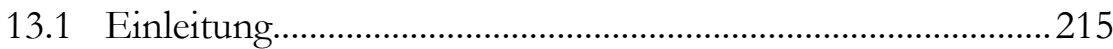

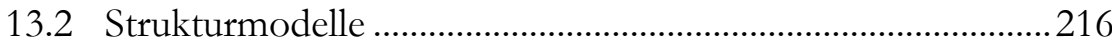

13.3 Das Recht des Patienten auf eine umfassende

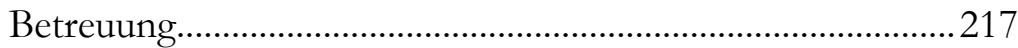

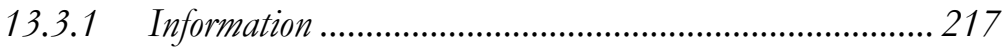

13.3.2 Assessment t................................................................. 217

13.3.3 Interdis₹iplinäre Kommunikation.................................. 218

13.3.4 Interdis₹iplinäre Fort- und Weiterbildung ....................... 218

13.3.5 Sektorenübergreifende vernetžte Versorgung..................... 219

13.4 Mindestanforderungen für eine Schnittstellengestaltung ...219

13.5 Fazit und Ausblick...........................................................................221

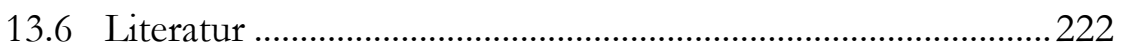


14. Perspektiven in der Onkologie 225

Prof. Dr. med. Florian Lordick

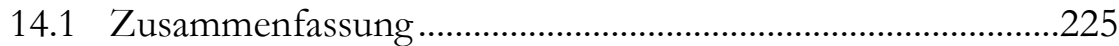

14.2 Stand des Wissens ......................................................................225

14.3 Personalisierte Krebstherapie - die molekulare Ära..............226

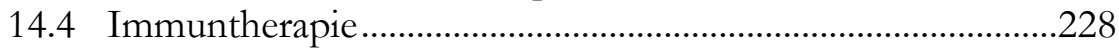

14.5 Palliativmedizin in der Onkologie ............................................230

14.6 Literatur.................................................................................230

$\begin{array}{ll}\text { Autorenverzeichnis } & 233\end{array}$ 
„Die letzten drei Jahre waren die Besten"

Wolfgang Herrndorf, Arbeit und Struktur, 13.08.2013 



\title{
Vorwort \\ Onkologie für die Palliativmedizin
}

\author{
PD Dr. med. Bernd Alt-Epping, Dr. med. Stefan Fuxius, \\ PD Dr. med. Ulrich Wedding
}

\section{Über dieses Buch}

Derzeit leiden über 90\% der in der spezialisierten Palliativversorgung betreuten Patienten an einer Krebserkrankung. Sowohl die frühzeitige, bedürfnisorientierte palliativmedizinische Mitbehandlung als auch die erhebliche Weiterentwicklung der Onkologie erfordern, dass auch in der Palliativversorgung Tätige ein Grundverständnis von der Tumorbiologie, von modernen onkologischen Therapiekonzepten und von supportivtherapeutischen Möglichkeiten haben.

Dieses Buch möchte dieses Grundverständnis der Krebserkrankung und ihrer onkologischen Behandlung in einer auch für Nicht-Onkologen verständlichen Form vermitteln. Neben den klinisch relevanten Aspekten der Tumorbiologie werden die Grundlagen onkologischer Therapieverfahren, verschiedene onkologische Behandlungskonzepte, aber auch deren mögliche Nebenwirkungen und Komplikationen sowie deren ethische Implikationen dargestellt.

Das Buch richtet sich vor allem an jene, die in der palliativmedizinischen Betreuung krebskranker Menschen involviert sind: Palliativärzte, Palliativpflegende, aber auch Haus- und Fachärzte, Physiotherapeuten, Seelsorger, Psychotherapeuten, und viele mehr. Es will kein Lehrbuch der Onkologie ersetzen, sondern eine Sammlung praxisorientierter, therapie- und versorgungsrelevanter Hilfestellungen 
im (palliativ-)medizinischen Arbeitsalltag sein - dort, wo es um eine umfassende Unterstützung von Krebspatienten geht.

Das Buch ist ein Projekt der „AG Interdisziplinäre Onkologie“ der Deutschen Gesellschaft für Palliativmedizin (DGP). Unser herzlichster Dank gilt allen Autoren, die ihre wissenschaftliche und klinische Expertise hier zusammen trugen, sowie der Lektorin, Frau Bergmann, und dem Universitätsverlag Göttingen für jede Unterstützung.

Das Buch ist für seine Leser geschrieben; sie sollen Antworten auf ihre Fragen finden. In diesem Sinne sind wir für Anregungen zur Verbesserung sehr dankbar.

Göttingen, Heidelberg und Jena,
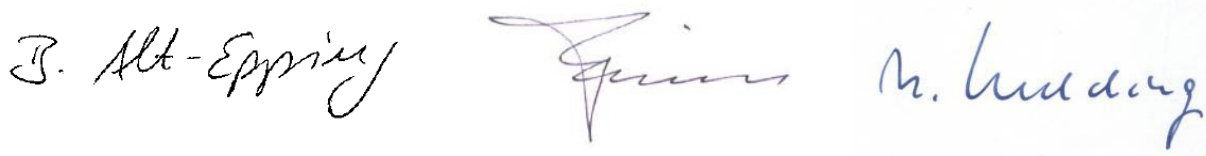


\section{Was ist Krebs? \\ Tumorbiologie für Nichtonkologen}

Prof. Dr. med. Norbert Frickhofen

Klinik für Hämatologie, Onkologie und Palliativmedizin

HELIOS Dr. Horst Schmidt Kliniken Wiesbaden

65199 Wiesbaden

\subsection{Zusammenfassung}

Krebs entsteht durch eine Schädigung des Genoms, d. h. der Steuerzentrale einer Zelle. Die genetischen Schäden können durch angeborene Defekte der Gene selbst oder der Reparatursysteme des Genoms entstehen. Häufiger sind Schädigungen durch krebserzeugende Umweltfaktoren oder durch zufällig auftretende Fehler in einem oder mehreren Genen, die sich bei langer Lebenszeit eines Menschen anhäufen. In der Regel sind es mehrere genetische Defekte, die zusammen eine Zelle zu einer Krebszelle machen. Durch die Entartung erwerben Krebszellen Fähigkeiten, die ein eigenständiges Überleben ermöglichen und den übrigen Körper schädigen, weil sie sich körpereigenen Kontrollmechanismen entziehen. Sie schädigen Gewebe am Ort ihres Wachstums und machen krank durch Verbrauch von Ressourcen des Körpers und indirekt durch krankmachende Abwehrversuche des Körpers. Bis auf wenige Ausnahmen ist eine Heilung nur durch Diagnose in einem frühen, nicht metastasierten Stadium möglich. Daher ist Vorbeugung und Früherkennung essenziell. 


\section{Was ist Krebs?}

\subsubsection{Definitionen}

Mit „Krebs“ bezeichnet man bösartige Neubildungen („Neoplasien“) als Folge eines unkontrollierten Zellwachstums.

Das wichtigste Merkmal von „Bösartigkeit“ ist die Fähigkeit von Zellen, in Nachbargewebe einzuwachsen und/oder über Blut- oder Lymphgefäße in entfernte Körperregionen zu streuen und dadurch Tochtergeschwülste („Metastasen“) fernab des Entstehungsortes zu verursachen, z. B. in Leber, Knochen oder Gehirn. Neubildungen, die das nicht können, bezeichnet man nicht als Krebs, sondern als gutartige Neubildungen.

Das Wort „Tumor“ meint prinzipiell das gleiche wie „Neubildung“, d. h. es kann gut- oder bösartiges Zellwachstum bedeuten. Tumor ist daher nicht das gleiche wie Krebs, sondern ein Überbegriff von gut- und bösartigen Neubildungen. Mediziner benutzen das Wort Tumor manchmal wertneutral im Sinne von „Raumforderung“. Damit ist eine Gewebeformation gemeint, die „Raum fordert“ (sich vor Ort ausdehnt), von der aber noch nicht klar ist, ob es unkontrolliertes Zellwachstum im Sinne von Krebs darstellt. Eine Raumforderung kann nicht nur durch gut- und bösartige Tumoren verursacht werden, sondern auch Folge z. B. einer Entzündung (z. B. ein Abszess) oder einer Flüssigkeitsansammlung (z. B. eine Zyste) sein. Diese feinen Unterschiede in der Sprache muss man beachten, wenn man Befunde liest oder mit Patienten spricht.

Metastasen haben vergleichbare Eigenschaften wie der „Primärtumor“, d. h. der Krebs am Ausgangsort, von dem sie abstammen. Die Lebermetastase eines Dickdarmkrebses ist daher kein Leberkrebs. Sie verhält sich als Tochtergeschwulst unter einer Therapie ähnlich wie der Primärtumor, in dem angenommenen Fall wie der Dickdarmkrebs (Einschränkungen siehe Kapitel 1.3.2). Ein Leberkrebs als Primärtumor (d. h. in der Leber entstanden) hätte ganz andere Eigenschaften und würde z. B. nicht auf Medikamente reagieren, die bei Dickdarmkrebs wirksam sind. Die Identifizierung einer Raumforderung als Primärtumor oder Metastase ist für die Einschätzung der Prognose einer Krebserkrankung und für ihre Therapie entscheidend.

Man unterscheidet „solide“ Tumoren von „flüssigen“ Tumoren. (Das Wort „flüssig“ ist unüblich und wird hier nur aus didaktischen Gründen im Gegensatz zu dem gebräuchlichen Begriff „,solide“ gebraucht.) Solide Tumoren stammen von abgrenzbaren, soliden Organen wie Brust, Lunge oder Darm ab. Flüssige Tumoren sind Tumoren des Knochenmarks und der lymphatischen Organe, die grundsätzlich diffus im ganzen Körper auftreten, z. B. Leukämien, Myelom (Plasmozytom) und Lymphome. Sie werden in der Fachliteratur als hämatologische Tumoren bezeichnet. Da hämatologische Tumoren grundsätzlich dazu neigen, sehr früh im ganzen Körper aufzutreten, spricht man nicht von Metastasen, wenn sie an mehreren Stellen im Körper nachgewiesen werden. So entspricht der Leberbefall durch 
eine Leukämie dem normalen Ausbreitungsmuster einer Leukämie, auch im Frühstadium. Der Leberbefall bei einem Dickdarmkrebs ist dagegen eine Metastase und Ausdruck einer fortgeschrittenen Krebserkrankung.

\subsubsection{Klassifikation und Stadieneinteilung}

Grundsätzlich kann sich jede Zelle des Körpers zu einem gut- oder bösartigen Tumor entwickeln. Es gibt daher hunderte verschiedene Tumorerkrankungen. Neben der Unterteilung in solide und hämatologische Tumoren (siehe 1.2.1) ist die Unterscheidung nach dem Entstehungsort üblich. Da dies in der Regel von dem Pathologen festgelegt wird, nennt man diese Unterteilung auch „histopathologische Klassifikation“ (Tabelle 1) im Unterschied zur „molekularpathologischen Klassifikation“, die unter therapeutischen Gesichtspunkten eine immer größere Rolle spielt (Kapitel 14 dieses Buches). Karzinome, von Geweben innerer oder äußerer Oberflächen (Epithelien) ausgehende Krebserkrankungen, stellen die überwiegende Zahl der Tumoren dar. Sie werden weiter unterteilt in Untergruppen, von denen die Adenokarzinome und Plattenepithelkarzinome die häufigsten sind. Diese Untergruppen spiegeln die Ähnlichkeit zum Ursprungsgewebe wider.

Tabelle 1: Histopathologische Einteilung von Krebserkrankungen. Es sind nur die wichtigsten Krebsformen aufgeführt. Gutartige Tumoren sind nicht berücksichtigt.

\begin{tabular}{|c|c|c|}
\hline Herkunft & Bezeichnung & $\begin{array}{l}\text { Beispiele häufiger } \\
\text { Krebserkrankungen }\end{array}$ \\
\hline \multicolumn{3}{|c|}{ Solide Tumoren } \\
\hline Epithel & Karzinom & $\begin{array}{l}\text { Brustkrebs, Lungenkrebs, Darm- } \\
\text { krebs, Prostatakrebs, Kehlkopf- } \\
\text { krebs, Melanom; } \\
\text { auch hormonbildende Krebsformen } \\
\text { wie Schilddrüsenkrebs oder Neben- } \\
\text { nierenkrebs }\end{array}$ \\
\hline $\begin{array}{l}\text { Stütz- und } \\
\text { Bindegewebe }\end{array}$ & Sarkom & $\begin{array}{l}\text { Osteosarkom (Knochenkrebs), Fib- } \\
\text { rosarkom (Bindegewebskrebs), Lip- } \\
\text { osarkom (Fettgewebskrebs), An- } \\
\text { giosarkom (Blutgefäßkrebs) }\end{array}$ \\
\hline $\begin{array}{l}\text { Zentrales } \\
\text { Nervensystem }\end{array}$ & Hirneigene Tumoren & $\begin{array}{l}\text { Gliome (z. B. Glioblastom, Astrozy- } \\
\text { tom) und Tumoren der Nerven und } \\
\text { der Hirnhäute }\end{array}$ \\
\hline Sonderformen & & $\begin{array}{l}\text { Neuroendokrine Tumoren, Keim- } \\
\text { zelltumore (z. B. Hodenkrebs); Me- } \\
\text { tastasen bei unbekanntem Primär- } \\
\text { tumor (CUP-Syndrom) }\end{array}$ \\
\hline
\end{tabular}




\begin{tabular}{|l|l|l|}
\hline \multicolumn{2}{|l|}{ Hämatologische Tumoren } \\
\hline $\begin{array}{l}\text { Blutbildendes und } \\
\text { lymphatisches Gewebe }\end{array}$ & Leukämie & $\begin{array}{l}\text { Akute myeloische Leukämie (AML), } \\
\text { chronische lymphatische Leukämie } \\
\text { (CLL) }\end{array}$ \\
\hline $\begin{array}{l}\text { Lymphatisches } \\
\text { Gewebe }\end{array}$ & Lymphom & $\begin{array}{l}\text { Hodgkin-Lymphom und Non- } \\
\text { Hodgkin-Lymphome, z. B. diffus } \\
\text { großzelliges Lymphom oder folliku- } \\
\text { läres Lymphom }\end{array}$ \\
\hline Plasmazellen & Plasmazellerkrankung & Multiples Myelom („Plasmozytom“) \\
\hline
\end{tabular}

Der Pathologe definiert nicht nur die Art der Tumorerkrankung, sondern kann auch anhand einer Gewebeprobe (,Zytologie“ oder „Histologie“, siehe Kapitel 3) erkennen, ob sie Merkmale einer bösartigen, also Krebserkrankung erfüllt. Neben Merkmalen der einzelnen Tumorzellen ist dabei v. a. von Bedeutung, ob sich der Tumor vor Ort über die anatomischen Grenzen hinaus ausdehnt hat. Durchbricht z. B. ein Brustkrebs die Epithelgrenzen („Basalmembran“), handelt es sich um Krebs, in dem Fall um ein „Mammakarzinom“. Respektiert der Tumor die Basalmembran, ist es ein frühes Tumorstadium, ein sog. „in situ Karzinom“ oder eine sog. „Präkanzerose“. ${ }^{1}$ Diese Unterschiede sind wichtig, da in situ-Tumoren und Präkanzerosen durch einfaches Entfernen heilbar sind (Kapitel 2).

Der Pathologe kann allerdings nur eine Aussage über das ihm überlassene Gewebe machen. Ist die Gewebeprobe nicht repräsentativ für den gesamten Tumor, indem sie z. B. in dem oben genannten Fall nur den Teil des Tumors erfasst hat, der noch auf das Epithel begrenzt ist, kann er mit seiner Klassifikation als gutoder bösartiger Tumor falsch liegen. Der diagnostisch tätige Onkologe hat die Aufgabe, dem Pathologen Material zu schicken, das repräsentativ für den gesamten Tumor ist. Darüber hinaus muss er feststellen, ob Metastasen vorhanden sind. Ein Tumor kann am Entstehungsort lokal begrenzt erscheinen, jedoch bereits über Lymphbahnen oder Blutgefäße gestreut haben. Das kann nur durch sog. „StagingDiagnostik" (das Stadium definierende Untersuchungen) des übrigen Körpers mit Blutuntersuchungen, Sonographie und anderen in Kapitel 3 dieses Buches beschriebenen Verfahren festgestellt werden. Aus der Gesamtschau der Befunde Histologiebefund und Staging-Diagnostik - definiert der Onkologie das TNMStadium der Erkrankung (Kapitel 3) und damit mögliche Therapieformen.

\subsubsection{Epidemiologie}

Tumorerkrankungen sind häufig. Die Mehrzahl aller Menschen entwickelt in ihrem Leben einen oder mehrere gutartige Tumoren, die entweder erfolgreich behandelt werden oder mit dem Träger versterben ohne ihn je zu gefährden. Etwa die Hälfte

\footnotetext{
${ }^{1}$ Genaueres zu diesen Unterscheidungen ist der Fachliteratur zu entnehmen.
} 
der Deutschen entwickelt einen bösartigen Tumor, also eine Krebserkrankung. Jeder vierte Mann und jede fünfte Frau verstirbt an Krebs (1). Krebs ist nach den Herz-Kreislauferkrankungen die häufigste Todesursache.

Wie häufig und welche Formen von Krebserkrankungen auftreten, hängt entscheidend von den Lebensumständen und der Altersstruktur einer Bevölkerung ab. Darauf wird näher in Kapitel 1.4.1 eingegangen. Für die Palliativmedizin ist weniger entscheidend, wie häufig eine Krebserkrankung diagnostiziert wird, sondern wie häufig sie zum Tode führt. In Deutschland sind die tödlichsten Krebserkrankungen der Männer Lungen-, Darm und Prostatakrebs; bei den Frauen sind es Brust-, Lungen- und Darmkrebs (Abbildung 1). Häufigkeit und Tödlichkeit einer Krebserkrankung können dramatisch unterschiedlich sein, abhängig von ihrem natürlichen Verlauf und der Therapierbarkeit. So wird in Deutschland der Prostatakrebs etwa doppelt so häufig diagnostiziert wie der Lungenkrebs, führt aber viel seltener zum Tode, und steht daher nur an dritter Stelle der Krebs-Todesursachen (Abbildung 1). Diese Zusammenhänge wie auch die weltweiten epidemiologischen Unterschiede sind sehr gut grafisch illustriert in einer im Internet einsehbaren Publikation aus dem Jahr 2014 (2).

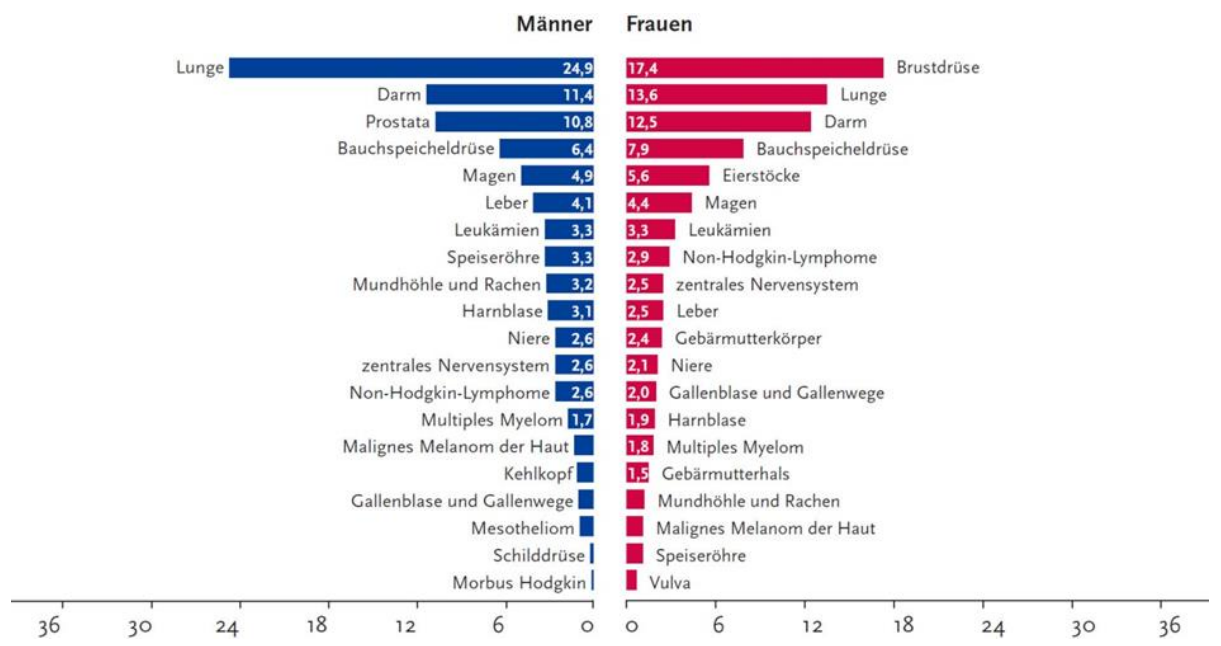

Abbildung 1: Prozentualer Anteil der bäufigsten Tumorlokalisationen an allen Krebssterbefällen in Deutschland 2010. Originalabbildung aus „Krebs in Deutschland 2009/2010“(1). 


\subsection{Wie entsteht Krebs?}

\subsubsection{Eine Erkrankung der genetischen Maschinerie}

Krebs entsteht, wenn das Zellwachstum so gestört ist, dass ein Gewebe unkontrolliert wächst. Dies ist entweder Folge einer Schädigung der Gene, die das geordnete Leben einer Zelle regulieren, oder der Maschinerie, die diese genetische Information in Strukturen und Funktionen umsetzt. Man spricht von genetischen oder epigenetischen Mechanismen.

Krebs verursachende genetische oder epigenetische Schädigungen können zu Störungen lebenswichtiger Funktionen einer Zelle auf allen Ebenen führen. Betroffen sein können die Zellteilung (Mitose), die Einordnung in den Gewebeverband (Motilität), die Reifung zur Erlangung der vollen Funktionalität (Differenzierung), das Altern (Seneszenz) und das Sterben (Apoptose). Wichtige betroffenen Gene sind sog. Onkogene und Tumorsuppressorgene. Sie kodieren häufig Signalmoleküle (Transkriptionsfaktoren) und Kommunikationsstrukturen (Rezeptoren).

Wenn man weiß, dass z. B. täglich alleine etwa 10 Milliarden weiße Blutzellen produziert werden, ist es nicht verwunderlich, dass bei dem täglich viele Milliarden-fachen Kopieren der genetischen Information in den Zellen des Körpers Fehler entstehen. Außerdem wirken auf das Genom und dessen Steuerungsmaschinerie Schadstoffe wie Strahlen oder Chemikalien ein, die zusätzlich Schäden in der DNA oder Fehler bei der Umsetzung des genetischen Codes verursachen können. Dass dies keine wissenschaftliche Spekulation ist, zeigen Untersuchungen an gesunden Personen: Bei etwa $10 \%$ scheinbar Gesunder finden sich im Alter über 65 Genmutationen, wie man sie bei Blutkrebs findet. Diese Menschen entwickeln dann auch überzufällig häufig Leukämien und sterben häufiger als Menschen ohne solche Spontanmutationen (3); (4).

Wir würden diese häufigen Genschäden nicht überleben, hätte die Natur nicht Kontrollmechanismen entwickelt, die solche Fehler erkennen und reparieren. Gelingt die Reparatur, besteht keine Gefahr und die Zelle lebt weiter. Gelingt dies nicht und ist der entstandene Schaden schwerwiegend, z. B. indem er die Zelle zu unkontrolliertem Wachstum treibt, wird ein Selbstmordprogramm der Zelle aktiviert („Apoptose"), und die Zelle stirbt ab. So schützt sich der Körper vor der Weitergabe von genetischen Defekten bei der Zellteilung. Ist die Apoptose gestört, kann die abnorme Zelle weiterleben und gibt ihren genetischen Schaden an die Tochterzellen weiter.

Sind die genetischen Reparatursysteme und/oder die Apoptose defekt, häufen sich genetische Schäden mit zunehmendem Alter immer mehr an und dies kann zur Entstehung von Krebs führen. Mutationen in den Genen, die für Reparaturproteine kodieren, können angeboren sein oder durch Mutationen des genetischen Codes erworben werden. Angeborene Defekte findet man bei 5-20\% aller Menschen mit Krebserkrankungen. Bekanntestes Beispiel ist das Reparatursystem „BRCA“ (5): Wenn bei einer Frau von Geburt an eine Mutation in dem BRCA-1- 
Gen vorliegt, steigt ihr Risiko an einem Brust- oder Eierstockkrebs zu erkranken bis zum Alter von 70 Jahren auf etwa $60 \%$ an (6). Das Brustkrebsrisiko kann durch Entfernung beider Brüste minimiert werden. Aus diesem Grund hat sich Angelina Jolie im Alter von 37 Jahren zu dieser radikalen Maßnahme entschlossen. Da die BRCA-1-Mutation auch ein erhöhtes Risiko für Eierstockkrebs bedeutet, hat sie sich danach auch beide Eierstöcke entfernen lassen.

Das Wachstum von Geweben durch Proliferation (Zellvermehrung durch Zellteilung) ist eng mit dem Absterben durch Apoptose verknüpft. Komplexe Signalwege koordinieren diesen $\mathrm{Zu}$ - und Abfluss von Zellen. Störungen in beiden Prozessen können den Weg zur Entstehung von Krebs ebnen oder direkt Krebs verursachen (Abbildung 2): die eine Sorte Krebs entsteht vorrangig durch vermehrte Proliferation, also abnorm gesteigertes Zellwachstum. Ein Beispiel dafür ist ein aggressives Lymphom, charakterisiert durch eine massiv gesteigerte Zellteilung. Apoptose hält mit der Anhäufung der Zellen nicht Schritt und es entsteht ein Zuviel an Zellen. Neben diesem landläufig bekannten Modell „Krebs durch vermehrtes Zellwachstum“ kann die Proliferation normal sein, aber die Zellen sterben als Folge eines Apoptosedefekts nicht ab und häufen sich an. Ein Beispiel dafür ist die chronische lymphatische Leukämie. Beides ergibt in der Bilanz ein Zuviel an Zellen, einen Tumor, vergleichbar der Überschwemmung einer Flusslandschaft, die sowohl durch zu viel Regen („Proliferation“) als auch durch einen gestörten Abfluss des Wassers („Apoptose“) verursacht werden kann. Beide Prozesse können parallel ablaufen, mit Überwiegen des einen oder anderen. 


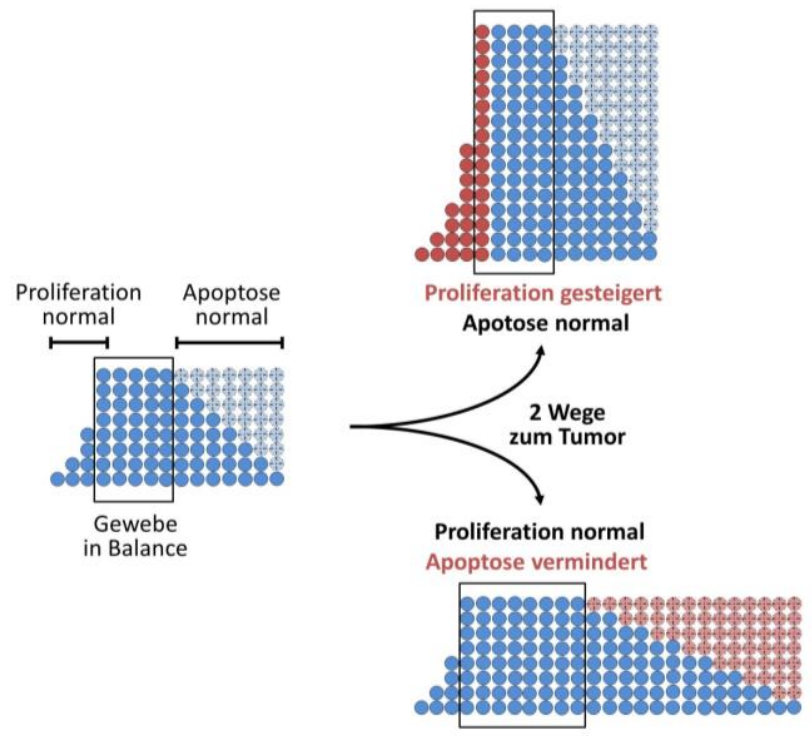

Abbildung 2: Die unkontrollierte Wucherung von Krebszellen im Sinne einer Gewebsvermehrung (,Tumor") kann entweder durch eine vermehrte Produktion von Zellen („Proliferation", rechts oben) oder durch ein vermindertes Absterben (,Apoptose", rechts unten) verursacht werden. Links der Normalzustand, in dem Proliferation und Apoptose eines Gewebes so koordiniert ablaufen, dass immer eine konstante, normale Menge an Zellen vorbanden ist. In dem Schema rechts oben ist die Proliferation pathologisch gesteigert (rote Symbole), sodass sich bei normaler Apoptose Zellen anbäufen. Rechts unten ist die Proliferation normal, aber die Apoptose ist vermindert (blassrote Symbole), sodass sich ebenfalls Zellen anbäufen (Grafik: N. Frickhofen).

Im Verlauf eines Lebens häufen sich nicht korrigierte genetische Defekte an. Es ist nur eine Frage der Zeit, wann Schädigungen in der Summe problematisch werden oder kritische Stellen im Regelsystem einer Zelle betroffen sind und sie dadurch unkontrolliert wächst. Kritische Stellen kennt man heute in etwa 140 regulatorisch wichtigen Genen. Diese Gene gehören zu zwölf Signalwegen, die drei lebensnotwendige Prozesse einer Zelle betreffen: 1. Wachstum und Entwicklung („Differenzierung" ${ }^{6}$, 2. Überleben und 3. Erhalt der Integrität des Genoms (7).

Am besten belegt ist dies für den Dickdarmkrebs: Hier reichen 2-8 kritische Mutationen in diesen wichtigen Signalwegen, um eine Zelle zu einer Krebszelle zu machen. Wenn diese kritischen Mutationen in einer Zelle mit Stammzelleigenschaften auftreten, ist damit eine unsterbliche Krebszelle entstanden.

Krebs erzeugende Mutationen treten selten plötzlich und in einem Schritt auf, sondern in der Regel langsam und schrittweise im Verlauf von vielen Jahren. Bei den meisten soliden Tumoren dauert es 10-30 Jahre, in denen eine Zelle eine kriti- 
sche Mutation nach der anderen erwirbt. Man bezeichnet die oben geschilderten kritischen Mutationen als „Fahrermutationen“ und die vielen Tausend Genveränderungen, die man zusätzlich in den meisten Krebszellen nachweisen kann, als „Passagier-Mutationen“ (im Englischen „driver“" und „passenger“) (7). Wie in einem Bus ist es der Fahrer, der die Richtung der Fahrt entscheidet. Aber die Passagiere können ihn beeinflussen, sind also für das weitere Schicksal der Fahrt durchaus bedeutsam.

\subsubsection{Außerordentliche Fähigkeiten}

Defekte Gene erklären, wie eine Zelle entartet und zu einer Krebszelle „transformiert". Diese genetischen Veränderungen in Schlüsselpositionen der Steuerung einer Zelle verleihen der Krebszelle außerordentliche, für den Organismus aber gefährliche Fähigkeiten. Es werden lebenserhaltende Abläufe destabilisiert und es werden Programme reaktiviert, die sonst nur in der Embryonalzeit benutzt werden. Beides bringt Chaos in einen erwachsenen Organismus, der auf hochgradig koordinierte Abläufe angewiesen ist.

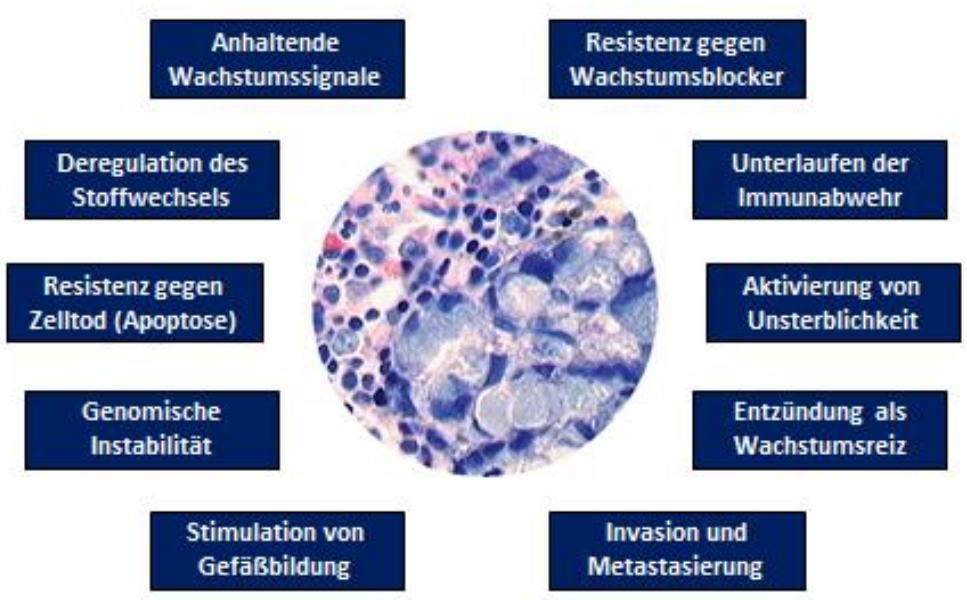

Abbildung 3: Merkmale von Krebszellen und Einflussfaktoren auf das Krebswachstum. Schema in Anlehnung an das Modell von Hanahan und Weinberg (8). Genomische Instabilität wird als eine Grundlage der Krebsentstehung und Entzündung als Wachstumsreiz angesehen. Deregulation des Stoffwechsels und Unterlaufen der Immunabwebr sind neue, in ihrer Bedeutung noch nicht ausreichend einschätzbare Merkmale. Im Zentrum eine Adenokarzinom-Metastase im Knochenmark (N. Frickhofen). 
Die hoch komplexen Merkmale von Krebszellen und Einflussfaktoren haben Hanahan und Weinberg in einem Schema zusammengefasst, das in Abbildung 3 in deutscher Übersetzung widergegeben ist. Es soll zeigen, warum sich Krebszellen vermehren und ausbreiten: Sie nutzen überschießende Wachstumssignale, sind gleichzeitig resistent gegen Wachstumsblocker, inaktivieren den natürlichen Zelltod (Apoptose) und aktivieren Unsterblichkeitsprogramme. Sie können dies, weil sie den Stoffwechsel für ihr eigenes Wachstum anpassen und dafür sorgen, dass sich neue Blut- und Lymphgefäße für die Energieversorgung bilden. Die neuen Blutund Lymphgefäße verschaffen ihnen Anschluss an die normalen Verkehrswege des Körpers und ermöglichen damit eine Verbreitung von Tochtergeschwülsten in andere Organe (Metastasen). Begünstigt wird dies durch Entzündungsprozesse, bei denen eigentlich nützliche Abwehrreaktionen zu Wachstumshilfen missbraucht werden. Das alles geschieht, indem Immunreaktionen gegen das abnorme Zellwachstum unterlaufen werden, weil sich die Zellen unsichtbar machen können oder sie in der Lage sind, Immunreaktionen zu blockieren. Grundlage von all dem ist eine genomische Instabilität, wie sie in Kapitel 1.1.2 beschrieben wurde.

\subsection{Was verursacht Krebs?}

\subsubsection{Unterschiedliche Ursachen in unterschiedlichen Populationen}

Es gibt nicht „die eine Ursache“ von Krebs. Alleine der Blick auf epidemiologische Zahlen verdeutlicht, dass die Ursachen von Krebs in der Welt sehr unterschiedlich sein müssen (2). So ist Brustkrebs ein typischer Krebs der Industrienationen. Ursachen sind v. a. Ernährungsfaktoren und das damit zusammenhängende Übergewicht. Die Häufigkeit von Lungenkrebs hängt mit dem Anteil von Rauchern in der Bevölkerung und mit dem Grad der Umweltverschmutzung zusammen. In Asien und im südlichen Afrika sind infektionsgetriggerte Krebserkrankungen von Leber, Magen und Gebärmutterhals häufiger als im Rest der Welt. Alle diese Beobachtungen weisen auf Umweltfaktoren hin. Diese erklären jedoch nicht alles. Lebenszeit und erbliche Faktoren tragen zum Krebsrisiko bei.

\subsubsection{Vererbung, Umwelt oder einfach nur Pech}

Eine Publikation in „Science“ im Jahr 2015 (9) hat die Diskussion darüber in Gang gebracht, welche Anteile die einzelnen Faktoren für die Entstehung einer Krebserkrankung haben. Aus der Diskussion wurde die griffige Analogie zu dem Auftreten eines Defekts bei einer Autofahrt geboren (Tabelle 2): So wie das Risiko eines Defekts mit der Länge der Autofahrt steigt, steigt das Krebsrisiko mit zunehmendem Alter. Ursache der Alterskrebse ist die Anhäufung zufällig aufgetretener Fehler im Genom oder in der Genregulation (s. 1.3.1). Das Altersrisiko muss man als Basisrisiko annehmen, dem jeder Mensch unterliegt. Es ist „einfach Pech“, wie es 
die Autoren der zitierten Arbeit formulierten, wenn im Alter kritische Mutationen zusammenkommen und Krebs verursachen. Darauf pfropfen sich Umweltfaktoren auf, so wie es eher zu einem Defekt am Auto kommen kann, wenn die Straßenoder Wetterverhältnisse schlecht sind. Schließlich bringen 5-20\% der Menschen angeborene Defekte mit, die wie bei einem „Montagsauto“ zu einem gehäuften und i. d. R. vorzeitigen Auftreten von Schäden, in dem Fall Krebs, führen können (s. Kapitel 1.3.1).

Welchen Anteil die einzelnen Faktoren spielen, ist damit erklärbar unterschiedlich: Der gesund lebende Mensch in einer heilen Umwelt wird am ehesten einen Alterskrebs entwickeln. Der rauchende Mensch in China wird am ehesten einen durch selbst zugeführte oder Umweltschadstoffe verursachten Krebs entwickeln. Schließlich wird der Krebs des Menschen aus einer „Krebsfamilie“ am ehesten durch angeborene Defekte seines Genoms bedingt sein.

Tabelle 2: Risiken der Entstehung von Krebs ähneln den Risiken einer Autofahrt. *Zur Erklärung der Bezeichnungen für angeborene Krebsdispositionen sei auf andere Kapitel dieses Buches und die Fachliteratur verwiesen.

\begin{tabular}{|c|c|c|}
\hline $\begin{array}{l}\text { Ursache eines } \\
\text { Defekts am Auto }\end{array}$ & $\begin{array}{l}\text { Analogie für die } \\
\text { Krebsentstehung }\end{array}$ & $\begin{array}{l}\text { Mechanismen der Krebsent- } \\
\text { stehung } \\
\text { Beispiele }\end{array}$ \\
\hline Lange Autofahrt & $\begin{array}{l}\text { Anhäufung geneti- } \\
\text { scher Defekte in } \\
\text { einem langen Leben }\end{array}$ & $\begin{array}{l}\text { Zufällige Mutationen in Stammzel- } \\
\text { len, umso häufiger, je mehr Stamm- } \\
\text { zellen sich in einem Gewebe teilen } \\
\text { und je länger der Mensch lebt } \\
\text { Beispiele: Lungenkrebs des Nichtrauchers, } \\
\text { Dickdarmkrebs, Altersleukämie }\end{array}$ \\
\hline $\begin{array}{l}\text { Schlechte Straßen- } \\
\text { oder } \\
\text { Wetterverhältnisse }\end{array}$ & $\begin{array}{l}\text { Krebs erzeugende } \\
\text { Umweltfaktoren }\end{array}$ & $\begin{array}{l}\text { Schädigung der Gene, der geneti- } \\
\text { schen Maschinerie oder des Immun- } \\
\text { systems } \\
\text { Beispiele: Krebs von Lunge, Bauchspeichel- } \\
\text { drüse, Blase u.a. Organen durch Rauchen } \\
\text { und kanzerogene Umweltstoffe, Leberkrebs } \\
\text { durch Hepatitis B-Virus, Gebärmutter- } \\
\text { balskrebs durch Papillomaviren, follikulä- } \\
\text { rer Schilddrüsenkrebs durch radioaktive } \\
\text { Strablen }\end{array}$ \\
\hline $\begin{array}{l}\text { Schlechter Zustand } \\
\text { des Autos („Montags- } \\
\text { auto“) }\end{array}$ & $\begin{array}{l}\text { Angeborene, vererb- } \\
\text { bare Defekte }\end{array}$ & $\begin{array}{l}\text { Defektes Reparatursystem des Ge- } \\
\text { noms } \\
\text { Beispiele: Brustkrebs durch BRCA- } \\
\text { Mutationen, Dickdarmkrebs bei Lynch- } \\
\text { Syndrom, Krebs der endokerinen Drüsen bei } \\
\text { MEN-Syndrom* }\end{array}$ \\
\hline
\end{tabular}




\subsubsection{Bedeutung für Prophylaxe und Früherkennung von Krebs}

Die in Tabelle 2 erläuterte Klassifikation der Krebsentstehung hat unmittelbare Konsequenzen für die Prophylaxe und Früherkennung von Krebs: Durch Vermeiden Krebs erzeugender Schadstoffe kann man der Entstehung von Krebs vorbeugen („Prophylaxe“). Die Früherkennung ist Domäne der Alterskrebse und der Krebserkrankungen durch angeborene Defekte. Der Zeitpunkt der Früherkennung richtet sich nach dem typischer Erkrankungsalter, d. h. spät bei den Alterskrebsen und früh bei den angeborenen Krebserkrankungen. Näheres dazu wird in Kapitel 3 dieses Buches erläutert.

\subsection{Welche Auswirkungen hat Krebs?}

\subsubsection{Effekte am Ort des Krebswachstums}

Am Ort des Krebswachstums kommt es zu „Raumforderung“ und zu lokalen Komplikationen wie der Verdrängung oder Schädigung von Nachbargeweben.

Verdrängungserscheinungen sind z. B. sicht- oder tastbare Knoten oder Verhärtungen des Gewebes. Diese können, müssen aber nicht schmerzhaft sein. Es können Entzündungen als lokale Reaktion auf den Tumor auftreten, die sich stärker bemerkbar machen als der Tumor selbst.

Lokale Komplikationen entstehen durch Einwachsen in das Nachbargewebe (z. B. Brustkrebs in die Haut oder die Brustwand), Abdrücken von Hohlorganen (z. B. Aufstau des Harnleiters und der Nieren durch einen Blasenkrebs), Blutungen aus angegriffenen Blutgefäßen (z. B. durch Krebs von Dickdarm, Gebärmutter oder Blase), Schleimhautschäden durch einwachsenden Tumor (z. B. Hustenreiz oder Blutung bei Lungenkrebs) oder durch Schädigung der Funktion von Organen (z. B. Knochenbruch durch eine Knochenmetastase oder Krampfanfall durch Hirntumoren oder -metastasen).

\subsubsection{Effekte auf den gesamten Organismus}

Tumoren haben nicht nur Auswirkungen am Ort des Tumorwachstums, sondern können den ganzen Organismus belasten. Am wichtigsten sind Auswirkungen von Fernmetastasen und Abwehrreaktionen des Körpers.

Eine Fernmetastasierung, d. h. die Absiedelung von Tochtergeschwülsten in Körperregionen, die nicht unmittelbar dem Tumor benachbart sind, kann über die örtlichen Lymphbahnen oder Blutgefäße geschehen (,lymphatische“ oder „,hämatogene Metastasierung"). Eine lymphatische Metastasierung folgt den typischen lymphatischen Abflussbahnen eines Organs. Ein Beispiel ist die Entstehung von Lymphknotenmetastasen in der Achselhöhle oder in der Gegend des Schlüsselbeins beim Brustkrebs. Lymphknotenmetastasen sind ein Zeichen für einen fortge- 
schrittenen Tumor, müssen aber nicht Unheilbarkeit bedeuten. Sie müssen radikal entfernt werden, und es schließt sich in der Regel eine sog, „adjuvante Therapie“ an, um kleinste, nicht erkennbare Metastasen in den Abflusswegen oder im übrigen Körper zu beseitigen (Kapitel 2).

Eine hämatogene Metastasierung führt zu einem Befall der Organe, die im venösen Abflussgebiet des Tumors und darüber hinaus liegen. Typisch sind Lebermetastasen bei Tumoren im Bauchraum. Finden Tumorzellen Anschluss an den gesamten Blutkreislauf, können prinzipiell alle Organe befallen werden, am häufigsten Lunge, Knochen oder Gehirn. Welche Organe befallen werden, hängt auch damit zusammen, ob sie für die einzelnen Tumorzellen gute Wachstumsbedingungen bieten. So ist der Knochen ein typisches Organ für Metastasen des Prostatakrebs und des Brustkrebs und der Lungenkrebs siedelt sich besonders gerne in der nicht befallenen Lunge und der Nebenniere ab.

Krebs kann unabhängig von dem Grad der Ausbreitung den betroffenen Menschen krank machen. So sind Fieber, Appetitlosigkeit und Gewichtsabnahme charakteristische Symptome von bestimmten Lymphomen. Sie können auftreten, obwohl der Tumor noch örtlich begrenzt wächst. Thrombosen können ein Erstsymptom einer Tumorerkrankung sein. Man führt diese Phänomene auf Entzündungserscheinungen und immunologische Abwehrreaktionen des Organismus zurück. Diese „Allgemeinsymptome“ können stärker belasten als der Tumor selbst und Monate vor Diagnosestellung auftreten. Man spricht allgemein von „Paraneoplasien“, also Nebenerscheinungen einer Krebserkrankung. Sie können Körperfunktionen isoliert beeinträchtigen und daher zunächst nicht als Paraneoplasie erkannt werden. Beispiele sind Hauterscheinungen wie Juckreiz und Ausschlag, Lähmungen, rheumatische Beschwerden oder Störungen der Blutsalze wie ein erhöhtes Kalzium.

\subsubsection{Bedeutung für Diagnostik und Therapie}

Ob ein Tumor im Früh- oder Spätstadium entdeckt wird, hängt v. a. von der Lokalisation und den Symptomen ab, die er verursacht. Ein kleiner Tumor an einer sichtbaren oder für die Funktion kritischen Stelle wird früh erkannt. Beispiele sind Hauttumoren, die man früh sieht; ein Brustkrebs, der von der Frau früh ertastet wird; ein Blasentumor, der blutet oder den Harnleiter blockiert; oder ein Gallengangskrebs, der durch lokalen Verschluss zu einer Gelbsucht führt. Tumoren die nicht sichtbar sind oder in unkritischen Regionen wachsen, können dagegen sehr groß werden, bevor sie diagnostiziert werden. Beispiele sind Lungentumoren mitten im Lungengewebe, die weder Schmerzen noch Blutungen verursachen oder Weichgewebstumoren (Sarkome), die langsam im Muskelgewebe oder im Bauchraum wachsen. Paraneoplastische Syndrome weisen meist auf eine fortgeschrittene Krebserkrankung hin.

Einzelheiten zur Therapie von Krebserkrankungen sind in Kapitel 2 beschrieben. Hier sei nur darauf hingewiesen, dass Chirurgie und Strahlentherapie die wirk- 
samsten Krebstherapien sind, wenn der Tumor nicht gestreut hat. Es sollte daher alles daran gesetzt werden, einen Tumor frühzeitig zu erkennen und ihn lokal zu therapieren. Das beinhaltet auch die gezielte Früherkennung bei Risikopersonen (Kapitel 1.4.2). Systemische Therapien mit Antihormonen, Zytostatika, molekular gezielt wirkenden Medikamenten und Immuntherapien (Kapitel 7 und 14) sind bei den meisten soliden Tumoren nur bei Einsatz als adjuvante Therapie kurativ („,heilend") wirksam. Bei fortgeschrittenen Tumoren wirken sie meist nur palliativ, d. h. symptomkontrollierend und/oder lebensverlängernd. Ausnahmen sind hochgradig Chemotherapie-sensible Tumoren wie bestimmte Leukämien und Lymphome oder Hodentumore.

Wer mehr über die Geschichte der Krebsforschung und die aktuellen Entwicklungen der Therapie erfahren will, dem sei das fesselnd und gut verständlich geschriebene Buch „Der König aller Krankheiten, Krebs - eine Biographie“ empfohlen (10).

\subsection{Literatur}

(1) Kaatsch P, Spix C, Hentschel S, Katalinic A, Luttmann S, Stegmaier K. Krebs in Deutschland 2009/2010. Robert Koch-Institut und die Gesellschaft der epidemiologischen Krebsregister in Deutschland e.V., 9. Ausgabe. 2013. Berlin.

(2) May M. Cancer Death Rate Depends on Geography. Sci Am 2014 June 17. http://www.scientificamerican.com/article/cancer-death-rate-depends-ongeography/

(3) Genovese G, Kahler AK, Handsaker RE, Lindberg J, Rose SA, Bakhoum SF, et al. Clonal hematopoiesis and blood-cancer risk inferred from blood DNA sequence. N Engl J Med 2014 Dec 25; 371(26):2477-87.

(4) Jaiswal S, Fontanillas P, Flannick J, Manning A, Grauman PV, Mar BG, et al. Age-related clonal hematopoiesis associated with adverse outcomes. N Engl J Med 2014 Dec 25; 371(26):2488-98.

(5) Meindl A, Ditsch N, Kast K, Rhiem K, Schmutzler RK. Familiäres Mamma- und Ovarialkarzinom. Dtsch Arztebl Int 2011 May; 108(19):323-30.

(6) Mavaddat N, Peock S, Frost D, Ellis S, Platte R, Fineberg E, et al. Cancer risks for BRCA1 and BRCA2 mutation carriers: results from prospective analysis of EMBRACE. J Natl Cancer Inst 2013 Jun 5; 105(11):812-22.

(7) Vogelstein B, Papadopoulos N, Velculescu VE, Zhou S, Diaz LA, Jr., Kinzler KW. Cancer genome landscapes. Science 2013 Mar 29; 339(6127):1546-58. 
(8) Hanahan D, Weinberg R A. Hallmarks of cancer: the next generation. Cell 2011 Mar 4; 144(5):646-74.

(9) Tomasetti C, Vogelstein B. Cancer etiology. Variation in cancer risk among tissues can be explained by the number of stem cell divisions. Science 2015 Jan 2; 347(6217):78-81.

(10) Mukherjee S. Der König aller Krankheiten. Krebs -- eine Biographie. 4 ed. Köln: DuMont Buchverlag; 2012. 



\section{Grundlagen der Tumortherapie}

PD Dr. med. Ulrich Wedding

Universitätsklinikum Jena,

Klinik für Innere Medizin II, Abteilung Palliativmedizin

65199 Wiesbaden

\subsection{Einleitung}

Diagnostik und Therapie gehen in der Onkologie Hand in Hand. Für die meisten onkologischen Erkrankungen sind diagnostische und therapeutische Algorithmen etabliert, die über Leitlinien im Internet aufrufbar sind oder in Übersichtsarbeiten oder Lehrbücher nachgelesen werden können. Empfohlene Links finden sich am Ende des Kapitels.

Zudem ergeben sich rasch Neuerungen, sodass es in diesem Beitrag Ziel ist, Grundlagen darzustellen, prinzipielle Vorgehensweisen zu erläutern und Begriffe zu erklären, nicht aber für einzelne Erkrankungen das diagnostische und therapeutische Vorgehen zu erläutern. 


\subsection{Diagnose}

Am Anfang steht die Diagnose. Sie beinhaltet drei Bereiche:

1.) die histologische (oder zytologische) Sicherung der Diagnose

2.) die Festlegung des Stadiums der Erkrankung, der Risiko- und Prognosefaktoren

3.) die Erfassung der gesamtgesundheitlichen Situation des Patienten

Die Ausgangssituationen, aus denen heraus die Diagnose einer Krebserkrankung gestellt wird, sind vielfältig. Drei Grundmuster lassen sich beschreiben:

1.) Entdeckung bei einem asymptomatischen Patienten im Rahmen von Screening- bzw. Früherkennungsuntersuchungen

₹. B. Mammographie $\rightarrow$ Brustkrebs/Koloskopie $\rightarrow$ Darmkrebs

2.) Entdeckung im Rahmen der Abklärung von Symptomen, die den Patienten zum Arzt geführt haben

₹. B. persistierender Husten $\rightarrow$ Bronchialkarzinom

3.) Nebenbefundliche Entdeckung im Rahmen von anderen Untersuchungen, z. B. Sonographie $\rightarrow$ Nierentumor

Der Zeitpunkt der Erstdiagnose ist wichtig und wird immer mitberichtet, zum einen um die bisherige Überlebenszeit mit der Krebserkrankung oder nach kurativer Therapie ohne Rezidiv abschätzen zu können, zum anderen um beurteilen zu können, ob die Therapien, die bisher durchgeführt wurden, den Standards entsprachen und ob es ggf. weitere Therapieoptionen gibt. Bei einer kurativ behandelten Erkrankung steigt mit dem zeitlichen Abstand zur Erstdiagnose die Wahrscheinlichkeit, dass die Erkrankung wirklich geheilt ist. Bei einer nicht-kurativen Behandlungssituation steigt mit dem zeitlichen Abstand zur Erstdiagnose die Wahrscheinlichkeit innerhalb eines zukünftigen Zeitintervalls, z. B. dem nächsten Jahr, an der Erkrankung zu sterben.

Beispiel: Hat ein Patienten mit Kolonkarzinom, das R0 reseziert wurde und anschließend mit einer adjuvanten Chemotherapie behandelt wurde, drei Jahre ohne Rezidiv überlebt, so ist die Wahrscheinlichkeit hoch, dass er auch zukünftig tumorfrei bleiben wird, da $80 \%$ der Rezidive innerhalb der ersten zwei bis drei Jahre nach Erstdiagnose auftreten.

Beispiel: Hat ein Patient mit einem metastasierten Pankreaskarzinom ein Jahr überlebt, obwohl die mediane Lebenswertung ca. neun Monate beträgt, so ist die Wahrscheinlichkeit noch ein zweites Jahr zu überleben, geringer. 


\subsection{Stadium und Prognose}

Das Stadium legt die Ausdehnung der Krebserkrankung fest. Die Prognose beschreibt die Überlebenswahrscheinlichkeit. Oft besteht ein enger Zusammenhang zwischen Stadium und Prognose. Die Festlegung der Stadieneinteilung basiert häufig auf ihrer Relevanz für die Prognose. Über das Stadium hinaus existieren aber weitere Faktoren, welche die Prognose beeinflussen, z. B. bestimme Laborwerte, der Allgemeinzustand (Karnofsky- oder ECOG-Performance-Status) etc. Diese fließen dann neben dem Stadium in die Prognoseeinteilung mit ein.

Neben der histologischen (oder zytologischen) Sicherung der Diagnose ist die zunächst prätherapeutische Festlegung des Stadiums der Erkrankung eine weitere Aufgabe der Diagnostik. Ist die chirurgische Therapie Teil des Behandlungskonzepts, folgt der prätherapeutischen Festlegung die definitive pathologische Festlegung.

Die Einteilung der Stadien erfolgt je nach Diagnose nach festgelegten Untersuchungsmethoden, z. B. CT oder MRT, und Klassifikationen, z. B. TNM-Klassifikation mit daraus resultierendem UICC-Stadium (UICC $=$ Union internationale contre le cancer).

Der Begriff TNM-Stadium setzt sich aus folgenden Kategorien zusammen: $\mathrm{T}=$ Tumor, $\mathrm{N}=$ Nodus (Lymphknoten), $\mathrm{M}=$ Metastasen. Den einzelnen Buchstaben der Kategorien können weitere Buchstaben vorangestellt werden (Präfixe), um zu verdeutlichen, mit welcher Methode das Stadium bzw. die jeweilige Kategorie festgelegt wurde: $\mathrm{p}=$ pathologisches Stadium, $\mathrm{c}=$ klinisches Stadium, $\mathrm{r}=\mathrm{Re}$ zidiv, $\mathrm{u}=$ Ultraschalldiagnostik, $\mathrm{y}=$ Zustand nach Therapie, $\mathrm{a}=$ Autopsie. Zudem können Buchstaben hintangestellt werden (Suffixe): $\mathrm{m}=$ multiple Tumoren im gleichen Gebiet, is = Carcinoma in situ, cy = zytologisch. Die TNM Klassifikation wird für die meisten soliden Tumoren verwendet und regelmäßig aktualisiert.

Die Festlegung des initialen Stadiums wird nicht verändert, sollte im Verlauf ein Rezidiv auftreten. Es wird dann zusätzlich der Zeitpunkt des Rezidivs angegeben, z. B. Kolonkarzinom Stadium UICC III ED 12/2013, Lebermetasten $12 / 2014$.

Für die meisten soliden Tumoren ist die auf der TNM-Klassifikation basierende UICC-Einteilung der Stadien die wichtigste prognostische Einteilung. Die Einteilung des Stadiums kann sich von der der Prognose unterscheiden. Als eine alternative Systematik der prognostischen Zuordnung wird z. B. bei Keimzelltumoren die der International Germ Cell Cancer Collaboration Group (IGCCCG), die u. a. die Tumormarker mitberücksichtigt, verwendet. Bei den Sarkomen wird zur Beurteilung der Prognose z. B. das Grading ergänzt.

Die Stadieneinteilung der malignen hämatologischen Erkrankungen erfolgt nach anderen Kriterien. In der Regel handelt es sich bei den hämatologischen malignen Erkrankungen von Anfang an um systemische Erkrankungen. So existieren für die akuten Leukämien und die myeloproliferativen Neoplasien gar keine Stadieneinteilungen. Die malignen Lymphome werden nach Ann-Arbor in vier Stadien 
eingeteilt, jeweils mit dem Zusatz A, wenn keine, und B, wenn B-Symptome vorliegen. Die chronisch lymphatische Leukämie ist zwar auch ein malignes Lymphom, wird aber nach der Binet oder der RAI Klassifikationen einem Stadium zugeordnet. Auch für die multiplen Myelome, auch eine B-Zell-Neoplasie, erfolgt die Stadienfestlegung aufgrund einer anderen Klassifikation, nämlich der nach Salmon und Durie.

Die Zuordnung der Prognose der hämatologischen Erkrankungen erfolgt nach gesonderten Kategorien, z. B. legt die Ann-Arbor-Klassifikation das Stadium eines malignen Lymphoms fest. Die Prognose wird anhand zusätzlicher Kategorien im Internationalen Prognostischen Index (IPI) erfasst, der neben dem Stadium der Ann-Arbor-Klassifikation das Vorliegen einer LDH-Erhöhung, den ECOGPerformance-Status, den extranodalen Befall und das Alter berücksichtigt. Wiederum andere Prognosescores existieren z. B. für die chronisch-lymphatische Leukämie, das Multiple Myelom oder das Myelodysplastische Syndrom.

Die Prognosebeurteilung ist ein wesentlicher Baustein im Rahmen der Therapieentscheidung.

\subsection{Therapieziel}

Das Ziel der Tumortherapie wird zum einen von der Art der Erkrankung, dem Stadium, den prognostischen Faktoren und der gesamtgesundheitlichen Situation des Patienten bestimmt, zum anderen davon, inwieweit (nach dem aktuellen Stand des medizinischen Wissens mit einer gewissen Wahrscheinlichkeit) in dieser Situation das im Rahmen einer Tumortherapie angestrebte Therapieziel erreichbar ist.

Von einem kurativen Therapieziel spricht man, wenn die Erkrankung durch therapeutische Maßnahmen geheilt werden kann. Kann eine Erkrankung nicht geheilt werden, so ist das Therapieziel palliativ, oder besser nicht-kurativ. Kurativ ist das Therapieziel dann, wenn die Tumortherapie auf ein Leben ohne die Erkrankung abzielt, nicht-kurativ dann, wenn Therapieziel das Leben mit der Erkrankung ist. Korrekt müsste es „potentiell kuratives Therapieziel“ heißen, da die Definition des Therapieziels immer eine probabilistische Aussage, also eine in die Zukunft gerichtete, auf Wahrscheinlichkeiten basierende Aussage ist, und die Erkrankung im Einzelfall stets anders verlaufen kann. Eine Definition dafür, ab welchem Grad Wahrscheinlichkeit einer Heilung man noch von kurativem Therapieziel sprechen kann, bzw. dieses im Rahmen der Therapie verfolgt, und ab wann von einem nicht-kurativen Therapieziel gesprochen wird, existiert nicht.

Beispiel: Die Wahrscheinlichkeit für das Erreichen einer Heilung im Rahmen der intensiven chemotherapeutischen Behandlung eines Patienten mit akuter myeloischer Leukämie (AML) beträgt $20 \%$. Das heißt, es existiert ein kurativer Therapieansatz, aber nur einer von fünf Patienten profitiert von diesem Ansatz.

Im Rahmen des nicht-kurativen Therapieziels können unterschiedliche Ziele im Fokus stehen: 
- Verlängerung des Überlebens

- Verlängerung der Zeit ohne Beschwerden/ohne Einschränkungen der Lebensqualität

- Reduktion von Beschwerden/Einschränkungen der Lebensqualität

- Würdiges Sterben

Diese nicht-kurativen Ziele schließen sich nicht gegenseitig aus, dennoch gehört es zu einem klaren Entscheidungsprozess, zu definieren und im Behandlungsteam und mit dem Patienten zu kommunizieren, welches Ziel im Vordergrund steht.

Ein einmal festgelegtes Therapieziel bedarf immer wieder der Überprüfung, ob es im Behandlungsverlauf noch realistisch ist. Schreitet die Erkrankung trotz Therapie fort oder verschlechtert sich der Allgemeinzustand des Patienten so, dass die Belastungen durch die Therapie größer werden, gewinnen andere Ziele für den Patienten an Bedeutung. Gerade im Verlauf der Betreuung von Patienten mit nicht-kurativem Therapieziel ist die Änderung des Therapieziels die Regel und nicht die Ausnahme. Immer wieder erneut gilt es, mit dem Patienten abzustimmen, in welchem Umfang die Therapie noch indiziert und seinem Willen entspricht, oder ob eine Begrenzung der Therapie indiziert und seinem Willen entsprechend ist.

\subsection{Therapie}

Tumorspezifische und nicht-tumorspezifische (supportive) Therapien ergänzen sich im Rahmen der onkologischen Therapie. Die tumorspezifische Behandlung der Krebserkrankung basiert auf drei klassischen Säulen: der chirurgischen (s. Beitrag Richter), der strahlentherapeutischen (s. Beitrag van Oorschott und Prott sowie Haberkorn) und der medikamentösen (s. Beitrag Fuxius). Als vierte Säule der tumorspezifischen Therapie entwickelt sich die immunologische Therapie (s. Beitrag Lordick).

Tumorspezifisch sind alle Therapiemaßnahmen, die direkt gegen den Tumor gerichtet sind, z. B. operative Resektion eines Kolonkarzinoms oder Bestrahlung eines stenosierenden Ösophaguskarzinoms oder Chemotherapie eines Hodenkarzinoms. Diese tumorspezifischen Therapiemaßnahmen können in kurativer und nicht-kurativer Zielsetzung erfolgen.

Eine besondere Situation einer kurativen Therapie ist die adjuvante Therapie. Sie unterstützt eine zuvor bereits erfolgte kurative Operation, ggf. zusätzlich zu einer Bestrahlung. Das heißt, der betroffene Patient ist primär durch die Operation geheilt - eine adjuvante Therapie reduziert das Risiko für das Wiederauftreten der Erkrankung (Rezidiv). Die adjuvante Therapie setzt in der Regel eine R0 Resektion voraus. Vorteil der adjuvanten Therapie ist die höhere Heilungschance für den Patienten, Nachteile sind die Nebenwirkungen und die fehlende Möglichkeit, ein 
Ansprechen auf die Erkrankung nachzuweisen, da der Tumor reseziert ist. Eine besondere Form der adjuvanten Therapie ist die neoadjuvante Therapie. Hier wird ergänzend vor der eigentlichen kurativ intendierten Operation eine systemische medikamentöse Therapie durchgeführt. Dies hat den Vorteil, dass das Ansprechen der Erkrankung auf die medikamentöse Therapie festgestellt werden kann. Zudem wird sie in der Regel besser vertragen.

Nicht-tumorspezifische Therapiemaßnahmen sind alle Maßnahmen, die nicht direkt gegen den Tumor gerichtet sind. Sie haben verschiedene Ziele:

- Verbesserung von Symptomen, die durch eine Tumorerkrankung verursacht werden, z. B. durch Schmerztherapie

- Reduktion der Nebenwirkungen einer tumorspezifischen Therapie, z. B. Reduktion der emetogenen Wirkung von Chemotherapie durch prophylaktische Gabe von Antiemetika

- Erlernen eines besseren Umgangs mit der Erkrankung, z. B. durch psychoonkologische Mitbetreuung

Für diese nicht-tumorspezifischen Therapiemaßnahmen wird häufig der Terminus supportive Therapie verwendet. Es existiert eine enge und eine weite Definition von supportiver Therapie. Die enge Definition versteht unter supportiver Therapie alle Maßnahmen, die zu einer Verbesserung der Wirkung tumorspezifischer Therapie oder einer Verringerung der untererwünschten Wirkung einer tumorspezifischen Therapie beitragen. Die weite Definition versteht unter supportiver Therapie alle Maßnahmen, die zu einer besseren Lebensqualität, Lebenslänge oder Heilung des Patienten und seiner Angehörigen beitragen und die keine tumorspezifischen Maßnahmen sind.

Unter beide Definitionen fallen z. B. die prophylaktische und therapeutische Gabe von Antiemetika im Rahmen einer Chemotherapie, die Gabe von Wachstumsfaktoren der Hämatopoese zur Reduktion der hämatologischen Toxizität, der Einsatz antimikrobieller Substanzen im Rahmen zur Prophylaxe oder Therapie infektiöser Komplikationen der Chemotherapie, die Transfusion von Blutprodukten, die Gabe von Bisphosphonaten zur Reduktion skelettaler Ereignisse bei Patienten mit ossären Metastasen, Ernährungstherapie, etc. (s. Beitrag Mousset und Kahl). Unter die weite Definition fallen zudem auch die psychoonkologische und die palliative Betreuung von Patienten. Sie dienen u. a. der Verbesserung der Lebensqualität der Patienten und ihrer Angehörigen und sind keine tumorspezifischen Verfahren.

Supportive Therapiemaßnahmen sind häufig entscheidend dafür, dass tumorspezifische Maßnahmen Erfolg haben können und dass die Belastungen der Therapie nicht ihren Vorteil überwiegen. Die Gefahr liegt nahe, tumorspezifische Therapiemaßnahmen als die eigentliche Therapie zu sehen, und damit den Stellenwert supportiver Maßnahmen zu vernachlässigen. Allerdings sollten supportive (besser nicht-tumorspezifische) Maßnahmen in jedem Fall erfolgen, unabhängig davon, ob 
eine tumorspezifische Therapie durchgeführt wird, und davon, ob das Therapieziel kurativ oder nicht-kurativ ist.

Der Terminus „best supportive care“ (BSC) wird im Kontext randomisierter klinischer Studien verwendet, in denen Patienten in einen Studienarm mit oder ohne eine spezifische tumortherapeutische Maßnahme randomisiert werden. „Best supportive care" beschreibt in diesem Kontext ein Spektrum flankierender Behandlungen, die entweder alleine oder zusätzlich zur experimentellen Therapiemaßnahme eingesetzt werden („BSC ohne oder mit Studientherapie“). Leider ist häufig unzureichend festgelegt, welche Maßnahmen „best supportive care“ eigentlich umfasst (z.B. ob dies auch spezialisierte palliativmedizinische Mitbetreuung mit all ihren Auswirkungen auf den Erkrankungsverlauf einschließt).

\subsubsection{Zusammenwirken tumorspezifischer Therapiemaßnahmen}

Oft werden im Rahmen der Behandlung der Krebserkrankung verschiedene tumorspezifische Verfahren in Kombination eingesetzt. Man spricht dann von einer multimodalen Therapie.

Multimodal sind Therapien, bei denen nicht nur eine der drei wesentlichen Therapiekomponenten (medikamentöse tumorspezifische Therapie, Bestrahlung und Chirurgie) zum Einsatz kommt, sondern eine Kombination aus zwei oder drei Therapiekomponenten zum Therapieerfolg beiträgt. Adjuvante Therapien (s.o.) sind Teil einer multimodalen Therapie.

Beispiele:

- präoperative (neoadjuvante) Radiochemotherapie vor kurativer chirurgischer Therapie eines Rektumkarzinoms im Stadium UICC II

- postoperative Bestrahlung nach kurativer operativer Therapie eines Mammakarzinoms und anschließende (adjuvante) Hormontherapie

\subsubsection{Festlegung des therapeutischen Vorgehens}

Da die Entscheidung über das beste therapeutische Vorgehen Kenntnisse unterschiedlicher medizinischer Disziplinen bedarf, wurden onkologische Tumorboards etabliert. In ihnen werden gemeinsam Therapieempfehlungen gegeben. Chirurgen, Strahlentherapeuten, internistische Onkologen, Radiologen und Pathologen gehören zum Kernteam. Befunde eines Patienten, die bereits eine Krebserkrankung bestätigen oder diese nahelegen, werden von einem den Patienten betreuenden Arzt vorgestellt, die bildgebende Diagnostik und ggf. die pathologischen Befunde werden ergänzt und gemeinsam wird eine Therapieempfehlung gegeben.

Beispiel: 70-jähriger Patient, Karnofsky-Performance-Status $90 \%$, der sich mit rektalen Blutabgängen vorstellte, die endoskopische Diagnostik zeigte einen Tumor in Höhe $10 \mathrm{~cm}$, der ca. 2/3 der Zirkumferenz einnimmt, die Biopsie ergab den Befund eines Adenokarzinoms des Rektums, endosonographisch sind regiona- 
le Lymphknoten befallen, die CT-Diagnostik ergab keinen Hinweis auf Fernmetastasen. Empfehlung: präoperative Radiochemotherapie gefolgt von einer anterioren Rektumresektion.

Der Vorteil des Tumorboards besteht darin, alle Fachvertreter um einen Tisch versammelt zu haben, gemeinsam eine Therapieempfehlung abstimmen und ggf. kritische Befunde bewerten zu können. Systematische Analysen zeigen eine Verbesserung der Behandlungsergebnisse, wenn die Therapieentscheidungen in einem interdisziplinären Tumorboard getroffen werden. Nachteil ist der Zeitaufwand und dass der Patient bei solch einem Tumorboard nicht eingebunden ist. Zudem liegen häufig relativ wenige Informationen zum Patienten vor, die nicht die Krebserkrankung betreffen, z. B. über Begleiterkrankungen, die soziale Situation des Patienten etc. Auch diese Aspekte können für eine Therapieentscheidung relevant sein.

Eine Therapieentscheidung basiert immer auf zwei Säulen: Indikation und Patientenwille. Die Therapieempfehlung des Tumorboards ist der erste Schritt im Rahmen der Therapieentscheidung, er nimmt zum Thema Indikation Stellung. Im zweiten Schritt ist der Patientenwille entscheidend. Der Patient hat selbstverständlich jederzeit das Recht, sich gegen eine Therapieempfehlung zu entscheiden.

Im Verlauf sollte eine erneute Vorstellung des Patienten im Tumorboard erfolgen, wenn

a) die Primärbehandlung abgeschlossen ist, z. B. nach Operation zur Empfehlung, ob postoperative Therapien empfohlen werden oder lediglich eine Nachsorge oder

b) die Erkrankung rezidiviert oder progredient ist und damit über eine Änderung der Therapie zu entscheiden ist.

\subsubsection{Beurteilung des Ansprechens auf eine medikamentöse Tumortherapie}

Die Fortführung ineffektiver Therapien ist onkologisch nicht sinnvoll, belastet den Patienten und ist teuer. Mit Beginn einer medikamentösen Therapie sollte daher festgelegt werden, anhand welcher Parameter die Effektivität der Therapie beurteilt wird, welche Untersuchungen zur Beurteilung dieser Parameter erforderlich sind und in welchem zeitlichen Abstand zum Therapiebeginn dies erfolgen soll. Die Beurteilung des Ansprechens einer Krebserkrankung auf eine medikamentöse Tumortherapie ist eine wesentliche Aufgabe des behandelnden Onkologen.

Das Ansprechen wird mit definierten Untersuchungsmethoden und in definierten Zeitabständen durchgeführt, das Ergebnis wird nach klaren Kriterien definiert, den sogenannten RECIST-Kriterien (www.eortc.org/recist/). Von „Ansprechen" spricht man, wenn eine komplette Remission (complete remission, CR) oder eine partielle Remission (partial remission, PR) vorliegen, in Publikationen werden $\mathrm{CR}$ und PR zur Remissionsrate (remission rate, RR) zusammengefasst. Damit von einer partiellen Remission gesprochen werden kann, muss eine Verkleinerung des 
Tumors um mindestens $30 \%$ vorliegen. Eine Größenzunahme um mindestens $20 \%$ von vorher bekannten Tumormanifestationen oder das Auftreten von Tumormanifestation an Orten, an denen sich vorher keine befanden, wird als Progress (progressive disease, PD) gewertet. Liegt eine Größenabnahme um weniger als $30 \%$ oder eine Größenzunahme von weniger als $20 \%$ vor, spricht man von einer stabilen Erkrankungen (stable disease, SD) oder einer unveränderten Situation (no change, NC).

Für solide Tumoren werden zu Beurteilung des Ansprechens die RECIST Kriterien eingesetzt (1).

Manche Autoren verwenden den Terminus „clinical benefit response“ synonym mit den Ansprechkriterien CR, PR oder SD. Andere Autoren verwenden diesen Terminus im Sinne einer Verbesserung der Symptombelastung.

Weitere Begriffe zur Beurteilung der Effektivität einer Therapie sind die Gesamtüberlebenszeit (overall survival, OS), das progressionsfreie Überleben (progression free survival, PFS), die Zeit bis zum Therapieversagen (time to treatment failure, TTF), oder krankheitsfreies Überleben (disease free survival, DFS). Bei diesen Parametern handelt es sich um zeitabhängige Variable. Das Gesamtüberleben beschreibt die Zeit von der Erstdiagnose bis zum Tod, das progressionsfreie Überleben die Zeit vom Beginn der Therapie bis zum Auftreten einer PD-Situation und die Zeit bis zum Therapieversagen meint die Zeit vom Beginn der Therapie bis zum Auftreten einer PD-Situation, bis zum Abbruch der Therapie wegen Toxizität oder auf Wunsch des Patienten, oder bis zum Tod des Patienten. Das krankheitsfreie Überleben ist dann als Zielpunkt wichtig, wenn die Therapie adjuvant erfolgt, das heißt, wenn keine Erkrankung nachweisbar war oder wenn eine komplette Remission vorliegt. Sie erfasst die Zeit vom Vorliegen einer R0-Situation oder einer kompletten Remission bis zum Wiederauftreten der Erkrankung oder dem Tod.

Abhängig von der Länge des Zeitraums zwischen der primären „Tumorfreiheit" und dem Wiederauftreten der Erkrankung spricht man von einem Früh- oder Spätrezidiv. Ein Wiederauftreten innerhalb von sechs Monaten gilt in der Regel. als Frührezidiv, ein Spätrezidiv, wenn die Zeit länger als sechs (oder zwölf) Monate beträgt.

Neben der Effektivität der medikamentösen Tumortherapie fließt in die Entscheidung über die subsequente Fortsetzung die Beurteilung der Verträglichkeit ein. Die unerwünschten Wirkungen der medikamentösen Tumortherapie (Toxizität) werden in den Common Terminology Criteria of Adverse Events (CTC-AE) systematisch erfasst. Diese werden vom National Cancer Institut (NCI) der US publiziert und regelmäßig aktualisiert. Nebenwirkungen von Grad 3 oder 4 werden als schwer oder sehr schwer/lebensbedrohlich gewichtet. Die Klassifizierung dient der „objektiven“ Erfassung der Toxizität. Systematisch werden die CTC-Kriterien allerdings nur im Rahmen klinischer Studien eingesetzt. Ergänzt werden sie durch die „subjektive“ Toxizität, das heißt die Bewertung der Belastung durch die Therapie insgesamt und die spezifischen Nebenwirkungen durch den Patienten. Ein Teil 
der Erfassung der Lebensqualität mit standardisierten Fragebögen bildet diese subjektive Toxizität ab.

Beispiel: Eine Grad 3 Leukopenie $(<2,0-1,0 \mathrm{Gpt} / \mathrm{L})$ ist ggf. nur im Labor festzustellen und nur aufgrund des erhöhten Infektionsrisikos relevant, während eine Grad 3 Diarrhoe (7-9 Stühle pro Tag) den betroffenen Patienten in seinem Alltag sehr viel mehr belastet.

Der effektivste Weg zur Vermeidung von Toxizität ist der Verzicht auf die Durchführung einer systemischen medikamentösen Tumortherapie, allerdings mit Ausbleiben der gewünschten Wirkung. Zudem gibt es für eine Reihe von Tumorerkrankungen und ihre Therapie einen Zusammenhang zwischen der Toxizität und der Effektivität. So hatten Patienten mit einem kleinzelligen Bronchialkarzinom, bei denen im Rahmen der Chemotherapie eine Grad 3-4 Toxizität auftrat, ein höheres Ansprechen und sie lebten länger. Bei der Bewertung, ob die Therapie ein Erfolg ist, muss daher immer zwischen der gewünschten und der unerwünschten Wirkung abgewogen werden. Sie bleibt relativ und subjektiv.

\subsubsection{Wertung des Ansprechens als Therapieerfolg}

$\mathrm{Ob}$ das aus der Verlaufsuntersuchung abgeleitete Ansprechen als Therapieerfolg oder Therapieversagen zu werten ist, hängt von der Art der Grunderkrankung und dem Therapieziel ab. Besteht ein kuratives Therapieziel, so ist dies in der Regel nur über eine komplette Remission erreichbar. Zeigt die Erstlinienchemotherapie, die in kurativer Intention appliziert wurde, in einer ersten Verlaufskontrolle keine Abnahme der Tumorgröße, so ist von einem Therapieversagen, einer primären Resistenz auszugehen.

Bei den meisten soliden Tumoren in metastasierter Situation ist das Erreichen einer stable disease/no change-Situation in der Erstlinientherapie als Therapieerfolg zu werten, der mit einer Verringerung der Symptome und einer Verbesserung der Überlebenszeit assoziiert ist. Dies gilt nicht für rasch verlaufende Erkrankungen wie Keimzelltumoren oder das kleinzellige-Bronchialkarzinom (SCLC), die in der Regel gut auf eine Chemotherapie ansprechen. Hier sollte in der ersten Verlaufskontrolle mindestens eine partielle Remission erreicht worden sein.

\subsection{Betreuung im Team}

Onkologie ist Teamarbeit. In Anlehnung an das afrikanische Sprichwort „it takes a village to raise a child" (es bedarf eines Dorfes, um ein Kind aufzuziehen), titelte ein Editorial ,it takes a village to help our patients through their journey” (es bedarf eines Dorfes, um unseren Patienten auf ihrem Weg zu begleiten) (2). Viele Fachdisziplinen und Professionen müssen ihre spezifische Expertise einbringen, um sie zu einer guten Therapie zusammenzuführen. Hierbei bedarf es eines respektvollen Umgang in der Anerkennung der jeweiligen Expertise. Nicht jedem im 
Behandlungsteam wird der Patient die gleichen Informationen geben. Oft steht der behandelnde Onkologe für die Patienten für Hoffnung; seine Belastungen im Rahmen der Therapie, seine gleichzeitig bestehende Skepsis oder seine Verzweiflung wird er ggf. eher gegenüber einer anderen Person, etwa einer Pflegekraft oder einem Psychoonkologen äußern. Diese verschiedenen Aspekte zu einem runden Bild zusammenzufügen ist gemeinsame Aufgabe im Team.

\section{$2.7 \quad$ Literatur}

1) Eisenhauer E A, Therasse P, Bogaerts J, Schwartz L H, Sargent D, Ford R, Dancey J, Arbuck S, Gwyther S, Mooney M, Rubinstein L, Shankar L, Dodd L, Kaplan R, Lacombe D, Verweij J. New response evaluation criteria in solid tumours: revised RECIST guideline (version 1.1). Eur J Cancer 2009; 45(2):228-247.

2) Earle C C. It takes a village. J Clin Oncol 2012; 30(4):353-354.

\section{Links}

www.onkopedia.com/de/homepage-view

www.leitlinienprogramm-onkologie.de/

www.cancer.gov/publications/pdq

www.eortc.org/news/recist-news-and-updates/ 



\title{
3. Grundlagen der onkologischen Diagnostik
}

\author{
Dr. med. Mathias Kleiß, Prof. Dr. med. Stefan Delorme, \\ Dr. med. Stefan Fuxius
}

Rotes Kreuz Krankenhaus Kassel, 34121 Kassel

Deutsches Krebsforschungszentrum, 69120 Heidelberg

Onkologische Schwerpunktpraxis Heidelberg, 69115 Heidelberg

\subsection{Einleitung}

Die korrekte Diagnosestellung ist Voraussetzung einer Therapie. In der Palliativmedizin können onkologische Therapieverfahren zur Symptomlinderung, aber auch zur Verlangsamung des Krankheitsprogresses und damit zur möglichen Lebensverlängerung eingesetzt werden. Auf den Allgemeinzustand des Patienten abgestimmte Therapien sind möglich. Dadurch findet die Durchführung diagnostischer Maßnahmen auch in der Palliativmedizin ihre Berechtigung. Vor „Schubladendenken" muss ausdrücklich gewarnt werden. Die Betreuung eines Palliativpatienten mit einer onkologischen Erkrankung sollte immer in Zusammenarbeit mit einem medizinischen Onkologen erfolgen.

Onkologische Palliativpatienten können natürlich auch unter anderen, mit der onkologischen Diagnose nicht zusammenhängenden, dennoch bedrohlichen Krankheitszuständen leiden. Insofern ist bei der Begleitung von Palliativpatienten entsprechende Wachsamkeit geboten. Das folgende Fallbeispiel soll verdeutlichen, wohin „Schubladendenken“ führen kann. 


\section{Fallbeispiel}

Der 75-jährige Patient leidet an einem weit fortgeschrittenen Plasmozytom. Er versorgt sich eingeschränkt selbständig, Karnofsky-Index 60\%. Das Plasmozytom wird palliativ medikamentös therapiert. Wäbrend eines stationären Aufenthaltes auf der onkologisch/palliativmedizinisch ausgerichteten Station verschlechtert sich der Allgemeinzustand des Patienten kurafristig rapide. Das nahende Sterben des Patienten wird vorbereitet, eine Kerze wird angezündet. Der binzugerufene Oberarzt bemerket Maschinenatmung, bämmernden Puls und Kaltschweißigkeit des Patienten. Der Blutdruck ist stark erböht (220/120 mmHg), über den Lungen lässt sich feuchtes Rasseln als Hinweis auf ein Lungenödem auskultieren. Der Patient wird auf die Intensivstation verbracht, wo er sich unter blutdrucksenkender Medikation rasch erbolt. Monate später ist der Patient am Leben und füblt sich relativ wobl.

\subsection{Der palliative Patient}

Die Deutsche Gesellschaft für Palliativmedizin definiert Palliativmedizin folgendermaßen (1):

„Palliativmedizin ist die Behandlung von Patienten mit einer nicht heilbaren progredienten und weit fortgeschrittenen Erkrankung mit begrenzter Lebenserwartung, für die das Hauptziel der Begleitung die Lebensqualität ist. Palliativmedizin soll sich dabei nicht auf die letzte Lebensphase beschränken.“

Das Vorliegen einer „,nicht heilbaren progredienten [...] Erkrankung“ muss an sich schon durch diagnostische Prozeduren bestätigt werden. Das heißt, dass diese nach Möglichkeit auch bei einem klinisch schwer kranken Menschen, bei dem eine fortgeschrittene Krebserkrankung vermutet werden muss, gesichert werden sollte. Erst nach korrekter Diagnosestellung kann eine Erkrankung exakt klassifiziert und demnach als heilbar oder unheilbar eingestuft werden. Zur Planung bzw. zur Evaluation der Möglichkeiten einer tumorspezifischen onkologischen Therapie ist eine korrekte Diagnose unbedingte Voraussetzung. 


\section{Fallbeispiel}

Die 92-jährige, bislang trotz ibres Alters recht rüstige und mobile Patientin wird mit kurafristig aufgetretener, rasch zunehmender Dyspnoe im Krankenhaus aufgenommen. Ursächlich für die Dyspnoe findet sich ein ausgedehnter Tumor im Bereich der Scbilddrüse und der Halslymphknoten mit hochgradiger Einengung der oberen Atemwege. Die ultraschallgesteuerte Nadelbiopsie ergibt die histologische Diagnose eines aggressiven B-Zell-Non-Hodgkin-Lymphoms. Weitere Lymphommanifestationen finden sich nicht. Bereits unter einer Vorphasetherapie mit Prednisolon lässt sich eine deutliche Größenreduktion der Tumormassen erkennen. Eine nachfolgende Dosis-angepasste ChemoImmunotherapie mit Rituximab und Bendamustin wird von der Patientin sehr gut vertragen, eine Remission wird erreicht.

\subsection{Therapeutische Konsequenz}

Die Stellung einer korrekten Diagnose ist Voraussetzung einer Therapie. Selbstverständlich stehen die Erhebung der Anamnese und die körperliche Untersuchung des Patienten an erster Stelle. Darüber hinaus sind aber weitere Untersuchungen indiziert, um eine Diagnose als Voraussetzung für ein differenziertes Behandlungskonzept erstellen zu können. Grundsätzlich gilt, wie immer in der Medizin, dass nur diagnostische Maßnahmen von klinischer Relevanz durchgeführt werden dürfen (2). Untersuchungen, aus denen keine (Therapie-)Konsequenz resultiert, sind nicht indiziert. Gerade einem Palliativpatienten darf auf keinen Fall unnötig Schaden zugefügt werden, weswegen risikoreiche Prozeduren vermieden werden müssen. Die Entscheidung zur Durchführung einer onkologischen Therapie, im engeren Sinne häufig als medikamentöse tumorspezifische Therapie (z. B. zytostatische Chemotherapie), hängt von der Art und damit der therapeutischen Beeinflussbarkeit der onkologischen Erkrankung ab, vom Wunsch des Patienten und vom Allgemeinzustand des Patienten (3). So ist die Möglichkeit der Symptomreduktion durch eine medikamentöse Tumortherapie gegeben (4).

Patienten mit einem ausreichenden Allgemeinzustand, definiert als ein Karnofsky-Index $>50 \%$, kommen für eine medikamentöse Tumortherapie in Frage, Patienten mit einem schlechteren Allgemeinzustand profitieren in der Regel nicht davon. Allerdings muss hier immer im Einzelfall entschieden werden. Patienten mit einer chemosensiblen Krebserkrankung, die bis zum Eintreten der Krebserkrankung uneingeschränkt leistungsfähig waren, können von einer Chemotherapie profitieren, selbst wenn sich ihr Allgemeinzustand bedingt durch die Krebserkrankung stark verschlechtert hat. Der Patient muss genau über die diagnostischen und therapeutischen Möglichkeiten aufgeklärt werden, über die möglichen Nutzen und Risiken dieser Maßnahmen sowie über die Alternativen. Ohne Zustimmung des 
Patienten können diagnostische Maßnahmen weder juristisch noch ethisch vertretbar durchgeführt werden (5). Ein weiteres sinnvolles Kriterium, ob mit einer Chemotherapie gestartet werden soll oder nicht, ist die geschätzte Lebenserwartung eines Patienten. Neben der Einschätzung der Lebenserwartung durch erfahrene Professionelle (Arzt oder Krankenpfleger usw.) ist die Benutzung von ScoringSystemen, z. B. des „Palliative Prognostic Index“, sinnvoll (6). Vor Beginn einer Chemotherapie sollte die geschätzte Lebenserwartung des Patienten mindestens drei Monate betragen, da die meisten Therapien mindestens acht bis zwölf Wochen brauchen, um eine klinische Wirkung entfalten zu können. Ausnahmen hiervon sind hämatologische Neoplasien wie aggressive Lymphome oder akute Leukämie.

Die fachärztlich-onkologische Beurteilung eines Patienten kann nur durch einen entsprechend erfahrenen Arzt, beispielsweise einen medizinischen Onkologen, geleistet werden. Nur ein onkologisch erfahrener Arzt kann diagnostische Prozeduren und therapeutische Optionen in einen Kontext mit dem individuellen Patienten, seinen Allgemeinzustand und seinen Komorbiditäten, stellen.

\subsection{Onkologische Diagnostik - allgemein}

Eine onkologische Diagnose setzt fast immer die Entnahme und Untersuchung einer geeigneten Gewebeprobe voraus. Hämatologische Erkrankungen (z. B. akute oder chronische Leukämien, hämatogen ausschwemmende Lymphome) können aus dem Blut oder Knochenmark diagnostiziert werden. Bei soliden Tumoren ist die Biopsieentnahme aus dem Primärtumor oder aus Metastasen (z. B. mittels Endoskopie oder Stanzbiopsie) notwendig. Das am wenigsten beeinträchtigende Verfahren soll gewählt werden. 
Tabelle 1: Diagnostik in Abhängigkeit vom Allgemeinzustand

\begin{tabular}{|l|l|}
\hline Karnofsky-Index & Diagnostik \\
\hline $100-70(60) \%$ & $\begin{array}{l}\text { Alle diagnostischen Maßnahmen können durchgeführt werden. } \\
\text { Patient ist für onkologische Therapie ausreichend belastbar. }\end{array}$ \\
\hline$(60) 50-40 \%$ & $\begin{array}{l}\text { a)Verdacht auf hämatologische Neoplasie (Leukämie, Lym- } \\
\text { phom): Diagnostik indiziert, der Allgemeinzustand darf erst nach } \\
\text { Durchführung einer Vorphase-Chemotherapie beurteilt werden. } \\
\text { b)Verdacht auf soliden Tumor: Zurückhaltung bei Diagnostik, } \\
\text { Patient ist für eine intensive Therapie nicht belastbar. }\end{array}$ \\
\hline $30-10 \%$ & $\begin{array}{l}\text { Verzicht auf onkologische Diagnostik, da eine tumorspezifische } \\
\text { Therapie nicht durchführbar ist. Symptomkontrolle. }\end{array}$ \\
\hline
\end{tabular}

\subsection{Diagnostische Massnahmen in der Onkologie - speziell}

\subsubsection{Untersuchung von Blut und Knochenmark (7)}

Durch die mikroskopische Untersuchung von Blut bzw. Knochenmark lassen sich hämatologische Erkrankungen diagnostizieren und gegebenenfalls durch zusätzliche Untersuchungen weiter charakterisieren. Die Immunphänotypisierung erlaubt die Unterscheidung myeloischer und lymphatischer Zellen sowie eine exakte Einordnung von Zellpopulationen (z. B. Blasten bei einer akuten Leukämie, verschiedene Arten von Non-Hodgkin Lymphomen usw.). Zytogenetische und molekulargenetische Untersuchungen ermöglichen die Identifikation charakteristischer genetischer Veränderungen, z. B. den Nachweis des sogenannten „PhiladelphiaChromosoms“ (einer Translokation $\mathrm{t}(9 ; 22)$ ) bei der chronischen myeloischen Leukämie (die t(9;22) kommt aber auch bei manchen akuten Leukämien vor). Das „Philadelphia-Chromosom“ kodiert für eine pathologische Tyrosinkinase, die das maligne Verhalten der Blutzellen hervorruft. Diese Tyrosinkinase lässt sich mit oralen Tyrosinkinaseinhibitoren hemmen und so die Erkrankung in Remission bringen. Die genannten Untersuchungen sind am peripheren Blut durchführbar. Bei der Knochenmarkpunktion wird am dorsalen Beckenkamm unter örtlicher Betäubung Knochenmark entnommen. Wenn der Patient dies wünscht, ist die Prozedur aber auch unter Sedierung sehr risikoarm durchführbar. Allerdings setzt die Durchführung einer Sedierung die Möglichkeit der Monitorüberwachung des Patienten voraus. In der fortgeschrittenen Palliativsituation kann meistens auf eine Knochenmarkpunktion verzichtet werden. 


\subsubsection{Mikroskopie}

Die Mikroskopie von Ausstrichpräparaten von Blut-, Knochenmarks- oder Tumorbiopsien ist technisch sehr einfach und schnell durchführbar. Vielfach kann eine hämatologische Erkrankung, z. B. eine akute Leukämie, eine chronische myeloische Leukämie, eine chronische lymphatische Leukämie oder andere hämatogen ausschwemmende Non-Hodgkin-Lymphome auf diese Weise erkannt werden.

\subsubsection{Immunphänotypisierung}

Durch die „Anfärbung“ von spezifischen Markern auf der Oberfläche (CDAntigene) oder im Zytoplasma von Tumorzellen in Blut oder Knochenmark können Zellpopulationen identifiziert und so hämatologische Erkrankungen weiter spezifiziert werden. Beispielsweise findet man bei der chronischen lymphatischen Leukämie zahlreiche Lymphozyten sowie Kernschatten im mikroskopischen Blutausstrich. Die ergänzende Immunphänotypisierung kann diese lymphatische Zellpopulation als typische chronische lymphatische Leukämie charakterisieren und so gegen andere hämatogen ausschwemmende Non-Hodgkin-Lymphome oder akute Leukämien abgrenzen.

\subsubsection{Zytogenetische Untersuchung}

Die zytogenetische Untersuchung von Tumorzellen im Blut oder Knochenmark dient in der Regel zur weiteren Risiko- und Prognoseabschätzung bei hämatologischen Erkrankungen und ist daher in der fortgeschrittenen Palliativsituation verzichtbar. In einzelnen Fällen, speziell bei der chronisch-myeloischen Leukämie oder bestimmten Formen der akuten lymphatischen Leukämie ist der Nachweis des „Philadelphia-Chromosoms“ aber wichtig, da hieraus die Möglichkeit entsteht, eine Therapie mit einem gut verträglichen, oral einzunehmenden Tyrosinkinasehemmer mit sehr guten Behandlungschancen einzuleiten. Nach klinisch relevanten genetischen Veränderungen kann sehr rasch und kostengünstig mittels FISHDiagnostik gesucht werden.

\subsubsection{Molekulare Diagnostik}

Die molekulare Diagnostik dient der Identifizierung typischer „Treibermutationen“. So werden genetische Veränderungen von Rezeptoren oder intrazellulären Signaltransduktionsmolekülen bezeichnet, die kritisch für das maligne Verhalten bzw. das Überleben einer Krebszelle sind (8). Beispielhaft kann hier eine aktivierende Mutation des EGF-Rezeptors bei nicht-kleinzelligen Bronchialkarzinomen erwähnt werden. Die Blockade dieser pathologisch aktivierten RezeptorTyrosinkinase führt zum Absterben der Tumorzellen und zu vielfach ganz beein- 
druckendem klinischen Ansprechen. Dieses währt allerdings in der Regel nur einige Monate, da es bei Blockade eines Aktivierungsmechanismus in den Krebszellen zu alternativen Aktivierungsmechanismen kommt.

\subsubsection{Punktion von Körperhöhlen}

Ascites- und Pleurapunktion zur zytologischen und laborchemischen Diagnostik

Die sonographisch kontrollierte Punktion von Ascites oder Pleurarguss ist sehr risikoarm und für den Patienten kaum belastend unter Lokalanästhesie durchzuführen. Die hierbei gewonnenen Ergussproben können zytologisch und laborchemisch untersucht werden. Bei malignen Ergüssen sind zumindest die ungefähre Eingrenzung der zugrunde liegenden Krebserkrankung sowie die Abgrenzung gegen benigne Erkrankungen vielfach möglich. Beispielsweise ist es durch die laborchemische und zytologische Untersuchung von Ascites zumeist möglich, Ascites bei dekompensierter Leberzirrhose von einer spontan-bakteriellen Peritonitis oder malignem Ascites zu unterscheiden.

\subsubsection{Endoskopie}

Endoskopische Verfahren erlauben die Identifikation einer malignomverdächtigen Struktur im oberen oder unteren Gastrointestinaltrakt, im Bronchialsystem oder in der Harnblase, wobei aus karzinomverdächtigen Veränderungen unmittelbar Gewebeproben entnommen werden können (9). Endoskopische Untersuchungen können sehr risikoarm unter Sedierung durchgeführt werden und sind dann für den Patienten kaum belastend. Vor endoskopischen Untersuchungen sollte die Blutgerinnung kontrolliert und gegebenenfalls optimiert werden. Bei Einnahme von Antikoagulanzien sollten diese vor der Endoskopie pausiert werden. Üblicherweise braucht ASS in der üblichen Dosis vor endoskopischen Untersuchungen nicht pausiert zu werden.

\subsection{8 Ösophago-Gastro-Duodenoskopie}

Die Ösophago-Gastro-Duodenoskopie sollte bei Beschwerden oder bei Verdacht auf ein Malignom im oberen Gastrointestinaltrakt durchgeführt werden, beispielsweise bei neu aufgetretener Übelkeit oder Erbrechen, Schmerzen im Oberbauch oder unklarer Gewichtsabnahme. Sollten primär Metastasen, z. B. in der Leber oder im Knochen, aufgefallen sein, so ist die Gastroskopie zur Primärtumorsuche indiziert. Die Untersuchung erlaubt die Begutachtung des oberen Gastrointestinaltraktes, von der Speiseröhre bis zum Zwölffingerdarm. Während der Untersuchung können direkt Gewebeproben mittels Zangenbiopsie aus verdächtigen Arealen entnommen werden. Darüber hinaus können gegebenenfalls tumorbedingte Stenosen begutachtet werden; eventuell ist eine Stent-Anlage in palliativer Intenti- 
on zur Überbrückung der Tumorstenose und Wiederherstellung der Nahrungspassage möglich. Bei nicht zu überwindender post-gastraler Stenose kann eine AblaufPEG (Perkutane Endoskopische Gastrostomie) dem Patienten Erbrechen ersparen und die orale Nahrungsaufnahme ermöglichen (wobei der Mageninhalt natürlich durch die PEG wieder abläuft).

\subsubsection{Coloskopie}

Die Coloskopie erlaubt die risikoarme Untersuchung des gesamten Dickdarmes. $\mathrm{Da}$ auch diese Untersuchung unter Sedierung durchgeführt werden kann, ist die Belastung für den Patienten gering. Allerdings muss der Dickdarm zur Vorbereitung der Coloskopie gereinigt werden, weil die Verschmutzung des Darmes durch Stuhl die Beurteilbarkeit stark beeinträchtigen kann bzw. die Untersuchung sogar unmöglich macht. Diese vorbereitenden Maßnahmen können für den Patienten durchaus belastend sein. Aus tumorverdächtigen Veränderungen können Zangenbiopsien zur histologischen Untersuchung entnommen werden. Bei Tumorstenosen im Colon ist eventuell auch eine Stent-Implantation möglich.

\subsubsection{Bronchoskopie}

Die Bronchoskopie erlaubt die Probenentnahme aus endobronchial bzw. intrapulmonal gelegenen Prozessen, sofern diese über das Bronchialsystem zugänglich sind (10). Auch die Bronchoskopie kann unter Sedierung risikoarm und wenig belastend für den Patienten durchgeführt werden. Aus zentral gelegenen endobronchialen Veränderungen können unter direkter Sicht Gewebeproben mittels Bürste (für die zytologische Untersuchung) und Biopsiezange (für die histologische Untersuchung) gewonnen werden. Tumoren, die in der Lungenperipherie gelegen sind, entziehen sich der direkten Darstellbarkeit und sind daher weniger sicher zu erreichen. Hilfsmittel zur Biopsieentnahme aus peripheren Lungenherden sind die unterstützende Anwendung einer endobronchialen Ultraschall-Minisonde oder, bei radiologisch darstellbaren Tumoren, die gezielte Biopsie unter Röntgendurchleuchtung. Mittels endobronchialen Ultraschalls (EBUS) können Tumoren bzw. Lymphknoten, die paratracheal oder parabronchial gelegen sind, dargestellt werden. Dadurch wird eine ultraschall-gezielte Nadelbiopsie aus entsprechenden Tumoren möglich. Mittels endobronchialem Ultraschall gesteuerten Nadelbiopsien können zwar lediglich zytologische Untersuchungen durchgeführt werden. Jedoch ist hier durch ergänzende immunzytochemische Untersuchungen in den meisten Fällen eine Diagnosestellung möglich. Auch molekulargenetische Untersuchungen können am zytologischen Material durchgeführt werden (z. B. zum Nachweis einer aktivierenden EGF-Rezeptor-Mutation beim nicht-kleinzelligen Bronchialkarzinom). 


\subsection{Perkutane Punktion von Tumoren}

Oberflächlich gelegene Tumoren wie beispielsweise Lymphknoten oder Tumoren in der Mamma können sehr einfach durch perkutane Punktion erreicht werden. Die Punktion wird unter örtlicher Betäubung durchgeführt. Die Prozedur ist sehr risikoarm und für den Patienten kaum schmerzhaft. Bei Verwendung entsprechender Biopsienadeln zur Gewinnung von Stanzbiopsien ist das komplette Spektrum der histologischen Aufarbeitung möglich. Einige Tumoren, die der Endoskopie nicht zugänglich sind, können mittels perkutaner Punktion unter Zielsteuerung durch ein bildgebendes Verfahren erreicht werden. Üblicherweise kommen Ultraschall oder Computertomographie zur Zielkontrolle zum Einsatz. Unter Sicht kann die Biopsienadel an die Zielstruktur herangeführt werden. Ein automatischer Mechanismus erlaubt dann das Vorschnellen der Biopsienadel in die Zielläsion, wobei ein Gewebezylinder in einer Hohlnadel gewonnen und abgeschnitten wird. Der Gewebszylinder kann histologisch untersucht werden. Dieses Verfahren kann immer zum Einsatz kommen, wenn keine gefährlichen Strukturen, z. B. Blutgefäße, im Punktionsgebiet liegen. Beispielsweise können Tumoren in der Leber oder abdominelle Lymphknoten oft sehr gut erreicht werden. Vor Nadelbiopsien muss ebenfalls die Blutgerinnung kontrolliert und Antikoagulanzien (außer ASS in üblicher Dosis) pausiert werden. Der Patient muss über das Verletzungs- und Blutungsrisiko bei der Prozedur aufgeklärt werden. Ultraschall- oder CT-gesteuerte Nadelbiopsien aus Lungentumoren sind ebenfalls möglich. Bei sehr peripher gelegenen Lungenherden mit Kontakt zur Brustwand ist das Verfahren sehr risikoarm, bei Tumoren ohne breiten Kontakt der Brustwand muss allerdings aufgrund der notwendigen Verletzung der Lunge mit einem Pneumothorax gerechnet werden.

\section{Fallbeispiel}

Ein 54-jähriger Patient kommt mit multiplen hepatischen Herdsetzungen zur stationären Aufnahme. Eine Gastroskopie und eine Coloskopie ergeben keinen pathologischen Befund und keinen Hinweis auf einen Primärtumor. Eine CT-Untersuchung von Thorax und Abdomen zeigt eine kleine Raumforderung des Pankreas. Die ultraschallgesteuerte Punktion eines Leberherdes erbringt die Diagnose eines Adenokarzinomes, vereinbar mit einem Pankreaskarzinom. Der Patient ist in einem guten Allgemeinzustand, Karnofsky-Index $80 \%$. Eine palliative Chemotherapie nach dem FOLFIRINOX-Schema wird eingeleitet. 


\subsection{Chirurgische/Invasive Verfahren}

Thorakoskopie, diagnostische Laparoskopie

Aufgrund ihrer Invasivität sollten chirurgische Verfahren das letzte diagnostische Mittel darstellen. Wenn eine Diagnosestellung anders nicht möglich ist, kann aber auch eine Thorakoskopie zur Beurteilung des Thoraxraumes bzw. der Lunge oder eine Laparoskopie zur Untersuchung des Bauchraumes sehr risikoarm durchgeführt werden. Eine Narkose ist für die Untersuchung notwendig. Möglicherweise ist ein operativer Eingriff zur Symptomkontrolle vorgesehen, beispielsweise eine Thorakoskopie zur Durchführung einer Pleurodese oder eine Laparotomie zur Anlage einer Gastroenterostomie. Dann kann im Rahmen dieses Eingriffs gleichzeitig eine Gewebeprobe entnommen werden.

Tabelle 2: Diagnostik und mögliche therapeutische Konsequenz

\begin{tabular}{|l|l|}
\hline Untersuchung & Mögliche Konsequenz (Beispiele) \\
\hline $\begin{array}{l}\text { Untersuchung von } \\
\text { Blut/Knochenmark } \\
\text { Immunphänotypisierung } \\
\text { Zytogenetik }\end{array}$ & $\begin{array}{l}\text { Diagnose einer chronisch lymphatischen/myeloischen } \\
\text { Leukämie mit Option einer ausreichend gut verträglichen } \\
\text { Oralen Therapie. } \\
\text { Diagnose einer akuten Leukämie mit Option einer palliati- } \\
\text { ven milden, gut verträglichen Chemotherapie. }\end{array}$ \\
\hline $\begin{array}{l}\text { Punktion von Ascites/ } \\
\text { Pleuraerguß }\end{array}$ & $\begin{array}{l}\text { Zytologische Diagnosestellung einer Krebserkrankung } \\
\text { Abgrenzung gegen andere Ergussursachen (Infektion usw.) }\end{array}$ \\
\hline $\begin{array}{l}\text { Ösophago-Gastro- } \\
\text { Duodenoskopie }\end{array}$ & $\begin{array}{l}\text { Histologiegewinnung zur Diagnostik } \\
\text { Identifikation einer funktionell wirksamen Stenose, Eva- } \\
\text { luation der Möglichkeit einer palliativen Stent-Anlage. }\end{array}$ \\
\hline Coloskopie & $\begin{array}{l}\text { Histologiegewinnung zur Diagnostik } \\
\text { Identifikation einer funktionell wirksamen Stenose, Eva- } \\
\text { luation der Möglichkeit einer palliativen Stent-Anlage }\end{array}$ \\
\hline Bronchoskopie & $\begin{array}{l}\text { Histologie-/Zytologiegewinnung zur Diagnostik } \\
\text { Identifikation einer Bronchusobstruktion durch Tumor, } \\
\text { Evaluation der Möglichkeit der Tumorabtragung, evtl. mit } \\
\text { Stent-Anlage zur Wiederbelüftung eines Lungenabschnit- } \\
\text { tes. }\end{array}$ \\
\hline $\begin{array}{l}\text { Thorakoskopie } \\
\text { Hei ausreichender diagnostischer Sicherheit Vermeidung } \\
\text { weiterer invasiver Untersuchungen (zum Beispiel operative } \\
\text { Probenentnahme) }\end{array}$ \\
\hline \begin{tabular}{l} 
Histologie-/Zytologiegewinnung zur Diagnostik \\
\hline
\end{tabular}
\end{tabular}




\begin{tabular}{|l|l|}
\hline Untersuchung & Mögliche Konsequenz (Beispiele) \\
\hline Laparoskopie & In gleichem Eingriff Pleurodese möglich \\
& $\begin{array}{l}\text { Histologie-/Zytologiegewinnung zur Diagnostik } \\
\text { Prüfung der Operabilität bei abdominellen Tumoren } \\
\text { Überprüfung, ob eine Peritonealkarzinose vorliegt }\end{array}$ \\
\hline
\end{tabular}

\subsection{Bildgebende Diagnostik in der Palliativmedizin}

In der Palliativmedizin hat die bildgebende Diagnostik die Aufgabe, die Ursache von Symptomen zu klären und zu ihrer raschen Behandlung beizutragen. Der Aufwand der Diagnostik richtet sich ganz entscheidend nach der klinischen Situation des Patienten und den therapeutischen Möglichkeiten, die für ihn oder sie in Frage kommen. Der Begriff „Palliativsituation“ umfasst das gesamte Spektrum, vom grundsätzlich zwar nicht heilbaren, aber noch wenig symptomatischen Patienten mit möglicherweise längerer Lebenserwartung bis hin zum terminal Kranken. Dementsprechend können auch in der Palliativsituation aufwendige oder invasive Maßnahmen indiziert sein, wenn auch allein im Interesse der Lebensqualität und nicht mit dem Ziel der Heilung.

Im Vordergrund steht bei der Diagnostik die Verträglichkeit und ZweckmäBigkeit. Keineswegs schließt dies apparativ aufwendige oder invasive Diagnostik aus. Im Gegenteil ist gerade in der Palliativmedizin eine Stufendiagnostik möglichst zu vermeiden. Sehr häufig kann z. B. der Ultraschall, wenn er vom Arzt vor Ort selbst durchgeführt wird, für die weitere Planung richtungsweisend sein. Muss der Patient hierfür erst an eine andere Stelle überwiesen werden, kann die Untersuchung erst mit Verzug erfolgen, oder ist die Expertise der sonographierenden Kollegen nicht klar, muss man überlegen, ob man nicht mit einer CT oder MRT rascher zum Ziel kommt. Der erhoffte Informationsgewinn und dessen Konsequenzen müssen gegen die Belastung durch Transport und die Untersuchung selbst abgewogen werden. Einige Indikationen (z. B. Dyspnoe, Bluthusten, obere Einflussstauung) erfordern schnelles Handeln und mit wenig invasiven Untersuchungen begrenzter Aussagekraft darf keine Zeit vertan werden. Patienten mit solchen Symptomen sollten dort weiter untersucht werden, wo man nötigenfalls auch die Ursache der Symptome rasch behandeln kann. Somit hängt das Vorgehen sehr von den Möglichkeiten und der „Logistik“ vor Ort ab.

Die folgenden Tabellen geben eine Übersicht über die wichtigsten Symptome in der Palliativmedizin, ihre häufigsten Ursachen und therapeutischen Konsequenzen sowie geeignete Verfahren zur Abklärung. Sie sind angelehnt an die „Orientierungshilfe für bildgebende Untersuchungen“ der Strahlenschutzkommission und den analogen ,iRefer“-Empfehlungen des British College of Radiologists, aber nur der Form und dem Aufbau nach. Die Empfehlungsgrade im Einzelnen sind ihnen 
nicht entnommen, sondern stellen Empfehlungen der Autoren selbst dar, die den Besonderheiten in der Palliativmedizin Rechnung tragen.

\subsubsection{Schmerz}

\begin{tabular}{|c|c|c|c|c|}
\hline $\begin{array}{l}\text { Lokalisa- } \\
\text { tion }\end{array}$ & $\begin{array}{l}\text { Mögliche } \\
\text { Ursache }\end{array}$ & $\begin{array}{l}\text { Mögliche } \\
\text { Konsequenzen } \\
\text { (neben } \\
\text { Schmerz- } \\
\text { therapie) }\end{array}$ & $\begin{array}{l}\text { Bildgebendes } \\
\text { Verfahren }\end{array}$ & Erläuterungen \\
\hline \multirow[t]{3}{*}{ Knochen } & Osteolyse & Strahlentherapie & \multirow{3}{*}{$\begin{array}{l}\text { Planare } \\
\text { Radiographie } \\
\text { (p), } \\
\text { CT (p), } \\
\text { MRT (w), } \\
\text { Skelettszinti- } \\
\text { graphie (n) }\end{array}$} & \multirow{3}{*}{$\begin{array}{l}\text { Planare Radiogra- } \\
\text { phie am periphe- } \\
\text { ren Skelett und } \\
\text { CT am Stamms- } \\
\text { kelett zeigen } \\
\text { Schäden am mine- } \\
\text { ralisierten Kno- } \\
\text { chen. Eine Mark- } \\
\text { rauminfiltration } \\
\text { ist am peripheren } \\
\text { Skelett mit CT } \\
\text { oder MRT dar- } \\
\text { stellbar, am } \\
\text { Stammskelett nur } \\
\text { mit der MRT. }\end{array}$} \\
\hline & Fraktur & $\begin{array}{l}\text { Operative oder } \\
\text { interventionelle } \\
\text { Stabilisierung, } \\
\text { Strahlentherapie }\end{array}$ & & \\
\hline & $\begin{array}{l}\text { Knochen- } \\
\text { marksinfilt- } \\
\text { ration }\end{array}$ & $\begin{array}{l}\text { Ggf. erneute } \\
\text { antitumoröse } \\
\text { Therapie }\end{array}$ & & \\
\hline \multirow[t]{3}{*}{ Kopf } & $\begin{array}{l}\text { Tumor oder } \\
\text { Metastase }\end{array}$ & $\begin{array}{l}\text { Strahlenthera- } \\
\text { pie, } \\
\text { antiödematöse } \\
\text { Therapie, } \\
\text { operative } \\
\text { Entlastung oder } \\
\text { Resektion }\end{array}$ & \multirow[t]{3}{*}{$\begin{array}{l}\text { CT (p), } \\
\text { MRT (w), } \\
\text { planare } \\
\text { Radiographie } \\
\text { bei lokalisier- } \\
\text { ten Schmer- } \\
\text { zen der } \\
\text { Kalotte (p) }\end{array}$} & \multirow{3}{*}{$\begin{array}{l}\text { MRT ist zwar } \\
\text { sensitiver } \\
\text { als CT für Tumo- } \\
\text { ren, wenn } \\
\text { sich diese aber } \\
\text { durch } \\
\text { Schmerzen mani- } \\
\text { festieren, } \\
\text { sind sie ebenso } \\
\text { wie ein } \\
\text { Ödem in der CT } \\
\text { in der Regel dar- } \\
\text { stellbar. }\end{array}$} \\
\hline & Ödem & $\begin{array}{l}\text { Antiödematöse } \\
\text { Therapie oder } \\
\text { operative } \\
\text { Druckentlastung }\end{array}$ & & \\
\hline & Knöchern & Strahlentherapie & & \\
\hline $\begin{array}{l}\text { Nervales } \\
\text { Areal oder } \\
\text { Dermatom }\end{array}$ & $\begin{array}{l}\text { Kompressi- } \\
\text { on, } \\
\text { Fraktur }\end{array}$ & $\begin{array}{l}\text { Resektion, } \\
\text { Strahlentherapie }\end{array}$ & $\begin{array}{l}\text { MRT (p) bei } \\
\text { radikulärer } \\
\text { oder plexus- } \\
\text { bezogener } \\
\text { Symptomatik. } \\
\text { US (p), CT (p) } \\
\text { oder MRT (w) }\end{array}$ & $\begin{array}{l}\text { Nervensonogra- } \\
\text { phie erfordert } \\
\text { spezifische } \\
\text { Fachkenntnisse. } \\
\text { Bei wirbelsäulen- } \\
\text { nahen Prozessen } \\
\text { MRT wegen ho- }\end{array}$ \\
\hline
\end{tabular}




\begin{tabular}{|c|c|c|c|c|}
\hline \multirow[t]{2}{*}{$\begin{array}{l}\text { Lokalisa- } \\
\text { tion }\end{array}$} & $\begin{array}{l}\text { Mögliche } \\
\text { Ursache }\end{array}$ & $\begin{array}{l}\text { Mögliche } \\
\text { Konsequenzen } \\
\text { (neben } \\
\text { Schmerz- } \\
\text { therapie) }\end{array}$ & $\begin{array}{l}\text { Bildgebendes } \\
\text { Verfahren }\end{array}$ & Erläuterungen \\
\hline & & & $\begin{array}{l}\text { bei V.a. Läsi- } \\
\text { on eines peri- } \\
\text { pheren Ner- } \\
\text { ven, je nach } \\
\text { vermuteter } \\
\text { Lokalisation } \\
\text { und mögli- } \\
\text { chem sono- } \\
\text { graphischen } \\
\text { Zugang. } \\
\text { Planare Radi- } \\
\text { ographie (n) }\end{array}$ & $\begin{array}{l}\text { hen Weichteilkon- } \\
\text { trasts. }\end{array}$ \\
\hline \multirow[t]{4}{*}{ Bauch } & Abszess & $\begin{array}{l}\text { Invasive Drai- } \\
\text { nage, } \\
\text { antibiotische } \\
\text { Therapie }\end{array}$ & \multirow{3}{*}{$\begin{array}{l}\text { US (p), } \\
\text { planare Radi- } \\
\text { ographie (p), } \\
\text { CT (p), } \\
\text { MRT (w) }\end{array}$} & \multirow{3}{*}{$\begin{array}{l}\text { Diagnose einer } \\
\text { Pankreatitis pri- } \\
\text { mär laborche- } \\
\text { misch. } \\
\text { Aussagekraft des } \\
\text { US von Expertise } \\
\text { des Untersuchers } \\
\text { abhängig, im } \\
\text { Zweifelsfall CT. } \\
\text { MRT meist } \\
\text { nicht erforderlich. } \\
\text { Planare Radiogra- } \\
\text { phie bei V.a. Ileus, } \\
\text { Subileus oder } \\
\text { Perforation. }\end{array}$} \\
\hline & Pankreatitis & $\begin{array}{l}\text { Spezifische } \\
\text { internistische } \\
\text { Therapie der } \\
\text { Pankreatitis, ggf. } \\
\text { Stenteinlage, } \\
\text { Steinextraktion } \\
\text { bei chologener } \\
\text { Pankreatitis. }\end{array}$ & & \\
\hline & $\begin{array}{l}\text { Peritoneal- } \\
\text { karzinose }\end{array}$ & $\begin{array}{l}\text { Diätetische } \\
\text { Maßnahmen, } \\
\text { ggf. parenterale } \\
\text { Ernährung, } \\
\text { Spasmolytika, } \\
\text { OP bei um- } \\
\text { schriebener } \\
\text { Darmobstrukti- } \\
\text { on, } \\
\text { ggf. erneute } \\
\text { antitumoröse } \\
\text { Therapie }\end{array}$ & & \\
\hline & $\begin{array}{l}\text { Stenose } \\
\text { oder Perfo- } \\
\text { ration eines }\end{array}$ & $\mathrm{OP}$ & & \\
\hline
\end{tabular}




\begin{tabular}{|c|c|c|c|c|}
\hline $\begin{array}{l}\text { Lokalisa- } \\
\text { tion }\end{array}$ & $\begin{array}{l}\text { Mögliche } \\
\text { Ursache }\end{array}$ & $\begin{array}{l}\text { Mögliche } \\
\text { Konsequenzen } \\
\text { (neben } \\
\text { Schmerz- } \\
\text { therapie) }\end{array}$ & $\begin{array}{l}\text { Bildgebendes } \\
\text { Verfahren }\end{array}$ & Erläuterungen \\
\hline & \multicolumn{2}{|l|}{ Hohlorgans } & & \\
\hline & $\begin{array}{l}\text { Leberkap- } \\
\text { selspannung }\end{array}$ & $\begin{array}{l}\text { Ggf. erneute } \\
\text { antitumoröse } \\
\text { Therapie, } \\
\text { stereotaktische } \\
\text { Strahlentherapie } \\
\text { oder lokal abla- } \\
\text { tive Maßnah- } \\
\text { men }\end{array}$ & & \\
\hline
\end{tabular}

Empfehlungsgrade: $\mathrm{p}=$ primär indiziert, $\mathbf{w}=$ weiterführende Untersuchung, $\mathrm{s}=$ Spezialverfahren, $\mathrm{n}=$ nicht indiziert

\subsubsection{Nervensystem}

\subsubsection{Paresen}

\begin{tabular}{|c|c|c|c|c|}
\hline $\begin{array}{l}\text { Neurolo- } \\
\text { gische } \\
\text { Zuord- } \\
\text { nung }\end{array}$ & $\begin{array}{l}\text { Mögliche } \\
\text { Ursache }\end{array}$ & $\begin{array}{l}\text { Mögliche } \\
\text { Konsequenz }\end{array}$ & $\begin{array}{l}\text { Bildgebendes } \\
\text { Verfahren }\end{array}$ & Erläuterungen \\
\hline \multirow[t]{4}{*}{ Gehirn } & $\begin{array}{l}\text { Tumor oder } \\
\text { Metastasen }\end{array}$ & Strahlentherapie & \multirow{4}{*}{$\begin{array}{l}\text { CT (p), } \\
\text { MRT (w), } \\
\text { Planare Radi- } \\
\text { ographie (n), } \\
\text { US (n) }\end{array}$} & \multirow{4}{*}{$\begin{array}{l}\text { CT bei ZNS- } \\
\text { Symptomen oft } \\
\text { trotz geringerer } \\
\text { Sensitivität als die } \\
\text { MRT richtungs- } \\
\text { weisend. MRT } \\
\text { klar überlegen in } \\
\text { der hinteren } \\
\text { Schädelgrube und } \\
\text { bei V.a. radioge- } \\
\text { nen Läsionen. }\end{array}$} \\
\hline & Blutung & $\begin{array}{l}\text { Operative Aus- } \\
\text { räumung }\end{array}$ & & \\
\hline & Infarkt & $\begin{array}{l}\text { Am ehesten } \\
\text { konservatives } \\
\text { Vorgehen }\end{array}$ & & \\
\hline & Radiogen & $\begin{array}{l}\text { Konservatives } \\
\text { Vorgehen, } \\
\text { antiödematöse } \\
\text { Therapie, } \\
\text { invasive Entlas- } \\
\text { tung }\end{array}$ & & \\
\hline $\begin{array}{l}\text { Rücken- } \\
\text { mark }\end{array}$ & $\begin{array}{l}\text { Intra- } \\
\text { medulläre } \\
\text { Metastasen }\end{array}$ & $\begin{array}{l}\text { Operative Ent- } \\
\text { lastung, } \\
\text { Strahlentherapie }\end{array}$ & $\begin{array}{l}\text { MRT (p), } \\
\text { CT (w), } \\
\text { Planare Radio- }\end{array}$ & $\begin{array}{l}\text { MRT primär indi- } \\
\text { ziert und meist } \\
\text { zielführend. CT }\end{array}$ \\
\hline
\end{tabular}




\begin{tabular}{|c|c|c|c|c|}
\hline $\begin{array}{l}\text { Neurolo- } \\
\text { gische } \\
\text { Zuord- } \\
\text { nung }\end{array}$ & $\begin{array}{l}\text { Mögliche } \\
\text { Ursache }\end{array}$ & $\begin{array}{l}\text { Mögliche } \\
\text { Konsequenz }\end{array}$ & $\begin{array}{l}\text { Bildgebendes } \\
\text { Verfahren }\end{array}$ & Erläuterungen \\
\hline & $\begin{array}{l}\text { Meningeale } \\
\text { Metastasen }\end{array}$ & Strahlentherapie & \multirow[t]{4}{*}{$\begin{array}{l}\text { graphie (n), } \\
\text { US (n) }\end{array}$} & \multirow{4}{*}{$\begin{array}{l}\text { bei Nachweis } \\
\text { knöcherner Läsi- } \\
\text { onen in der MRT } \\
\text { zur Beurteilung } \\
\text { der Stabilität. }\end{array}$} \\
\hline & $\begin{array}{l}\text { Knochen- } \\
\text { metastasen }\end{array}$ & Strahlentherapie & & \\
\hline & Frakturen & $\begin{array}{l}\text { Invasive oder } \\
\text { konservative } \\
\text { Stabilisierung, } \\
\text { Strahlentherapie }\end{array}$ & & \\
\hline & Radiogen & $\begin{array}{l}\text { Analgesie, neu- } \\
\text { roprotektive } \\
\text { Medikamente, } \\
\text { Dexamethason }\end{array}$ & & \\
\hline Plexus & Infiltration & $\begin{array}{l}\text { Operative Ent- } \\
\text { lastung, } \\
\text { Strahlentherpie, } \\
\text { Analgesie, neu- } \\
\text { roprotektive } \\
\text { Medikation }\end{array}$ & $\begin{array}{l}\text { MRT (p), } \\
\text { CT (p), } \\
\text { US (p), } \\
\text { planare Radi- } \\
\text { ographie (n) }\end{array}$ & $\begin{array}{l}\text { Wahl der Metho- } \\
\text { de abhängig von } \\
\text { der vermuteten } \\
\text { Lokalisation. } \\
\text { Neurosonogra- } \\
\text { phie erfordert } \\
\text { spezifische } \\
\text { Kenntnisse, } \\
\text { Nachweis größe- } \\
\text { rer Tumoren im } \\
\text { Bereich des pl. } \\
\text { Cervicobrachialis } \\
\text { sonographisch } \\
\text { aber meist pro- } \\
\text { blemlos möglich. }\end{array}$ \\
\hline $\begin{array}{l}\text { Periphere } \\
\text { Nerven }\end{array}$ & Infiltration & $\begin{array}{l}\text { Operative Ent- } \\
\text { lastung } \\
\text { Strahlentherapie } \\
\text { Analgesie, neu- } \\
\text { roprotektive } \\
\text { Medikation, } \\
\text { Dexamethason }\end{array}$ & $\begin{array}{l}\text { US (p) } \\
\text { MRT (w) } \\
\text { CT (w) }\end{array}$ & $\begin{array}{l}\text { Wahl der Metho- } \\
\text { de abhängig von } \\
\text { der vermuteten } \\
\text { Lokalisation. } \\
\text { Neurosonogra- } \\
\text { phie erfordert } \\
\text { spezifische } \\
\text { Kenntnisse. Ner- } \\
\text { ven infiltrierende } \\
\text { Tumoren in den } \\
\text { Extremitäten sind } \\
\text { sonographisch gut } \\
\text { zugänglich. Bei }\end{array}$ \\
\hline
\end{tabular}




\begin{tabular}{|c|c|c|c|c|}
\hline $\begin{array}{l}\text { Neurolo- } \\
\text { gische } \\
\text { Zuord- } \\
\text { nung }\end{array}$ & $\begin{array}{l}\text { Mögliche } \\
\text { Ursache }\end{array}$ & $\begin{array}{l}\text { Mögliche } \\
\text { Konsequenz }\end{array}$ & $\begin{array}{l}\text { Bildgebendes } \\
\text { Verfahren }\end{array}$ & Erläuterungen \\
\hline & & & & $\begin{array}{l}\text { V.a. Läsion im } \\
\text { Körperstamm } \\
\text { vorzugsweise } \\
\text { MRT. CT wenn } \\
\text { MRT kontraindi- } \\
\text { ziert oder nicht } \\
\text { zumutbar ist. }\end{array}$ \\
\hline \multirow[t]{3}{*}{$\begin{array}{l}\text { Sehstö- } \\
\text { rungen/ } \\
\text { Gesichts- } \\
\text { feld- } \\
\text { ausfälle }\end{array}$} & $\begin{array}{l}\text { Optikus- } \\
\text { läsion }\end{array}$ & $\begin{array}{l}\text { Antiödematöse } \\
\text { Therapie } \\
\text { (Dexamthason), } \\
\text { Strahlen- } \\
\text { therapie }\end{array}$ & \multirow[t]{3}{*}{$\begin{array}{l}\text { MRT (p), } \\
\text { CT (p) }\end{array}$} & \multirow[t]{3}{*}{$\begin{array}{l}\text { MRT aufgrund } \\
\text { des Weichteilkon- } \\
\text { trasts vorzuzie- } \\
\text { hen. CT behelfs- } \\
\text { weise, wenn MRT } \\
\text { nicht möglich. }\end{array}$} \\
\hline & $\begin{array}{l}\text { Chiasma- } \\
\text { läsion }\end{array}$ & $\begin{array}{l}\text { Antiödematöse } \\
\text { Therapie } \\
\text { (Dexamthason), } \\
\text { Strahlen- } \\
\text { therapie }\end{array}$ & & \\
\hline & $\begin{array}{l}\text { Motilitäts- } \\
\text { störungen/ } \\
\text { Doppel- } \\
\text { bilder }\end{array}$ & $\begin{array}{l}\text { Antiödematöse } \\
\text { Therapie } \\
\text { (Dexamthason), } \\
\text { Strahlen- } \\
\text { therapie }\end{array}$ & & \\
\hline
\end{tabular}

Empfehlungsgrade: $\mathrm{p}=$ primär indiziert, $\mathrm{w}=$ weiterführende Untersuchung, $\mathrm{s}=$ Spezialverfahren, $\mathrm{n}=$ nicht indiziert 
3.8.2.2 Zentralnervöse Symptome

\begin{tabular}{|c|c|c|c|c|}
\hline Symptom & $\begin{array}{l}\text { Mögliche } \\
\text { Ursache }\end{array}$ & $\begin{array}{l}\text { Mögliche } \\
\text { Konsequenz }\end{array}$ & $\begin{array}{l}\text { Bildgebendes } \\
\text { Verfahren }\end{array}$ & Erläuterungen \\
\hline \multirow[t]{2}{*}{$\begin{array}{l}\text { Somno- } \\
\text { lenz/ } \\
\text { Koma }\end{array}$} & Hirnödem & $\begin{array}{l}\text { Antiödematöse } \\
\text { Therapie, } \\
\text { operative Ent- } \\
\text { lastung }\end{array}$ & \multirow[t]{4}{*}{$\begin{array}{l}\operatorname{MRT}(p), \\
\text { CT }(p)\end{array}$} & \multirow{4}{*}{$\begin{array}{l}\text { MRT wegen guten } \\
\text { Weichteilkontrasts } \\
\text { vorzuziehen. CT } \\
\text { bei V.a. akute } \\
\text { Blutung (z. B. } \\
\text { akuter Symptoma- } \\
\text { tik) der MRT } \\
\text { überlegen, an- } \\
\text { sonsten nur, wenn } \\
\text { MRT nicht mög- } \\
\text { lich. }\end{array}$} \\
\hline & Metabolisch & $\begin{array}{l}\text { Medikamentöse } \\
\text { Korrektur }\end{array}$ & & \\
\hline \multirow[t]{2}{*}{ Anfälle } & Metastase & $\begin{array}{l}\text { Antiepileptische } \\
\text { Therapie, } \\
\text { Strahlen- } \\
\text { therapie }\end{array}$ & & \\
\hline & Blutung & $\begin{array}{l}\text { Operative Aus- } \\
\text { räumung }\end{array}$ & & \\
\hline
\end{tabular}

Empfehlungsgrade: $\mathrm{p}=$ primär indiziert, $\mathrm{w}=$ weiterführende Untersuchung, $\mathrm{s}=$ Spezialverfahren, $\mathrm{n}=$ nicht indiziert

\subsubsection{Gastrointestinale Symptome}

\begin{tabular}{|c|c|c|c|c|}
\hline Symptom & $\begin{array}{l}\text { Mögliche } \\
\text { Ursache }\end{array}$ & $\begin{array}{l}\text { Mögliche Kon- } \\
\text { sequenz }\end{array}$ & $\begin{array}{l}\text { Bildgebendes } \\
\text { Verfahren }\end{array}$ & Erläuterungen \\
\hline \multirow[t]{3}{*}{ Übelkeit } & $\begin{array}{l}\text { Obstruktion } \\
\text { /Motilitäts- } \\
\text { störung }\end{array}$ & $\begin{array}{l}\text { Bei lokalisierter } \\
\text { Stenose ggf. } \\
\text { OP, ansonsten } \\
\text { medikamentöse } \\
\text { Behandlung }\end{array}$ & \multirow[t]{3}{*}{$\begin{array}{l}\mathrm{US}(\mathrm{p}), \\
\mathrm{CT}(\mathrm{p}), \\
\operatorname{MRT}(\mathrm{w})\end{array}$} & \multirow{3}{*}{$\begin{array}{l}\text { Ultraschall ermög- } \\
\text { licht Untersu- } \\
\text { chung der Motili- } \\
\text { tät in Echtzeit } \\
\text { und den sensiti- } \\
\text { ven Nachweis } \\
\text { freier Flüssigkeit. } \\
\text { CT ist überlegen, } \\
\text { insbesondere zum } \\
\text { Nachweis einer } \\
\text { lokalen Obstruk- } \\
\text { tion und von } \\
\text { diskreten Zeichen } \\
\text { einer Peritoneal- } \\
\text { karzinose. MRT } \\
\text { ist für diese Fra- } \\
\text { gestellungen nicht } \\
\text { überlegen, kann }\end{array}$} \\
\hline & $\begin{array}{l}\text { Peritone- } \\
\text { alkarzinose }\end{array}$ & $\begin{array}{l}\text { Bei lokalisierter } \\
\text { Stenose ggf. } \\
\text { OP, ansonsten } \\
\text { medikamentöse } \\
\text { Behandlung }\end{array}$ & & \\
\hline & $\begin{array}{l}\text { Metabo- } \\
\text { lisch/Thera- } \\
\text { pieneben- } \\
\text { wirkung }\end{array}$ & $\begin{array}{l}\text { Medikamentöse } \\
\text { Korrektur, an- } \\
\text { tiemetische } \\
\text { Therapie }\end{array}$ & & \\
\hline
\end{tabular}




\begin{tabular}{|c|c|c|c|c|}
\hline Symptom & $\begin{array}{l}\text { Mögliche } \\
\text { Ursache }\end{array}$ & $\begin{array}{l}\text { Mögliche Kon- } \\
\text { sequenz }\end{array}$ & $\begin{array}{l}\text { Bildgebendes } \\
\text { Verfahren }\end{array}$ & Erläuterungen \\
\hline & & & & $\begin{array}{l}\text { aber in Einzelfäl- } \\
\text { len ergänzend } \\
\text { eingesetzt werden. }\end{array}$ \\
\hline \multirow[t]{2}{*}{$\begin{array}{l}\text { Häma- } \\
\text { temesis/ } \\
\text { Teer- } \\
\text { stuhl }\end{array}$} & $\begin{array}{l}\text { Ulzerieren- } \\
\text { der Tumor }\end{array}$ & $\begin{array}{l}\text { Endoskopische } \\
\text { Unterspritzung, } \\
\text { Operation, } \\
\text { konservatives } \\
\text { Vorgehen (med. } \\
\text { Säureblockade) }\end{array}$ & \multirow[t]{2}{*}{$\begin{array}{l}\text { Endoskopie } \\
(\mathrm{p}) \\
\text { CT (w), } \\
\text { MRT (w) }\end{array}$} & \multirow{2}{*}{$\begin{array}{l}\text { Endoskopie er- } \\
\text { möglicht Inter- } \\
\text { vention in gleicher } \\
\text { Sitzung. CT oder } \\
\text { MRT bei negati- } \\
\text { vem Befund zur } \\
\text { Suche nach einer } \\
\text { Blutungsquelle im } \\
\text { Dünndarm. }\end{array}$} \\
\hline & Ulkus & $\begin{array}{l}\text { Endoskopische } \\
\text { Unterspritzung, } \\
\text { Operation, } \\
\text { konservatives } \\
\text { Vorgehen (med. } \\
\text { Säureblockade) }\end{array}$ & & \\
\hline \multirow[t]{2}{*}{$\begin{array}{l}\text { Obsti- } \\
\text { pation }\end{array}$} & Subileus & $\begin{array}{l}\text { Diätetische und } \\
\text { medikamentöse } \\
\text { Maßnahmen, } \\
\text { parenterale Er- } \\
\text { nährung (wenn } \\
\text { indiziert und } \\
\text { gewollt) }\end{array}$ & \multirow{2}{*}{$\begin{array}{l}\text { Planare Radi- } \\
\text { ographie: } \\
\text { Abdomen- } \\
\text { Leeraufnahme } \\
\text { im Stehen } \\
\text { oder Linkssei- } \\
\text { tenlage (w), } \\
\text { US (w), } \\
\text { CT (w) }\end{array}$} & \multirow{2}{*}{$\begin{array}{l}\text { In aller Regel } \\
\text { keine bildgebende } \\
\text { Diagnostik erfor- } \\
\text { derlich. Bei V.a. } \\
\text { eine morphologi- } \\
\text { sche Ursache oder } \\
\text { einen Subileus ist } \\
\text { eine Abdomen- } \\
\text { Leeraufnahme im } \\
\text { Stehen zunächst } \\
\text { der Standard zur } \\
\text { Verifikation einer } \\
\text { schwerwiegenden } \\
\text { Motilitätsstörung, } \\
\text { Ultraschall und } \\
\text { CT zur Klärung } \\
\text { möglicher mor- } \\
\text { phologischer Ur- } \\
\text { sachen. }\end{array}$} \\
\hline & $\begin{array}{l}\text { Medikamen- } \\
\text { tös }\end{array}$ & $\begin{array}{l}\text { Therapieumstel- } \\
\text { lung }\end{array}$ & & \\
\hline \multirow[t]{2}{*}{ Ileus } & Paralytisch & $\begin{array}{l}\text { Medikamentöse } \\
\text { Stimulation, } \\
\text { Regulation des } \\
\text { Flüssigkeits- } \\
\text { haushaltes }\end{array}$ & \multirow{2}{*}{$\begin{array}{l}\text { Planare Radi- } \\
\text { ographie: } \\
\text { Abdomen- } \\
\text { Leeraufnahme } \\
\text { im Stehen } \\
\text { oder Linkssei- } \\
\text { tenlage (p), }\end{array}$} & \multirow{2}{*}{$\begin{array}{l}\text { Abdomen- } \\
\text { Leeraufnahme im } \\
\text { Stehen ist Stan- } \\
\text { dard für die Veri- } \\
\text { fikation eines } \\
\text { Ileus. CT und US } \\
\text { sind grundsätzlich }\end{array}$} \\
\hline & $\begin{array}{l}\text { Mechanisch } \\
\text { lokal }\end{array}$ & $\mathrm{OP}$ & & \\
\hline
\end{tabular}




\begin{tabular}{|c|c|c|c|c|}
\hline Symptom & $\begin{array}{l}\text { Mögliche } \\
\text { Ursache }\end{array}$ & $\begin{array}{l}\text { Mögliche Kon- } \\
\text { sequenz }\end{array}$ & $\begin{array}{l}\text { Bildgebendes } \\
\text { Verfahren }\end{array}$ & Erläuterungen \\
\hline & $\begin{array}{l}\text { Mechanisch } \\
\text { diffus }\end{array}$ & $\begin{array}{l}\text { Am ehesten } \\
\text { konservativ- } \\
\text { medikamentöses } \\
\text { Vorgehen }\end{array}$ & $\begin{array}{l}\text { US (p), } \\
\text { CT (p) }\end{array}$ & $\begin{array}{l}\text { ebenso leistungs- } \\
\text { fähig, haben aber } \\
\text { den Vorteil, dass } \\
\text { auch die Ursache } \\
\text { eines Ileus nach- } \\
\text { gewiesen werden } \\
\text { kann. }\end{array}$ \\
\hline \multirow[t]{2}{*}{ Diarrhoe } & Enteritis & $\begin{array}{l}\text { Flüssigkeits- } \\
\text { haushalt ausglei- } \\
\text { chen, Antidiar- } \\
\text { rhoika, } \\
\text { ggf. Antibiotika, } \\
\text { Kortison }\end{array}$ & \multirow[t]{2}{*}{ US (w) } & \multirow{2}{*}{$\begin{array}{l}\text { Zunächst keine } \\
\text { bildgebende Di- } \\
\text { agnostik erforder- } \\
\text { lich. US bei Per- } \\
\text { sistenz der Symp- } \\
\text { tome, weitere } \\
\text { Diagnostik ggf. } \\
\text { abhängig vom } \\
\text { sonographischen } \\
\text { Befund. }\end{array}$} \\
\hline & $\begin{array}{l}\text { Medikamen- } \\
\text { tös }\end{array}$ & Therapiewechsel & & \\
\hline \multirow[t]{5}{*}{ Aszites } & $\begin{array}{l}\text { Peritone- } \\
\text { alkarzinose }\end{array}$ & $\begin{array}{l}\text { Ggf. erneute } \\
\text { antitumoröse } \\
\text { Therapie, ggf. } \\
\text { Punktion wenn } \\
\text { unvermeidbar } \\
\text { (Symptomatik) }\end{array}$ & \multirow[t]{5}{*}{$\begin{array}{l}\text { US (p), } \\
\text { CT (w), } \\
\text { Echokardio- } \\
\text { graphie (w) }\end{array}$} & \multirow{5}{*}{$\begin{array}{l}\text { US des Abdo- } \\
\text { mens oft ausrei- } \\
\text { chend zum } \\
\text { Nachweis der } \\
\text { Ursache. CT } \\
\text { wenn sonogra- } \\
\text { phisch und echo- } \\
\text { kardiographisch } \\
\text { keine Ursache } \\
\text { nachweisbar ist. }\end{array}$} \\
\hline & $\begin{array}{l}\text { Hepatisch: } \\
\text { Tumor }\end{array}$ & $\begin{array}{l}\text { Ggf. lokoregio- } \\
\text { näre Maßnah- } \\
\text { men (RFA, } \\
\text { Strahlenthera- } \\
\text { pie, etc.) }\end{array}$ & & \\
\hline & $\begin{array}{l}\text { Hepatisch: } \\
\text { Zirrhose }\end{array}$ & $\begin{array}{l}\text { Diätetische und } \\
\text { medikamentöse } \\
\text { Maßnahmen }\end{array}$ & & \\
\hline & $\begin{array}{l}\text { Kardial: } \\
\text { Komorbidi- } \\
\text { tät }\end{array}$ & $\begin{array}{l}\text { Kardiologische } \\
\text { Therapie der } \\
\text { Herzinsuffizienz }\end{array}$ & & \\
\hline & $\begin{array}{l}\text { Kardial: } \\
\text { Medikamen- } \\
\text { tös }\end{array}$ & $\begin{array}{l}\text { Therapieumstel- } \\
\text { lung }\end{array}$ & & \\
\hline
\end{tabular}

Empfehlungsgrade: $\mathrm{p}=$ primär indiziert, $\mathrm{w}=$ weiterführende Untersuchung, $\mathrm{s}=$ Spezialverfahren, $\mathrm{n}=$ nicht indiziert 


\subsubsection{Niere und Harnwege}

\begin{tabular}{|c|c|c|c|c|}
\hline Symptom & $\begin{array}{l}\text { Mögliche } \\
\text { Ursache }\end{array}$ & $\begin{array}{l}\text { Mögliche Kon- } \\
\text { sequenz }\end{array}$ & $\begin{array}{l}\text { Bildgebendes } \\
\text { Verfahren }\end{array}$ & Erläuterungen \\
\hline \multirow[t]{2}{*}{ Anurie } & Prärenal & $\begin{array}{l}\text { Flüssigkeitsaus- } \\
\text { gleich und kau- } \\
\text { sale Therapie }\end{array}$ & \multirow[t]{3}{*}{$\begin{array}{l}\text { US (p), } \\
\text { CT (w) }\end{array}$} & \multirow{3}{*}{$\begin{array}{l}\text { Sonographisch } \\
\text { kann eine Hydro- } \\
\text { nephrose verifi- } \\
\text { ziert werden, ggf. } \\
\text { auch eine steno- } \\
\text { sierende Raum- } \\
\text { forderung im } \\
\text { Verlauf der ablei- } \\
\text { tenden Harnwege. } \\
\text { CT bei sonogra- } \\
\text { phisch nachweis- } \\
\text { barer Hydroneph- } \\
\text { rose und schlech- } \\
\text { ter Einsehbarkeit } \\
\text { der ableitenden } \\
\text { Harnwege. }\end{array}$} \\
\hline & Obstruktiv & $\begin{array}{l}\text { Beseitigung der } \\
\text { Obstruktion } \\
\text { invasiv oder } \\
\text { durch Ureter- } \\
\text { schienung }\end{array}$ & & \\
\hline Urämie & Obstruktiv & $\begin{array}{l}\text { Beseitigung der } \\
\text { Obstruktion } \\
\text { invasiv oder } \\
\text { durch Ureter- } \\
\text { schienung }\end{array}$ & & \\
\hline \multirow[t]{3}{*}{ Hämaturie } & $\begin{array}{l}\text { Nierentu- } \\
\text { mor }\end{array}$ & $\begin{array}{l}\text { Operative Ent- } \\
\text { fernung wenn } \\
\text { möglich }\end{array}$ & \multirow{3}{*}{$\begin{array}{l}\text { US (p), } \\
\text { CT nativ (p), } \\
\text { CT mit KM } \\
\text { (w) }\end{array}$} & \multirow{3}{*}{$\begin{array}{l}\text { US primär indi- } \\
\text { ziert zum Nach- } \\
\text { weis eines Tu- } \\
\text { mors der Niere } \\
\text { oder der Harnbla- } \\
\text { se. CT mit KM ist } \\
\text { sensitiver und } \\
\text { erlaubt auch eine } \\
\text { Beurteilung der } \\
\text { Ureteren. CT } \\
\text { nativ bei klini- } \\
\text { schem Verdacht } \\
\text { auf Urolithiasis (z. } \\
\text { B. Hämaturie } \\
\text { verbunden mit } \\
\text { Koliken, Stein- } \\
\text { anamnese). }\end{array}$} \\
\hline & $\begin{array}{l}\text { Ableitende } \\
\text { Harnwege: } \\
\text { Tumor }\end{array}$ & $\begin{array}{l}\text { Operative Ent- } \\
\text { fernung wenn } \\
\text { möglich }\end{array}$ & & \\
\hline & $\begin{array}{l}\text { Ableitende } \\
\text { Harnwege: } \\
\text { Steine }\end{array}$ & $\begin{array}{l}\text { Operative Ent- } \\
\text { fernung wenn } \\
\text { erforderlich }\end{array}$ & & \\
\hline
\end{tabular}

Empfehlungsgrade: $\mathrm{p}=$ primär indiziert, $\mathbf{w}=$ weiterführende Untersuchung, $\mathrm{s}=$ Spezialverfahren, $\mathrm{n}=$ nicht indiziert 


\subsubsection{Haut und Weichteile}

\begin{tabular}{|c|c|c|c|c|}
\hline Symptom & $\begin{array}{l}\text { Mögliche } \\
\text { Ursache }\end{array}$ & $\begin{array}{l}\text { Mögliche Kon- } \\
\text { sequenz }\end{array}$ & $\begin{array}{l}\text { Bildgebendes } \\
\text { Verfahren }\end{array}$ & Erläuterungen \\
\hline \multirow[t]{3}{*}{ Ikterus } & Hepatisch & $\begin{array}{l}\text { Symptomatische } \\
\text { Maßnahmen, } \\
\text { ggf. Überwa- } \\
\text { chung Gerin- } \\
\text { nungssystem }\end{array}$ & \multirow[t]{3}{*}{$\begin{array}{l}\text { US (w), } \\
\text { CT (w), } \\
\text { ERC (s) }\end{array}$} & \multirow{3}{*}{$\begin{array}{l}\text { Zunächst labor- } \\
\text { chemische Verifi- } \\
\text { zierung der Hy- } \\
\text { perbilirubinämie } \\
\text { und Differenzie- } \\
\text { rung einer prähe- } \\
\text { patischen, hepati- } \\
\text { schen oder post- } \\
\text { hepatischen Ursa- } \\
\text { che. Verifizierung } \\
\text { einer mechani- } \\
\text { schen Cholestase } \\
\text { am einfachsten } \\
\text { mit US, hiermit } \\
\text { oft auch Nach- } \\
\text { weis der Ursache. } \\
\text { CT bei erschwer- } \\
\text { ter Einsehbarkeit } \\
\text { mit US. Endo- } \\
\text { skopische ret- } \\
\text { rograde Chole- } \\
\text { dochographie } \\
\text { (ERC) bei nach- } \\
\text { gewiesener me- } \\
\text { chanischer Cho- } \\
\text { lestase, zur Sten- } \\
\text { timplantation } \\
\text { bzw. Steinextrak- } \\
\text { tion. }\end{array}$} \\
\hline & Hämolyse & $\begin{array}{l}\text { Medikamentöse } \\
\text { Therapie je nach } \\
\text { Ursache, } \\
\text { ggf. Transfusion }\end{array}$ & & \\
\hline & $\begin{array}{l}\text { Mechani- } \\
\text { sche Cho- } \\
\text { lestase }\end{array}$ & $\begin{array}{l}\text { Wenn möglich } \\
\text { interventionelle } \\
\text { Entlastung } \\
\text { (Stent oder } \\
\text { perkutan) }\end{array}$ & & \\
\hline \multirow[t]{3}{*}{ Juckreiz } & $\begin{array}{l}\text { Hepatisch } \\
\text { (Gallensäu- } \\
\text { ren) }\end{array}$ & $\begin{array}{l}\text { Medikamentöse } \\
\text { Therapien, } \\
\text { Kleiebäder }\end{array}$ & \multirow[t]{3}{*}{$\begin{array}{l}\text { Zunächst } \\
\text { keine Bildge- } \\
\text { bung }\end{array}$} & \multirow{3}{*}{$\begin{array}{l}\text { Klärung anamnes- } \\
\text { tisch bzw. labor- } \\
\text { chemisch. Bei } \\
\text { mechanischer } \\
\text { Cholestase Vor- } \\
\text { gehen wie bei } \\
\text { Ikterus. }\end{array}$} \\
\hline & $\begin{array}{l}\text { Medikamen- } \\
\text { tös }\end{array}$ & $\begin{array}{l}\text { Therapieumstel- } \\
\text { lung }\end{array}$ & & \\
\hline & Allergisch & $\begin{array}{l}\text { Vermeidung der } \\
\text { Noxen }\end{array}$ & & \\
\hline
\end{tabular}




\begin{tabular}{|c|c|c|c|c|}
\hline Symptom & $\begin{array}{l}\text { Mögliche } \\
\text { Ursache }\end{array}$ & $\begin{array}{l}\text { Mögliche Kon- } \\
\text { sequenz }\end{array}$ & $\begin{array}{l}\text { Bildgebendes } \\
\text { Verfahren }\end{array}$ & Erläuterungen \\
\hline \multirow[t]{4}{*}{$\begin{array}{l}\text { Tastbare } \\
\text { Resistenz }\end{array}$} & $\begin{array}{l}\text { Haut- oder } \\
\text { Weichteil- } \\
\text { metastase }\end{array}$ & $\begin{array}{l}\text { Therapie je nach } \\
\text { Gesamtsituati- } \\
\text { on: konservativ } \\
\text { (inkl. Miltex o. } \\
\text { Ä.), Resektion } \\
\text { oder Bestrah- } \\
\text { lung }\end{array}$ & \multirow[t]{4}{*}{$\begin{array}{l}\mathrm{US}(\mathrm{p}), \\
\mathrm{CT}(\mathrm{w})\end{array}$} & \multirow{4}{*}{$\begin{array}{l}\text { US primär indi- } \\
\text { ziert zur Verifika- } \\
\text { tion und ggf. Art- } \\
\text { diagnose eines } \\
\text { Tastbefundes. } \\
\text { Abhängig vom } \\
\text { US-Befund CT } \\
\text { möglich zur ana- } \\
\text { tomischen Zu- } \\
\text { ordnung oder } \\
\text { zum Nachweis } \\
\text { weiterer Läsionen }\end{array}$} \\
\hline & $\begin{array}{l}\text { Lymphkno- } \\
\text { tenmetasta- } \\
\text { se }\end{array}$ & $\begin{array}{l}\text { OP oder Strah- } \\
\text { lentherapie bei } \\
\text { subjektiven } \\
\text { Beschwerden }\end{array}$ & & \\
\hline & $\begin{array}{l}\text { Pseudopro- } \\
\text { gression } \\
\text { unter } \\
\text { immunsti- } \\
\text { mulierender } \\
\text { Therapie }\end{array}$ & $\begin{array}{l}\text { Engmaschige } \\
\text { Überwachung }\end{array}$ & & \\
\hline & Hämatom & $\begin{array}{l}\text { Konservativ- } \\
\text { symptomatische } \\
\text { Maßnahmen }\end{array}$ & & \\
\hline
\end{tabular}

Empfehlungsgrade: $\mathrm{p}=$ primär indiziert, $\mathbf{w}=$ weiterführende Untersuchung, $\mathrm{s}=$ Spezialverfahren, $\mathrm{n}=$ nicht indiziert

\subsubsection{Thorax}

\begin{tabular}{|l|l|l|l|l|}
\hline Symptom & $\begin{array}{l}\text { Mögliche } \\
\text { Ursache }\end{array}$ & $\begin{array}{l}\text { Mögliche Kon- } \\
\text { sequenz }\end{array}$ & $\begin{array}{l}\text { Bildgebendes } \\
\text { Verfahren }\end{array}$ & Erläuterungen \\
\hline Husten & $\begin{array}{l}\text { Tumor mit } \\
\text { Bronchusin- } \\
\text { filtration }\end{array}$ & $\begin{array}{l}\text { Lokoregionäre } \\
\text { Maßnahmen } \\
\text { (Endoskopie } \\
\text { mit Untersprit- } \\
\text { zung, ggf. Ab- } \\
\text { tragung, Stent- } \\
\text { einlage und } \\
\text { endobronchialer } \\
\text { oder/und per- } \\
\text { kutaner Strah- } \\
\text { lentherapie) }\end{array}$ & $\begin{array}{l}\text { Röntgen- } \\
\text { Thorax (p), } \\
\text { CT Thorax } \\
\text { Bronchosko- } \\
\text { pie (s) }\end{array}$ & $\begin{array}{l}\text { Röntgen-Thorax } \\
\text { primär indiziert } \\
\text { zum Nachweis } \\
\text { von Infiltraten } \\
\text { oder einer Pneu- } \\
\text { monie. CT Tho- } \\
\text { rax bei unklarem } \\
\text { Röntgenbefund, } \\
\end{array}$ \\
\cline { 3 - 5 } & & & $\begin{array}{l}\text { Befundpersistenz } \\
\text { trotz normalen } \\
\text { Röntgenbefundes, } \\
\text { v. a. poststenoti- }\end{array}$ \\
\hline
\end{tabular}




\begin{tabular}{|c|c|c|c|c|}
\hline Symptom & $\begin{array}{l}\text { Mögliche } \\
\text { Ursache }\end{array}$ & $\begin{array}{l}\text { Mögliche Kon- } \\
\text { sequenz }\end{array}$ & $\begin{array}{l}\text { Bildgebendes } \\
\text { Verfahren }\end{array}$ & Erläuterungen \\
\hline & & & & \multirow[t]{5}{*}{$\begin{array}{l}\text { sche Pneumonie } \\
\text { bzw. Atelektase, } \\
\text { zur Erkennung } \\
\text { einer Lymphangi- } \\
\text { osis carcinomato- } \\
\text { sa sowie radioge- } \\
\text { ner oder pneumo- } \\
\text { toxischer Verän- } \\
\text { derungen. Bron- } \\
\text { choskopie bei V.a } \\
\text { Bronchusinfiltra- } \\
\text { tion oder Tumor- } \\
\text { bedingter Stenose } \\
\text { der Atemwege, } \\
\text { evtl. als interven- } \\
\text { tionelle Maßnah- } \\
\text { me. }\end{array}$} \\
\hline & $\begin{array}{l}\text { Lymphan- } \\
\text { giosis carci- } \\
\text { nomatosa }\end{array}$ & $\begin{array}{l}\text { Medikamentöse } \\
\text { Maßnahmen, } \\
\text { ggf. erneute } \\
\text { antitumoröse } \\
\text { Therapie }\end{array}$ & & \\
\hline & Pneumonie & $\begin{array}{l}\text { Antibiotika- } \\
\text { therapie }\end{array}$ & & \\
\hline & $\begin{array}{l}\text { Pneumoto- } \\
\text { xizität }\end{array}$ & $\begin{array}{l}\text { Therapieumstel- } \\
\text { lung }\end{array}$ & & \\
\hline & Radiogen & Steroidtherapie & & \\
\hline \multirow[t]{2}{*}{ Dyspnoe } & Obstruktion & $\begin{array}{l}\text { Entfernung der } \\
\text { Obstruktion (z. } \\
\text { B. endosko- } \\
\text { pisch), ggf. OP } \\
\text { oder Strahlen- } \\
\text { therapie }\end{array}$ & \multirow{2}{*}{$\begin{array}{l}\text { Röntgen- } \\
\text { Thorax (p), } \\
\text { CT Thorax } \\
\text { (w), } \\
\text { US Thorax } \\
\text { Echokardio- } \\
\text { graphie (w) }\end{array}$} & \multirow{2}{*}{$\begin{array}{l}\text { Röntgen-Thorax } \\
\text { primär indiziert } \\
\text { zum Nachweis } \\
\text { von Infiltraten, } \\
\text { einer Atelektase } \\
\text { oder einer Pneu- } \\
\text { monie. Echokar- } \\
\text { diographie bei } \\
\text { V.a. kardial be- } \\
\text { dingter Dyspnoe. } \\
\text { CT-Thorax bei } \\
\text { unklarem Rönt- } \\
\text { genbefund, Be- } \\
\text { fundpersistenz }\end{array}$} \\
\hline & $\begin{array}{l}\text { Lymphan- } \\
\text { giosis carci- } \\
\text { nomatosa }\end{array}$ & $\begin{array}{l}\text { Medikamentöse } \\
\text { Therapie (z. B. } \\
\text { Inhalationsthe- } \\
\text { rapie, Kortison } \\
\text { etc.) } \\
\text { ggf. erneute } \\
\text { antitumoröse } \\
\text { Therapie }\end{array}$ & & \\
\hline
\end{tabular}




\begin{tabular}{|c|c|c|c|c|}
\hline Symptom & $\begin{array}{l}\text { Mögliche } \\
\text { Ursache }\end{array}$ & $\begin{array}{l}\text { Mögliche Kon- } \\
\text { sequenz }\end{array}$ & $\begin{array}{l}\text { Bildgebendes } \\
\text { Verfahren }\end{array}$ & Erläuterungen \\
\hline & Pneumonie & $\begin{array}{l}\text { Antibiotikathe- } \\
\text { rapie }\end{array}$ & & $\begin{array}{l}\text { trotz normalen } \\
\text { Röntgenbefundes, }\end{array}$ \\
\hline & Pleuraerguss & $\begin{array}{l}\text { Entlastungs- } \\
\text { punktion, Di- } \\
\text { uretikatherapie }\end{array}$ & & $\begin{array}{l}\text { v. a. poststenoti- } \\
\text { sche Pneumonie } \\
\text { bzw. Atelektase, } \\
\text { zur Erkennung }\end{array}$ \\
\hline & Kardial & $\begin{array}{l}\text { Medikamentöse } \\
\text { Therapie (Herz } \\
\text { und Diurese) }\end{array}$ & & $\begin{array}{l}\text { einer Lymphangi- } \\
\text { osis carcinomato- } \\
\text { sa sowie radioge- } \\
\text { ner oder pneumo- } \\
\text { toxischer Verän- } \\
\text { derungen. Bron- } \\
\text { choskopie bei V.a. } \\
\text { Bronchusinfiltra- } \\
\text { tion oder tumor- } \\
\text { bedingter Stenose } \\
\text { der Atemwege, } \\
\text { evtl. als interven- } \\
\text { tionelle Maßnah- } \\
\text { me. }\end{array}$ \\
\hline \multirow[t]{2}{*}{ Bluthusten } & $\begin{array}{l}\text { Gefäßarro- } \\
\text { sion }\end{array}$ & $\begin{array}{l}\text { Akutinterventi- } \\
\text { on wenn ge- } \\
\text { wünscht }\end{array}$ & \multirow{2}{*}{$\begin{array}{l}\text { CT Thorax } \\
\text { (p), } \\
\text { Bronchos- } \\
\text { kopie (w), } \\
\text { Angiographie } \\
\text { (s) }\end{array}$} & \multirow{2}{*}{$\begin{array}{l}\text { CT primär indi- } \\
\text { ziert zum Nach- } \\
\text { weis der Ursache. } \\
\text { Bronchoskopie } \\
\text { zur lokalen Blut- } \\
\text { stillung. Ggf. } \\
\text { Angiographie und } \\
\text { Embolisation der } \\
\text { betroffenen } \\
\text { Bronchialarterien. }\end{array}$} \\
\hline & Pneumonie & $\begin{array}{l}\text { Antibiotikathe- } \\
\text { rapie }\end{array}$ & & \\
\hline $\begin{array}{l}\text { Obere } \\
\text { Einfluss- } \\
\text { stauung }\end{array}$ & $\begin{array}{l}\text { Mediastina- } \\
\text { ler Tumor }\end{array}$ & $\begin{array}{l}\text { Strahlen- } \\
\text { therapie }\end{array}$ & $\begin{array}{l}\text { US obere } \\
\text { Thoraxapertur } \\
\text { (p), } \\
\text { CT Thorax (p) }\end{array}$ & $\begin{array}{l}\text { US zur raschen } \\
\text { Verifikation der } \\
\text { Einflussstauung, } \\
\text { ggf. Nachweis } \\
\text { hoch sitzender } \\
\text { mediastinaler } \\
\text { Raumforderungen } \\
\text { möglich. Ansons- } \\
\text { ten CT mit KM, } \\
\text { ggf. zur Vorberei- } \\
\text { tung einer Not- } \\
\text { fallbestrahlung. }\end{array}$ \\
\hline
\end{tabular}

Empfehlungsgrade: $\mathrm{p}=$ primär indiziert, $\mathrm{w}=$ weiterführende Untersuchung, $\mathrm{s}=$ Spezialverfahren, $\mathrm{n}=$ nicht indiziert 


\subsection{Zusammenfassung}

Auch beim Palliativpatienten sollte eine onkologische Diagnostik zum Einsatz kommen, sofern aus den erhobenen Befunden therapeutische Konsequenzen gezogen werden. Sofern eine onkologische, also tumorspezifische Therapie eingeleitet werden soll, ist eine feingewebliche Diagnosestellung unverzichtbar. Viele diagnostische Maßnahmen sind mit geringer Belastung für den Patienten durchführbar. Eine onkologische Therapie kann eingeleitet werden, wenn

- der Patient einen ausreichenden Allgemeinzustand aufweist, also Karnofsky-Index $>50 \%$ (bei stark chemo-sensiblen Tumoren und vor der Erkrankung sehr gutem Allgemeinzustand des Patienten bis KarnofskyIndex $40 \%$ möglich)

- $\quad$ die Lebenserwartung des Patienten mindestens drei Monate beträgt (bei aggressiven Lymphomen oder akuter Leukämie Beurteilung der Lebenserwartung erst nach Durchführung einer Vorphase-Therapie)

- $\quad$ der Patient nach ausführlicher Aufklärung in die Maßnahmen einwilligt.

Durch Chemotherapie oder andere medikamentöse Tumortherapien („targeted therapies", Antikörper usw.) ist eine Beeinflussung einer Krebserkrankung mit dem Ziel der Symptomkontrolle und der Lebensverlängerung möglich. Aufgrund der Komplexität der Entscheidungen sollte immer ein medizinischer Onkologe oder ein onkologisch erfahrener Facharzt in die Behandlung mit einbezogen werden.

\subsection{Literatur}

(1) Radbruch L, Nauck F, Sabatowski R. Was ist Palliativmedizin. Stellungnahme der Deutschen Gesellschaft für Palliativmedizin; 2005. www.palliativmedizin.de $>$ Weitere Informationen $>$ Allgemeine Informationen $>$ Was ist Palliativmedizin?

(2) Alt-Epping B, Baumann R, Lindena G, Nauck F. Wieviel Diagnostik braucht die Palliativmedizin? - Ergebnisse einer multizentrischen Studie und Fallserie. Dtsch Med Wschr 2011; 136(45): 2297-2301

(3) Aulbert E, Nauck F, Radbruch L. Lehrbuch der Palliativmedizin. Stuttgart: Schattauer; 2008.

(4) Alt-Epping B, Jung W, Nauck F. Symptomkontrollierende Effekte der Chemotherapie. Der Onkologe 2007;13:619-624. 
(5) Woelk C, Harlos M, Guideline for Estimating Length of Survival in Palliative Patients. http://palliative.info

(6) Schrijvers D, Cherny NI. ESMO Clinical Practice Guidelines on palliative care: advanced care planning. Ann Oncol 2014;25 (Supl 3):iii138-iii142.

(7) Andreesen R, Heimpel H. Klinische Hämatologie. 3. Auflage. München: Urban \& Fischer; 2009.

(8) Wilhelm C, Neubauer A. Molekulare Tumortherapie. Der Internist 2008;5:581-590.

(9) Schmoll HJ, Höffken K, Possinger K. Kompendium internistische Onkologie. Heidelberg: Springer; 2006.

(10) Gompelmann D, Eberhardt R, Herth F. Möglichkeiten der Bronchoskopie in der Onkologie. Der Onkologe 2013;11:993-1002.

\section{Weitere Quellen:}

Strahlenschutzkommission: Orientierungshilfe für bildgebende Untersuchungen, 2. Aufl. 2010, Version vom 26.9.2011.

www.ssk.de/SharedDocs/Beratungsergebnisse_PDF/2008/Orientierungshilfe.pdf ?__blob=publicationFile

British College of Radiologists: The Royal College of Radiologists (RCR's) imaging referral guidelines, iRefer, 7. Aufl., 2012.

www.irefer.org.uk 


\section{Tumorchirurgische Verfahren - für Nichtchirurgen -}

Prof. Dr. med. habil. Konrad Klaus Ricbter

Southland Hospital und Dunedin School of Medicine

University of Otago

Invercargill 9879, Kew Road, New Zealand

\subsection{Einleitung}

Chirurgische Onkologie ist sowohl eine technische als auch eine kognitive Subspezialisierung der Allgemeinchirurgie. Der Chirurg, der oft am Anfang der Tumortherapie steht, diagnostiziert und operiert jedoch nicht nur, sondern führt ebenso Gewebediagnostik, Staging und palliative Chirurgie zur Symptomenkontrolle und prophylaktische Chirurgie aus. Die chirurgische Operation ist oft nur ein Teil einer der interdisziplinären Behandlung und wird mit der Medizinischen Onkologie, Radioonkologie, Pathologie, Radiologie und Psychoonkologie innerhalb eines interdisziplinären Tumorboards koordiniert. Der onkologisch tätige Chirurg sollte auch ein chirurgischer Onkologe sein, der nicht nur die operative Seite seines Faches exzellent beherrscht, sondern auch über umfassende Kenntnisse in den verfügbaren neoadjuvanten und adjuvanten Therapiemöglichkeiten sowie in molekularer Genetik und moderner Bildgebung verfügt. Er wird oft ein persönliches und auf Respekt begründetes Verhältnis zu seinem Patienten und dessen Familie entwickeln. Diesem Vertrauen sollte er durch Gewissenhaftigkeit in der Indikationsstellung, Sorgfalt bei den operationstechnischen Vorgängen und glaubwürdige 
Ausstrahlung seiner Persönlichkeit gerecht werden. Während der technischhandwerkliche Aspekt bei der Operation entscheidend für den Operationserfolg ist, erfordert die Kunst und Urteilsfähigkeit in der Chirurgie das grundlegende Wissen in Biologie, Anatomie, Pathophysiologie, klinischen Wissenschaften sowie den chirurgischen Komplikationen.

Der nachfolgende Übersichtsbeitrag basiert auf 25 Jahren chirurgischonkologischer Tätigkeit und beschreibt wichtige Aspekte der chirurgischen und multimodalen Behandlung häufiger Tumoren mit Schwerpunkt auf den Tumoren des Gastrointestinaltrakts, des Pankreas und des hepatobiliären Systems. Er soll auch dem Nichtchirurgen ein Verständnis der oft komplexen Zusammenhänge vermitteln und zum Weiterlesen aktueller Literatur anregen.

\subsection{Nomenklatur, Grading, Staging, Epidemiologie}

Tumoren können gutartige (benigne), bösartige (maligne) oder Übergangscharakteristika aufweisen. Die Nomenklatur bezieht sich auf das Ausgangsgewebe der Tumoren. Bösartige Tumoren, die von mesenchymalem Gewebe abstammen, werden als Sarkome bezeichnet und solche mit epithelialem Ursprung als Karzinome. Sarkome können sich von unterschiedlichen Ausgangsgeweben wie Knochenzellen (Osteosarkome), Muskelzellen (Leio- und Rhabdomyosarkome), Fettzellen (Liposarkome), Gefäßen (Angiosarkome) oder Bindegewebszellen (Fibrosarkome) entwickeln. Karzinome stammen von drüsenartigen Zellen (Adenokarzinome) oder Plattenepithelien (Plattenepithelkarzinome) ab.

Der Tumorgrad (Grading) ist eine wichtige Voraussetzung, um Verhalten und Prognose einschätzen und geeignete Therapien planen zu können. Grading bezieht sich auf die zellulare Differenzierung und beschreibt die Ähnlichkeit des Tumors zum Ausgangsgewebe unter Nutzung der folgenden Parameter: nuklearer Pleopolymorphismus, Zellularität, Nekrosen, zelluläre Invasivität und Anzahl der Mitosen. Tumoren, bei denen sich das Ausgangsgewebe nicht mehr erkennen lässt, werden als undifferenziert bezeichnet.

Das Tumorstaging erfasst das Ausmaß der Tumorerkrankung, gestattet prognostische Aussagen und beeinflusst maßgeblich die Therapieentscheidungen. Das klinische Staging basiert auf nicht-invasiver Anamnese und Bildgebung wie Magnetresonanztomographie (MRT), Computertomographie (CT) und Positronenemissionstomographie (PET) oder PET-CT. Pathologisches Staging beinhaltet die Untersuchung chirurgischer Gewebeproben und kann im Einzelfall auch eine offene oder laparoskopische Staging-Operation erfordern. Ein höheres Tumorstadium korreliert mit einer ungünstigen Prognose. Eine einheitliche Tumorklassifizierung und ein akkurates Staging sind die Voraussetzung für die Beurteilung der Prognose zum Zeitpunkt der Diagnose und gestatten die Durchführung von klinischen Studien. Das TNM-Stadium beinhaltet die Information für den Tumor (T), die regionalen Lymphknoten $(\mathrm{N})$ und die Metastasen (M). 
Für den onkologisch tätigen Chirurgen sind die zwei Parameter „Residualtumor“ und „Tumorresektionsrand“ besonders wichtig. Das Vorhandensein von Residualtumor wird durch den Buchstaben „R“ beschrieben. „R0“ bedeutet kein Residualtumor, „R1“ das Vorhandensein eines mikroskopischen, „R2“ eines makroskopischen und „RX“ das Vorhandensein eines nicht beurteilbaren Residualtumors. Residualtumor und Tumorresektionsrand beeinflussen sowohl das tumorfreie als auch das Gesamtüberleben. Das wichtigste Ziel der tumorchirurgischen Operation ist die Entfernung des Tumors im Gesunden, also die R0-Resektion.

\subsection{Tumorchirurgische Prinzipien}

$\mathrm{Zu}$ den wichtigen chirurgisch-onkologischen Prinzipien gehören die folgenden Kriterien: postoperative Tumor-Residualfreiheit mit adäquatem Sicherheitsabstand (R0-Resektion), multiviszerale Resektion, en-bloc-Resektion unter Mitnahme umliegender anatomischer Strukturen und Organe, und adäquate Lymphadenektomie. Die „no touch isolation technique“ (1) wird empfohlen und beinhaltet eine frühe lymphovaskuläre Ligatur noch vor der Mobilisierung und Resektion des Primärtumors. Sie basiert auf experimentellen Untersuchungen, die ein vermehrtes Auftreten von Tumorzellen u.a. in der Portalvene durch chirurgische Manipulation nachweisen konnten (2). Zur Qualitätssicherung und Prognoseverbesserung gehören ebenso die gründliche und sachgerechte Aufarbeitung des Tumorpräparates durch einen onkologisch ausgebildeten Pathologen. Nach der Tumorresektion spielt die optimale Rekonstruktion eine entscheidende Rolle für die postoperative Lebensqualität und Tumorrezidivfreiheit.

Mit dem wachsenden Verständnis über die Bedeutung genetischer Defekte für das Tumorwachstum führt der Chirurg auch prophylaktische Tumoroperationen bei phänotypisch gesunden Gendefektträgern aus. Beispiele dafür sind die prophylaktische Gastrektomie bei Mutationsträgern des E-Cadherin Gens CDH1, die bilaterale prophylaktische Mastektomie (BPM) bei BRCA1-Mutationsträgerinnen, die prophylaktische Thyroidektomie bei Patienten mit Multipler Endokriner Neoplasie Typ 2 (MEN2), die auf Mutationen im Bereich des RET-Protoonkogens des Chromosoms 10q13 beruhen, und die prophylaktische, oft laparoskopisch ausgeführte Dickdarmentfernung bei der Familiären Adenomatösen Polyposis (FAP). 


\subsection{Chirurgische Tumoren}

\subsection{1 Ösophaguskarzinome}

Plattenepithelkarzinome finden sich bevorzugt im mittleren und unteren Ösophagusdrittel, jedoch wird in westlichen Ländern eine steigende Inzidenz von Adenokarzinomen des unteren Ösophagus und der Kardia beobachtet. Rauchen und Alkohol sind die wichtigsten Risikofaktoren für die Entstehung eines Plattenepithelkarzinoms, jedoch auch Pilztoxine, Nitrite, heiße Getränke, strahlenbedingte Strikturen und Achalasie. Adenokarzinome entstehen bei gastroösopagealem Reflux und Adipositas. Beim Barrett-Ösophagus ist die DysplasieKarzinomsequenz etabliert und gestattet die Früherkennung und Überwachung. Die Metastasierung erfolgt im oberen und unteren Drittel aufgrund der Lymphund Venenblutdrainage unterschiedlich. Oft besteht bereits eine lymphogene Metastasierung, dagegen sind hämatogene Metastasen der Leber und Lunge seltener. Der Tumor kann sich makroskopisch unsichtbar in der Submukosa bis über $5 \mathrm{~cm}$ nach proximal ausbreiten. Demzufolge ist ein intraoperativer Schnellschnitt wichtig, um eine sichere R0-Resektion erzielen zu können. Das diagnostische Staging umfasst Endosonographie, Computertomographie, Magnetresonanztomorgraphie und Positronen-Emisions-Tomographie mit 18-Fluordesoxyglukose. Die prätherapeutische Diagnostik hat das Ziel, eine Metastasierung frühzeitig zu erkennen, die eine chirurgische Kuration ausschließen würde. Weiterhin sollen durch die präoperative Diagnostik Subgruppen von Patienten definiert werden, die von einer neoadjuvanten Therapie profitieren.

Aufgrund der Fortschritte in der Endoskopie werden zunehmend frühe hochgradig dysplastische Läsionen sowie intramukosale Frühkarzinome entdeckt. Diese können endoskopisch durch eine Mukosaresektion entfernt werden.

Die Mortalität nach chirurgischer Resektion beträgt in spezialisierten Zentren weniger als $5 \%$, liegt jedoch um $10 \%$ bei Betrachtung aller Studiendaten. Die beste Prognose ergibt sich bei einer R0-Resektion mit tumorfreien Resektionsrändern. Bei der Ösophagektomie gibt es viele Variablen, u.a. der chirurgische Operationszugang (transthorakal oder transhiatal), das Ausmass der Lymphadenektomie, der Typ und Art und Weise der Vorbereitung des Ösophagusersatzes, die Pylorusdrainage, die Rekonstruktion sowie die Anastomosentechnik. Das Standardverfahren bei thorakalen Karzinomen ist die abdominothorakale Ösophagusresektion mit Magenhochzug als Rekonstruktion. Als zweite Wahl der Kontinuitätswiederherstellung bietet sich die Koloninterposition an, wobei die fehlende Peristaltik und der störende Mundgeruch die Lebensqualität beeinträchtigen. Der thorakale Teil der Operation erfolgt als anteromediale rechtsseitige Thorakotomie. Die Anastomose erfolgt hoch intrathorakal oder zervikal. Die Operation kann offen als Laparotomie und Thorakotomie oder laparoskopisch bzw. thorakoskopisch mit Magenmobilization sowie zervikaler Ösophagogastrostomie erfolgen. 
Das Therapiekonzept für Ösophaguskarzinome ist multimodal und umfasst neben der chirurgischen Operation die Chemo- und Radiotherapie (neoadjuvant und adjuvant), die Brachytherapie, die kombinierte neoadjuvante Radiochemotherapie präoperativ oder diese als definitive Therapie. Allerdings beträgt die 5-JahresÜberlebensrate nach radikaler chirurgischer Resektion und bei positivem Lymphknotenbefall $(\mathrm{pN}+)$ weniger als $25 \%$.

Nichtoperable Ösophaguskarzinome können palliativ mit selbstexpandierenden Metallgitterstents, Lasertherapie, intralesionalen Injektionen von tumorwachstumshemmenden Substanzen sowie durch photodynamische Therapie behandelt werden.

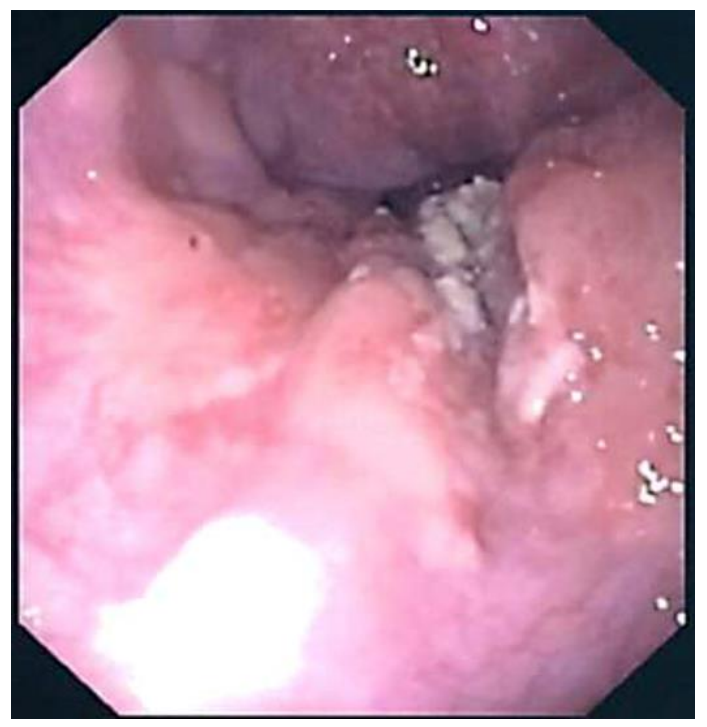

Abb. 1: Endoskopischer Befund eines Adenokarzinoms des unteren Ösophagus

\subsubsection{Magenkarzinome}

Die weltweite Inzidenz des Magenkarzinoms nimmt ab. Nur eine chirurgische komplette R0-Resektion gestattet die Hoffnung auf Heilung. Inkomplette Operationen (R1 und R2) bieten keine Hoffnung auf Heilung der Krankheit. Hochgradige Dysplasien und sehr frühe Tumorstadien, bei denen keine Lymphadenektomie erforderlich ist, können endoskopisch therapiert werden. Besonders in Japan werden Mukosa-assoziierte Tumoren von weniger als $2 \mathrm{~cm}$ mittels endoskopischer Mukosaresektion (EMR) oder endoskopischer submukosaler Dissektion (ESD) entfernt. Zunehmed wird nicht nur in Europa und Asien akzeptiert, dass eine Standard D2-Lymphadenektomie das Überleben verbessert - vorausgesetzt, dass die perioperative Morbidität und Mortalität gering ist. 
Bei fortgeschrittenem Magenkarzinom mit hohem Rezidivrisiko kann intraoperativ eine Aspirationszytologie während der Peritoneallavage durchgeführt werden. Eine positive Zytologie klassifiziert den Tumor dementsprechend als pM1. Die perioperative Chemotherapie vor und nach der chirurgischen Tumorresektion wird gegenwärtig weltweit als Standard betrachtet. Die MRC Adjuvant Gastric Infusional Chemotherapy-Studie (MAGIC) in England und die FFCD 9703-Studie in Frankreich haben signifikante Überlebensvorteile für Patienten nach perioperativer Chemotherapie nachgewiesen. Allerdings hat eine europäische Studie (EORTC trial) mit besserem präoperativem Staging keinen statistisch signifikanten Überlebensvorteil aufgezeigt. Demzufolge ist das präoperative Staging entscheidend, um unnötige zusätzliche Therapien bei frühen Tumorstadien wie pT1 zu verhindern.

Die Tumorabsetzungsränder sollten grösser als $5 \mathrm{~cm}$ für undifferenzierte Magenkarzinome sein; in Deutschland werden 8-10 cm für nach LAUREN klassifizierte undifferenzierte Magenkarzinome gefordert. Die Rekonstruktion erfolgt nach Roux-en-Y mit dem Hochzug einer proximalen Dünndarmschlinge mit besserer postoperativer Lebensqualität als die ebenfalls von noch einigen Autoren praktizierte BILLRO'TH-2-Rekonstruktion.

Eine Besonderheit stellen die Kardiakarzinome der Typen 1, 2 und 3 nach SIEWERT dar, die als Karzinome des gastroösophagealen Übergangs entsprechend der TNM-Klassifikation eine eigene Tumorentität darstellen (3). Die tumorchirurgische Therapie beinhaltet für Typ-1 Kardiakarzinome im oberen Kardiadrittel die transthorakale Ösophagusresektion en bloc mit ZweifeldLymphadenektomie, während Typ-2 und 3 Kardiakarzinome mit totaler Gastrektomie, D2-Lymphadenektomie sowie Lymphadenektomie des unteren Mediastinums behandelt werden. 

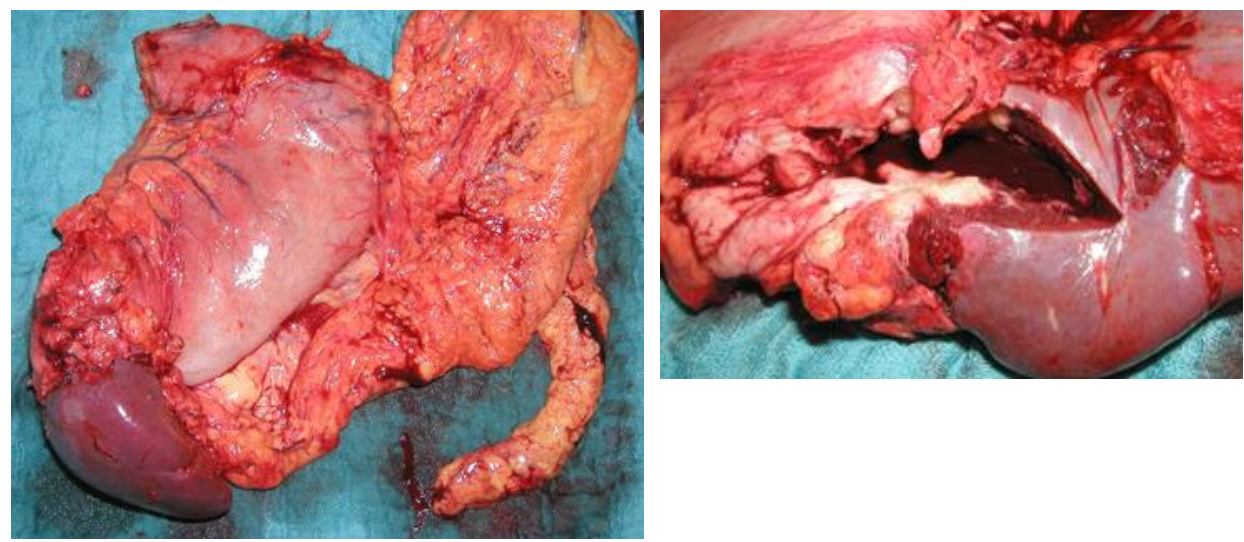

Abb. 2: Operationspräparat nach totaler Gastrektomie und multiviszeraler en-bloc-Resektion von Milz. und Diaphragma

\subsubsection{Kolorektale Karzinome}

Die höchste Inzidenz für kolorektale Karzinome findet sich in Neuseeland, Australien, Nordamerika, Japan und Westeuropa. Ca. 83\% aller kolorektalen Karzinome werden bei Patienten über 60 Jahre diagnostiziert; das Durchschnittsalter beträgt 70 Jahre. Allerdings hat sich die Inzidenz für jüngere Patienten unter 50 Jahren deutlich erhöht. Das Staging der kolorektalen Karzinome erfolgt entsprechend der TNM-Klassifikation, wobei die Tiefeninfiltration des Primärtumors in die Tela submucosa als T1 bezeichnet wird, in die Tunica muscularis als T2, in die Subserosa als T3, und die Infiltration von Nachbarorganen oder des Bauchfells als T4. Entscheidende Fortschritte bei der chirurgischen Behandlung kolorektaler Karzinome wurden durch die Einführung der Fast-Track-Philosophie (FT) bzw.von ERAS (Enhanced Recovery After Surgery) durch Henrik Kehlet erzielt (4). FT hat das Ziel, Morbidität, Mortalität und postoperativen Stress zu reduzieren, die Krankenhausverweildauer zu verringern sowie die postoperative Erholungsphase zu optimieren Ein multidisziplinäres ERAS-Team besteht aus Chirurgen, Pflegepersonal, Ernährungsberatern und Anaesthestisten. ERAS beinhaltet die folgenden Prinzipien: gründliches präoperatives Konsil mit dem Patienten und der Familie, keine mechanische Darmvorbereitung bzw. nur eine leichte Darmreinigung, reichliche präoperative Flüssigkeits- und Kohlenhydrateinnahme, Vermeidung von langwirksamen Opioiden, Vermeidung von Magensonden und Drainagen, Frühmobilisierung, frühe Entfernung des Harnblasenkatheters und Bevorzugung von laparoskopischen Operationen.

Die anatomische Unterscheidung zwischen Kolon- und Rektumkarzinomen erfolgt weltweit unterschiedlich. Gemessen wird ab der Anokutanlinie mit dem starren Rektoskop. Während in Europa die Kolonkarzinome $16 \mathrm{~cm}$ oberhalb der Anokutanlinie gemessen werden, definieren in Amerika die National Comprehen- 
sive Cancer Network-Richtlinien den Abstand bei $12 \mathrm{~cm}$ (gemessen vom Analrand mit dem starren Rektoskop). Die präoperative Ausbreitungsdiagnostik umfasst eine vollständige Koloskopie, Abdomensonographie, Röntgenthorax, starre Rektoskopie, Computertomographie von Thorax, Abdomen und Becken, und die rektale Endosonographie. Ein präoperatives Magnetresonanztomogramm des Beckens dient der Beurteilung des zirkumferentiellen Resektionsabstandes des Rektumkarzinoms zur mesorektalen Hüllfaszie (5). Präoperativ wird der Tumormarker Carcinoembryonales Antigen (CEA) als Basismarker und postoperativ als Verlaufsmarker bestimmt.

Die chirurgische Operation kann konventionell offen, laparoskopisch oder hand-assistiert laparoskopisch erfolgen. Die laparoskopische Resektion kolorektaler Karzinome führt bei entsprechender Expertise des Operateurs und bei geeigneter Patientenselektion zu vergleichbaren onkologischen Ergebnissen gegenüber der offenen Operation. Die Qualität des Chirurgen und seiner Operationstechnik kann anhand des Resektates durch den Pathologen beurteilt werden.

Bei Karzinomen des Kolon ascendens erfolgt die Rechtshemikolektomie, bei Transversuskarzinomen die erweiterte Rechtshemikolektomie oder subtotale Kolektomie, bei Deszendenskarzinomen die Linkshemikolektomie und bei Sigmakarzinomen die Sigmaresektion. Die Lymphadenktomie gilt als Surrogatmarker für die Behandlungsqualität, d.h. je grösser die Anzahl der untersuchten Lymphknoten, desto besser ist die Prognose. Mindestens 12 Lymphknoten, besser jedoch 25, werden entfernt und pathohistologisch untersucht. Die chirurgische Resektion eines Kolonkarzinoms erfolgt durch die komplette mesokolische Exzision (complete mesocolic excision, CME) mit adäquater Lymphadenektomie, hoher Ligatur des lymphovaskulären Bündels und ausreichendem Sicherheitsabstand. Analog wird beim oberen Rektumkarzinom die partielle mesorektale Resektion (PME) und bei Tumoren der beiden unteren Rektumdrittel die totale mesorektale Exzision (TME) ausgeführt. Die Einführung der TME hat die Lokalrezidivrate von 20\% vor 1990 auf unter $5 \%$ gesenkt. Obere Rektumkarzinome werden mittels tiefer anteriorer Rektumresektion operiert und mittlere und untere Rektumkarzinome werden durch tiefe bzw. ultratiefe anteriore Rektumresektion behandelt. Bei ultratiefen Rektumkarzinomen mit einem distalen Tumorrand von weniger als einem (oder zwei) Zentimeter oberhalb der Linea dentata erfolgt die abdominoperineale Rektumexstirpation (APR) kombiniert mit der Anlage eines endständigen Kolostomas.

Frühe pT-Rektumkarzinome mit einem Durchmesser bis $3 \mathrm{~cm}$ und guter oder mässiger Differenzierung (G1, G2) ohne Lymphgefäßinvasion können mittels Rektumvollwandresektion durch Transanale Endoskopische Mikrochirurgie (TEM) reseziert werden, solange die Absetzungsränder tumorfrei bleiben (R0). Die Vorteile der TEM bestehen gegenüber der komplexeren abdominellen Operation in einer niedrigen Komplikationsrate, der geringeren sexuellen und Blasendysfunktion, dem Vermeiden von Bauchwandnarben, dem geringeren Auftreten posteroperativer Diarrhoe sowie in einer wesentlich schnelleren postoperativen 
Erholungsphase. Es besteht allerdings ein leicht erhöhtes Risiko eines Lokalrezidivs.

In Abhängigkeit von der Größe und dem zirkumferenziellen Rand werden Rektumkarzinome des mittleren und unteren Rektumdrittels neoadjuvant entweder mit dem „Kurzzeitschema“ von 5 x 5 Gy über eine Woche radiotherapiert oder mit dem „Langzeitschema“" von 25 x 1.8 Gy über 5 Wochen kombiniert mit 5Fluorourazil und Leukovorin radiochemotherapiert. Damit lässt sich die Lokalrezidivrate senken und potentiell auch das Langzeitüberleben verlängern.

Patienten mit kolorektalen Karzinomen werden heutzutage idealerweise in einer interdisziplinären Tumorkonferenz diskutiert.
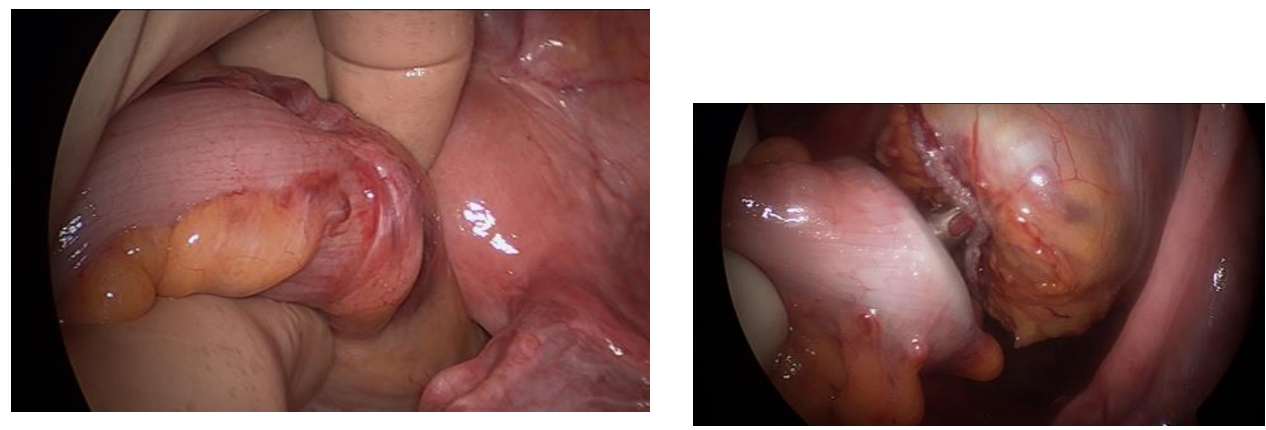

Abb. 3: Intraoperativer Befund eines oberen Rektumkarzinoms vor geplanter band-assistierter laparoskopischer tiefer anteriorer Rektumresektion und primärer Anastomose

Synchrone Lebermetastasen können bei geeigneten Patienten mit geringen Komorbiditäten gleichzeitig mit kurativer Intention reseziert werden. Die Operation kann offen oder laparoskopisch erfolgen und wird mit neoadjuvanter (günstiger, erfolgversprechender) oder postoperativer (adjuvanter) Chemotherapie kombiniert. Lebermetastasen, die kleiner als $3 \mathrm{~cm}$ sind, können mittels ablativer Verfahren, wie z.B. Radiofrequenzablation, Kryoablation, TACE oder stereotaktischer Körperbestrahlung behandelt werden (6). Metachrone Lebermetastasen werden häufig vor der Resektion neoadjuvant chemotherapiert (7). Heutzutage sind für einen erfahrenen Leberchirurgen mehr als 5 Lebermetastasen keine Kontraindikation mehr, vorausgesetzt, eine R0-Resektion wird erreicht und es verbleiben mehr als $30 \%$ an funktionellem Lebergewebe erhalten. 


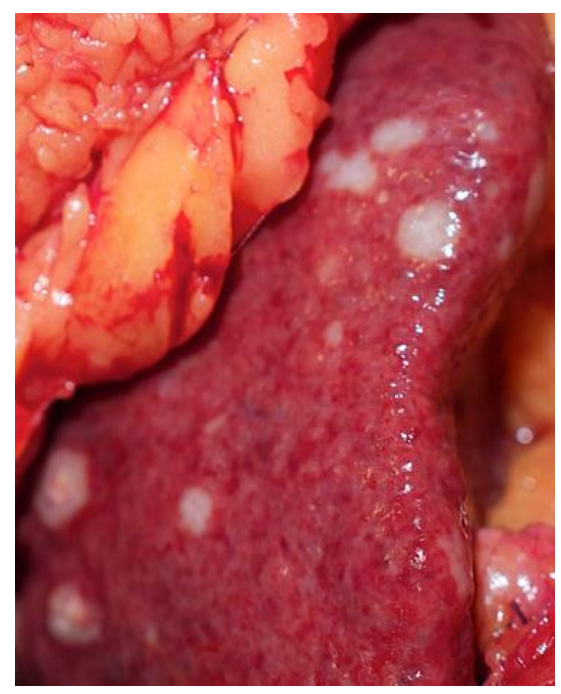

Abb. 4: Intraoperativer Operationsbefund einer nichtresektablen Lebermetastasierung

\subsubsection{Hepatobiliäre und Pankreastumoren}

$\mathrm{Zu}$ den primären malignen Lebertumoren zählen das hepatozelluläre Karzinom (HCC), das auf dem Boden einer Leberzirrhose oder -fibrose entsteht, und das intrahepatische Cholangiokarzinom (CC). Die einzige Möglichkeit für eine Heilung besteht in der kompletten Resektion (R0) oder der Lebertransplantation. Sekundäre maligne Lebertumoren sind vor allem Metastasen kolorektaler Karzinome, Mamma-, Nieren-, Magen- und Pankreaskarzinome. Sie treten entweder zusammen mit dem Ursprungstumor (synchrone Metastasen) oder im zeitlichen Verlauf (metachrone Metastasen) auf. Die Diagnostik erfolgt mittels Sonographie, CT, MRT sowie PET-CT.

Die Regenerationsfähigkeit der Leber ist beachtlich, d.h. bei einer gesunden nicht zirrhotisch geschädigten Leber können bis zu 75\% des Lebergewebes entfernt werden.

Die Chirurgie von Tumoren der Leber umfasst die anatomische, atypische oder erweiterte Resektion von primären und sekundären Lebertumoren sowie die Lebertransplantation. Dies kann allein oder in Kombination mit neoadjuvanter und adjuvanter Chemotherapie, Radiofrequenzablation (RFA), laserinduzierter Thermotherapie (LITT), Pfortaderembolisation, intraarterieller Chemotherapie, TACE und TIPS erfolgen. Während atypische Resektionen nicht an die Segmentgrenzen gebunden sind, werden anatomische Resektionen entlang der natürlich vorkommenden Segmentgrenzen durchgeführt. Anatomische Resektionen können als Monosegmentresektion bis zur erweiterten Halbseitenentfernung rechts (Segmente $1+4+5$ bis 8 ) ausgeführt werden. Tumoren im linken Leberlappen werden mit 
einer Halbseitenentfernung links behandelt (Segmente 1 bis 4). Die Durchtrennung des Lebergewebes erfolgt standardmässig mittels Ultraschallmesser (Harmonic Scalpel) oder Wasserstrahldissektor (Waterjet). Eine präoperativ durchgeführte Thrombosierung der Pfortader (portal vein embolisation) kann zur Volumenzunahme des zu verbleibenden Leberrestgewebes führen und somit eine ausgedehntere Leberresektion gestatten. Zunehmend werden Leberresektionen auch laparoskopisch ausgeführt. 5-Jahres-Überlebensraten für Patienten mit komplett resezierten kolorektalen Lebermetastasen betragen in spezialisierten Leberchirurgiezentren bis zu $60 \%$. Die Leberresektion heutzutage gilt als sicher, effektiv und potentiell kurativ, allerdings sind nur etwa $20 \%$ der Patienten mit kolorektalen Lebermetastasen resektabel. Wenn ein kompletter Resektionsrand erzielt werden kann, scheint die Leberresektion der Radiofrequenzablation überlegen zu sein (8). Die komplette Resektion kombinierter Lungen- und Lebermetastasen führt zu vergleichbaren Überlebensraten wie bei der kompletten Resektion von isolierten Lebermetastasen.

Gallenblasenkarzinome sind seltene und ausserordentlich aggressive Tumoren mit einer allgemeinen 5-Jahres-Überlebensrate von weniger als $5 \%$ und einem mittleren Überleben von weniger als 6 Monaten. Nach einer einfachen Cholecystektomie werden selten Gallenblasenkarzinome gefunden (bis 1,5\%). Nur eine frühe Diagnose und eine chirurgische Resektion gestattet die Hoffnung auf eine Heilung. Eine effektive Chemotherapie existiert nicht.

Das Pankreaskarzinom ist ein aggressiver und oft schnell wachsender Tumor. Spätsymptome sind schmerzloser Ikterus, Tastbarkeit einer schmerzlosen vergröBerten prall elastischen Gallenblase unter dem rechten Rippenbogen (CourvoisierZeichen), Juckreiz und unklare Oberbauchschmerzen. Die Diagnostik erfolgt mittels CT, MRI, Endosonographie oder auch PET-CT. Der Tumormarker CA 19-9 und evtl. auch CEA sind häufig erhöht. Die Standardoperation für ein Pankreaskopfkarzinom ist die Operation nach KAUSCH / WHIPPLE (Pankreatoduodenektomie), d.h. die Entfernung des Pankreaskopfes, des Zwölffingerdarms, des unteren Teils des Gallenganges, der Gallenblase sowie u.U. des unteren Teils des Magens (Antrum). Bei der pyloruserhaltenden WHIPPLE-Operation nach TRAVERSO bleibt der Magen erhalten. Tumoren im Pankreaskorpus und -schwanz werden mittels Pankreaslinksresektion operiert.

\subsubsection{Lungentumoren}

Lungentumoren gehören zu den häufigsten Tumoren (20\% bei Männern und $12 \%$ bei Frauen). Die Inzidenz innerhalb der Europäischen Union liegt für 35jährige bei 7 / 100000 für Männer und 3 / 100000 für Frauen. Sie beträgt jedoch 440 / 100000 und 72 / 100000 für über 75-jährige. Rauchen und Passivrauchen sind die dominanten Risikofaktoren für Männer und Frauen und stellen die Ursache in $80-90 \%$ der Erkrankungen dar. Weitere Risikofaktoren sind u.a. ionisierende Strahlen, Feinstaub, Asbest, berufliche Exposition von Arsen, Cadmium, 
Chrom, Nickel und polyzyklischen aromatischen Kohlenwasserstoffen sowie Lungenkarzinome bei Verwandten ersten Grades. Dementsprechend besteht die Prävention in Nichtrauchen, Vermeiden von Risikostoffen, körperlicher Aktivität und gesunder Ernährung.

Chronischer Husten mit oder ohne Sputumproduktion, Dyspnoe, Hämoptysen und Thoraxschmerzen sind charakteristische Leitsymptome. Spätsymptome sind Dysphagie, Stridor, Heiserkeit, HORNER-Syndrom (Infiltration des Ganglion stellatum), Knochenschmerzen (Metastasen) und Ikterus (Lebermetastasen). Lungenkarzinome metastasieren häufig in Knochen, Nebennieren und Gehirn. Das Screening von Risikogruppen mittels Computertomographie ermöglicht die Früherkennung, ist jedoch bisher nicht als Programm implementiert. Die Prognose ist vom Stadium, dem Genotyp, der Histologie, dem Geschlecht, dem Allgemeinzustand und der Komorbidität abhängig. Es werden zwei Hauptgruppen von Lungenkarzinomen entsprechend ihrer Größe und dem Aussehen ihrer Zellen unterschieden: die kleinzelligen und die nicht-kleinzelligen Lungenkarzinome. Die genaue histologische Klassifikation unterscheidet nach Plattenepithelkarzinomen, Adenokarzinomen, großzelligen Karzinomen, adenosquamösen Karzinomen, sarkomatoiden Karzinomen, kleinzelligen Karzinomen und Neurendokrinen Tumoren (NET). Insbesondere die NET haben eine große therapeutische Relevanz.

Die Klassifikation der TNM-Stadien beurteilt sowohl die Tumorgröße sowie die Infiltration in Zwerchfell, Pleura, Bronchus, sowie umliegende Organe, als auch die Anzahl und Lokalisation der Lymphknoten- und Fernmetastasen.

Die Diagnose erfolgt mittels Labor, CT Thorax und Abdomen, Bronchoskopie mit Biopsie, evtl. transthorakaler Biopsie und im Einzelfall mit PET-CT, Mediastinoskopie oder Knochenszintigraphie. Die Therapie erfolgt entsprechend der TNM-Klassifikation stadienabhängig. Bei frühen nicht-kleinzelligen Karzinomen erfolgt die Operation mit kurativer Intention, möglicherweise gefolgt von adjuvanter Chemotherapie und Bestrahlung.

Die Operation ist noch immer die wesentliche Therapiemodalität mit kurativem Anspruch. Standard ist die Lobektomie (9). Bei frühen Tumoren (T1, T2) kann eine minimal-invasive, videoassistierte thorakoskopische Operation (VATS) mit potentiell geringeren pulmonalen Komplikationen erfolgen. Eine umfangreichere Operation muss gegen die postoperativ verbleibende Lungenfunktion abgewogen werden. Bei zentralem Lungentumor kann eine Pneumektomie oder eine Lobektomie mit Bronchus- bzw. Gefäßmanschettenresektion indiziert sein. Bei Lymphknotenentfernung werden die systematische Lymphknotenresektion sowie das systematische und punktuelle Lymphknotensampling unterschieden.

Regional fortgeschrittene Stadien werden entweder definitiv radiochemotherapiert, gefolgt von einer Operation, oder induktions-chemotherapiert gefolgt von einer Operation gefolgt von einer Bestrahlung. Pancoast-Tumoren (sog. Super Sulcus Tumoren mit lokalem Wachstum und Infiltration neuraler und ossärer Strukturen) werden radiochemotherapiert gefolgt von einer Operation. Die Strahlentherapie erfolgt mit 40 - 50 Gy konventionell oder hyperfraktioniert (2-3 Frak- 
tionen pro Tag mit Reduktion der Gesamtdosis auf 1.2 Gy) akzeleriert (2-3 Fraktionen pro Tag mit Einzeldosen von 1.6 Gy - $1.8 \mathrm{~Gy}$ ) oder stereotaktisch hypofraktioniert.. Die Kombination einer Strahlentherapie mit einer Chemotherapie ist effektiver als die Strahlentherapie allein. Effektive Chemotherapiemedikamente sind Cisplatin, Carboplatin, Etoposid und Paclitaxel. Die Prognose wird tumorchirurgisch generell vom primären Lymphknotenstatus sowie dem Erreichen einer R0-Resektion bestimmt. Palliative Chemotherapie führt zur Symptomlinderung und einer geringen Überlebenszeitverlängerung, die mediane Überlebenszeit liegt bei 8 bis 12 Monaten. Die Kenntnis des EGFR-Mutationsstatus sowie des ALK(Gen der Anaplastic Lymphoma Kinase) und des ROS1-Translokationsstatus ermöglicht den Einsatz gezielter Therapien.

Ein fortgeschrittener Lungentumor kann zu endoluminalem Tumorwachstum und externer Kompression führen. Zu den palliativen Therapiemöglichkeiten gehören endoluminale Stents, Nd-YAG-Laser, Argon-Plasma-Coagulationund Kryotherapie. Bei malignem Pleuraerguss bieten sich in erster Linie eine thorakoskopische Talkumpleurodese bzw. Talkumapplikationen via Katheter, getunnelte Pleuradrainagen oder Jodinstillationen an.

\subsection{Chirurgische Notfälle bei Tumorpatienten}

$\mathrm{Zu}$ den häufigen chirurgischen Notfällen bei Tumorpatienten gehören der Darmverschluss, die obere und untere gastrointestinale Blutung sowie die Tumorperforation. Die Diagnose erfolgt mit einem Kontrastmittel-CT, das eine 94-100\%ige Spezifität und Sensitivität für eine mögliche Ursache aufweist (10). Eine Obstruktion kann partiell oder komplett sein und den proximalen oder distalen Dünndarm sowie das Kolorektum betreffen. Die Entscheidung für oder gegen eine Operation ist für den Tumorchirurgen eine der schwierigsten Herausforderungen. Etwa 50 \% der Dünndarmobstruktionen können durch Adhäsionen verursacht sein. Ein operativer Eingriff ist durch hohe Mortalität und Morbidität sowie ReObstruktionsraten gekennzeichnet (11). Die bestmögliche Lebensqualität sollte das primäre Behandlungsziel sein. Das Vorhandensein von Aszites ist ein ungünstiger prognostischer Parameter. Das Behandlungsziel besteht in der Wiedererlangung der Nahrungsaufnahmefähigkeit, einer normalen Darmpassage, der Entlassung in das häusliche Umfeld sowie der Wiederherstellung der sozialen Akzeptanz und Selbstachtung. Wenn eine medikamentöse konservative Therapie keine Besserung erzielt, kommen die endoskopische Implantation von selbstexpandierenden Stents, die chirurgische Tumorresektion mit tumorfreien Resektionsrändern, die chirurgische Umgehungsanastomose oder die Stomaanlage als Dünn- und Dickdarm-, Schlingen- und Endstoma in Betracht.

Wenn bei oberen gastrointestinalen Blutungen medikamentöse Maßnahmen wie Antazida, Protonenpumpenhemmer, Somatostatin und Octreotide zur Reduktion des mesenterialenarteriellen Flusses und Hemmung der Magensäure- und Pepsin- 
produktion, Hemmung der Angiogenese und Thrombozytenaggregation und Pressine versagen, besteht die Möglichkeit der endoskopischen Blutkontrolle durch thermale Koagulierung, Injektion von blutungshemmenden Substanzen und Clipapplikation. Weiterhin kann die angiographische interventionelle Embolisierung versucht werden. Die Operationsmethode für ein blutendes und konservativ nicht kontrollierbares Magenkarzinom ist die Gastrektomie. Bei den unteren gastrointestinalen Blutungen wird zunächst koloskopisch eine Blutstillung versucht. Eine mesenterische Angiographie bedarf eines Blutflusses von mindestens $1-1.5 \mathrm{ml} /$ min, um die Blutungsursache darzustellen. Die Operation beinhaltet die Resektion der Blutungsursache und kann eine Magen-, Dünn- oder Dickdarmresektion erfordern. Bei tumorbedingter Magen- oder Darmperforation stellt die Operation oft die einzige Überlebenschance für den Patienten dar. Die chirurgische Intervention ist jedoch mit einer hohen Morbidität und Mortalität behaftet.

\subsection{Kurative, nicht-kurative und palliative Chirurgie}

Auch mit dem Wissen um den eigenen Tod bleibt die Hoffnung auf eine würdige, schmerzfreie oder beschwerdearme verbleibende Lebenszeit. Entscheidend in der palliativen Chirurgie ist die Selektion geeigneter Patienten, die von einem chirurgischen Eingriff oder einer chirurgischen Intervention profitieren. Dazu bedarf es der gründlichen und sensiblen Planung durch einen erfahrenen Chirurgen und der Diskussion mit dem Patienten, seiner Familie und den Mitgliedern des Palliativteams. Der chirurgische Onkologe ist mit nicht-chirurgischen palliativen Behandlungsmethoden wie Bestrahlung, Chemotherapie und Hormontherapie sowie alternativen Möglichkeiten vertraut und kann so dem Patienten ein optimales individuelles Behandlungskonzept anbieten.

Palliative Chirurgie soll Patienten vorbehalten bleiben, die symptomatisch sind. Operationen, die nicht radikal ausführbar sind und bei denen Residualtumorgewebe in situ verbleibt, werden als „nicht-kurativ“ bezeichnet. Somit kann zwischen palliativen, nicht-kurativen und kurativen Operationen unterschieden werden. Die palliative Chirurgie hat die optimale Symptomkontrolle und die Wiederherstellung der Lebensqualität zum Ziel. Obwohl die Morbidität bei palliativen Eingriffen 40\% betragen kann, gibt es nur geringe Unterschiede zu der Morbidität von Patienten, die mit nicht-kurativer und solchen die mit palliativer Intention operiert werden. Patienten mit einer Lebenserwartung von weniger als 6 Monaten profitieren weniger von einem komplexen chirurgischen palliativen Eingriff. Der chirurgische Onkologe, ausgerüstet mit umfassender chirurgischer Expertise und erwartungsvoll unterstützt durch den Patienten und den medizinischen Onkologen, muss den Nutzen seiner Intervention abwägen. Dabei wird er die folgenden Aspekte berücksichtigen: die Schwierigkeit des chirurgischen Eingriffes, die Dauer des Krankenaufenthaltes, die Rekonvaleszenzphase zu Hause, die Chancen, das Palliationsziel zu erreichen, die Palliationsdauer und den zu erwartenden Tumorprogress. 


\subsection{Literatur}

(1) Turnbull, R.B., Jr., et al., Cancer of the colon: the influence of the notouch isolation technic on survival rates. Ann Surg, 1967. 166(3): p. 420-7.

(2) Wiggers, T., et al., No-touch isolation technique in colon cancer: a controlled prospective trial. Br J Surg, 1988. 75(5): p. 409-15.

(3) Siewert, J.R., M. Feith, and H.J. Stein, Biologic and clinical variations of adenocarcinoma at the esophago-gastric junction: relevance of a topographicanatomic subclassification. J Surg Oncol, 2005. 90(3): p. 139-46; discussion 146.

(4) Kehlet, H. and K. Slim, The future of fast-track surgery. Br J Surg, 2012. 99(8): p. 1025-6.

(5) Pox, C., et al., [S3-guideline colorectal cancer version 1.0]. Z Gastroenterol, 2013. 51(8): p. 753-854.

(6) Tanis, E., et al., Local recurrence rates after radiofrequency ablation or resection of colorectal liver metastases. Analysis of the European Organisation for Research and Treatment of Cancer \#40004 and \#40983. Eur J Cancer, 2014. 50(5): p. 912-9.

(7) Nordlinger, B., et al., Perioperative FOLFOX4 chemotherapy and surgery versus surgery alone for resectable liver metastases from colorectal cancer (EORTC 40983): long-term results of a randomised, controlled, phase 3 trial. Lancet Oncol, 2013. 14(12): p. 1208-15.

(8) Bai, H., et al., The effect of radiofrequency ablation vs. liver resection on survival outcome of colorectal liver metastases (CRLM): a meta-analysis. Hepatogastroenterology, 2015. 62(138): p. 373-7.

(9) Brunelli, A., et al., ERS/ESTS clinical guidelines on fitness for radical therapy in lung cancer patients (surgery and chemo-radiotherapy). Eur Respir J, 2009. 34(1): p. 17-41.

(10) Abbas, S., I.P. Bissett, and B.R. Parry, Oral water soluble contrast for the management of adhesive small bowel obstruction. Cochrane Database Syst Rev, 2007(3): p. CD004651.

(11) Cirocchi, R., et al., Non-resection versus resection for an asymptomatic primary tumour in patients with unresectable stage IV colorectal cancer. Cochrane Database Syst Rev, 2012. 8: p. CD008997. 



\section{Palliative Strahlentherapie}

PD Dr. med. Birgitt van Oorschot, Prof. Dr. med. Franz-Josef Prott, Prof. Dr. rer. medic. Uwe Haverkamp

Universitätsklinikum Würzburg, 97080 Würzburg

RNS Gemeinschaftspraxis Wiesbaden, 65189 Wiesbaden

Universitätsklinikum Münster, 48149 Münster

\subsection{Zusammenfassung}

Strahlentherapie hat als lokales Therapieverfahren einen hohen Stellenwert in der Palliativmedizin. Durch symptomorientierte Bestrahlung und präventive palliative Tumorreduktion können rasche und anhaltende Effekte mit minimalen Nebenwirkungen erzielt werden. Dabei wirkt die Strahlentherapie nicht nur lokal tumorverkleinernd, sondern bereits im Niedrigdosisbereich auch antiinflammatorisch, antisekretorisch, antiödematös und analgetisch. Bei der Indikationsstellung wird das Behandlungsziel individuell festgelegt (Zugewinn an Lebenszeit, Lebensqualität und/oder Symptomlinderung). Art, Gesamtdosis und Fraktionierung der Strahlentherapie sind abhängig von dem Behandlungsziel, der Lokalisation der Tumormanifestationen und der Gesamtprognose des Patienten. Bei eingeschränkter Lebenserwartung ist eine hypofraktionierte Bestrahlung mit kurzer Behandlungsdauer empfehlenswert. 


\subsection{Basiswissen}

5.2.1 Unterscheidung zwischen befund- und symptomorientierter palliativer Strahlentherapie, Therapieziele und Bewertung des Therapienutzens

Für das Verständnis der strahlentherapeutischen Optionen in der Palliativsituation ist es hilfreich, die im angloamerikanischen übliche Unterscheidung zwischen Befunden ( $=$ in der Bildgebung oder in Laborparametern nachweisliche Krankheitszeichen, die nicht mit dem subjektiven Beschwerdegrad korrelieren müssen) und Symptomen (= Beschwerden und Leiden der Patienten) aufzugreifen. Eine Strahlentherapie in palliativer Intention kann entweder befundorientiert mit dem Ziel der zeitbegrenzten Lebensverlängerung oder vor allem orientiert an den Symptomen zur Verbesserung der Lebensqualität durchgeführt werden. Die Patienten können bei der palliativen befundorientierten Strahlentherapie in Bezug auf die lokalen Befunde zu Therapiebeginn durchaus noch kompensiert, d. h. oligosymptomatisch und individuell wenig belastet sein, sodass eher der Erhalt als die Verbesserung der Lebensqualität intendiert ist. Die medizinische Indikation für eine befundorientierte palliative Strahlentherapie ergibt sich aus der Bildgebung unter Berücksichtigung der Gesamtprognose des Patienten. Bei einer symptomorientierten palliativen Bestrahlung ist die Behandlung aufgrund der körperlichen Beschwerden des Patienten (z. B. Schmerzen, Luftnot, Schluckstörungen, Paresen, Geruchsbelästigung etc.) indiziert, ggfs. unter Vernachlässigung der Grunderkrankung oder weiterer Tumormanifestationen an anderer Stelle. Diese Form der Strahlentherapie zur Linderung belastender Beschwerden gehört zu den wesentlichen Maßnahmen palliativmedizinischer Interventionen bei Tumorpatienten und wird auch als „Strahlentherapie in der Palliativmedizin“ bezeichnet. Zur Erfassung des patientenbezogenen Nutzens einer palliativen Strahlentherapie können auch palliativmedizinische Symptomerfassungsbögen eingesetzt werden (1). Möglichkeiten und Grenzen der Strahlentherapie in der Palliativsituation und am Lebensende sind in aktuellen Übersichtsarbeiten dargestellt $(2,3,4)$.

\subsubsection{Formen der Strahlentherapie}

Meistens wird die Bestrahlung als Teletherapie (von griech. tele $=$ fern) am Linearbeschleuniger mit hochenergetischen Photonen oder Elektronen durchgeführt, d. h. die Strahlung wirkt von außen perkutan auf den Körper des Patienten ein. Bei anatomisch sicher lokalisierbaren Zielgebieten und im Notfall ist eine Direkteinstellung der Bestrahlungsfelder am Beschleuniger möglich. Komplexe Zielvolumina erfordern eine CT-gestützte dreidimensionale Planung (3-D-Planung), die genauen Aufschluss über die Dosisverteilung am Tumor und an Risikoorganen 
gibt und so die Voraussetzung für eine sichere und schonende Behandlung auch bei höheren Strahlendosen ist.

Die intensitätsmodulierte Strahlentherapie (IMRT) ist eine Weiterentwicklung der hochkonformalen 3-D-Bestrahlung. Computerunterstützt wird die Dosisverteilung bei einem komplex gestalteten Zielvolumen mit strahlensensiblen Strukturen in der Nachbarschaft optimiert. So wird eine Dosisverteilung erzeugt, bei der die Intensität der Bestrahlung innerhalb des Zielgebietes nach Wunsch variiert werden kann (im Tumor höher als in der Peripherie). Gleichzeitig können innerhalb des Zielgebietes gelegene Risikoorgane maximal geschützt werden. Eine besondere Variante der perkutanen Bestrahlung ist die Stereotaxie, die als hochdosierte Strahlentherapie aus vielen Einstrahlrichtungen in einer einzigen oder wenigen einzelnen Sitzungen durchgeführt wird. Die stereotaktische Einzeitbestrahlung wird auch als Radiochirurgie bezeichnet. Wegen der hohen Einzeldosen eignen sich für dieses Behandlungskonzept insbesondere umschriebene solide Raumforderungen, die möglichst nicht von strahlensensiblen Strukturen durchdrungen sind. Die Hochpräzisionsbestrahlungen (Stereotaxien und IMRT-Protokolle) verlangen eine exakte Lagerung, für die zur Entlastung der Patienten spezielle Lagerungshilfen verwendet werden. Diese Therapien sind aufgrund der Behandlungszeit von 20-50 Minuten pro Sitzung anstrengend und setzen voraus, dass der Patient kooperationsfähig und in relativ gutem Allgemeinzustand ist.

Bei der Brachytherapie (von griech. brachy = nah) wird eine Strahlenquelle direkt an den Tumor gebracht, deren therapeutische Reichweite im Gewebe nur wenige Millimeter beträgt, sodass bei maximaler Schonung des umgebenden Gewebes hohe Dosen an der Tumormanifestation appliziert werden können. Heute wird die Brachytherapie in der Regel als high-dose-rate (= HDR-Brachytherapie) im Afterloading-Verfahren (= Nachladeverfahren) durchgeführt. Das bedeutet, dass die Strahlenquelle nur für einige Minuten (nach im Computer vorausberechneter Zeit) im Patienten verbleibt und aus Strahlenschutzgründen erst dann über spezielle Applikatoren eingebracht wird, wenn das medizinische Personal nicht mehr im Behandlungsraum ist.

\subsubsection{Grundlagen der Fraktionierung und Bedeutung der Prognose}

Zellen des Normalgewebes erholen sich in der Regel besser und rascher von einem Strahlenschaden als Tumorzellen. Deshalb wird die für die Tumortherapie erforderliche Gesamtdosis auf mehrere Sitzungen (= Fraktionen) verteilt. In der Zeit zwischen den Strahlentherapiesitzungen kann sich das Normalgewebe erholen und aufgetretene subletale Schäden reparieren. International hat sich die perkutane Bestrahlung mit Einzeldosen von 1,8-2 Gy an Werktagen inzwischen als Standard für eine konventionelle Fraktionierung durchgesetzt. Dabei ist das Risiko für Spätnebenwirkungen (erwartbar frühestens nach 90 Tagen, in der Regel nach Monaten bis Jahren) an gesunden Nachbarorganen wie z. B. Rückenmarks- und Nervenschäden oder auch Fibrosierungen gering. Da das Risiko für Spätnebenwirkun- 
gen mit der Höhe der Einzeldosis zunimmt, werden konventionell geplante Konzepte mit höherer Einzeldosis (in der Regel 3-8 Gy) als hypofraktionierte Bestrahlung nur in der Palliativsituation unter Berücksichtigung der Prognose eingesetzt. Durch hypofraktionierte Bestrahlung kann die Behandlungsdauer in der Regel ohne Wirkungsverlust verkürzt werden, der erwünschte Effekt tritt früher ein und die Behandlungsbelastung der Patienten durch Transport und Lagerung ist geringer.

Akutnebenwirkungen treten insbesondere in rasch regenerierenden Geweben auf, d. h. vor allem in der Haut, den Schleimhäuten oder auch als Hämatotoxizität im Blutbild erkennbar. Die Wahrscheinlichkeit für das Auftreten von Akutnebenwirkungen hängt $u$. a. ab von:

- Bestrahlungsvolumen (je größer das Bestrahlungsvolumen, desto höher die Akuttoxizität),

- Dosis-Zeit-Verhältnis (in kurzer Zeit verabfolgte Dosis wie z. B. Einzeitbestrahlung oder hypofraktionierte Konzepte; hat eine höhere Akuttoxizität als normofraktionierte Konzepte)

- Organ- und Gewebesensibilität

- Individuelle Faktoren und Vortherapien

Akutnebenwirkungen treten bei konventioneller Fraktionierung in der Regel am Ende der zweiten Bestrahlungswoche auf und klingen nach vier bis spätestens sechs Wochen wieder ab. Strahlentherapiebedingte körperliche Beschwerden sind - bis auf Fatigue - lokale Reaktionen. Sie treten nur in Organen oder Geweben auf, die sich in der Einstrahlrichtung oder der Nachbarschaft der Zielvolumina befinden. Deshalb müssen bei der Einschätzung des Nebenwirkungsrisikos unbedingt die anatomischen Gegebenheiten sowie die Toleranzdosen der verschiedenen Gewebe und Organe berücksichtigt werden. Die Bestrahlung einer Knochenmetastase im Bereich der oberen Brustwirbelsäule oder eines zentralen Bronchialkarzinoms kann z. B. zu Schluckbeschwerden durch Schleimhautschädigung der Ösophaguswand führen, nicht aber zu einer Diarrhoe.

Früher wurden Tumore wie z. B. das Nierenzellkarzinom oder das maligne Melanom als „strahlenresistent“ bezeichnet. Damit war gemeint, dass mit konventioneller Technik in üblicher Dosierung und ohne schwerwiegende Schäden an gesundem Gewebe keine kurative Tumorvernichtung möglich war. Auch bei diesen Entitäten allerdings war die Wirksamkeit der perkutanen Strahlentherapie bei symptomatischen Metastasen in der Palliativsituation unbestritten. Mit der Weiterentwicklung der Planungsverfahren und durch die neuen Techniken kann inzwischen mit höheren Einzeldosen ohne mehr Nebenwirkungen auch bei diesen $\mathrm{Tu}$ morentitäten eine langfristige Kontrolle von intra- und extrakraniellen Metastasen erreicht werden.

Die Dauer der lokalen Kontrolle ist dosisabhängig, d. h. die Zeit bis zu einem lokalen Rezidiv/Progress ist nach höheren Gesamtdosen in den meisten Fällen 
deutlich länger als nach den für die Symptomlinderung erforderlichen palliativen Dosen (ca. 2/3 der Kurativdosis). Deshalb kommen hypofraktionierte und dosisreduzierte Konzepte nur für Patienten mit limitierter Prognose infrage. Wegen der erforderlichen Abwägung zwischen Behandlungsbelastung, eventuellen Spätnebenwirkungen und einem Rezidivrisiko ist eine Prognoseeinschätzung in der palliativen Strahlentherapie unverzichtbar - und diese ist in der Strahlentherapie nicht weniger schwierig als in anderen Kontexten. Nur die Minderzahl der ärztlichen Prognoseeinschätzungen ist korrekt, die meisten Patienten leben kürzer als erwartet $(5,6)$. Deshalb wurden auch aus der Strahlentherapie heraus retrospektiv Scoring-Systeme entwickelt, die eine Einschätzung der Überlebenszeit erleichtern können. Im Survival Prediction Score Toronto werden tumorspezifische Parameter (Tumorentität, Lokalisation der Metastasen), der Allgemeinzustand und klinische Symptome (Fatigue, Appetit, Dyspnoe) berücksichtigt (7). In das TEACHHModell fließen neben der Tumorentität und dem Allgemeinzustand noch Alter, die Anzahl vorhergehender Chemotherapien, die Häufigkeit stationärer Aufenthalte und das Vorhandensein von Lebermetastasen ein (8). In der Analyse von Angelo et al 2014 erwiesen sich ein schlechter Allgemeinzustand (ECOG 3-4), Anämie, Opiat- oder Steroidtherapie und Tumorprogress außerhalb der bestrahlten Regionen als prediktive Einflussfaktoren für den Tod innerhalb von 30 Tagen nach Ende einer palliativen Bestrahlung (9). Darüber hinaus gibt es Scores, die gezielt in der metastasierten Situation anwendbar sind: der Score der Dutch Bone Metastasis Study Group bei Knochenmetastasen (10), der Recursive Partitioning Analysis (RPA)-Score (11) und die Survival-Scores Ganzhirnbestrahlung bei Hirnmetastasen $(12,13)$ sowie das Survival-Scoring-System MSCC bei spinaler Kompression (14). Der Einsatz von Scores darf die klinische Entscheidung nicht ersetzen.

\subsubsection{Prognosebezogene Fraktionierungsschemata und Ansprechraten}

Patienten mit relativ günstiger Prognose (Lebenserwartung länger als ein Jahr) werden zur Vermeidung späterer Nebenwirkungen eher mit konventionellen Einzeldosen normal fraktioniert bestrahlt. Dabei müssen die verbleibenden chemotherapeutischen Optionen in Bezug auf die Lebenserwartung genauso berücksichtigt werden wie das möglicherweise durch vorangegangene Chemotherapien/Operationen/Bestrahlungen erhöhte Nebenwirkungsrisiko in Bezug auf die Akut- und Spättoxizität. Mögliche Behandlungsschemata sind in Tabelle 1 dargestellt. 
Tabelle 1: Palliative Strahlentherapie - Fraktionierungsschemata und Ansprechraten

\begin{tabular}{|c|c|c|c|}
\hline Dosierung & Prognose und Indikationen & $\begin{array}{l}\text { Therapie- } \\
\text { dauer }\end{array}$ & Ansprechen \\
\hline 1 x 8 Gy & $\begin{array}{l}\text { Prognose: Lebenserwartung unter } \\
3 \text { Monaten } \\
\text { schmerzhafte, unkomplizierte } \\
\text { Knochenmetastasen }\end{array}$ & $1 \mathrm{~d}$ & $60-90 \%$ \\
\hline $2 \times 7,5$ Gy & $\begin{array}{l}\text { Prognose: Lebenserwartung wenige Wochen } \\
\text { Bronchialkarzinom mit Bronchusver- } \\
\text { schluss/Kompression }\end{array}$ & $1 \mathrm{Wo}$ & $30-90 \%$ \\
\hline $\begin{array}{l}4-6 \times 0,5-1 \\
\text { Gy }\end{array}$ & Entzündungshemmung & $1 \mathrm{Wo}$ & $70-90 \%$ \\
\hline 5 x 3-4 Gy & $\begin{array}{l}\text { Prognose: Lebenserwartung unter } \\
\text { 3-6 Monaten } \\
\text { Knochenmetastasen mit Weichteilanteil, } \\
\text { metastasiertes Bronchialkarzinom mit } \\
\text { drohendem Bronchusver- } \\
\text { schluss/Blutung, } \\
\text { exulzerierte oder schmerzhafte Weich- } \\
\text { teilmetastasen, } \\
\text { multiple Hirnmetastasen, schlechter AZ } \\
\text { und nicht kontrollierte extrakranielle } \\
\text { Tumormanifestationen }\end{array}$ & $1 \mathrm{Wo}$ & $60-90 \%$ \\
\hline $10 \times 3 G y$ & $\begin{array}{l}\text { Prognose: Lebenserwartung unter einem Jahr } \\
\text { Knochenmetastasen mit dem Ziel der } \\
\text { Rekalzifizierung, } \\
\text { fortgeschrittenes Bronchialkarzinom } \\
\text { multiple Hirnmetastasen, Karnofsky- } \\
\text { Index über } 70 \%\end{array}$ & $2 \mathrm{Wo}$ & $60-90 \%$ \\
\hline $\begin{array}{l}13-15 x \\
3 G y\end{array}$ & $\begin{array}{l}\text { Prognose: Lebenserwartung nicht deutlich mehr } \\
\text { als ein Jahr } \\
\text { Knochenmetastasen ohne weitere } \\
\text { Tumormanifestationen, } \\
\text { fortgeschrittenes Bronchialkarzinom, } \\
\text { mäßiger Allgemeinzustand, Komorbidi- } \\
\text { täten }\end{array}$ & $3 \mathrm{Wo}$ & $60-90 \%$ \\
\hline $\begin{array}{l}20-30 x \\
2 G y\end{array}$ & $\begin{array}{l}\text { Prognose: Lebenserwartung über einem Jahr } \\
\text { fortgeschrittenes Bronchialkarzinom im } \\
\text { Stadium III und gutem AZ (evtl. auch }\end{array}$ & 4-6 Wo & $60-90 \%$ \\
\hline
\end{tabular}




\begin{tabular}{|l|l|l|l|}
\hline Dosierung & Prognose und Indikationen & $\begin{array}{l}\text { Therapie- } \\
\text { dauer }\end{array}$ & Ansprechen \\
\hline & als palliative Radiochemotherapie) & & \\
\hline $\begin{array}{l}20-30 \mathrm{x} \\
\text { IMRT }\end{array}$ & $\begin{array}{l}\text { ausreichender Allgemeinzustand mit } \\
\text { fortgeschrittenen HNO-Tumoren, } \\
\text { Wiederholungsbestrahlungen, } \\
\text { guter Allgemeinzustand mit z. B. } \\
\text { isolierten paraspinalen Metastasen, } \\
\text { isolierte Wirbelkörpermetastasen mit } \\
\text { intraspinalem Anteil }\end{array}$ & $5-6 \mathrm{Wo}$ & $65-90 \%$ \\
\hline $\begin{array}{l}\text { 1-3 x } \\
12-26 \text { Gy } \\
\text { Stereotaxie }\end{array}$ & $\begin{array}{l}\text { guter Allgemeinzustand mit einzel- } \\
\text { nen/wenigen solitären oder singulären } \\
\text { Hirnmetasten, } \\
\text { einzelne/wenige solitäre Lungen- oder } \\
\text { Lebermetastasen }\end{array}$ & max. 1 Wo & $80-90 \%$ \\
\hline
\end{tabular}

\subsubsection{Patientenpräferenzen}

Es liegt nahe, in der Palliativsituation und insbesondere bei Patienten mit schlechter Prognose längere strahlentherapeutische Behandlungen möglichst zu vermeiden. Patientenbefragungen allerdings zeigen, dass es keine eindeutige Präferenz für möglichst kurze Behandlungszeiten gibt. Für die Behandlung von Knochenmetastasen konnte gezeigt werden, dass Patienten in gutem Allgemeinzustand aufgrund des zu erwartenden geringeren Frakturrisikos und der seltener erforderlichen späteren Re-Bestrahlungen eher eine fraktionierte Bestrahlung und damit eine längere Therapiezeit bevorzugen (15). Für die Wahl eines von zwei vorgeschlagenen Therapieregimes zur Symptomkontrolle bei Patienten mit fortgeschrittenem Bronchialkarzinom (2 x 8,5 Gy 1x/Wo versus 13 x 3 Gy werktäglich) wurde mit Erfolg ein Decision-Board zur Patienteninformation über die Vor-und Nachteile der beiden Konzepte eingesetzt. $55 \%$ der befragten Patienten $(n=92)$ entschieden sich für das längere Behandlungsschema. Argumente waren eine zu erwartende längere Überlebenszeit und bessere lokale Kontrolle. Die Kurzzeitbestrahlung wurde wegen des geringeren zeitlichen Aufwandes, der Kostenersparnis und der besseren Symptomkontrolle gewählt (16). Die Patientenbefragungen zeigten, dass auch bezüglich der Fraktionierung in der palliativen Strahlentherapie eine partizipative Entscheidungsfindung möglich und gewünscht ist. Dies sollte bei Konzeptentscheidungen nicht unberücksichtigt bleiben. 


\subsection{Knochen- und Hirnmetastasen}

\subsubsection{Knochenmetastasen}

Eine Vielzahl von randomisierten, prospektiven Studien belegen die Wirksamkeit der perkutanen Strahlentherapie bei Knochenmetastasen (in Übersicht dazu das aktuelle Review von Chow und Kollegen (17). Eine Verbesserung um zwei Punkte auf einer Zehn-Punkte-Analogskala ohne Intensivierung der Schmerzmedikation oder die Reduktion des Analgetikabedarfs um $25 \%$ ohne Schmerzzunahme werden als partielles Ansprechen gewertet (18). Bei unkomplizierten, schmerzhaften Knochenmetastasen soll die Dosis einer Einzeitbestrahlung 8 Gy betragen. Gemäß vierer Metaanalysen ist die Einzeitbestrahlung mit 1 × 8 Gy den fraktionierten Kurzzeit- und Langzeit-Regimes hinsichtlich partiellem Ansprechen und Schmerzfreiheit nicht unterlegen. Somit ist die Einzeitbestrahlung mit $1 \times 8$ Gy bei der Behandlung von unkomplizierten, schmerzhaften Knochenmetastasen zu empfehlen. Davon profitieren auch Patienten mit einer verbleibenden Lebenszeit von bis zu zwölf Wochen $(19,20)$. Mehr als $50 \%$ der Patienten zeigen ein partielles Ansprechen und zwischen 20 und $33 \%$ der Patienten erreichen völlige Schmerzfreiheit und können die Analgetikaeinnahme beenden. Die Behandlungsbelastung wird zumeist überschätzt, ergänzende Angebote (palliativmedizinische Dienste, psychoonkologische Mitbetreuung und Einbeziehung des Sozialdienstes) können die Belastung der Patienten eher vermindern als der Verzicht auf strahlentherapeutische Behandlungssitzungen durch Hypofraktionierung. Wegen der möglichen vorübergehenden Verstärkung der Schmerzen (lagerungsbedingt und „Pain Flare-Phänom“, s. u.) sollten die Schmerzen vor Beginn der Radiatio möglichst optimal eingestellt sein. Dazu gehört immer auch die Verordnung einer entsprechenden Bedarfsmedikation.

Während der Strahlentherapie bzw. 3-5 Tage nach Einzeitbestrahlung kann es zu einer vorübergehenden Schmerzzunahme kommen. Die Häufigkeit dieses als „Pain Flare“ bezeichneten Phänomens liegt zwischen 14 und $44 \%$ und kann durch die prophylaktische Gabe von Dexamethason deutlich gesenkt werden. Bei Chow et al. kam es nach der Gabe von $8 \mathrm{mg}$ Dexamethason vor der Bestrahlung mit $1 \mathrm{x}$ 8 Gy nur bei $3 \%$ der Patienten zu einem „Pain Flare“ (21).

Trotz überzeugender Evidenz hat sich die Einzeitbestrahlung für unkomplizierte Knochenmetastasen weder international noch in Deutschland durchgesetzt (22). Mögliche Gründe werden derzeit intensiv diskutiert. Inwieweit Abrechnungsaspekte eine Bedeutung haben ist unklar. Argumente für den Einsatz fraktionierter Konzepte sind u. a. die ärztliche Betreuung durch den Strahlentherapeuten in der Phase des „Pain Flare“ (Anpassung der Schmerztherapie) und die Prognoseunsicherheit (erwartetes Erleben eines Benefits durch die Remineralisierung nach drei Monaten). Gleichzeitig gibt es Hinweise, dass eine Strahlentherapie zur Schmerzlinderung von Palliativstationen und/oder aus Hospizen heraus eher zu selten eingesetzt wird (23). 


\subsubsection{Re-Bestrahlung bei unkomplizierten Knochenmetastasen}

Die erneute Bestrahlungsrate nach Einzeitbestrahlung ist signifikant höher als nach fraktionierter Bestrahlung. Diese Ergebnisse wurden in den Metaanalysen bestätigt (Tabelle 2). Ob die Tatsache, dass eine Re-Bestrahlung erforderlich ist, als negativ bewertet werden muss, ist derzeit Gegenstand von Diskussionen. Auch die ReBestrahlung ist effektiv, sicher, nebenwirkungsarm und mit vergleichbar hohen Ansprechraten ebenso wirksam.

Ist nach fraktionierter Bestrahlung mit höherer Gesamtdosis eine ReBestrahlung erforderlich, so sollte zur besseren Schonung des gesunden Gewebes der Einsatz von Hochpräzisions-Bestrahlungstechniken erwogen werden. Dies gilt insbesondere für eine Re-Bestrahlung der Wirbelsäule, des knöchernen Beckens und der Schädelbasis. Hochpräzisions-Techniken sind z. B. intra- und extrakranielle stereotaktische Bestrahlung, Radiochirurgie (Einzeit-Bestrahlung) und intensitätsmodulierte Strahlentherapie (IMRT). Eine signifikante Schmerzlinderung wird in über $80 \%$ der Fälle erreicht. In der Serie von Gerszten et al. (N=336) gaben $86 \%$ der Patienten nach median 21 Monaten noch eine deutliche Besserung der vor der Therapie bestehenden Schmerzen an (24).

\subsubsection{Strahlentherapie komplizierter Knochenmetastasen}

Von komplizierten Knochenmetastasen spricht man, wenn zusätzlich zu der Schmerzsymptomatik schwerwiegende Komplikationen wie z. B. eine pathologische Fraktur oder eine metastatisch bedingte Rückenmarkskompression vorliegen. Diese Komplikationen haben einen wesentlichen Einfluss auf die Wahl des Strahlentherapieregimes. Eine pathologische Fraktur sollte ggf. zunächst osteosynthetisch stabilisiert werden, sofern dies chirurgisch möglich und onkologisch sinnvoll ist. Da eine Operation nicht zu einer vollständigen Vernichtung des Tumorgewebes führt, ist eine postoperative Bestrahlung erforderlich, um einem Rezidiv sowie einer Lockerung und Dislokation des osteosynthetischen Materials vorzubeugen. Wesentliches Ziel der postoperativen Bestrahlung ist neben der Schmerzlinderung die Remineralisierung des frakturierten Knochens, die nach drei bis sechs Monaten erwartet werden kann. Die Remineralisierung nach einer Einzeitbestrahlung ist zumeist unzureichend. Darum sollte im Fall einer pathologischen Fraktur bei Patienten mit einer Prognose länger als drei Monate ein Langzeit-Regime (zumeist $10 \mathrm{x}$ 3 Gy in zwei Wochen) verwendet werden.

\subsubsection{Metastatisch bedingte Rückenmarkskompression}

Bei der Strahlentherapie der metastatisch bedingten Rückenmarkskompression sind die Einzeitbestrahlung mit 1 × 8 Gy, die fraktionierte Kurzzeit-Bestrahlung mit 5 x 4 Gy und Langzeit-Regimes wie 10 × 3 Gy, 15 x 2,5 Gy oder 20 × 2 Gy hinsichtlich ihres Effekts auf die motorische Funktion vergleichbar (25). Die An- 
sprechraten (Verbesserung der motorischen Funktion oder Verhindern eines neurologischen Progresses) betragen etwa $85 \%$. Allerdings kommt es nach Einzeitoder fraktionierter Kurzzeitbestrahlung signifikant häufiger zu einem Rezidiv innerhalb des Bestrahlungsfeldes als nach Bestrahlung mit einem Langzeit-Regime. In einer prospektiven nicht-randomisierten Studie betrugen die Raten für die lokale Kontrolle nach einem Jahr $81 \%$ und $61 \%$, p=0,005 (26). Somit sollten Patienten mit besserer Überlebensprognose eine Langzeit-Bestrahlung mit z. B. 10 x 3 Gy erhalten.

\subsubsection{Hirnmetastasen}

Bei vielen Tumorerkrankungen, wie z. B. Lungen- und Brustkrebs, besteht das Risiko einer Entstehung von Hirnmetastasen, sodass sich bei mehr als $25 \%$ aller Patienten mit systemischen Malignomen zerebrale Metastasen entwickeln (27, 28). Hirnmetastasen bilden so einen Anteil zwischen 30 und $40 \%$ aller Hirntumoren. Die mediane Überlebenszeit der Hirntumoren liegt bei 1-2 Monaten ohne Therapie, verlängert sich mit der Steroidtherapie auf 2,5 Monate, nach Ganzhirnstrahlentherapie (WBRT) mit 30-40 Gy liegt die mediane Überlebenszeit bei 3-6 Monaten, Einjahresüberlebenszeiten bis $25 \%$ werden beschrieben. Nach OP und Ganzhirnbestrahlung liegt die mediane Überlebenszeit bei 6-20 Monaten, hier werden Einjahresüberlebenszeiten von 20-60\% beschrieben. Nach Radiochirurgie liegt die mediane Überlebenszeit bei 5-18 Monaten, die Einjahresüberlebenszeit bei 15-55 $\%$ (31). Im Kindesalter finden sich vor allem Gliome und Medulloblastome, während bei Erwachsenen Gliome und gutartige Meningeome als primäre Hirntumoren dominieren. Der aktuellen deutschen Statistik zufolge (29), liegt die mittlere Häufigkeit an einem bösartigen primären Hirntumor zu erkranken in Deutschland bei 9,7 (Männer) bzw. 7,3 (Frauen) je 100.000 Einwohner, mit zunehmendem Lebensalter steigt das Erkrankungsrisiko an. Die Inzidenz der Hirnmetastasen liegt bei beiden Geschlechtern etwa bei 8,3 Patienten pro 100.000 Einwohner und ist damit nahezu gleich hoch der Erkrankungswahrscheinlichkeit an primären Hirntumoren. Mit dem Wissen, dass die Lebenserwartung der Patienten mit zerebralen Metastasen kurz ist, stellen die Behandlungsmethoden eine wissenschaftliche interdisziplinäre Herausforderung dar. Die Hirnmetastasen entwickeln sich sehr schnell (die mediane Tumorwachstumsrate liegt bei $12,10 \mathrm{~mm}^{3}$ pro Tag) (30), überdies treten Symptome bei zerebralen Metastasen relativ spät auf.

\subsubsection{Therapieoptionen}

Die Entscheidung zur Therapiemodalität hängt von der Gesamtprognose ab, dabei sind eine kontrollierte Systemerkrankung, das Alter, der KPS (Karnofsky Performance Scale), die Anzahl der Metastasen und die extrazerebrale Tumormanifestationen die wichtigsten Faktoren. Zur Therapie von Hirnmetastasen stehen derzeit hauptsächlich drei Standardverfahren zur Verfügung: die Operation, die Strahlen- 
therapie und die Chemotherapie. Als symptomatische Palliativtherapie kann z. B. eine Cortison-Therapie verabreicht werden, die parallel oder auch als alleinige Therapie gegeben werden kann.

\section{Chirurgie}

Bei operablen Hirnmetastasen (großvolumig, geeignete Lokalisation, z. B. in der hinteren Schädelgrube) kommt die chirurgische Tumorresektion zum Einsatz, entweder mit dem Ziel der Entfernung des sichtbaren Tumors oder auch zur Entlastung, um vorliegende Beschwerden zu lindern wie z. B. Hirndruckerhöhung. Die Operation verbessert das Überleben allein oder in Kombination mit der Radiotherapie (32).

\section{Chemotherapie}

In Bezug auf die Hirnmetastasen haben chemotherapeutische Ansätze bisher keinen eindeutigen Nutzen zeigen können. Außerdem gibt es kein Standardkonzept für eine Chemotherapie. Da aber alle Chemotherapien mit Nebenwirkungen behaftet sind, sollte ihre Durchführung eine Einzelfallentscheidung bleiben $(33,34)$.

\section{Strahlentherapie}

Die strahlentherapeutischen Optionen für die Hirnmetastasen sind die Bestrahlung des ganzen Hirns WBRT (Whole Brain Radiotherapy) und die Stereotaxie bzw. stereotaktische Radiochirurgie SRS (Stereotactic radiosurgery), wobei die Bestrahlung lokal auf das Zielvolumen fokussiert.

\section{Ganzhirnbestrahlung (WBRT)}

Die Ganzhirnbestrahlung als primäre Therapie ist eine wirksame palliative Behandlung von Hirnmetastasen, vor allem bei Patienten mit multiplen zerebralen Metastasen. Den Leitlinien der Deutschen Gesellschaft für Neurologie (35) zufolge, sollte eine primäre palliative WBRT bei folgenden Voraussetzungen in Betracht gezogen werden:

1. Multiple Hirnmetastasen, insbesondere bei chemotherapie-unsensitiven Tumoren

2. 1-4 Hirnmetastasen, die nicht für die Operation oder Radiochirurgie oder deren Kombination in Frage kommen

3. Solitäre und singuläre Metastasen bei inoperabler Lokalisation oder allgemeiner Inoperabilität oder progredienten extrazerebralen Metastasen, ggf. in Kombination mit der Radiochirurgie

4. Ggf. in Kombination mit Chemotherapie bei kleinzelligem Bronchialkarzinom oder Keimzelltumoren 
In der Regel erfolgt eine Bestrahlung über zwei seitlich opponierende Felder mit 6 MV-Photonen, bei einer Gesamtdosis von 10 x 3 Gy. In der Literatur lassen sich unterschiedliche Fraktionierungsschemata finden: 5 x 4 Gy bzw. 15 x 2 Gy (31). Über akute Nebenwirkungen wie z. B. Kopfschmerzen, Hautrötungen, Haarausfall, Müdigkeit, Schlafstörung, Erbrechen und Übelkeit wurde in den Studien berichtet $(36,37)$. Für Patienten mit einer singulären Hirnmetastase kann die Ganzhirnbestrahlung die Gesamtüberlebenszeit auf das Zwei- bis Dreifache im Vergleich zur alleinigen symptomatischen Palliativtherapie verlängern $(38,39)$.

Aus Studien der RTOG (Radiation Therapy Oncology Group) und basierend auf Daten von 1200 Patienten wurden statistisch signifikant drei prognostische Klassen (RPA classes I-III) definiert. Diese drei RPA Klassen unterscheiden sich in den prognostischen Faktoren und zeigen einen signifikanten Unterschied in der medianen Überlebenszeit.

Tabelle 2: RPA (Recursive Partitioning Analysis (42))

\begin{tabular}{|lll|}
\hline RPA-Klassen & Prognostische Faktoren & $\begin{array}{l}\text { Mediane Überlebenszeit nach } \\
\text { Ganzhirnbestrahlung (Monate) }\end{array}$ \\
Klasse I & $\begin{array}{l}\text { Alter }<65, \text { KPS }>=70, \\
\text { keine oder kontrollierte } \\
\text { extrakranielle Manifestationen }\end{array}$ & 7.1 \\
Klasse II & Patienten weder I noch III & 4.2 \\
& KPS $<70$ & 2.3 \\
\hline
\end{tabular}


In zahlreichen randomisierten Phase-III-Studien der RTOG zur Ganzhirnbestrahlung sind unterschiedliche Fraktionierungsschemata zur Dosisfindung bei Patienten mit multiplen Hirnmetastasen untersucht worden. Das mediane Überleben lag für alle Schemata zwischen drei und sechs Monaten (31).

Um die mit der Ganzhirnbestrahlung verbundenen neurotoxischen Spätfolgen zu vermeiden und eine Verlängerung der neurologischen Remissionszeit zu ermöglichen, wird bei gutem Allgemeinzustand (KPS >70) eher die Radiochirurgie oder die stereotaktische Mehrzeitbestrahlung (2-4 Fraktionen) durchgeführt.

Stereotaktische Radiochirurgie (SRS) und die adjuvante Ganzhirnbestrahlung Die Stereotaxie bzw. stereotaktische Radiochirurgie kurz (SRS) ist erstmals 1951 von dem schwedischen Neurochirurgen Lars Leksell vorgestellt worden. Dabei benötigt der Patient eine spezielle Immobilisation. Im Vergleich zu Standardtherapien werden nicht coplanare Strahlengänge bevorzugt.

Geeignete Bestrahlungsgeräte sind das Gammaknife, das Cyberknife oder Linearbeschleuniger mit spezieller Zusatzausrüstung. Aufgrund der Konzentration der Dosis im Zielvolumen und der weitgehenden Schonung des Normalgewebes kann von der Standardfraktionierung auf eine Hypofraktionierung übergegangen werden, ohne eine erhöhte Nebenwirkungsrate zu befürchten (40). Für die Zielvolumendefinition und die Abgrenzung der Risikoorgane wird zunächst eine Planungsbildgebung durchgeführt, dabei ist immer eine Computertomographie notwendig, wahlweise eine Kernspintomographie. Die Lagerung der Patienten ist sehr wichtig für die Qualität der Behandlung, es sind Lokalisationsfehler zu vermeiden und es ist sicherzustellen, dass der Tumor über den gesamten Behandlungszeitraum von der entsprechenden Referenzisodose umschlossen wird. Die früher ausschließlich übliche scharfe Fixierung ist weitgehend durch entsprechendes Maskensystem ersetzt worden. Zur Qualitätssicherung wird ein on board imaging durchgeführt, entweder mit der Therapiestrahlung (MV) oder über eine externe, an das Gerät angedockte kV-Bildgebung (IGRT Image Guided Radiotherapy). Die kVBildgebung kann entweder als Radiographie oder Computertomographie erfolgen. Dadurch lässt sich die tägliche Reproduzierbarkeit der Strahlenbehandlung gewährleisten. Die Vorteile der IGRT für die SRS wurden z. B. in der Arbeit von Guckenberger et al. 2012 (42) diskutiert. Die Autoren konnten zeigen, dass der SetupFehler von 3,9 $\pm 1,7 \mathrm{~mm}$ auf $0,9 \pm 0,6 \mathrm{~mm}$ reduziert werden konnte. Bei der Verwendung von Rundkollimatoren kann die Dosisverteilung durch eine Art „Kugelhaufen" weitgehend konformal realisiert werden, allerdings müssen Überlappungen der „Kugeln“ und damit Überdosierungen in Kauf genommen werden. Bei Multileafkollimatoren tritt dieser Effekt nicht auf (43). 


\subsubsection{Fraktionierungsschemata (Einzeit/Mehrzeit)}

Einzeitbestrahlung: Radiochirurgie oder Stereotactic Radio-Surgery (SRS)

Die stereotaktische Einzeitbestrahlung kommt typischerweise bei einzelnen Hirnmetastasen (nicht mehr als drei Herde) zum Einsatz, dabei wird die verordnete Dosis (zwischen 15 und 25 Gy) in einer einzigen Sitzung appliziert. Die medianen Überlebenszeiten nach Radiochirurgie von Hirnmetastasen verschiedener Primärtumoren liegen zwischen sechs und zwölf Monaten (44).

Eine Einzeldosis von 20 Gy stellt einen sinnvollen Kompromiss zwischen dem zu erreichenden therapeutischen Effekt (lokale Kontrolle, partielle Remission) und den möglichen Spätnebenwirkungen dar. Höhere Dosen (22-25 Gy) können für kleinere Läsionen $(<1 \mathrm{~cm})$ verwendet werden. Da die Infiltrationszone von Hirnmetastasen klein ist, ist evtl. eine Dosisreduktion auf 18 Gy bei größeren Metasta$\operatorname{sen}(>2,5-3 \mathrm{~cm})$ erforderlich (45).

Fraktionierte Stereotaxie: Stereotaktischen Radiotherapie (SRT)

Bei ungünstig lokalisierten Hirnmetastasen bietet sich die Mehrzeitbestrahlung an, dabei wird die Gesamtdosis auf mehrere Fraktionen aufgeteilt. Das übliche Fraktionierungsschema ist die Zweizeitbestrahlung (20 Gy à 10 Gy je Fraktion oder dreimalige Bestrahlung à 7 Gy je Fraktion) aber auch die Normalfraktionierung (50.4 Gy bzw. 45 Gy à 1.8 Gy) ist möglich. Dies ist insbesondere dann vorteilhaft, wenn sensible Strukturen wie die Sehnerven, das Chiasma oder der Hirnstamm in der unmittelbaren Nachbarschaft eines Zielvolumens liegen. Die fraktionierte stereotaktische Bestrahlungstherapie stellt eine sichere und vom Patienten gut tolerierte Möglichkeit der Tumorbehandlung dar (31).

Dem bisherigen Stand der Forschung zufolge sollten Patienten mit soliden Tumoren (ausgenommen Keimzelltumoren und kleinzellige Bronchialkarzinome), die eine Lebenserwartung von mehr als drei Monaten und singuläre Hirnmetastasen $(<3 \mathrm{~cm})$ haben, für die SRS in Betracht gezogen werden. Insbesondere bei inoperablen Metastasen, Hirnstammmetastasen und bei Metastasen ohne Masseneffekt (lebensbedrohende Kompression) sollte die SRS angeboten werden (45).

Mit SRS als primärer Therapie sollten ebenfalls Patienten mit multiplen Metastasen (2-4), dabei alle mit einem Durchmesser $<2,5 \mathrm{~cm}$ und bei einer Lebenserwartung von mehr als drei Monaten behandelt werden (statt einer Ganzhirnbestrahlung). Eine adjuvante WBRT nach SRS von 1-4 Hirnmetastasen erhöht die lokale Kontrolle und reduziert das Auftreten weiterer Hirnmetastasen, verlängert aber das Gesamtüberleben im Vergleich zu einer primären, alleinigen SRS nicht (45).

Der Nachweis einer solitären oder singulären Hirnmetastase schließt das Vorhandensein von weiteren nicht bildgebend relevanten Läsionen nicht aus. Somit hat sich die Ganzhirnbestrahlung als adjuvante Therapie bei Patienten mit zerebra- 
len Metastasen nach zuvor erfolgter lokaler Therapie als sinnvoll etabliert. Es verringert sich die Wahrscheinlichkeit eines intrakraniellen Rezidivs durch die WBRT von $80 \%$ auf $50 \%$.

Die Studie 22952-26001 der European Organization for Research and Treatment of Cancer (EORTC) zum Stellenwert der Ganzhirnbestrahlung als konsolidierende Therapie nach Operation oder Radiochirurgie von 1-3 Hirnmetastasen hat Einschränkungen in der Lebensqualität (physische und kognitive Funktionen; Müdigkeit) nach Ganzhirnbestrahlung bestätigt (46). Der Stellenwert der Einschränkungen ist aber umstritten (39).

Die Radiochirurgie wird derzeit meist als primäre Behandlung einzelner oder multipler Läsionen mit einem Durchmesser von 15 bis zu 30 mm oder als Rezidivbehandlung bei Patienten eingesetzt, die ein Rezidiv in einer zuvor konventionell bestrahlten Region zeigen. Die lokalen Kontrollraten liegen in einem Bereich von 73-94\% (35). Retrospektive Kohortenstudien weisen auf eine Gleichwertigkeit von Radiochirurgie und neurochirurgischer Resektion hin $(47,49)$.

\subsubsection{Lebensqualität mit Hirnmetastasen}

Im Allgemeinen hängt die strahlentherapieinduzierte Neurotoxizität von der applizierten Gesamtdosis, aber auch von der Höhe der Einzeldosen ab. Die Entscheidung über die therapeutische Strategie ist abhängig vom klinisch-neurologischen Status des Patienten, von der Biologie des Primärtumors und der Anzahl und Lokalisation der Metastasen.

Da die Patienten im Allgemeinen nur eine kurze Lebenserwartung haben, bleibt - nach klinischen Erfahrungen - die mit WBRT verbundene Risikowahrscheinlichkeit neurokognitiver Spätfolgen sehr gering. Auch die Annahme des Vorhandenseins von bildgebend nicht nachweisbaren Läsionen im Gehirn lässt den Einsatz der adjuvanten Ganzhirnbestrahlung zu. Einen Überlebensvorteil für eine zusätzliche Ganzhirnbestrahlung zeigten nur Patienten mit guten prognostischen Faktoren der RPA-Klasse I.

\subsection{Symptomlinderung exemplarisch}

\subsubsection{Obstruktions- und Kompressionssyndrome}

Wenn ein Tumor in Hohlorgane einwächst und diese komprimiert, gehört die Strahlentherapie zum Notfallkonzept. In 60-80 \% der Fälle ist ein palliativer Effekt $\mathrm{zu}$ erreichen (Befundverkleinerung, Symptomlinderung, vgl. Tabelle 3). Je nach Lokalisation und Ausdehnung des Befundes eignen sich die perkutane Strahlentherapie oder die Brachytherapie als Methoden. Die Brachytherapie ermöglicht die Applikation hoher Einzeldosen mit schnellem Wirkeintritt bei geringer Belastung des umgebenden Gewebes (z. B. endobronchialer Tumor, tumoröse Ösopha- 
gusstenose). Wenn angesichts der Lokalisation und der Tumorausdehnung eine Brachytherapie nicht möglich oder alleine nicht ausreichend ist, wird perkutan bestrahlt. Übliche Konzepte für die perkutane Strahlentherapie, z. B. bei einer oberen Einflussstauung, sind 3-4 x 4 Gy nach konventioneller Lokalisation oder Direkteinstellung, dann ggf. Umstellung auf CT-geplante Strahlentherapie je nach Histologie und Tumorstadium. Parallel dazu werden Korticosteroide gegeben (z. B. Dexamethason 12-16 mg 1-0-0).

Tabelle 3: Klinische Symptome bei tumorbedingter Obstruktion bzw. Kompression von Hohlorganen

\begin{tabular}{|l|l|}
\hline Organ & Symptom \\
\hline Ösophagus & Schluckstörung, Passagestop, Regurgitation \\
\hline Trachea, Bronchialsystem & Dyspnoe, Stridor, Angst, Unruhe \\
\hline Darm & Ileus, Übelkeit, Erbrechen, Schmerzen \\
\hline V. cava superior Syndrom & $\begin{array}{l}\text { Obere Einflussstauung, Dyspnoe, Schwindel, Kopf- } \\
\text { schmerzen, Angst, Unruhe }\end{array}$ \\
\hline Leberpforte, Gallengänge & Ikterus, Schmerzen, Pruritus \\
\hline Hirnventrikel & Hirnödem, Erbrechen \\
\hline Myelon & Querschnittssymptomatik \\
\hline Gefäße & Thrombose, Ödem, Schmerzen, Schwellung \\
\hline Ureteren & Harnstau, Schmerzen \\
\hline
\end{tabular}

\subsubsection{Strahlentherapie zur Linderung von Dyspnoe}

Bei einer durch eine Kompression/Infiltration der Trachea oder der großen Bronchien oder durch kompressionsbedingte poststenotische Atelektasen hervorgerufenen Luftnot kann eine lokale Strahlentherapie ergänzend zur medikamentösen Therapie zur Symptomlinderung beitragen. Klinisch unter dem Bild der „oberen Einflussstauung" wird oft gleichzeitig die obere Hohlvene komprimiert bzw. infiltriert. Insgesamt wird die Luftnot bei 35-90 \% der Patienten wirksam gelindert. In einer Studie zur hypofraktionierten palliativen Bestrahlung beim nichtkleinzelligen Bronchialkarzinom hielt die Wirkung im Mittel 7-14 Wochen an und umfasste damit gut $50 \%$ der medianen Überlebenszeit der Studienpatienten (50). Da eine Wirkung der Strahlentherapie bereits nach 3-4 Tagen erwartet werden kann, profitieren auch Patienten mit sehr limitierter Prognose von der Behandlung. Bezüglich Ausmaß und Dauer der Symptomlinderung sind Kurzzeitkonzepte (2 x 7,5 Gy, 5 x $4 \mathrm{~Gy}$ ) nicht schlechter als moderat hypofraktionierte Konzepte (12-15 x 3Gy) (51). Durch eine Kurzzeitbestrahlung tritt die Linderung schneller ein. Patienten in schlechtem Allgemeinzustand sollten - unter adäquater supportiver Therapie - mit symptomorientierten Kurzzeitkonzepten behandelt werden. Patienten in gutem 
Allgemeinzustand (ECOG 0-1) und ohne Metastasen bzw. mit Oligometastasierung sollten wegen der länger anhaltenden lebensverlängernden Wirkung mit höheren Gesamtdosen moderat hypofraktioniert behandelt werden. Die Kombination von perkutaner Strahlentherapie mit Brachytherapie kann für Patienten mit lokalem Bronchusverschluss einen zusätzlichen Benefit bedeuten (52). Auch eine erneute Bestrahlung ist nicht ausgeschlossen. Kramer und Kollegen berichteten über eine Rückbildung von Hämoptysen und oberer Einflussstauung bei allen Patienten mit Bronchialkarzinomrezidiv nach Rebestrahlung $(n=28)$. Husten besserte sich bei $67 \%$, Dyspnoe bei $35 \%$. Der Effekt hielt im Median vier Monate an (53).

\subsubsection{Blutungen, Exulceration und Schwellungen}

Eine akute Blutung ist immer eine Notfallsituation und kann, wenn nicht operativ, so doch vielfach mit einer hochdosierten perkutanen Bestrahlung (hypofraktioniert) oder HDR-Brachytherapie zum Sistieren gebracht werden. Häufige Indikationen für die palliative Strahlentherapie sind vaginale Blutungen bei ausgedehnten Zervix- oder Corpuskarzinomen, exulcerierte, blutende Hauttumoren oder Metastasen ebenso wie Hämoptysen bei Bronchialkarzinom, gelegentlich bei auch blutende Harnblasen- oder Rektumkarzinomen. Die perkutane Strahlentherapie wird bei Blutungen immer notfallmäßig mit höheren Einzeldosen (3-4 Gy) begonnen und dann in Abhängigkeit von der erreichten Besserung, der Prognose und dem Gesamtzustand des Patienten umgestellt auf die übliche Fraktionierung mit 2 Gy Einzeldosis, eventuell auch in Kombination mit einer palliativen Chemotherapie. In der Regel sistiert die Blutung innerhalb von 24-48 Stunden nach der Bestrahlung bzw. nach Applikation von kumulativ 20 Gy.

Auch Patienten mit exulcerierten Hautmetastasen und Lymphknotenmetastasen, ausgedehnten exulcerierten Mammakarzinomen oder Tumoren im HNOBereich profitieren von einer in Abhängigkeit vom klinischen Ansprechen und der Verträglichkeit auch höher dosierten Strahlentherapie, die vielfach zu einer Verkleinerung der Befunde führt. Im Verlauf von Wochen ist auch eine Abheilung möglich. Durch die lokale Bestrahlung wird die Wundversorgung vereinfacht und Superinfektion, Geruchbelästigung sowie die kosmetische Beeinträchtigung (Ansehen, Würde) minimiert. Oberflächliche Tumoren werden mit Elektronen bestrahlt, tiefer gelegene Herde werden nach CT-Planung mit Photonen bestrahlt.

Bei schmerzhaften Schwellungen und Entzündungen (marantische Bursitis, Parotitis etc.) kann im Einzelfall auch eine niedrigdosierte Entzündungsbestrahlung mit 4-10 x 0,3-1 Gy wirkungsvoll eingesetzt werden. Splenomegalie und Leberkapselspannungsschmerz können mit gutem Erfolg mit 3-6 x 1-2 Gy gelindert werden. 


\subsection{Haut- und Schleimhautpflege}

Wesentliche Grundlage der Prophylaxe der Radiodermatitis ist die Reduktion des oberflächlichen Zellverlustes, da durch die Bestrahlung die für die Regeneration verantwortliche Basalzellschicht geschädigt wird. Deshalb sind radiogene Hautreaktionen nicht mit „Verbrennungen“ zu vergleichen. Der Erhalt der schützenden oberflächlichen Zellschichten kann durch weite, nicht abschließende, nicht scheuernde, luftdurchlässige Kleidung unterstützt werden. Duschen und normales Waschen mit vorsichtigem Abtrocknen wird empfohlen. Pflaster sollten nicht im Bestrahlungsfeld aufgeklebt werden. Dünne Applikation von Lotionen, Puder und Deodorant ist auch vor der täglichen Bestrahlung akzeptabel. Pflege mit Basiscreme oder Lipolotion unter Zusatz von Urea (2-5\%) ohne allergisierende Substanzen (Duftstoffe, pflanzliche Inhaltsstoffe) wird entsprechend allgemeingültiger dermatologischer Empfehlungen angeraten.

Die Pflege mit Puder ist über viele Jahre tradiert, es gibt aber keinen Nachweis dafür, dass Puder einer Pflege mit Creme oder ganz ohne zusätzliche Substanzen überlegen ist. Puder ist vor allem deshalb beliebt, weil es die Haftung der Anzeichnungen von Isozentrum und Feldkonturen auf der Haut verbessert. PuderFormulierungen sind jedoch aufgrund ihrer ungünstigen Eigenschaften (austrocknend und verklebend) für die topische Therapie aus heutiger dermatologischer Sicht allgemein nicht zu empfehlen.

Für die Therapie von Erythem und trockenen Epitheliolysen gelten die gleichen Grundsätze wie für die Prophylaxe. Bei radiogen bedingten feuchten Epitheliolysen, Nekrosen und Ulcerationen sind trockene Wundverbände (wirkstofffreie Fettgazen, Schaumstoffe aus z. B. Polyurethan, Calciumalginatwatten bzw. kompressen) und feuchte Wundverbände (Hydrogele, Hydrokolloide und hydroaktive Verbände) geeignete Verbandsstoffe. Ein genereller Vorteil von Wundauflagen, die eine feuchte Wundbehandlung ermöglichen, ist belegt. Aus der Behandlung venöser Ulcera besteht zudem Evidenz, dass die Schmerzhaftigkeit der Wunde unter hydrokolloidalen und Schaumstoff-Wundverbänden geringer ausgeprägt ist. Eine prinzipielle Überlegenheit einer bestimmten Wundauflage gegenüber anderen wurde bislang nicht gefunden. (Schaum-)Verbände können während der Bestrahlung belassen werden.

Relevante radiogene Schleimhautreaktionen können im Mund-Rachen-Bereich bei Bestrahlungen im Kopf-Hals-Bereich auftreten, genau wie Knochenmetastasen im Bereich obere HWS/Schädelbasis. Im Zusammenhang mit einer Bestrahlung von zentralen Lungenkarzinomen/mediastinalen Raumforderungen, Ösophaguskarzinomen oder auch von Knochenmetastasen im Bereich der unteren HWS oder der BWS können schmerzhafte Schleimhautreaktionen der Speiseröhre auftreten.

Bei der enoralen Mukositis sind eine Soorprophylaxe und ggfs. zügige Therapie (Amphomoronal Suspension) und Mundspülungen alle drei bis vier Stunden wichtig. Dabei sind Mundspüllösungen dem Wasser oder Panthenolspüllösungen nicht 
überlegen. Die Patienten sollten die Zahnpflege mit weichen Zahnbürsten durchführen. Die Schmerztherapie kann mit Lokalmaßnahmen durchgeführt werden (anästhesierende Spüllösung), ggf. ergänzt durch Novaminsulfon oder Stufe-2Opioide. Nur selten sind Opioide der WHO-Stufe 3 erforderlich. Gewichtsverlust durch schmerzbedingte Ernährungseinschränkungen sollte vermieden werden, kalorienreiche Zusatznahrung oder vorübergehend parenterale Ernährung sind indiziert. Bei einer schmerzhaften radiogenen Ösophagitis hat sich der Einsatz von Tepilta ${ }^{\circledR}$ (Oxetacain + Magnesiumhydroxid + Aluminiumhydroxid) oder Maaloxan ${ }^{\circledR}$ (Algeldrat + Magnesiumhydroxid) vor den Mahlzeiten und zur Nacht zur Verbesserung der Nahrungsaufnahme bewährt. Die Soorinfektion des Ösophagus sollte mit Fluconazol oral therapiert werden, Mundspülsuspensionen reichen in der Regel nicht aus.

Eine radiogene Mukositis tritt in der Regel in der zweiten oder dritten Bestrahlungswoche auf und klingt innerhalb von zwei bis drei Wochen nach Bestrahlungsende ab.

Die Ursachen für die vielfach berichtete Zunahme der Müdigkeit (Progress der Grunderkrankung, Fatigue) während einer Strahlentherapie sind multifaktoriell. Nach Ausschluss somatischer Ursachen (z. B. Anämie) ist durch moderate körperliche Bewegung, Physiotherapie oder Entspannungsverfahren mehr Besserung zu erwarten als durch Ruhe und den Verzicht auf körperliche Aktivitäten.

\subsection{Literatur}

(1) van Oorschot B, Schuler M, Simon A, Schleicher U, Geinitz H. Patterns of Care and Course of Symptoms in Palliative Radiotherapy: A Multicenter Pilot Study Analysis. Strahlenther Onkol 2011;187(8):461-466.

(2) van Oorschot B, Schulze W. Linderung von Schmerzen und Dyspnoe durch strahlentherapeutische Maßnahmen bei fortgeschrittenen Krebserkrankungen. Onkologe 2014;20:163-168.

(3) Lutz ST, Jones J, Chow E. Role of radiation therapy in palliative care of the patient with cancer. J Clin Oncol 10 2014;32(26):2913-9.

(4) Jones JA, Lutz ST, Chow E, Johnstone PA. Palliative radiotherapy at the end of life: a critical review. CA Cancer J Clin 2014;64(5):296-310.

(5) Glare PA, Sinclair CT. Palliative medicine review: prognostication. J Palliat Med. 2008; 11(1):84-103. Review

(6) Chow E, Davis L, Panzarella T et al. Accuracy of survival prediction by palliative radiation oncologists. Int J Radiat Oncol Biol Phys. 2005 61(3):870-3. 
(7) Chow E, Abdolell M, Panzarella T, Harris K et al. Validation of a predictive model for survival in metastatic cancer patients attending an outpatient palliative radiotherapy clinic. Int J Radiat Oncol Biol Phys. 2009;73(1):280-287.

(8) Krishnan MS, Epstein-Peterson Z, Chen YH et al. Predicting life expectancy in patients with metastatic cancer receiving palliative radiotherapy: the TEACHH model. Cancer. 2014;120(1):134-41.

(9) Angelo K, Norum J, Dalhaug A et al. Development and validation of a model predicting short survival (death within 30 days) after palliative radiotherapy. Anticancer Res 2014;34(2):877-85.

(10) van der Linden YM, Dijkstra SPVonk EJ et al. Prediction of survival in patients with metastases in the spinal column: results based on a randomized trial of radiotherapy. Cancer 2005;103(2):320-328.

(11) Nieder C, Nestle U, Motaref B et al. Prognostic factors in brain metastases: should patients be selected for aggressive treatment according to recursive partitioning analysis (RPA) classes? , Int J Radiat Oncol Biol Phys. 2000;46(2):297302.

(12) Rades D, Dunst J, Schild SE. A new scoring system to predict the survival of patients treated with whole-brain radiotherapy for brain metastases. Strahlenther Onkol 2008;184:251-255.

(13) Sperduto PW, Berkey B, Gaspar LE et al. A new prognostic index and comparison to three other indices for patients with brain metastases: an analysis of 1,960 patients in the RTOG database. Int J Radiat Oncol Biol Phys. 2008;70(2):510-514.

(14) Rades D, Rudat V, Veninga T et al. A score predicting posttreatment ambulatory status in patients irradiated for metastatic spinal cord compression. Int J Radiat Oncol Biol Phys 2008;72(3):905-908.

(15) Shakespeare TP, Lu JJ, Back MF et al. Patient preference for radiotherapy fractionation schedule in the palliation of painful bone metastases. J Clin Oncol 2003;21(11):2156-62.

(16) Tang JI, Shakespeare TP, Lu JJ et al. Patients' preference for radiotherapy fractionation schedule in the palliation of symptomatic unresectable lung cancerdagger. J Med Imaging Radiat Oncol 2008;52(5):497-502. 
(17) Chow E, Zeng L, Salvo N, et al. Update on the systematic review of palliative radiotherapy trials for bone metastases. Clin Oncol (R Coll Radiol) 2012;24:112-124.

(18) Chow E, Hoskin P, Mitera G et al. International Bone Metastases Consensus Working Party. Update of the international consensus on palliative radiotherapy endpoints for future clinical trials in bone metastases. Int J Radiat Oncol Biol Phys. 2012;82(5):1730-7.

(19) Dennis K, Wong K, Zhang L et al. Palliative radiotherapy for bone metastases in the last 3 months of life: worthwhile or futile? Clin Oncol (R Coll Radiol) 2011;10:709-715.

(20) Meeuse JJ, van der Linden YM, van Tienhoven G et al. Dutch Bone Metastasis Study Group: Efficacy of radiotherapy for painful bone metastases during the last 12 weeks of life: results from the Dutch Bone Metastasis Study. Cancer 2010;116(11):2716-25.

(21) Chow E, Loblaw A, Harris K, et al. Dexamethasone for the prophylaxis of radiation-induced pain flare after palliative radiotherapy for bone metastases - a pilot study. Support Care Cancer 2008;15:643-47.

(22) Nieder C, Pawinki A, Dalhaug A. Continuous controversy about radiation oncologists choice of treatment regimens for bone metastases: should we blame doctors, cancer-related features, or design of previous studies? Radiation Oncology 2013;8:85.

(23) Schuster J, Han T, Anscher M, et al. Hospice providers awareness of the benefits and avaiability of single-fraction palliative radiotherapy. J Hosp Palliat Nurs 2014;16:67-72.

(24) Gerszten PC, Burton SA, Ozhasoglu C, et al. Radiosurgery for spinal metastases: clinical experience in 500 cases from a single institution. Spine 2007;32:193-9.

(25) Rades D, Lange M, Veninga T, et al. Final results of a study comparing the local control of short-course and long-course radiotherapy for metastatic spinal cord compression. Int J Radiat Oncol Biol Phys. 2011.79(2):524-30.

(26) Rades D, Stalpers LJ, Veninga T, et al. Evaluation of five radiation schedules and prognostic factors for metastatic spinal cord compression. J Clin Oncol 2005;23:3366-75. 
(27) Gavrilovic IT, Posner JB. Brain metastases: epidemiology and pathophysiology J. Neuroonco 1 2005;75:514.

(28) Barnholtz-Sloan JS, Yu C, Sloan AE, et al. A nomogram for individualized estimation of survival among patients with brain metastasis. Neuro Oncol 2012;14:910-918.

(29) Robert Koch-Institut / Gesellschaft der epidemiologischen Krebsregister in Deutschland e.V. (Hrsg): Krebs in Deutschland 2009/2010. Häufigkeiten und Trends. 9. Ausgabe. Berlin; 2013. S. 104f.

(30) H. Yoo et al. Growth Rates of Metastatic Brain Tumors in Nonsmall Cell Lung Cancer. American Cancer Society Volume 113 / Number 5; 2008.

(31) Wannenmacher M, Wenz F, Debus J (Hrsg.): Strahlentherapie. Zentrales Nervensystem und Sinnesorgane. Berlin, Heidelberg: Springer-Verlag; 2013.

(32) Patchell RA, Tibbs PA, Regine WF, et al. Postoperative radiotherapy in the treatment of single metastases to the brain: a randomized trial. JAMA: the journal of the American Medical Association. Nov 4 1998;280(17): 1485-1489.

(33) Kristensen CA, Kristjansen PE, Hansen HH. Systemic chemotherapy of brain metastases From small cell lung cancer: a review. J Clin Oncol Sep 1992;10(9):1498-1502.

(34) Gerstner E, Fine R. Increased permeability of the Blood-Brain Barrier to chemotherapy in metastatic Brain tumors: establishing a treatment paradigm. J Clin Oncol 2007;25: 2306-12.

(35) Leitlinie der deutschen Gesellschaft für Neurologie: Metastasen und Meningeosis neoplastica; März 2014.

(36) Wong J, Hird A, Kirou-Mauro A, Napolskikh J, Chow E. Quality of life in brain metastases radiation trials: a literature review. Current Oncology Volume 15 2012, Number 5.

(37) McTyre E, Scott J, Chinnaiyan P. Whole brain radiotherapy for brain metastasis. Surg Neurol Int 2013;4,Suppl S4:236-44.

(38) Andrews DW, Scott CB, Sperduto PW et al. Whole brain radiation therapy with or without stereotactic radiosurgery boost for patients with one to three brain metastases: phase III results of the RTOG 9508 randomised trial. Lancet 2004;363:1665-1672. 
(39) Soon YY, Tham IWK, Lim KH, Koh WY, Lu JJ. Surgery or radiosurgery plus whole brain radiotherapy versus surgery or radiosurgery alone for brain metastases. Cochrane Database of Systematic Reviews 2014;Issue3.Art.No.:CD009454.

(40) Gaspar L, et al. Recursive partitioning analysis (RPA) of prognostic factors in three Radiation Therapy Oncology Group (RTOG) brain metastases trials. Int J Radiat Oncol Biol Phys. 1997;37(4):745-51.

(41) Gagnon GJ, Henderson FC, Gehan EA, Sanford D, Collins BT, Moulds JC, Dritschilo A. Cyber Knife Radiosurgery for Breast Cancer Spine Metastases: Cancer 2007; Issue 8,Volume 110:1796-1802.

(42) Guckenberger M, Roesch J, Baier K, Sweeney RA, Flentje M. Dosimetric consequences of translational and rotational errors in frame-less image-guided radiosurgery. Radiat Oncol 2012;7:63.

(43) Kondziolka D, Patel A, Lunsford LD, Kassam A, Flickinger JC. Stereotactic radiosurgery plus whole brain radiotherapy versus radiotherapy alone for patients with multiple brain metastases. Int. J. Radiat Oncol Biol Phys 1999;45:427-434.

(44) Li XP, Xiao JP, Chen XJ, Jiang XS, Zhang Y, Xu YJ. Fractionated stereotactic radiotherapy for small-cell lung cancer patients with brain metastases. J Can Res Ther 2014;10:597-602.

(45) Kocher M, Wirrig A, Pieroth MD, Treuer H, Seegenschmiedt H, Ruge M, Grosu AL, Guckenberger M. Stereotactic radiosurgery for treatment of brain metastases. A report of the DEGRO Working Group on Stereotactic Radiotherapy, Strahlentherapie und Onkologie 6/2014;190:521-532.

(46) Soffietti R, Cornu P, Delattre JY, et al. EFNS guidelines on diagnosis and treatment of brain metastases: report of an EFNS task force. Eur J Neurol 2006;13:674-681.

(47) Schoggl A, Kitz K, Reddy M et al. Defining the role of stereotactic radiosurgery versus microsurgery in the treatment of single brain metastases. Acta Neurochir 2000;142:621-626.

(48) Garell PC, Hitchon PW, Wen BC et al. Stereotactic radiosurgery versus microsurgical resection for the initial treatment of metastatic cancer to the brain. J Radiosurg 1999;2:1-5. 
(49) Zabel-du Bois A, Milker-Zabel S, Henzel M, Popp W, Debus J, Sack H, Engenhart-Cabillic R et al. Evaluation of time, attendance of medical staff, and resourcews during stereotactic radiotherapy/radiosurgery: QUIRO-DEGRO Trial. Strahlentherapie und Onkologie 9/2012, Volume 188,769-776.

(50) Lutz ST, Chow EL, Hartsell WF et al. A review of hypofractionated palliative radiotherapy. Cancer 2007;109(8):1462-1470.

(51) Beli I, Koukourakis G, Platoni K et al. Hypofractionated radiotherapy in non small cell lung cancer: a review of the current literature. Rev Recent Clin Trials 2010;5(2):103-11.

(52) Reveiz L, Rueda JR, Cardona AF. Palliative endobronchial brachytherapy for non-small cell lung cancer. Cochrane Database Syst Rev; 2012.

(53) Kramer GW, Gans S, Ullmann E et al. Hypofractionated external beam radiotherapy as retreatment for symptomatic non-small-cell lung carcinoma: an effective treatment? Int J Radiat Oncol Biol Phys 2004;58(5):1388-1393. 


\section{Nuklearmedizin - Endoradiotherapie mit spezifischen und unspezifischen Verfahren}

Prof. Dr. med. Uwe Haberkorn

Radiologische Universitätsklinik, 69120 Heidelberg

\subsection{Einleitung}

Unter Endoradiotherapie von Tumoren versteht man eine lokalisierte Einbringung radioaktiv markierter Teilchen oder Moleküle mit therapeutisch nutzbarer Strahlung. Dies kann entweder durch invasive Verfahren geschehen, bei denen radioaktiv markierte nicht tumor-affine Partikel direkt an das zu behandelnde Gewebe gebracht werden (unspezifische Verfahren) oder aber durch die Gabe von tumoraffinen Molekülen, die sich nach intravenöser Applikation im Tumor selektiv anreichern (spezifische Verfahren).

\subsection{Unspezifische Therapie - Selektive interne Radiotherapie (SIRT)}

Bei der SIRT werden Radionuklide nach Kopplung an Glas- oder KunstharzKügelchen (Mikrosphären) über die arteriellen Gefäße in den Tumor oder die Metastasen eingebracht. Die bei der SIRT eingesetzten Isotope sind 90Y, 131I und 188Re, wobei zur Zeit der Schwerpunkt auf den kommerziell erhältlichen 90YMikrosphären liegt. Therasphere ${ }^{\circledR s}$ sind nicht abbaubare Glas-Mikrosphären, in die $89 \mathrm{Y}$ eingearbeitet ist, welches durch Neutronenbeschuss in einem Reaktor zu 
90Y umgewandelt wird. Die SIR-Spheres ${ }^{\circledR}$ sind Kunstharzpartikel, an deren Oberfläche das Radionuklid gebunden wird. Therasphere ${ }^{\circledR}$ weist eine wesentlich höhere Aktivität pro Partikel als die SIR-Spheres ${ }^{\circledR}$ auf. Daher werden mit SIR-Spheres deutlich mehr Partikel benötigt als mit Theraspheres. Die höhere Anzahl der Partikel sowie der größere Durchmesser der SIR-Spheres ${ }^{\circledR}$ führen gewöhnlich zu einer Embolisation des Tumors und seiner zuführenden Gefäße. 90Y emittiert ß-Partikel mit einer Energie von 2,24 MeV und weist eine Halbwertszeit von 64 Stunden auf. Die B-Teilchen haben im Gewebe eine mittlere Reichweite von 2,5-3,5 mm.

Die SIRT-Therapie wird entweder zur Therapie von Lebermetastasen oder des hepatozellulären Karzinoms (HCC) eingesetzt. Die Therapie des HCC mit 90YMikrosphären basiert auf der starken arteriellen Hypervaskularisation dieser Tumoren. Da die arteriell injizierten Mikrosphären proportional zur Perfusion deponiert werden, ergibt sich im stark durchbluteten Tumor eine höhere Anreicherung als in der Leber und damit eine höhere Strahlendosis. Wichtige Vorraussetzungen neben dem Nachweis der Hypervaskularisierung sind eine verifizierte Tumordiagnose, eine adäquate Leberfunktion, fehlende extrahepatische Metastasen, kein oder ein korrigierbarer viszeraler Shunt, eine Shunt-bedingte Lungendosis unter 30 Gy, keine sonstigen gefäßanatomischen Kontraindikationen und eine fehlende Pfortaderthrombose (gilt nur SIR-Spheres) (1).

Bisher liegen für das HCC und bei Lebermetastasen lediglich nichtrandomisierte Studien vor. Dennoch belegen viele offene Phase-2-Studien trotz deren Heterogenität bezüglich der Patientenpopulationen sowie des Tumorstadiums einen positiven Effekt auf Überleben und Lebensqualität. Ebenso belegen diese Studien, dass die Toxizität der Therapie bei optimaler Vorbereitung des Patienten auf ein geringes Maß reduziert werden kann (2; 3; 4). Eine multivariate Analyse der Prognosefaktoren ergab, dass eine Dosis von >104 Gy, ein Tumor im Okuda-Stadium I und, im Hinblick auf die Verteilung der Mikrosphären, eine Tumor-zu-Leber-Ratio von $>2$ signifikant mit einem verbesserten Überleben korrelierten (2). Die mediane Überlebenszeit wird in verschiedenen größeren Studien für Okuda-I-Patienten mit 628 bis 649 Tagen und Okuda-II-Patienten mit 302 bis 324 Tagen angegeben und ist damit gegenüber der historischen Kontrolle mit 244 und 64 Tagen deutlich besser. Ein Vergleich mit der Chemoembolisation bezüglich des Postembolisationssysndroms (PES) mit Fieber, Übelkeit und abdominellen Schmerzen zeigte bei besserem radiologischen Tumoransprechen, dass das PES nach Therapie mit 90Y-Mikrosphären ca. viermal seltener auftrat als nach Chemoembolisation $(5 ; 6)$.

Mehrere Studien beschäftigten sich mit der Therapie von Lebermetastasen mit ebenfalls positiven Ergebnissen (7; 8). In einer großen aktuellen Studie führten Sato et al. 225 therapeutische Gaben bei 137 Patienten durch. Die Primärtumoren bei diesen Patienten waren im Kolon, Brust, neuroendokrine Tumoren, Pankreas, Lunge, Cholangiokarzinom, Melanom, Niere, Ösophagus, Ovar, Adenokarcinom unbekannten Ursprungs, Lymphom, Magen, Duodenum, Blase, Angiosarkom, Schilddrüse, Nebenniere und Parotis. Die mittlere Anzahl der Therapien betrug 
1,6, die mittlere Aktivität und die Dosis lagen bei 1,83 GBq und 112,8 Gy. An Nebenwirkungen traten Müdigkeit (56\%), abdominelle Schmerzen (26\%) und Übelkeit $(23 \%)$ auf. Die weitere Verlaufsbeobachtung zeigte ein Ansprechen bei 42,8 \% der Patienten (2,1\% komplett, 40,7\% partiell). Das mediane Überleben bei allen Patienten lag bei 300 Tagen (Einjahresüberleben 47,8 \%, Zweijahresüberleben $30,9 \%$ ). Bei Patienten mit kolorektalen Tumoren lag das mediane Überleben bei 457 Tagen, bei Patienten mit neuroendokrinen Tumoren sogar bei 776 Tagen (9).

\subsubsection{Tracer mit Anreicherung in Zonen des Knochenumbaus}

Patienten in Spätstadien ihrer Tumorerkrankungen weisen oft Knochenmetastasen mit starken Schmerzen auf. Hier hat die Radionuklidtherapie mit knochensuchenden Molekülen ein großes Potential. Das Verfahren wird eingesetzt, wenn im Knochenszintigramm multiple Läsionen mit assoziierter Schmerzsymptomatik dargestellt sind.

Die anionischen knochensuchenden Substanzen, meist basierend auf organischen Phosphaten, werden in die Knochenmatrix eingebaut. Rhenium und Samarium reichern sich dabei spezifisch an der Stelle der ossären Umbauzonen an. Dabei ermöglicht der $\gamma$-Anteil der Strahlung eine posttherapeutische Bildgebung bzw. die Verlaufsbeobachtung bei mehreren Zyklen (10).

Zunächst war diese Therapie eher in Spätstadien eingesetzt. Mittlerweile herrscht jedoch die Ansicht, dass ein früherer Einsatz auch zu einer Verlängerung des Überlebens führen könnte. Absolute Kontraindikationen sind Schwangerschaft und Stillen, relative Kontraindikationen sind niedrige hämatologische Parameter, d. h. Werte für Thrombozyten $<1.105 / \mu$ l, Leukozyten $<3.103 / \mu$ l, Erythrozyten $<$ $3.106 / \mu$ l, Hämoglobin $<12 \mathrm{~g} / 1$ oder Hämatokrit $<30 \%$. Einige randomisierte Studien zeigten eine signifikante Besserung der Schmerzsymptomatik für Rhenium (11) und Samarium (12) gegenüber der Placebogruppe mit Ansprechraten bezüglich der Schmerzreduktion von über $80 \%$. Bei 30-60 \% kam es zu einem kompletten Verschwinden der Schmerzen. Ein kurzfristiger Anstieg der Schmerzintensität („flare phenomenon“) kann beobachtet werden (in unter $10 \%$ der Fälle) und tritt gewöhnlich an Tag 2 oder 3 auf, um dann nach einer Woche wieder abzuklingen. Die Reduktion der Schmerzen kann bis zu einem Jahr dauern. Weiterhin kann es zu einer Stabilisierung oder sogar Regression der Läsionen kommen (13). Als weitere Effekte wurden Abfall der Tumormarker und bis zu einem Jahr verlängertes Überleben beschrieben (14), besonders bei frühzeitigem Einsatz.

Die hämatologische Toxizität ist in der Regel gering und nur transient mit einer Normalisierung innerhalb von drei Monaten. Der Nadir mit einem Abfall von 25-30 \% wird etwa nach zwei bis sechs Wochen erreicht. Faktoren, die Ausmaß und Dauer der Toxizität beeinflussen, sind die Dosis und begleitende Chemo- oder Strahlentherapie. Auch wiederholte Therapien mit Sm-153-EDTMP bei Patienten 
mit metastasierten Prostatakarzinomen führten nicht zu ausgeprägten und langanhaltenden hämatologischen Effekten.

Trotz der bekannten Wirkung bei geringen Nebenwirkungen wurde die Radionuklidtherapie mit Rhenium oder Samarium bisher nur in geringem Umfang von den onkologischen Kollegen genutzt (15).

Umso erstaunlicher ist die Akzeptanz von Radium-223-Chlorid (Xofigo). Radium-223 ist ein Alphastrahler mit einer Halbwertszeit von 11,4 Tagen und einer Penetrationsstrecke von 80-90 um. In einer multinationalen Phase-III-Studie (ALSYMPCA trial) wurden die Wirksamkeit und die Nebenwirkungen von Xofigo bei Patienten mit metastasiertem, kastrationsresistentem Prostatakarzinom gegenüber einer Placebogruppe evaluiert. Dabei verlängerte die Therapie mit Ra-223 das mediane Überleben um ca. drei Monate bei geringen hämatologischen und nichthämatologischen (Diarrhoe) Nebenwirkungen. Weiterhin kam es zu einer Verzögerung von ossären Komplikationen und einer Schmerzreduktion bei mindestens $50 \%$ der Patienten $(16 ; 17)$.

Eine kontrollierte Studie, die das therapeutische Potential von Rhenium und Samarium gegenüber Radium (Ra)-223 untersucht, wäre nun wünschenswert.

\subsection{Spezifische Verfahren}

Spezifische Verfahren nutzen Transportmoleküle, die spezifisch an Zielstrukturen binden. Diese Transportmoleküle können dann mit Chemotherapeutika oder radioaktiven Isotopen gekoppelt werden. In den meisten Fällen werden dafür Antikörper gegen Tumorantigene oder Peptide, die an überexprimierte Rezeptoren binden, eingesetzt. Dieser Abschnitt wird sich auf die Verwendung von tumor-affinen Peptiden bzw. deren Modifikationen konzentrieren.

\subsubsection{Peptid Rezeptor Radionuklidtherapie (PRRT)}

Peptide sind nützliche Moleküle für den zielgerichteten Transport von Radionukliden an den gewünschten Ort in einem Organismus. Wenn der entsprechende Rezeptor in einem Tumor überexprimiert ist, können dort therapeutisch relevante Dosen bei reduzierten Nebenwirkungen erreicht werden. Abhängig von den verwendeten Isotopen erlauben radioaktiv markierte Peptide zusätzlich noch eine Bildgebung. Das attraktive Merkmal besteht hier darin, dass zunächst das Peptid mit einem $\gamma$ oder Positronenemitter markiert und dieses dann dazu eingesetzt werden kann, um diejenigen Patienten zu identifizieren, die von einer PRRT profitieren können. Kriterium ist hier eine hohe Anreicherung im Tumor. Dann kann dasselbe Molekül mit einem $\alpha$ oder $\beta$-Emitter markiert und zur Therapie eingesetzt werden.

Ein weiterer Vorteil der Endoradiotherapie gegenüber traditionellen Therapien oder Immuntherapie liegt im Kreuzfeuereffekt, der durch die ß-Partikel induziert 
wird, die von der Bindungsstelle ausgehen. Diese Partikel führen zu einer Zerstörung multipler Zellen in der näheren Umgebung der rezeptor-positiven Zelle und können daher eine heterogene Expression der Zielstruktur im Tumor teilweise kompensieren. Dies kann mit nicht-radioaktiven Verfahren nicht erreicht werden, da hier gewöhnlich nur die Zellen zerstört werden, die das therapeutisch eingesetzte Molekül binden. Eine weitere Steigerung des Therapie-Effekts erfolgt durch den „radiation-induced bystander effect“ (RIBE). RIBE beschreibt die Situation, bei der Zellen, die nicht direkt ionisierender Strahlung ausgesetzt sind, sich so verhalten wie exponierte Zellen: Diese Zellen sterben ab oder zeigen chromosomale Instabilitäten. Obwohl der genaue Mechanimus der RIBE derzeit noch nicht vollständig aufgeklärt ist, gibt es Evidenz dafür, dass chemische Signalwege deletäre Informationen von strahlenexponierten Zellen an benachbarte Zellen weiterleiten.

\subsubsection{Somatostatin-Rezeptoren}

Die Bildgebung und Therapie mit Somatostatinrezeptorliganden kann als Paradigma für eine ganze Reihe von möglichen Verfahren angesehen werden, die auf der Verwendung von Peptiden beruhen. Die hohe Affinität der Peptide für den Rezeptor sowie die Internalisierung des Rezeptor-Peptid-Komplexes erleichtert die Retention der Strahlenquelle in Rezeptor-positiven Tumoren, während die relativ geringe Größe eine schnelle Clearance aus dem Blut ermöglicht. Somatostatinrezeptoren werden von einer Vielzahl von Tumoren exprimiert, wie neuroendokrine Tumoren von Pankreas und Intestinum, Hypophysenadenom, Phäochromozytom, Paragangliom, kleinzelligem Lungenkarzinom,Neuroblastom, medullärem Schilddrüsenkarzinom und Meningeom. Aufgrund ihrer hohen Rezeptordichte stellen gastroenteropankreatische neuroendokrine Tumoren, Phäochromozytomae, Paragangliome und bronchiale Karzinoide vielversprechende Kandidaten für die PRRT dar. In einzelnen Fällen können auch kleinzellige Lungenkarzinome und medulläre Schilddrüsenkarzinome oder ein geringer Anteil von nichtoperablen Meningeomen, Neuroblastomen, Schilddrüsenkarzinomen, Nierenzellkarzinomen oder Mammakarzinome behandelt werden.

Verschiedene Peptide wurden bereits für therapeutische Zwecke mit folgenden Radionukliden markiert: $111 \mathrm{In}, 90 \mathrm{Y}$ und $177 \mathrm{Lu}$. Aufgrund seiner hohen Partikelenergie und relativ kurzen Halbwertszeit (HWZ) führen 90Y-markierte Moleküle zu einer höheren Tumorzelldosis pro Peptid und zu einem besseren Kreuzfeuereffekt. Dieses Merkmal wird besonders bei der Behandlung größerer Tumoren und bei Tumoren mit heterogener Rezeptorexpression benötigt. Im Gegensatz dazu führen die niedrigere Energie und die geringere Partikelreichweite von $177 \mathrm{Lu} \mathrm{zu}$ einer besseren Absorption in kleineren Tumoren. Weiterhin kann die $\gamma$ Strahlung von 177Lu zusätzlich zur Bildgebung und Dosimetrie genutzt werden. Präklinische Studien an tumortragenden Tieren bestätigten diese Eigenschaften anhand exzellenter Anti-Tumor-Effekte und des erwarteten Einflusses der Tumorgröße. Daher wurde bereits eine Kombination beider Radionuklide zur Behandlung von Tumo- 
ren mit unterschiedlichen Größen und inhomogener Verteilung der Rezeptorexpression vorgeschlagen (18).

Die bisher verfügbaren klinischen Studien leiden etwas unter der Heterogenität der Patientenpopulationen und der Verwendung unterschiedlicher Isotope, Peptide und nicht-standardisierten Dosen. Im Unterschied zu Antikörpern bei Radioimmuntherapien wurden keine Hinweise auf eine Immunogenität der Peptide gefunden. Erste Studien mit hohen Dosen (kumulative Dosen zwischen 20 und $>100$ GBq) des Auger-Elektronen emittierenden [111In-DTPA0]octreotide bei Patienten mit metastasierten neuroendokrinen Tumors und in schlechtem klinischen Zustand ergaben positive Effekte bezüglich der Symptome, jedoch nur wenige partielle Remissionen (19). Toxizität wurde hauptsächlich in Form einer Knochenmarksuppression beobachtet.

[90Y-DOTA0,Tyr3]octreotide (DOTATOC) bindet an den Somatostatinrezeptor Subtyp 2 mit einer etwa zehnfach höheren Affinität als [111InDTPA0]octreotide. Daher wurden einige Phase-1- und Phase-2-PRRT-Studien mit diesem Molekül durchgeführt. Erste Versuche mit Dosen von 6 und $7.4 \mathrm{GBq}$, gegeben über vier Zyklen, zeigten eine generelle Ansprechrate von $24 \%$ oder $33 \%$ bei Gabe von 7.4 GBq in zwei Zyklen (20). Eine Dosiseskalation bis zu 5.6 $\mathrm{GBq} /$ Zyklus ergab keine schwerwiegenden akuten Reaktionen und eine reversible Grad 3 hämatologische Toxizität bei $43 \%$ der Patienten nach Gabe von 5.2 GBq. Diese Dosis wurde dann als maximal tolerierte Dosis pro Zyklus definiert. Der Anteil der partiellen (PR) und kompletten Remissionen (CR) lag bei $28 \%$ bei 87 Patienten (21). Andere Studien berichten über ähnliche Ergebnisse mit einem medianen Intervall bis zur klinischen Progression von 33 Monaten (22). Zusammengefasst lagen die CRs und PRs trotz der Unterschiede in den Protokollen bei den meisten dieser Studien mit [90Y-DOTA0,Tyr3]octreotide bei 10-30 \%, also höher als die mit [111In-DTPA0]octreotide erreichten Daten.

177Lu-DOTATATE war vergleichbar zu [111In-DTPA0]octreotide bezüglich seiner Anreicherung in Niere, Milz und Leber, zeigte jedoch eine drei- bis vierfach höhere Anreicherung in Tumoren (23). [177Lu-DOTA0,Tyr3]octreotate stellt eine interessante Entwicklung dar, da es zu höheren absorbierten Tumordosen bei vergleichbaren Dosen für möglicherweise dosis-limitierenden Organen führt. Therapie von Patienten mit gastroenteropankreatischen neuroendokrinen Tumoren mit [177Lu-DOTA0,Tyr3] octreotate führte zu kompletten oder partiellen Remissions bei $30 \%$, metabolischem Ansprechen bei $12 \%$, „stable disease“ bei $40 \%$ und Progression bei $18 \%$ von 76 Patienten. Die Tumorregression war dabei positiv korreliert zur Höhe des OctreoScan ${ }^{\circledR}$ Uptakes, einer limitierten hepatischen Tumormasse, und einem hohen Karnofsky-Index. Nebenwirkungen traten bei der Therapie mit [177Lu-DOTA0,Tyr3]octreotate nur selten und transient auf, hauptsächlich als geringe Kochenmarksuppression.

Zusammenfassend konnten Besserungen bezüglich der Symptome nach Therapie mit Somatostatinanaloga mit besseren Ergebnissen für die Tumorregression durch die Verwendung von [90Y-DOTA0,Tyr3]octreotide und [177Lu- 
DOTA0,Tyr3]octreotate beobachtet werden. Die Nierentoxizität konnte durch die simultane Infusion von Lysin und Arginin reduziert werden. Weitere Nebenwirkungen dieser Therapie traten nur gelegentlich und in milder Ausprägung auf. Die Dauer des Therapieansprechens lag bei beiden Radiopharmazeutika bei mehr als zwei Jahren. Unterschiede in der therapeutischen Effizienz sind höchstwahrscheinlich durch die bereits erwähnten Variationen der Dosen, Therapieschemata (dosiseskalierend versus fixierte Dosis) und Patientenpopulationen verursacht. Ein kritischer Punkt ist hier die angemessene Selektion der Patienten, die von einer Behandlung profitieren können. Kriterien für eine erfolgreiche Anwendung sind die Höhe des Uptakes bei der prätherapeutischen Bildgebung (d. h. die Rezeptordichte), die gesamte Tumorlast, und das Ausmaß der Leber- und Nieren-Anreicherung. Daher werden weiterhin randomisierte Studien zur Etablierung des optimalen Ablaufs und der verwendeten Tracer benötigt.

Zusätzlich zu Kombinationen von Peptidanalogen, die mit unterschiedlichen Radionukliden markiert sind, könnten zukünftige Aktivitäten mehrere Strategien anwenden: Hochregulation der Somatostatinrezeptor-Expression von Tumoren, frühe Diagnose mit PET-Tracern (könnte Patienten mit einer niedrigen Tumorlast und höherer Chance auf Ansprechen identifizieren), Peptide mit Bindung an mehrere Rezeptoren oder Rezeptorsubtypen und Kombination mit Radiosensitizern, Operation, Chemotherapie, Immuntherapie und Strahlentherapie.

\subsubsection{Liganden für das Prostata Spezifische Membranantigen (PSMA) zur Therapie des metastasierten Prostatakarzinoms}

PSMA ist ein Transmembran-Protein mit einer großen, 707 Aminosäuren langen, extrazellulären Domäne, das stabil an der Zellmembran verankert ist. Das Protein kommt in gutartigen Prostataveränderungen wie Hyperplasie nur wenig bis moderat vor, ist aber bei fast allen Prostatakarzinomen überexprimiert. Dabei steigt die PSMA-Expression mit zunehmender Aggressivität des Tumors, so dass diese am ausgeprägtesten bei höhergradigen Tumoren, Metastasen und Androgenunabhängigen Tumoren ist. Die PSMA-Expression in Prostatakarzinomen ist etwa zehnfach höher als in normalem Prostatagewebe. In den meisten anderen Organen wurde keine PSMA-Expression beobachtet. Lediglich eine geringe Expression konnte im Gehirn, Dünndarm, Leber, den proximalen Tubuli der Nieren und den Speicheldrüsen nachgewiesen werden. PSMA internalisiert sowohl spontan als auch nach Bindung von Antikörpern oder spezifischen Hemmstoffen. Dies ermöglicht die intrazelluläre Anreicherung von zytotoxischen Medikamenten oder Radionukliden (24;25). Für den diagnostischen und therapeutischen Einsatz wurden sogenannte „small molecules“ eingesetzt (26;27;28;29). Diese Moleküle sind derzeit in der Diagnostik anderen Ansätzen wie z. B. dem Cholin-PET/CT eindeutig überlegen. Für den therapeutischen Einsatz wurde zunächst ein mit I-131 markierter Ligand für PSMA (MIP-1095) bei Patienten mit metastasiertem kastrationsresistentem Prostatakarzinom eingesetzt. Ein Zyklus mit dem Liganden führte bei 
60,7 \% der Patienten zu einem Abfall der PSA-Werte $>50 \%$. 84.6\% der Patienten mit Knochenschmerzen erfuhren eine komplette oder teilweise Reduktion der Symptome. Die hämatologische Toxizität war gering. $25 \%$ der Patienten berichteten über einen transienten trockenen Mund. Nebenwirkungen bezüglich der Nieren waren nicht zu beobachten. Mittlerweile wurde ein weiterer Ligand synthetisiert, der eine Therapie mit 177Lu oder 225Ac ermöglicht. Hier konnten bereits vielversprechende Ergebnisse beobachtet werden.

\subsection{Literatur}

(1) Hilgard P, Müller S, Hamami M, Sauerwein WS, Haberkorn U, Gerken G, Antoch G. Selektive interne Radiotherapie (Radioembolisation) und Strahlentherapie beim HCC - Stand und Perspektiven. Z Gastroenterol 2009; 47:37-54.

(2) Dancey JE, Shepherd FA, Paul K, Sniderman KW, Houle S, Gabrys J, et al. Treatment of nonresectable hepatocellular carcinoma with intrahepatic ${ }^{90} \mathrm{Y}$ microspheres. J Nucl Med 2000; 41:1673-1681

(3) Goin JE, Salem R, Carr BI, Dancey JE, Soulen MC, Geschwind JF, et al. Treatment of unresectable hepatocellular carcinoma with intrahepatic yttrium 90 microspheres: factors associated with liver toxicities. J Vasc Interv Radiol 2005; $16: 205-213$

(4) Salem R, Thurston KG, Carr BI, Goin JE, Geschwind JF. Yttrium-90 microspheres: radiation therapy for unresectable liver cancer. J Vasc Interv Radiol 2002; 13:S223-S229

(5) Carr BI. Hepatic arterial ${ }^{90}$ Yttrium glass microspheres (Therasphere) for unresectable hepatocellular carcinoma: interim safety and survival data on 65 patients. Liver Transpl 2004; 10:S107-S110

(6) Geschwind JF, Salem R, Carr BI, Soulen MC, Thurston KG, Goin KA, et al. Yttrium-90 microspheres for the treatment of hepatocellular carcinoma. Gastroenterology 2004; 127(5 Suppl 1):S194-S205

(7) Herba MJ, Thirlwell MP. Radioembolization for hepatic metastases. Semin Oncol 2002; 29: 152-159.

(8) Lewandowski RJ, Thurston KG, Goin JE, et al. ${ }^{90} \mathrm{Y}$ microsphere (TheraSphere) treatment for unresectable colorectal cancer metastases of the liver: response to treatment at targeted doses of $135-150$ Gy as measured by $\left[{ }^{18} \mathrm{~F}\right]$ fluoro- 
deoxyglucose positron emission tomography and computed tomographic imaging. J Vasc Interv Radiol 2005; 16:1641-1651.

(9) Sato KT, Lewandowski RJ, Mulcahy MF, Atassi B, Ryu RK, Gates VL, Nemcek A, Barakat, O, Benson III A, Mandal R, Talamonti M, Wong CY, Miller FH, Newman SB, Shaw JM, Thurston KG, Omary KA, Salem R. Unresectable Chemorefractory Liver Metastases: Radioembolization with 90Y MicrospheresSafety, Efficacy, and Survival. Radiology 2008; 247:507-515.

(10) Turner JH, Martindale A, Sorby P, Hetgerington EL, Fleay RF, Hoffmann RF and Claringbold BG: Samarium-153-EDTMP therapy of disseminated skeletal metastases. Eur J Nucl Med 1989; 15:784-95.

(11) Han SH, de Klerk JM, Tan S, van het Schip AD, Derksen BH, van Dijk A, Kruitwagen CL, Blijham GH, van Rijk PP and Zonnenberg BA: The PLACORHEN study: a double-blind, placebo-controlled, randomized radionuclide study with (186)Re-etidronate in hormone-resistant prostate cancer patients with painful bone metastases. Placebo Controlled Rhenium Study. J Nucl Med 2002; 43:1150-6.

(12) Sartor O, Reid RH, Hoskin PJ, Quick DP, Ell PJ, Coleman RE, Kotler JA, Freeman LM and Olivier P; Quadramet 424Sm10/11 Study Group: Samarium153-Lexidronam complex for treatment of painful bone metastases in hormonerefractory prostate cancer. Urology 2004; 63:940-5.

(13) Sinzinger H, Palumbo B and Özker K: The Vienna protocol and perspectives in radionuclide therapy. Q J Nucl Med Mol imaging 2011; 55: 420-30.

(14) Resche I, Chatal JF, Pecking A, Ell P, Duchesne G, Rubens R, Fogelman I, Houston S, Fauser A, Fischer M and Wilkins D: A dose-controlled study of Sm153-ethylenediaminetetra-methylenephosphonate (EDTMP) in the treatment of patients with painful bone metastases. Eur J Cancer 1997; 33:1583-91.

(15) Papatheofanis FJ: Variation in oncologic opinion regarding management of metastatic bone pain with systemic radionuclide therapy. J Nucl Med 1999; 40:1420-3.

(16) Hoskin P, Sartor O, O’Sullivan JM, Johannessen DC, Helle SI, Logue J, et al. Efficacy and safety of radium-223 dichloride in patients with castrationresistant prostat cancer and symptomatic bone metastases, with or without previous docetaxel use: a prespecified subgroup analysis from the randomised, doubleblind, phase 3 ALSYMPCA trial. Lancet Oncol 2014;in press. 
(17) Sartor O, Coleman R, Nilsson S, Heinrich D, Helle SI, O’Sullivan JM, et al. Effect of radium-223 dichloride on symptomatic skeletal events in patients with castration-.resistant prostate cancer and bone metastases: results from a phase 3, double-blind, randomised trial. Lancet Oncol 2014 in press.

(18) Dejong M, Breeman WAP, Valkema R, Bernard BF. Krenning, EP. Combination radionuclide therapy using ${ }^{177} \mathrm{Lu}$ - and ${ }^{90} \mathrm{Y}$-labeled somatostatin analogs J Nucl Med 2005; 46: 13-17.

(19) Valkema R, de Jong M, Bakker WH, Breeman WA, Kooij PP, Lugtenburg PJ, DeJong FH, Christiansen A, Kam BL, DeHerder WW, Stridsberg M, Lindemans J, Ensing G, Krenning EP. Phase I study of peptide receptor radionuclide therapy with [In-DTPA]octreotide: the Rotterdam experience Semin. Nucl. Med. 2002; 32, 110-122.

(20) Waldherr C, Pless M, Maecke HR, Haldemann A, Mueller-Brand J. The clinical value of [90Y-DOTA]-D-Phe1-Tyr3-octreotide (90Y-DOTATOC) in the treatment of neuroendocrine tumours: a clinical phase II study. Ann Oncol 2001; 12:941-945.

(21) Chinol M, Bodei L, Cremonesi M, Paganelli G. Receptor-mediated radiotherapy with Y-DOTA-DPhe-Tyr-octreotide: the experience of the European Institute of Oncology Group- Semin Nucl Med 2002; 32:141-147.

(22) Bodei L, Cremonesi M, Zoboli S, Grana C, Mazzetta C, Rocca P, Caracciolo M, Mäcke HR, Chinol M, Paganelli G. Receptor-mediated radionuclide therapy with 90Y-DOTATOC in association with amino acid infusion: a phase I study. Eur J Nucl Med Mol Imaging 2003; 30:207-216.

(23) Kwekkeboom DJ, Bakker WH, Kooij PP, Konijnenberg MW, Srinivasan A.; et al. [ $\left[{ }^{177} \mathrm{Lu}-\mathrm{DOTAOTyr} 3\right]$ octreotate: comparison with $\left[{ }^{111} \mathrm{In}-\right.$

DTPAo]octreotide in patients- Eur J Nucl Med 2001; 28:1319-1325.

(24) Eder M, Schaefer M, Bauder-Wuest U, Hull WE, Wängler C, Mier W, Haberkorn U, Eisenhut M. The 68Ga-complex lipophilicity and the targeting property of a urea based PSMA inhibitor for PET imaging. Bioconjug Chem 2012;23:688-697.

(25) Eder M, Eisenhut M, Babich J, Haberkorn U. PSMA as a target for radiolabelled small molecules. Eur J Nucl Med Mol Imaging 2013;40:819-823.

(26) Afshar-Oromieh A, Zechmann CM, Malcher A, Eder M, Eisenhut M, Linhart HG, Holland-Letz T, Hadaschik BA, Giesel FL, Debus J, Haberkorn U. 
Comparison of PET imaging with a 68Ga-labelled PSMA-ligand and 18F-choline based PET/CT for the diagnosis of recurrent prostate cancer. Eur J Nuc Med Mol Imaging 2014;41:11-20.

(27) Afshar-Oromieh A, Avtzi E, Giesel FL, Holland-Letz T, Linhart HG, Eder M, Eisenhut M, Boxler S, Hadaschik BA, Kratochwil C, Weichert W, Kopka $\mathrm{K}$, Debus J, Haberkorn U. The diagnostic value of PET/CT imaging with the 68Ga-labelled PSMA ligand HBED-CC in the diagnosis of recurrent prostate cancer. Eur J Nucl Med Mol Imaging 2014; [Epub ahead of print].

(28) Kratochwil C, Giesel FL, Eder M, Afshar-Oromieh A, Benešová M, Mier W, Kopka K, Haberkorn U. $\left.{ }^{[17} \mathrm{Lu}\right]$ Lutetium-labelled PSMA ligand-induced remission in a patient with metastatic prostate cancer. Eur J Nucl Med Mol Imaging. 2015 Jan 9. [Epub ahead of print]

(29) Zechmann CM, Afshar-Oromieh A, Armor T, Stubbs JB, Mier W, Hadaschik B, Joyal J, Kopka K, Debus J, Babich JW, Haberkorn U. Radiation dosimetry and first therapy results with a 124I/ 131I-labeled small molecule (MIP1095) targeting PSMA for prostate cancer therapy. Eur J Nucl Med Mol Imaging 2014; 41:1280-92. See comment in PubMed Commons below.

\section{Weiterführende Literatur:}

Haberkorn U, Eisenhut M, Altmann A, Mier W. (2008) Endoradiotherapy with peptides - status and future development. Curr Med Chem 15:219-34.

Maecke HR, Hofmann M, Haberkorn U. (2005) Gallium-68 Labeled Peptides in Tumor Imaging. J Nucl Med 46:172-178.

Reubi JC, Schar JC, Waser B, Wenger S, Heppeler A, Schmitt JS. Mäcke HR. (2000) Affinity profiles for human somatostatin receptor subtypes SST1-SST5 of somatostatin radiotracers selected for scintigraphic and radiotherapeutic use. Eur J Nucl Med 27: 273-282. 



\section{Systemische/medikamentöse Tumortherapie}

Dr. med. Stefan Fuxius

Onkologische Schwerpunktpraxis Heidelberg, 69115 Heidelberg

\subsection{Zusammenfassung}

In der Onkologie werden heute im Rahmen der systemischen/medikamentösen Tumortherapie zahlreiche Substanzen mit unterschiedlichen Angriffspunkten eingesetzt, z.B. Zytostatika, Hormone bzw. Antihormone, monoklonale Antikörper, molekulare Wirkstoffe zur gezielten Signaltransduktionshemmung, antiangiogene Substanzen, Protease-Inhibitoren (sog. ,targeted therapies"), Impfstoffe etc. Eine besondere Form der Therapie stellt die Stammzelltherapie dar (1).

Während Zytostatika direkt in die Zellteilung eingreifen, zielt der Wirkmechanismus der anderen Medikationsgruppen in der Regel nicht direkt auf die Zellteilung. Sie werden daher auch nicht den Zytostatika zugerechnet. Dennoch sind sie systemisch, also im ganzen Körper wirksam (Abbildung 1). Ziel ist eine maximale Schädigung des Tumorgewebes bei möglichst weitgehender Schonung gesunder Zellen. Immer häufiger werden deshalb verschiedene Ansätze zur Effizienzsteigerung und Reduktion von Nebenwirkungen kombiniert. Auch können Substanzen in geringen Dosen (niedrige Toxizität) häufiger (täglich oder mehrmals täglich) verabreicht werden (z. B. „metronomische Therapie“). 


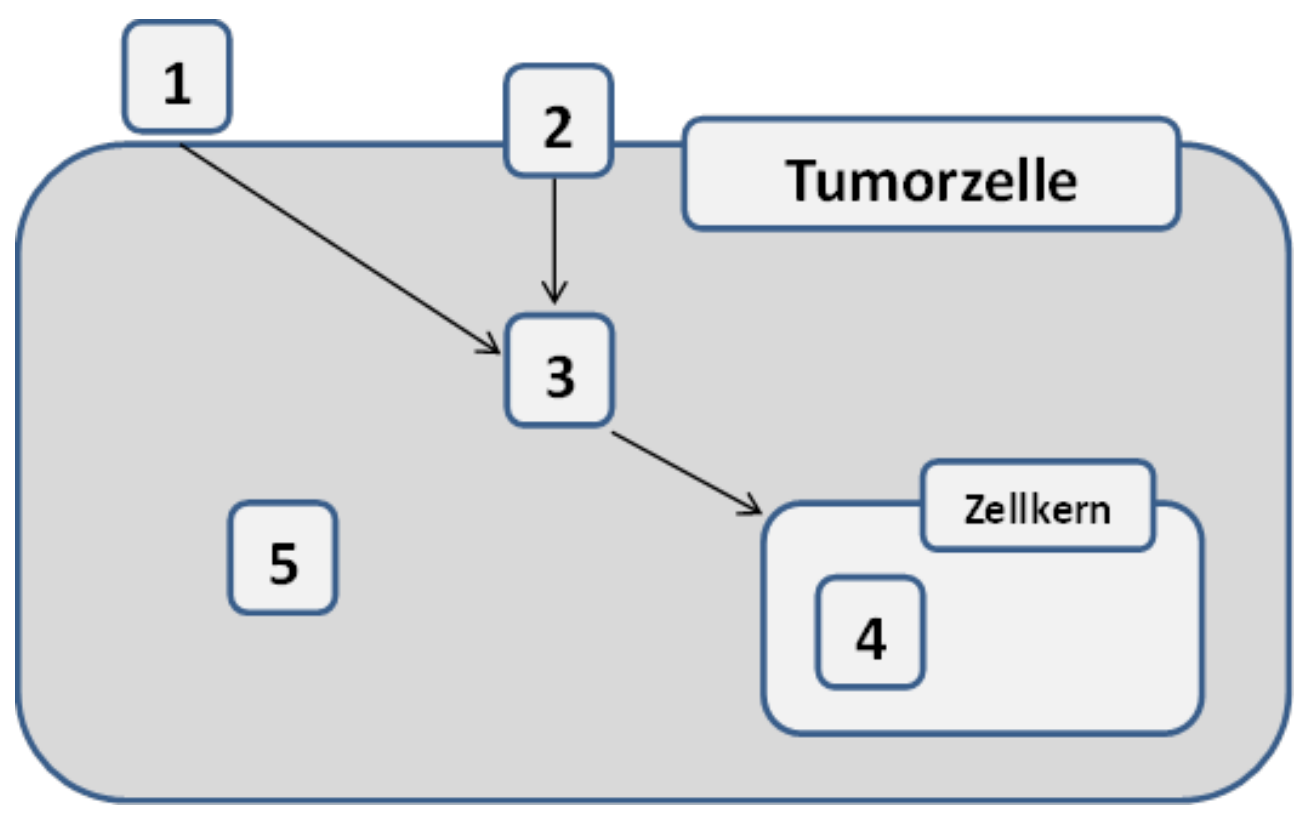

Abbildung 1: Zelluläre Angriffspunkte unterschiedlicher Therapieprinzipien

1: Extrazelluläre Matrix: Medikamente gegen Angiogenese (₹: B. Anti-VEGF-Antikörper), Integrine, Metalloproteinasen, etc;

2: Wachstumsfaktoren und deren Rezeptoren (₹. B. Her2neu, EGFR);

3: Inbibitoren der Signaltransduktionswege (Ras, raf, $M A P K, M E K, E R K, A K T$, Proteinkinase $C$, PI3K, etc);

4: Zerstörung der Zellkernfunktionen (Zytostatika, Cyklin-abbängige Kinasen (CDK), mTOR, cGMP, p53, bsl-2, etc);

5: Zerstörung der Zytosolfunktionen (Zytostatika, Proteasombeeinflussung, etc.).

In der Palliativsituation müssen möglicher Nutzen und Toxizität besonders sorgfältig abgewogen werden, wobei individuelle Umstände eine wichtige Rolle spielen (z. B. mehr oder weniger realistische Wunschvorstellungen, Alter, Komorbidität oder die häusliche Situation). Ein therapeutischer Nihilismus ist nicht angebracht. Auch die systemische Tumortherapie kann zu einer Linderung der Symptome beitragen, indem z. B. Schmerzen gelindert und der Bedarf an Analgetika vermindert, die Darmmotilität bei Peritonealkarzinose länger aufrechterhalten oder das Risiko pathologischer Frakturen reduziert werden. Im Mittelpunkt steht dabei aber stets die Voraussetzung, dass die Therapie nicht belastender als der natürliche Erkrankungsverlauf wird.

Im Folgenden werden die verschiedenen Möglichkeiten der systemischen/medikamentösen Tumortherapie in der Palliativmedizin vorgestellt. 


\subsection{Zytostatika}

Tumorzellen haben bei erhöhter Zellteilungsrate nur eingeschränkte Reparaturkapazitäten. Dadurch sind sie empfindlicher gegenüber Substanzen, die die Zellteilung stören, als gesunde Körperzellen. Dies liegt der therapeutischen Breite vieler Zytostatika zugrunde und ist somit die Basis für deren Einsatz. So hemmen sie z. B. das Zellwachstum, indem sie den Wachstumszyklus in dem Moment behindern, in dem sich die Zelle in einer aktiven Replikationsphase befindet. Befindet sich die Zelle in einer anderen Phase ihres Zellzyklus, ist die Therapie u. U. wirkungslos und es bedarf daher wiederholter Gaben der Zytostatika um eine ausreichende Menge aktiver Tumorzellen in ihrer „vulnerablen“ Phase angreifen zu können (Tabelle 1).

Tabelle 1: Substanzgruppen mit Wirkmechanismus, Toxizität und Resistenzmechanismen mit Beispielen im Einzelnen.

\begin{tabular}{|c|c|c|c|}
\hline $\begin{array}{l}\text { Substanz- } \\
\text { gruppe }\end{array}$ & Wirkmechanismus & Toxizität & $\begin{array}{l}\text { Resistenz- } \\
\text { mechanismen }\end{array}$ \\
\hline $\begin{array}{l}\text { Alkylan- } \\
\text { zien }\end{array}$ & $\begin{array}{l}\text { Kopplung von rea- } \\
\text { giblen Alkylgruppen } \\
\text { an die DNS, Vernet- } \\
\text { zung der DNS; }\end{array}$ & $\begin{array}{l}\text { Hämatotoxizität: Cyclo- } \\
\text { phosphamid: Neutropenie }> \\
\text { Thrombopenie (Aldehyd- } \\
\text { Dehydrogenase in Megakary- } \\
\text { ozyten); Verzögerte Restitu- } \\
\text { tion durch Nitrosoharnstoffe } \\
\text { (4-6 Wo.); Immunsuppres- } \\
\text { sion; } \\
\text { Gastrointestinale Toxizität: } \\
\text { Nausea / Emesis (Hochdo- } \\
\text { sierte Therapien hoch eme- } \\
\text { togen); Gonadale Toxizität } \\
\text { (bis Infertilität) und Terato- } \\
\text { genität; } \\
\text { Pulmonale Toxizität: } \\
\text { Pneumonitis und Fibrose; } \\
\text { Induktion von Zweitneo- } \\
\text { plasien }\end{array}$ & $\begin{array}{l}\text { Steigerung der } \\
\text { DNA- } \\
\text { Reparatur, Re- } \\
\text { sistenzmecha- } \\
\text { nismen gegen- } \\
\text { über Cisplatin: } \\
\text { Reduzierte } \\
\text { intrazelluläre } \\
\text { Platinakkumu- } \\
\text { lation durch } \\
\text { verminderte } \\
\text { Aufnahme; } \\
\text { Inaktivierung; }\end{array}$ \\
\hline $\begin{array}{l}\text { Beispiele: } \\
\text { Stickstoff } \\
\text { Chlorambu } \\
\text { Alkylsulfo } \\
\text { Nitrosoha } \\
\text { Platinana } \\
\text { Andere: P }\end{array}$ & $\begin{array}{l}\text { ost-Derivate: Cycloph } \\
\text { 1, Estramustin, Bendar } \\
\text { te: Busulfan, Treosulf } \\
\text { stoffe: Carmustin, Lo1 } \\
\text { ga: Carboplatin, Cispla } \\
\text { carbazin, Dacarbazin, ' }\end{array}$ & $\begin{array}{l}\text { hamid, Ifosfamid, Trofosfamid } \\
\text { stin, Nimustin, Streptozotocin } \\
\text { Oxaliplatin } \\
\text { nozolomid, Thiotepa }\end{array}$ & Melphalan, \\
\hline
\end{tabular}




\begin{tabular}{|c|c|c|c|}
\hline $\begin{array}{l}\text { Substanz- } \\
\text { gruppe }\end{array}$ & Wirkmechanismus & Toxizität & $\begin{array}{l}\text { Resistenz- } \\
\text { mechanismen }\end{array}$ \\
\hline $\begin{array}{l}\text { Antibio- } \\
\text { tika: }\end{array}$ & $\begin{array}{l}\text { Interkalierende To- } \\
\text { poisomerase II Inhi- } \\
\text { bitoren; meist DNS- } \\
\text { Vernetzung; DNS / } \\
\text { RNS Polymerasen } \\
\text { Hemmung; Radikal- } \\
\text { bildung; Zellmem- } \\
\text { bran-Interferenz, } \\
\text { Chelatbildung }\end{array}$ & $\begin{array}{l}\text { Hämatotoxizität: Myelo- } \\
\text { suppression; } \\
\text { Gastrointestinale Toxizität: } \\
\text { Nausea \& Emesis;, Mukositis } \\
\text { \& Stomatitis; } \\
\text { Hauttoxizität: Erytheme / } \\
\text { Recall-Phänomene; Alopezie: } \\
\text { Pegyliertes Doxorubicin } \\
\text { induziert weniger Alopezie } \\
\text { als freies Doxorubicin; } \\
\text { Bleomycin induziert rever- } \\
\text { sible Hyperpigmentierung } \\
\text { und Lungenfibrose (Recall- } \\
\text { Effekt auch Jahre später) } \\
\text { Kardiotoxizität: V. a. Anth- } \\
\text { racycline, akut und chro- } \\
\text { nisch durch freie Sauerstoff- } \\
\text { Radikale, Fehlen der Super- } \\
\text { oxid-Dismutase, etc. Ursache } \\
\text { u. A. Ruptur der Myofibril- } \\
\text { len, Lmphozyteninfiltration, } \\
\text { Gefügedilatation, Fibro- } \\
\text { sen.(2) Reduktion der Kardi- } \\
\text { otoxizität durch liposomale } \\
\text { Galenik bei äquivalenter } \\
\text { Wirksamkeit. } \\
\text { Nekrosebildung bei Para- } \\
\text { vasat (,Alles was Farbe } \\
\text { hat‘): Therapieoptionen: } \\
\text { Kühlen, (DMSO), Dexrazo- } \\
\text { xane, Chirurgische Sanierung. }\end{array}$ & $\begin{array}{l}\text { Multi-Drug } \\
\text { Resistence. } \\
\text { Aktivitätssteige- } \\
\text { rung Gluta- } \\
\text { thion S Tran- } \\
\text { ferase, Erhöhte } \\
\text { DNS Reparatur }\end{array}$ \\
\hline
\end{tabular}

\section{Beispiele:}

Anthracene: Mitoxantron, Lysoxatron

Anthrazykline: Adriamycin, Aclarubicin, Daunorubicin, Epirubicin, Idarubicin

Phenoxazone: Actinomycin-D; Chronomycine, Mithramycin

Sonstige: Bleomycin (Glykopeptidanalogon); Mitomycin-C (Alkylans) 


\begin{tabular}{|c|c|c|c|}
\hline $\begin{array}{l}\text { Substanz- } \\
\text { gruppe }\end{array}$ & Wirkmechanismus & Toxizität & $\begin{array}{l}\text { Resistenz- } \\
\text { mechanismen }\end{array}$ \\
\hline $\begin{array}{l}\text { Antime- } \\
\text { taboliten: }\end{array}$ & $\begin{array}{l}\text { Strukuranaloga der } \\
\text { DNS Basen -> kom- } \\
\text { petitive Verdrängung } \\
\text { einer natürlichen } \\
\text { Base, Einbau in DNS } \\
\text { und RNS als } \\
\text { „falsche“ Base. } \\
\text { Inhibition von } \\
\text { Schlüsselenzymen. }\end{array}$ & $\begin{array}{l}\text { Hämatotoxizität: Myelo- } \\
\text { suppression; } \\
\text { Gastrointestinale Toxizität: } \\
\text { Mukositis; } \\
\text { Hepatotoxizität (akut und } \\
\text { chronisch); Pneumonitiden; } \\
\text { Nephrotoxizität durch Aus- } \\
\text { kristallisation in den Nieren- } \\
\text { tubuli; } \\
\text { - Wichtiger „Interaktionsort“ } \\
\text { ist die Niere; Interaktion mit } \\
\text { Cotrimoxazol und Penicillin: } \\
\text { Verminderte tubuläre Sekre- } \\
\text { tion und Verdrängung aus } \\
\text { der Plasmaproteinbindung } \\
\text { => MTX Spiegel erhöht => } \\
\text { Hämatotoxizität erhöht } \\
\text { - Auch PPIs hemmen die } \\
\text { MTX - Elimination } \\
\text { Gemcitabine (Myelosupp- } \\
\text { ression, Grippe ähnliches } \\
\text { Syndrom, Ödemneigung, } \\
\text { Dyspnoe, z.T. Bronchospas- } \\
\text { tik, Pruritus, Proteinurie / } \\
\text { Hämaturie }\end{array}$ & $\begin{array}{l}\text { Resistenzver- } \\
\text { mittlung bei } \\
\text { Methotrexat via } \\
\text { Thymidin - } \\
\text { Salvage Path- } \\
\text { way und } \\
\text { Genamplifika- } \\
\text { tion }\end{array}$ \\
\hline \multicolumn{4}{|c|}{$\begin{array}{l}\text { Beispiele: } \\
\text { Folsäureantagonisten: MTX, Pemetrexed } \\
\text { Purinanaloga: Azathioprin, Cladribin, Fludarabin, Mercaptopurin, Pentostatin, Thi- } \\
\text { oguanin } \\
\text { Pyrimidinanaloga: Azacytidin, Capecitabin, Cytarabin, Decitabin, Fluorouracil, Gemci- } \\
\text { tabin }\end{array}$} \\
\hline
\end{tabular}




\begin{tabular}{|c|c|c|c|}
\hline $\begin{array}{l}\text { Substanz- } \\
\text { gruppe }\end{array}$ & Wirkmechanismus & Toxizität & $\begin{array}{l}\text { Resistenz- } \\
\text { mechanismen }\end{array}$ \\
\hline $\begin{array}{l}\text { Mitose } \\
\text { gifte: }\end{array}$ & $\begin{array}{l}\text { Störung der Struktur } \\
\text { der Mikrotubuli und } \\
\text { Mitosespindeln: } \\
\text { Vinca-Alkaloide } \\
\text { inhibieren die Poly- } \\
\text { merisation der Tubu- } \\
\text { li-M-Phasen Syn- } \\
\text { chronisation; Taxa- } \\
\text { ne / Epothilone } \\
\text { inhibieren die Depo- } \\
\text { lymerisation der } \\
\text { Tubuli - G2/M Ar- } \\
\text { rest } \\
\text { Neue Taxane (La- } \\
\text { rotaxel und Cabacit- } \\
\text { axel) sind schlechte } \\
\text { Substrate für P170 } \\
\text { Glykoprotein, passie- } \\
\text { ren die Blut-Hirn- } \\
\text { Schranke, haben } \\
\text { Aktivität bei } \\
\text { Doxorubicin-, Vin- } \\
\text { blastin- und Taxan- } \\
\text { resistenz. Cabazitaxel } \\
\text { zugelassen für Kast- } \\
\text { rationsrefraktäres } \\
\text { und Docetaxel vor- } \\
\text { behandeltes Prosta- } \\
\text { takarzinom. (3) }\end{array}$ & $\begin{array}{l}\text { Vincaalkaloide: } \\
\text { Hämatotoxizität: dosislimi- } \\
\text { tierend Neutropenie, Anä- } \\
\text { mie; } \\
\text { Neurotoxizität (Vincristin): } \\
\text { Periphere Polyneuropathie, } \\
\text { aber auch Obstipation, Para- } \\
\text { lyt. Ileus (Vinblastin), } \\
\text { Sonstiges: Alopezie, RR- } \\
\text { Alteration, Anorexie, Asthe- } \\
\text { nie, Mukositis, Brust- } \\
\text { Bauchschmerzen (Vinorelbi- } \\
\text { ne). Phlebitis unter Vinorel- } \\
\text { bin (Therapieoptionen: } \\
\text { Wärmen, Hyaluronidase, } \\
\text { chirurgische Sanierung). } \\
\text { Taxane: } \\
\text { Hämatotoxizität: dosislimi- } \\
\text { tierend Neutropenie, Anä- } \\
\text { mie; } \\
\text { Neurotoxizität: Periphere } \\
\text { Polyneuropathie / Myalgien, } \\
\text { Sonstiges: Hypersensitivi- } \\
\text { tätsreaktionen Kardiotoxizi- } \\
\text { tät (Bradykardien, AV- } \\
\text { Blockierungen, Ergüsse, } \\
\text { Ödeme, Flüssigkeitsretention } \\
\text { (Membranpermeabilitätsstö- } \\
\text { rung - Ergüsse durch Diure- } \\
\text { tika nicht mobilisierbar), } \\
\text { Nageldystrophie, Onycholy- } \\
\text { se. }\end{array}$ & $\begin{array}{l}\text { Zentraler Me- } \\
\text { chanismus ist } \\
\text { MDR-1: Vinca- } \\
\text { Alkaloide: Mul- } \\
\text { tidrug re- } \\
\text { sistance (MDR- } \\
1 \text { P-170 GP): } \\
\text { hyperstabile } \\
\text { Tubuli, Tubu- } \\
\text { linmutation } \\
\text { (Bindungskapa- } \\
\text { zität } \downarrow) \text {; Taxane } \\
\text { Multidrug re- } \\
\text { sistance (MDR- } \\
1 \text { P-170 GP): } \\
\text { insuffiziente } \\
\text { Tubuli }\end{array}$ \\
\hline \multicolumn{4}{|c|}{$\begin{array}{l}\text { Beispiele: } \\
\text { Vinca-Alkaloide (Inhibition des Tubulusapparates): Vinblastin, Vincristin, Vindesin, } \\
\text { Vinflunin Vinorelbin, } \\
\text { Taxane (Hyperstabilisation des Tubulusapparates): Docetaxel, Cabazitaxel, Larotaxel, } \\
\text { Paclitaxel } \\
\text { Epothilone: Ixabepilon, Patupilon } \\
\text { Sonstige: Eribulin }\end{array}$} \\
\hline
\end{tabular}




\begin{tabular}{|c|c|c|c|}
\hline $\begin{array}{l}\text { Substanz- } \\
\text { gruppe }\end{array}$ & Wirkmechanismus & Toxizität & $\begin{array}{l}\text { Resistenz- } \\
\text { mechanismen }\end{array}$ \\
\hline $\begin{array}{l}\text { Topo- } \\
\text { isomera- } \\
\text { sehem- } \\
\text { mer: }\end{array}$ & $\begin{array}{l}\text { bewirken DNS- } \\
\text { Strangbrüche und } \\
\text { spontane Vernetzun- } \\
\text { gen } \\
\text { Topoisomerasen sind } \\
\text { nukleäre Enzyme zur } \\
\text { Erzeugung und Re- } \\
\text { paratur von Einzel- } \\
\text { strangbrüchen, Auf- } \\
\text { hebung und Einlei- } \\
\text { tung der Überspirali- } \\
\text { sierung (Supercoiling } \\
\text { der DNS), Vorberei- } \\
\text { tung von Translati- } \\
\text { on, Transkription } \\
\text { und Reparaturpro- } \\
\text { zessen. } \\
\text { • Topoisomerase I: } \\
\text { Induktion von } \\
\text { Strangbrüchen für } \\
\text { die Replikationsgabel } \\
\text { • Topoisomerase II: } \\
\text { Überspiralisierung / } \\
\text { Entwindung }\end{array}$ & $\begin{array}{l}\text { Neutropenie und Diarrhoe } \\
\text { sind dosislimitierend, Diar- } \\
\text { rhoe durch cholinerges Früh- } \\
\text { syndrom (Irinotecan); Atro- } \\
\text { pin s.c./i.v. oder Scopolamin, } \\
\text { die Spätdiarrhoe ähnelt kli- } \\
\text { nisch der Cholera - } \\
\text { Loperamid 2-4 mg alle } 2 \\
\text { Stunden, nach } 48 \text { Stunden: } \\
\text { Ciprofloxazin, nach } 72 \text { Stun- } \\
\text { den: Hospitalisation + i.v. } \\
\text { Hydratation (Reservemedi- } \\
\text { kamente: Octreotid / Bude- } \\
\text { sonid) Achtung Irinotecan } \\
\text { bei M. Meulengracht (Wir- } \\
\text { kungsverstärkung) }\end{array}$ & $\begin{array}{l}\text { Übliche Resis- } \\
\text { tenzmechanis- } \\
\text { men s. o. ; De- } \\
\text { toxifikation via } \\
\text { UDP- } \\
\text { Glucoronyl- } \\
\text { Transferase }\end{array}$ \\
\hline $\begin{array}{r}\text { Topoisom } \\
\text { Cam } \\
\text { Topoisom } \\
\text { Epip } \\
\text { Antitumor } \\
\text { Sonstige: } A\end{array}$ & $\begin{array}{l}\text { ote I } \\
\text { otecine: Irinotecan, ToI } \\
\text { ophe II } \\
\text { tibiotika: Anthrazykline } \\
\text { ssacrin }\end{array}$ & Anthracene, Actinomycin D & \\
\hline \multicolumn{4}{|l|}{ Varia: } \\
\hline $\begin{array}{l}\text { L- } \\
\text { Aspara- } \\
\text { ginase }\end{array}$ & $\begin{array}{l}\text { depletiert Asparagin } \\
\text { (manche Leukämie- } \\
\text { zellen können kein } \\
\text { Asparagin syntheti- } \\
\text { sieren) }\end{array}$ & $\begin{array}{l}\text { Myelotoxizität, allerg. Reakti- } \\
\text { onen, Abfall der Glucoseto- } \\
\text { leranz, Lethargie, Somnolenz }\end{array}$ & \\
\hline
\end{tabular}




\begin{tabular}{|l|l|l|l|}
\hline $\begin{array}{l}\text { Hydroxy- } \\
\text { carbamid } \\
\text { (Hydroxy- } \\
\text { urea) }\end{array}$ & $\begin{array}{l}\text { hemmt die Ribonu- } \\
\text { kleotid-Reduktase }\end{array}$ & $\begin{array}{l}\text { Myelotoxizität, Mucositis, } \\
\text { Neurotoxizität, Hauttoxizität } \\
\text { (Pigmentierung, Nagelatro- } \\
\text { phie) }\end{array}$ & (Übelkeit, Durchfall und \\
\hline Mitotan & $\begin{array}{l}\text { hemmt spezifisch } \\
\text { Nebennierenrinden- } \\
\text { tumore }\end{array}$ & $\begin{array}{l}\text { Schwindel bis hin zu Sprech- } \\
\text { störungen }\end{array}$ & \\
\hline $\begin{array}{l}\text { Trabec- } \\
\text { tedin }\end{array}$ & $\begin{array}{l}\text { hemmt durch Bin- } \\
\text { dung an DNA die } \\
\text { Transkription von } \\
\text { Genen }\end{array}$ & $\begin{array}{l}\text { Fatigue, Myelotoxizität, } \\
\text { Übelkeit, Erbrechen }\end{array}$ & \\
\hline
\end{tabular}

Zudem existieren primäre Resistenzen gegen Zytostatika, auch scheinen Tumorstammzellen grundsätzlich schlechter beeinflussbar zu sein. Sekundäre Resistenzen entstehen durch Selektion unter Behandlung. Die Mechanismen sind vielfältig: unzureichende Aufnahme der Zytostatika in die Zelle, vermehrte Ausschleusung (multi drug resistance-Mechanismus, MDR) oder rascher intrazellulärer Abbau. Vermutlich kann eine Zytostatikatherapie immer nur einen bestimmten Anteil an Tumorzellen erfassen (z. B. nach einem Zyklus $90 \%$ der Tumorzellen, nach dem zweiten Zyklus insgesamt $99 \%$, nach dem dritten Zyklus 99,9\%, usw.) (4). Durch schlechte Vaskularisierung und damit schlechte Nährstoffversorgung kann bei großen Tumoren das Wachstum behindert sein, sodass eine medikamentös induzierte Verkleinerung eines Tumors ein erneutes Wachstum begünstigen wird (5). Hinzu kommt eine ungünstige Pharmakokinetik bei schlecht perfundierten Tumoren. Die Aktivierung mehrerer Resistenzmechanismen wird durch eine höhere genetische Instabilität und höheren Selektionsdruck der Tumore gefördert. Mit zunehmender Größe des Tumors steigt somit die Wahrscheinlichkeit, daß bereits resistente Klone vorliegen (6).

Nebenwirkungen (NW) stellen fast ausnahmslos ein limitierendes Problem aller Therapiemodalitäten dar. Akute NW beruhen auf Schädigungen vieler schnell wachsender Gewebe wie Knochenmark, Schleimhäute, Haare und Gonaden. Hinzu kommen substanzabhängige organspezifische NW wie z. B. Neurotoxizität von Tubulingiften, Nephrotoxizität von Platinderivaten sowie Oto-, Neuro- und Kardiotoxizität von Anthrazyklinen. Wenn bei einer palliativen Chemotherapie die Lebensqualität oberstes Gebot ist, müssen sie durch geeignete Substanzauswahl, Einsatz von Mono- statt Kombinationstherapien oder Dosisanpassungen soweit möglich und sinnvoll minimiert werden. Langzeit-NW sind naturgemäß im Rahmen der Palliativmedizin irrelevant.

$\mathrm{Ob}$ ihrer hohen Relevanz für die Therapieentscheidung werden die Nebenwirkungen gesondert bei den entsprechenden Substanzgruppen in Tabelle 1 erwähnt. 


\subsection{Hormone bzw. Antihormone}

Manche Neoplasien (z. B. Mamma-Ca oder Prostata-Ca) unterliegen (zumindest anfänglich) noch einer gewissen hormonellen Kontrolle, die allerdings mit zunehmender Entdifferenzierung abnimmt. In der Phase der Hormonabhängigkeit können einige Substanzen hemmend in die Regelkreise eingreifen und das Wachstum bremsen (Tabelle 2).

Tabelle 2: Antihormonelle Substanzen im Einzelnen

\begin{tabular}{|l|l|}
\hline Antihormone: Blockade der Hormonrezeptoren auf der Tumorzelloberfläche \\
\hline Antiöstrogen (Mamma-Ca) & Tamoxifen, Fulvestrant \\
\hline Antiandrogen (Prostata-Ca) & Bicalutamid \\
\hline Hemmung der Hormonsynthese \\
\hline Aromatasehemmer (Mamma-Ca) & Anastrozol, Letrozol, Exemestan \\
\hline (Prostata-Ca) & Abirateron \\
\hline Kontrasexuelle Hormone \\
\hline \multicolumn{2}{|}{$\begin{array}{l}\text { Gabe männlicher Hormone beim Mamma-Ca bzw weibli- } \\
\text { cher Hormone beim Prostata-Ca }\end{array}$} \\
\hline Hormonentzug & $\begin{array}{l}\text { Operativ oder medikamentös mittels GnRH-Agonisten u. } \\
\text {-Antagonisten (Mamma-Ca oder Prostata-Ca) }\end{array}$ \\
\hline Kastration
\end{tabular}

\subsection{Antikörper, Signaltransduktionshemmer und andere molekulare Therapien}

Neue Substanzgruppen richten sich z. B. gegen extrazelluläre (membranständige) Bestandteile (Rezeptoren) oder sind in der Lage, die Signalkaskaden wichtiger Stoffwechselwege an einer oder mehreren Stellen intrazellulär zu unterbrechen. Man spricht daher von molekularen oder zielgerichteten („targeted“) Therapien (einige Beispiele in Tabelle 3). Das Ziel ist die selektive Blockade unkontrollierter Informationsweiterleitung in aberranten Zellen. Diese findet weit weniger in gesunden Zellen statt, welche durch diese Therapien weniger beeinträchtigt werden sollten. Teilweise sind diese Substanzen nur bei bestimmten Mutationen im Tumor wirksam, sodass die Tumorproben zunächst hierauf untersucht werden müssen (z. B. Cetuximab bei All-RAS-Mutationen oder Vemurafenib bei BRAFMutationen). 
Tabelle 3: Monoklonale Antikörper, deren Rezeptorstrukturen und klinischer Einsatz

\begin{tabular}{|c|c|c|}
\hline \multicolumn{3}{|c|}{ (Namensendung „-mab“) } \\
\hline Name & $\begin{array}{l}\text { Struktur, gegen die der } \\
\text { AK gerichtet ist }\end{array}$ & Indikation \\
\hline Alemtuzumab & CD52 & CLL, bestimmte NHL \\
\hline Bevacizumab & VEGF & Endothel versch. Tumoren \\
\hline Brentuximab vedotin & $\begin{array}{l}\text { CD30 (AK gekoppelt mit } \\
\text { dem Zytostatikum Mono- } \\
\text { methylauristatin E) }\end{array}$ & M. Hodgkin, NHL (sALCL) \\
\hline Catumaxomab & EpCam & maligner Aszites \\
\hline Cetuximab & EGFR & kolorektales Ka., HNO-Tumoren \\
\hline Denosumab & RANKL & Knochenmetastasen \\
\hline Eculizumab & C5 & PNH, HUS \\
\hline $\begin{array}{l}\text { Gemtuzumab- } \\
\text { Ozogamicin }\end{array}$ & CD33 & AML \\
\hline $\begin{array}{l}\text { Ibritumumab- } \\
\text { Tiuxetan }\end{array}$ & $\begin{array}{l}\text { CD20 (AK gekoppelt mit } \\
\text { 90Y) }\end{array}$ & follikuläres NHL \\
\hline Ipilimumab & CTLA4 & malignes Melanom \\
\hline $\begin{array}{l}\text { Obinutuzumab } \\
\text { (GA101) }\end{array}$ & CD20 & CLL, NHL \\
\hline Panitumumab & EGFR & kolorektales Ca. \\
\hline Pertuzumab & Her2/Neu & Mamma-Ca \\
\hline Rituximab & CD20 & $\begin{array}{l}\text { NHL, CLL, rheumatoide Arthri- } \\
\text { tis u.a. Autoimmunerkrankungen }\end{array}$ \\
\hline Trastuzumab & Her2/neu & Mamma-Ca., Magen-Ca. \\
\hline $\begin{array}{l}\text { Trastuzumab } \\
\text { Emtansin }\end{array}$ & $\begin{array}{l}\text { Her2/neu (AK gekoppelt } \\
\text { mit dem Zytostatikum } \\
\text { Mertansin) }\end{array}$ & Mamma-Ca. \\
\hline
\end{tabular}

Man unterscheidet murine Antikörper (Endung -omab), z. B. Catumaxomab (Removab®), chimäre Antikörper, d. h. nur der variable Teil des AK ist von der Maus (-ximab), z. B. Cetuximab, humanisierte Antikörper, d. h. nur noch die Antigenbindungsstelle ist von der Maus (-zumab), z. B. Pertuzumab und vollständig humanisierte Antikörper (-umab), z. B. Panitumumab. 
Eine wichtige Struktur bei den molekularen Therapien solider Tumoren stellt der „Epidermal growth factor receptor (EGFR)“ dar. Der Rezeptor besitzt eine extrazelluläre und eine intrazelluläre Domäne. Er dimerisiert (zwei Rezeptoren gehen zusammen) in seinem aktiven Zustand und eine Ligandenbindung führt zur Aktivierung des RAS-Onkogens mit seinen drei Isoformen (H-RAS, N-RAS, KRAS). Diese beeinflussen die Regulation diverser Signaltransduktionswege für Wachstum, Proliferation, Differenzierung, Überleben/Apoptose und Angiogenese (5). Der EGFR findet sich bei vielen Tumoren (Kopf/Hals-Tumore (SCC) in 90$100 \%$; Prostata und NSCLC in 40-80 \%; Mammakarzinom in 14-91 \%; Kolorektales Karzinom in bis zu $80 \%$, etc.). Therapeutisch nutzen z. B. Cetuximab und Panitumumab den extrazellulären Platz als Liganden. Monoklonale Antikörper dringen nicht in die Zellen ein (Tabelle 3).

Gefitinib, Erlotinib, und Afatinib sind Anti-EGF-R Tyrosinkinaseinhibitoren (TKI, Tabelle 4). Sie dringen in die Zellen ein und führen zu einem Zellzyklusarrest in der G1-Phase und somit zur konsekutiven Apoptose. Ein Synergismus mit Chemotherapie ist nur in präklinischen Modellen beschrieben. Objektive Remissionen werden nur in ca. $10 \%$ der Fälle erreicht, jedoch kommt es in 30-50 \% der Fälle zur Stabilisierung des Gesundheitszustandes. Die Substanzen sind relativ gut verträglich und gut kombinierbar mit anderen therapeutischen Prinzipien. Typische Nebenwirkungen sind Hautreaktionen mit periungualen Granulationen und Akne. Das Ansprechen korreliert mit dem Ausmaß dieser kutanen Effloreszenzen.

Tabelle 4: In der Hämato-Onkologie eingesetzte TKI

Kleine Moleküle (sog. „small molecules“: Namensendung „-nib“ oder „-mib“)

\begin{tabular}{|l|l|l|}
\hline Name & Gerichtet gegen & Indikation \\
\hline Afatinib & EGFR & NSCL \\
\hline Axitinib & VEGFR1-3,c-KIT, PDGFR $\beta$ & Nierenzell-Ca. \\
\hline Bosutinib & BCR/ABL, SRC & CML \\
\hline Crizotinib & EML4-ALK & NSCLC \\
\hline Dabrafenib & BRAF-V600F & malignes Melanom \\
\hline Dasatinib & BCR/ABL, SRC, c-KIT & CML, ALL \\
\hline Erlotinib & EGFR & NSCLC, Pankreas-Ca. \\
\hline Gefitinib & EGFR & NSCLC \\
\hline Ibrutinib & Bruton-Tyrosinkinase & CLL \\
& & \\
\hline
\end{tabular}




\begin{tabular}{|l|l|l|}
\hline Imatinib & BCR/ABL, PDGRF, c-KIT & $\begin{array}{l}\text { CML, GIST, bestimm- } \\
\text { te Formen des HES, } \\
\text { der Mastozytose, Der- } \\
\text { matofibrosarcoma } \\
\text { protuberans }\end{array}$ \\
\hline Lapatinib & HER2/Neu & Mamma-Ca. \\
\hline Nilotinib & BCR/ABL, c-KIT, PDGFR 3 & CML, ALL \\
\hline Pazopanib & VEGFR/PDGFR/c-KIT & Nierenzell-Ca. \\
\hline Ponatinib & BCR/ABL incl. T315I & CML \\
\hline Ruxolitinib & JAK1/2 & OMF \\
\hline Sorafenib & VEGFR/PDGFR/FLT3/RAF & $\begin{array}{l}\text { Nierenzell-Ca., Leber- } \\
\text { zell-Va. }\end{array}$ \\
\hline Sunitinib & VEGFR/PDGFR/c-Kit, FLT3 & $\begin{array}{l}\text { Nierenzell-Ca., GIST, } \\
\text { pankr. NET }\end{array}$ \\
\hline Vandetanib & RET/VEGFR/EGFR & $\begin{array}{l}\text { Medulläres Schilddrü- } \\
\text { sen-Ca. }\end{array}$ \\
\hline Vemurafenib & BRAF-V600F & malignes Melanom \\
\hline
\end{tabular}

GIST = gastrointestinaler Stromatumor; HES = hypereosinophiles Syndrom; NET $=$ neuroendokriner Tumor; $\mathrm{OMF}=$ Osteomyelofibrose, bzw. primäre Myelofibrose 
1971 publizierte J. Folkmann seine Hypothese zur Neo-Angiogenese, d. h. der Notwendigkeit der Entstehung von neuen Gefäßen zum Wachstum von Tumoren ab einer bestimmten Größe (8). 1989 wurde einer der entscheidenden Faktoren charakterisiert („vascular epithelial growth factor“ - VEGF, bzw. der Rezeptor VEGFR) und 1997 wurde in Deutschland die erste klinische Studie mit einem Angiogeneseinhibitor durchgeführt (9). 2004 erhielt „Bevacizumab“ als erste Substanz die Zulassung beim kolorektalen Karzinom. Seither wurden viele Substanzen mit diesem Wirkmechanismus in klinischen Studien getestet oder sind bereits zugelassen worden (Aflibercept, Regorafinib, etc.) (Abbildung 2). Erschwerend hat sich gezeigt, dass verschiedene Signalwege zur Angioneogenese beitragen und bei Blockade eines Weges die anderen Wege hochreguliert und somit wirksam werden.

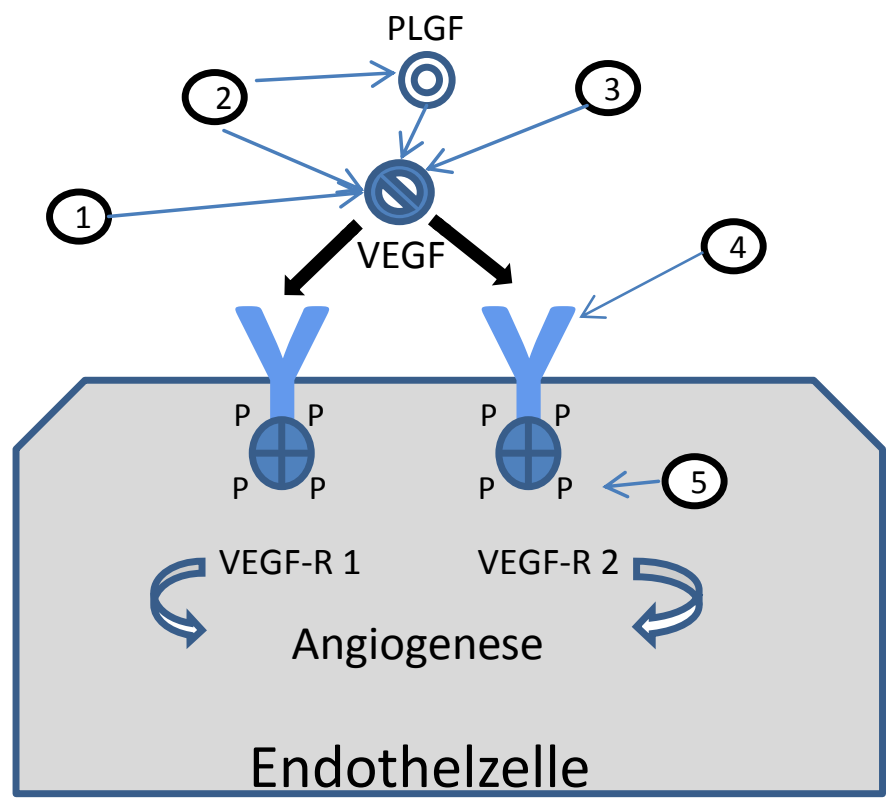

Abbildung 2: Wirkmechanismen von Anti-VEGF und Anti-VEGFR Therapien (8)

1. Anti-VEGF-Antikörper (z: B. Bevacizumab); 2. Lösliche VEGF-Rezeptoren (FEGF-Trap: ₹. B. Aflibercept); 3. Anti-VEGF-Aptamere (z. B. Pegaptanib); 4. Anti-VEGFR-Antikörper (z. B. Ramucirumab); 5. VGFR-TKI (₹. B. Regorafinib); PLGF: placenta growth factor. 
Die Hemmung des Histondeacetylase-Proteinkomplexes durch Histondeacetylase-Inhibitoren spielt bei der Transkription von Genen eine wichtige Rolle. Vorinostat und Romidepsin sind für die klinische Anwendung beim kutanen T-ZellLymphom in den USA zugelassen.

Proteasominhibitoren hemmen die proteolytische Aktivität des Proteasoms. Es kommt zur Akkumulation von ,alten“ Proteinen in der Zelle und dadurch zum Wachstumsstillstand (Bortezomib, Carfilzomib). Problematisch erweist sich für die Patienten eine kumulierende Neurotoxizität.

mTOR-Inhibitoren („Mammalian target of rapamycin“) gehören zu den intrazellulären Serin/Threonin-Proteinkinasen, die ebenfalls in das Zellwachstum eingreifen. Eine orale Form (Everolimus für fortgeschrittenes Nierenzell-Ca., Mamma-Ca. und pNET des Pankreas) und eine intravenöse Form (Temsirolimus für fortgeschrittenes Nierenzell-Ca. und rezidiviertes oder refraktäres MantelzellLymphom) sind zugelassen. Haut- und Schleimhautveränderungen sowie Lungenschäden (Pneumonitis) erweisen sich als dosislimitierend.

\subsection{Immuntherapie}

Immuntherapien beeinflussen das Immunsystem. Dazu zählen multiple Therapieverfahren, von denen die wenigsten wissenschaftlich belegt sind. Das Immunsystem als „Black Box“ bietet reichlich Raum für komplementärmedizinische oder „alternative“ Ansätze, die eine „natürliche Krebsabwehr“ versprechen und für viele Patienten naturgemäß attraktiv sind. Klar ist: Es gibt immuntherapeutische Ansätze, die vielversprechende Erfolge zeigen und mit denen große Hoffnungen verknüpft werden (s. PD1 und PDL1-Inhibitoren im Kapitel 14: Perspektiven in der Onkologie). Frei von Nebenwirkungen sind sie aber keineswegs: Das Spektrum reicht derzeit von Abgeschlagenheit bis hin zu lebensbedrohlichen Immunreaktionen.

Thalidomid, Lenalidomid und Pomalidomid gehören zur Gruppe der „,immunomodulatory drugs" (Immunmodulatoren - IMiDs). Der genaue Wirkmechanismus ist unbekannt, jedoch haben sie z. B. Einfluss auf Zytokine und TLymphozyten. Sie induzieren unter anderem eine Angiogenesehemmung und die Apoptose von Tumorzellen. Dosislimitierend ist dabei ihre Neuro- und Hämatotoxizität.

Bei Interferon u/o Interleukin-2 handelt es sich um körpereigene Zytokine (zelluläre Botenstoffe). Diese induzieren direkt oder indirekt durch die Freisetzung von Mediatoren (IL-6, etc.) Entzündungsreaktionen, die unspezifisch auch gegen Tumorzellen wirksam sein können (u. a. Nierenzell-Ca, Melanom, indolente Lymphome). Die notwendigen hohen (überphysiologischen) Dosen, die dafür benötigt werden, schränken aber ihren Einsatz ein, zumal ihre Nebenwirkungen (Akutphasereaktion mit Fieber, Schüttelfrost und grippalem Gefühl) die Lebensqualität deutlich beeinträchtigen können. 
Seit vielen Jahren werden Tumor-Impfungen versucht. Dazu werden autologe oder allogene Tumorzellen verwendet, die entsprechend attenuiert (verändert) werden, ebenso wie Oligopeptide von Tumoren. Diese werden zusammen mit antigenpräsentierenden Zellen (dendritischen Zellen) appliziert, woraus eine TZell-Antwort resultiert. Diese seriösen Ansätze sind bisher noch experimentell. Hieraus ergibt sich eine einfache Regel für Patienten: Seriöse Anbieter von Therapien verlangen beim aktuellen Stand des Wissens für die Therapie kein Geld!

Erstmalig ist beim Melanom mit dem Antikörper Ipilimumab die Aktivierung der körpereigenen Immunabwehr klinisch erfolgreich geglückt. Eine Expression von CTLA4 auf T-Helferlymphozyten bremst die körpereigene Immunreaktion gegen die Tumorzellen. Ipilimumab blockiert CTLA4, wodurch das Immunsystem wieder gegen den Tumor aktiv wird. Allerdings braucht das Immunsystem ausreichend Reaktionszeit und der Effekt ist bisher von begrenzter Dauer.

Antikörper gegen den Programmed-Death-1 (PD-1)-Rezeptor oder seinen Ligandnen (PDL-1) auf T-Lymphozyten (Nivolumab, Lambrolizumab, Pembrolizumab und Pidilizumab) haben eine ähnliche das Immunsystem aktivierende Wirkung (Einsatz bei Melanom, NSCLC, Nierenzell-Ca, u.v.m.). Die therapievermittelte entzündliche Infiltration der Tumoren kann vorübergehend eine Zunahme der Größe (und damit auch der Symptome) verursachen und eine Progression vortäuschen (Pseudoprogression). Gefürchtete, teils lebensbedrohliche Nebenwirkungen sind z. B. Hypophysitis oder Sarkoidose-ähnliche Krankheitsbilder. Diese Substanzgruppe zeigt aber derzeit die höchsten Ansprechraten und das bei diversen Tumorentitäten und zum Teil erheblich vorbehandelten Patienten. Zumeist sind die Nebenwirkungen dabei doch so akzeptabel, dass in Kürze mehrere Substanzen zugelassen werden dürften, die durchaus auch bei Palliativpatienten in Betracht zu ziehen sind.

Aktuell ist auch die Gabe von tumorzellzerstörenden Lymphozyten, die in vivo oder in vitro expandiert wurden. Dieser Ansatz wurde bisher bei einer therapierefraktären ALL mit genetisch veränderten T-Lymphozyten erfolgreich getestet und soll auch bei CLL wirksam sein (11).

\subsection{Gentherapie}

Auch in der onkologischen Gentherapie bestehen unterschiedliche Ansätze. Zur Steigerung der Immunantwort gegenüber Tumorzellen dient z. B. eine direkte Steigerung der Immunantwort (Aktivitätssteigerung tumorinfiltrierender Lymphozyten und ihrer Zytokinproduktion) oder die bessere Erkennbarkeit der Tumorzellen für das Immunsystem durch Gene für spezielle Oberflächenantigene, die dann spezifisch von den Tumorzellen exprimiert und vom Immunsystem erkannt werden können.

Es besteht die Möglichkeit der Einbringung von Tumorsuppressorgenen in die malignen Zellen als Gegenspieler von Onkogenen. Eine weitere Möglichkeit be- 
steht darin, Antikörper gegen die von den Onkogenen exprimierten Proteine oder Antisense-Oligonukleotide einzusetzen, die die mRNA der Onkogene inaktivieren und somit einer Expression entgegenwirken können.

Selbstmord-Gene können für Enzyme kodieren, die ungiftige Prodrugs in giftige Metabolite umwandeln (z. B. Thymidinkinase). Damit werden nur Zellen durch das Medikament geschädigt, die diese Enzyme exprimieren: vorzugsweise Tumorzellen.

So mächtig alle diese Ansätze sind, so schwierig sind sie. Die wichtigste Herausforderung liegt in der Selektivität: Wie trifft man mit eingebrachten Genen (aber auch mit Medikamenten oder Strahlen) vorzugsweise den Tumor und schont das normale Gewebe? Bis heute bietet die Gentherapie keinen klinisch relevanten Durchbruch - erst recht nicht für Patienten in der Palliativsituation.

\subsection{Stammzelltherapie}

Stammzelltherapien (SZT) (intravenöse Gabe von Stammzellen der Hämatopoese) spielen in palliativen Situationen eine untergeordnete Rolle. Dennoch können sie auch in nicht kurativer Intention langanhaltende Remissionen herbeiführen (z. B. Myelom) und manche Patienten in der Palliativsituation werden eine solche Behandlung zumindest in der Vergangenheit erhalten haben. Daher sollen auch die Grundlagen zu diesem Behandlungskonzept dargestellt werden.

Unter einer autologen Stammzelltherapie versteht man die Sammlung von Stammzellen eines Patienten nach einer mobilisierenden Chemotherapie. Diese werden kryokonserviert und nach einer Hochdosistherapie (HD) demselben Patienten wieder infundiert. Die „myeloablative HD“ dient der Eradikation (Vernichtung) aller vorhandenen hämatopoetischen Zellen. Die transfundierten Stammzellen besiedeln erneut das Knochenmark und bilden wieder Tochterzellen. Bei einer allogenen Stammzelltherapie stammen die Zellen von einem anderen Individuum, der sie als Spender zur Verfügung stellt.

\subsubsection{Autologe Stammzelltransplantation}

Da der Empfänger bei der autologen SZT gleich dem Spender ist (eigene Stammzellen), entsteht in der Regel kein Immunkonflikt. Allerdings besteht auch die Gefahr der Wiedergabe kranker Zellen. Eine „Reinigung“ von diesen Zellen ist bis heute noch umstritten und nicht gänzlich möglich. Die häufigsten Indikationen sind das multiple Myelom und Lymphome. Zweck der autologen Transplantation ist ausschließlich, eine Hochdosis-Chemotherapie zu ermöglichen, die sonst wegen ihrer Myelotoxizität nicht vertragen würde.

Typische NW der Hochdosischemotherapie sind Übelkeit, Erbrechen, Tachykardie und Hypotoniel. In der Phase der tiefen Leukozytopenie nach Restitution tritt eine Gefährdung durch Infekte ein. Die körpereigene Immunabwehr bricht 
zusammen und die Besiedelung durch körpereigene oder nosokomiale Erreger wird möglich (40-60\% febrile Neutropenien). Nur ein entsprechendes Management dieser Situation macht die Therapie überhaupt überlebbar. Nach Rekonstitution der Myelopoese kommt es zu einer mehrwöchigen lymphatischen Abwehrschwäche. Hier besteht die Gefahr der Reaktivierung von Viren, z. B. der Herpesgruppe (HSV, CMV), oder einer Pneumocystis jirovecii-Infektion. Auch heute noch liegt die transplantationsbezogene Mortalität (TRM) bei 2-5\%. Im Allgemeinen ist eine autologe SZT bis zum 65. -70. Lebensjahr möglich, allerdings abhängig vom klinischem Kontext und dem biologischen Alter der Patienten.

\subsubsection{Allogene Stammzelltransplantation}

Die Gabe nicht eigener Zellen hat zwei Folgen: Zum einen ermöglicht sie es dem Patienten, ein neues, gesundes KM aufzubauen, zum anderen setzen sich seine neuen Zellen mit den „Wirtszellen“ auseinander. Dies bedeutet einen immuntherapeutischen Effekt der Spenderzellen gegen die jeweilige hämatologische Neoplasie („Graft-versus-Leukämie“-, bzw. „Graft-versus-Lymphom“-Effekt) und ist erwünscht. Hierin liegt auch der grundlegende Unterschied zur autologen Transplantation. Allerdings kommt es je nach Stärke des Effektes zu einer ,graft versus host disease“ (GvHD, ,Spender-gegen-Wirt-Erkrankung"), die äußerst problematisch sein kann. Indikationen zur allogenen SZT sind akute Leukämien, myelodysplastische Syndrome, schwere aplastische Anämien und primäre/sekundäre Myelofibrosen.

Die transplantationsbezogene Mortalität ist abhängig von Grunderkrankung, Komorbidität, Alter der Patienten, Konditionierungsverfahren und HLAÜbereinstimmung zwischen Patient und Spender. Sie liegt immer noch zwischen 10 und $40 \%$. Die Nebenwirkungen ähneln denen der autologen SZT (beides Hochdosischemotherapien), können aber schwerwiegender verlaufen. Wegen Spätkomplikationen (Zweitneoplasien, Kataraktbildung, Lungenfibrosen) ist eine langfristige Nachsorge notwendig.

\subsection{Literatur}

(1) Preiss, Dornhoff, Schmieder, Honecker, Claßen (Hsgb): Taschenbuch Onkologie 2014/15. Zuckschwendverlag München; 2014

(2) Northfelt et al., ASCO 1994; O`Brien, Ann Oncol 2004

(3) Engels et al., Br J Cancer 2005; Brooks et al., Mol Cancer Ther 2003; Sessa et al., Ann Oncol 2002; Gelmon et al., J Clin Oncol 2000; Sartor et al., ASCO 2010, Abs \#9 
(4) Skipper HE: Perspectives in Cancer Chemotherapy: Therapeutic Design. Cancer Res 1964; 24:1295-1302

(5) Norton L, Simon R. The Norton-Simon hypothesis revisited. Cancer Treat Rep 1986; 70:163-169

(6) Goldie, JH and Coldman, AJ. A mathematical model for relating the drug sensitivity of tumors to their spontaneous mutation rate. Cancer Treatment Reports 1979; 63:1727-1733.

(7) Downward J. Targeting RAS signalling pathways in cancer therapy. Nat Rev Cancer 2003;3:11-22.

(8) Folkmann,J. Angiogenesis: New concept for Therapy of solid Tumors. Ann Surg. 1972;175: 409-416.

(9) Drevs J, Mross K, Fuxius S, Muller M, Dugan M, Peng B, Chong J, Henry A, Laurent D, Putz B, Marme D, Unger C. A Phase-1 dose escalating and pharmacokinetic (PK) study of the VEGF-receptor-inhibitor PTK787/ZK222584 $(\mathrm{PTK} / \mathrm{ZK})$ in patients with liver metastasis of advanced cancer. Proc. Am. Soc. Clin. Oncol. 2001;20:100.

(10) Schematisiert nach: Podar \& Anderson, Blood 2005;105:1383-1395.

(11) Porter DL, NEJM 2011, Porter D L et al, ASH 2012, Abstr. \#717. 


\section{Lebensqualität unter (und durch) Tumortherapie}

PD Dr. med. Bernd Alt-Epping

Universitätsmedizin Göttingen, 37075 Göttingen

\subsection{Einleitung}

Für an Krebs Erkrankte stellt es wesentliche Behandlungsziele dar, durch die Tumortherapie länger und/oder besser leben zu können. Oft ist eine Heilung und damit eine weitgehend normale Lebenserwartung ein realistisches Behandlungsziel, aber auch dann, wenn eine Heilung nicht zu erwarten ist, können durch die Tumortherapie häufig sowohl die Lebenslänge als auch möglicherweise die Lebensqualität verbessert werden. Tabelle 1 stellt den Zusammenhang zwischen Lebenslänge und Lebensqualität im Kontext der medizinischen Indikationsstellung zur Tumortherapie schematisch dar. Sehr vereinfacht dargestellt, treten vor allem dann weitere individuelle Aspekte der Entscheidungsfindung hinzu, wenn die Einleitung einer Tumortherapie bei einem der beiden vorrangigen Therapieziele, Lebenszeit bzw. Lebensqualität, zu negativen Auswirkungen führen würde. Rechtfertigt z. B. eine mit hoher Wahrscheinlichkeit anzunehmende vorübergehende Einschränkung der Lebensqualität durch die Tumortherapie einen (mit nicht so hoher Wahrscheinlichkeit erhofften) Lebenszeitgewinn? Entscheidungen für oder gegen eine Tumortherapie sind immer in die Zukunft gerichtet und implizieren die Abwägung von Wahrscheinlichkeiten. Diese Wahrscheinlichkeiten werden unter anderem beeinflusst durch die Charakteristika der Tumorerkrankung (z. B. tumorbiologische Eigenschaften) sowie die klinische Situation der Patienten selbst (z. B. ein prätherapeutisch guter oder kompromittierter Allgemeinzustand). Für die Betroffenen selbst stellt die Zustimmung zur Tumortherapie jedoch immer eine ein- 
malige Situation dar, in der eine Vielzahl subjektiver Bewertungsmomente und individueller Erfahrungen zur Geltung kommen (1).

Tabelle 1: Medizinische Entscheidung für oder gegen eine Tumortherapie in einer nicht heilbaren Behandlungssituation mit Blick auf zwei vorrangig empfundene Therapieziele (Lebenszeitgewinn bzw. Lebensqualitätsverbesserung)

\begin{tabular}{|l|l|c|c|c|}
\hline \multicolumn{2}{|l|}{ Therapieentscheidung } & \multicolumn{2}{|l|}{ Lebenszeit } \\
\cline { 2 - 5 } \multicolumn{2}{l|}{} & länger & gleich & kürzer \\
\hline \multirow{3}{*}{ Lebensqualität } & besser & + & + & $?$ \\
\cline { 2 - 5 } & gleich & + & - & - \\
\cline { 2 - 5 } & schlechter & $?$ & - & - \\
\hline
\end{tabular}

+ Tumortherapie indiziert

- keine Indikation zur Tumortherapie

? individuelle Abwägung, auch unter Einbezug der Präferenzen des Patienten

Die Konzeption von „Lebensqualität“ ist daher bei der Behandlung von Patienten mit Krebserkrankungen von zentraler Bedeutung. Nachfolgend soll daher eine Definition von Lebensqualität gegeben werden sowie Methoden der Erfassung und ein Verständnis von Lebensqualität als Ziel onkologischer Behandlungen innerund außerhalb von Studien dargestellt werden.

\subsection{Erfassung von „Lebensqualität“}

Der Begriff „Lebensqualität“ (quality of life, QoL) beschreibt Aspekte des Befindens und der Eigenwahrnehmung und spielt insbesondere in der umfassenden Behandlung und Versorgung von Patienten mit Krebserkrankungen eine herausragende Rolle.

Die subjektive Wahrnehmung der Lebensqualität durch Patienten mit Krebserkrankungen wird geprägt von Symptomen und Belastungen (tumorbedingt oder tumortherapiebedingt), aber auch von psychischen, sozialen und existenziellen/spirituellen Dimensionen. Daher haben weitere Begriffe wie „Leid“ (engl.: suffering), „Patientenbelastung“ (engl.: distress) (2), „Patientenautonomie“ (engl.: autonomy) (3) und „Würde“ (engl.: dignity) neben der Lebensqualität einen wichtigen Stellenwert, überlappen sich aber auch und lassen sich nicht immer klar voneinander trennen.

In randomisierten klinischen Studien zeigte sich, dass eine frühzeitige, strukturierte Erfassung und Berücksichtigung von Lebensqualitätsaspekten nicht nur mit 
einer Verbesserung der erfassten Lebensqualitätsparameter selbst, sondern mit einer Besserung weiterer klinischer Outcome-Parameter einhergeht (4).

Für die Erfassung einzelner Lebensqualitätsparameter, wie der gesundheitsbezogenen Lebensqualität (health related quality of life, HR QoL), aber auch globalerer QoL-Parameter steht eine Vielzahl von Instrumenten zur Verfügung, die derzeit vor allem im Studienkontext genutzt werden und auch spezifische tumortherapiebedingte Belastungen mit erfassen. Der in Europa am häufigsten genutzte Fragebogen zur strukturierten Erfassung der Lebensqualität von Patienten mit Krebserkrankungen ist der EORTC-QLQ-C30-Fragebogen ${ }^{1}$. Dieser Fragebogen kann durch Module für spezifische Krebserkrankungen (z. B. Brustkrebs/EORTCQLQ-BR23), für spezielle Behandlungssituationen (z. B. palliative Betreuung/EORTC-QLQ-P15) oder für Patientengruppen (z. B. alte Patienten/EORTCQLQ-ELD14) ergänzt werden.

Ein strukturiertes Basis-Screening von Symptomen und Belastungen, wie es in der Palliativmedizin gebräuchlich ist, wird jedoch nicht nur im Rahmen von Studien, sondern auch für den klinischen Alltag in der Onkologie empfohlen. Dies kann und darf jedoch das eingehende Gespräch mit dem Patienten nicht ersetzen.

Krankheitsassoziierte Belastungen und die damit verbundenen Beeinträchtigungen verschiedener Lebensqualitätsdimensionen schlagen sich auch in einer reduzierten verbleibenden Lebenszeit nieder; insofern ist die selbsteingeschätzte Lebensqualität des Patienten mit Krebserkrankung auch prognostisch relevant (5).

\subsection{Studienendpunkte in der Onkologie}

In den letzten Jahrzehnten hat sich das wissenschaftliche, klinische und auch das öffentliche Interesse (u. a. von Zulassungsbehörden) $(6,7)$ bei der Behandlung von inkurabel erkrankten Krebspatienten sehr auf die Verbesserung der verbleibenden Lebenszeit der Patienten fokussiert (8). Bei einer inkurablen Krebserkrankung werden in der Regel mehrere Substanzen sequentiell appliziert, weshalb der Einfluss einzelner Substanzen auf die Gesamtlebenszeit nur schwer erfassbar ist. In diesem Kontext werden häufig auch mittel- und kurzfristige Zielparameter, so genannte Surrogatparameter, wie das progressionsfreie Überleben (progression free survival, PFS) oder die Zeit bis zum erneuten Voranschreiten der Erkrankung (time to progression, TTP) als Studienzielparameter in den Vordergrund gestellt - auch wenn noch nicht endgültig geklärt ist, ob diese zeitbezogenen Parameter wirklich mit einer Verlängerung der verbleibenden Gesamtüberlebenszeit korrelieren.

Aus palliativmedizinischer Perspektive stellen PFS oder TTP insofern interessante Zielparameter onkologischer Studien dar, als dass es Hinweise gibt und dem Verständnis der Tumorbiologie entspricht, dass ein Aufhalten des Fortschreitens einer Tumorerkrankung mit einer Stabilisierung der Symptomlast und anderer

\footnotetext{
${ }^{1}$ EORTC $=$ European Organization for Research and Treatment of Cancer; QLQ $=$ Quality of life questionnaire; $\mathrm{C}=$ Cancer; $30=30$ Fragen
} 
Belastungen einhergeht, und umgekehrt ein Voranschreiten der Grunderkrankung mit einer Zunahme der palliativmedizinisch relevanten Symptome und Bedürfnisse einhergeht.

Zudem sollte berücksichtigt werden, dass die Verlängerung der Lebenszeit für viele Patienten ein wichtiges Behandlungsziel darstellt, auch im Kontext einer inkurablen („palliativen“) Erkrankungssituation: In einer Befragung von Chu (2009) äußerten sich $60 \%$ der Patienten mit nicht-kleinzelligem Bronchialkarzinom (NSCLC) im Stadium IV vor Einleitung ihrer Erstlinienchemotherapie (in palliativer Intention), dass ihre Hoffnung an die Chemotherapie sei, eine maximale Verlängerung ihres Überlebens unter Inkaufnahme hoher Toxizitäten zu erreichen. (Es gibt jedoch keine Folgebefragung derselben Patienten nach Applikation der cisplatinhaltigen Kombinationschemotherapie und dem tatsächlichen Erleben von tumortherapieassoziierter Toxizität.)

\subsection{Lebensqualität als klinische Outcome-Parameter in onkologischen Studien}

Andererseits steht jedoch außer Frage, dass auch der Erhalt oder die Wiederherstellung von Lebensqualität selbst weitere wichtige und relevante Ziele therapeutischer Interventionen in der Onkologie aus Sicht von Therapeuten und Patienten selbst sind (9). Gerade vor den palliativen Rahmenbedingungen einer inkurablen Grunderkrankung muss sich der Therapieerfolg tumorspezifischer Maßnahmen u. a. daran bemessen lassen, inwieweit therapieassoziierte Schäden und Belastungen für den Patienten vermieden werden, und ob durch die Tumortherapie nicht auch Symptome und Belastungen der Grunderkrankung selbst aufgehalten oder gar verringert werden können (siehe Tabelle 1).

Diese Erwartung spiegelt sich auch in Patientenbefragungen wieder, in denen deutlich wird, dass für Patienten neben dem Wert eines verlängerten Lebens (10) auch der Erhalt und die Wiederherstellung von Lebensqualität wichtige Ziele der Tumortherapie selbst darstellen (11, vgl. auch 9). Diese lebensqualitätsbezogenen Zielparameter sowie die Bedeutung der subjektiven Bewertung von Therapieerfolg an sich schlagen sich unter anderem nieder in der Begrifflichkeit der sog. ,patient reported outcomes".

Untersuchungen zur Wirkung von Tumortherapie auf Lebensqualitätsaspekte betrafen nicht nur den Einsatz zytotoxischer Chemotherapien, sondern auch von Tyrosinkinasehemmern (z. B. 12,13), Antikörpern (z. B. 14,15) oder antihormonellen Substanzen (z. B. 16).

Für viele interventionelle Maßnahmen im palliativen Kontext, insbesondere bei lokalen Medikamentenapplikationen (z. B. intrathekal bei Meningeosis carcinomatosa), bei strahlentherapeutischen oder nuklearmedizinischen Verfahren (z. B. bei ossären Metastasen) oder bei endoskopischen Prozeduren (z. B. Stenteinlagen bei Bronchusobstruktion), stehen diese Aspekte der Symptomkontrolle und Le- 
bensqualität mit einer größeren Selbstverständlichkeit noch mehr im Vordergrund als bei den systemischen (medikamentösen) Tumortherapien.

$\mathrm{Zu}$ den systemischen (medikamentösen) Tumortherapien finden sich nur sehr wenige Studien (Phase II/III oder Therapieoptimierungsstudien nach Zulassung), die das Kriterium der Lebensqualität(sverbesserung) oder der Symptomkontrolle als primären Studienendpunkt verfolgten $(17,18)$. Die meisten Lebensqualitätsdaten, die von Krebspatienten vor und unter einer Tumortherapie existieren, stellen studienbegleitende QoL-Erfassungen dar, die im Nebengang zu zeitbezogenen Studienendpunkten mit durchgeführt wurden. Leider erfolgen diese QoLMiterfassungen nicht bei allen onkologischen Studien und werden auch nicht routinemäßig explizit publiziert (19). Dies impliziert auch, dass über Patienten, die nicht im onkologischen Studienkontext behandelt wurden, noch weniger Daten zur Symptomlast und anderen Belastungen unter Tumortherapiebedingungen in inkurabler Situation existieren, obwohl davon auszugehen ist, dass deren Belastungen und Einschränkungen größer sind als diejenigen von (in der Regel „,fitten“) Studienpatienten.

Ein nicht unerheblicher Teil der im oben genannten systematischen Review gefundenen Studien mit Merkmalen der Symptomverbesserung als primäre Studienendpunkte bezieht sich auf ältere Studien zu Patienten mit Oberbauchtumoren wie Magen-, Gallengangs- und Pankreastumoren (20,21). Für die Chemotherapiewirkung auf Patienten mit Pankreaskarzinom wurde eigens ein Index (clinical benefit response) definiert, der sich aus Schmerzintensität, Karnofsky-Index und Körpergewicht zusammen setzt (22). Inwieweit dieser Index mit der subjektiv empfundenen Perzeption von Symptomen und Belastungen korreliert, ist weiterhin in der Diskussion (23), dennoch wurde der Index "clinical benefit response" auch noch später und bei anderen Tumorentitäten als Zielkriterium verwendet (z. B. 24). Aber auch aus jüngerer Zeit gibt es eine nicht unerhebliche Anzahl von Hinweisen, dass ein differenzierter Einsatz von Tumortherapeutika im Vergleich zu einem tumortherapiefreien Vorgehen nicht nur zu keiner relevanten Beeinträchtigung der Lebensqualität, sondern auch zu einer Verbesserung oder Stabilisierung von Lebensqualitäts- und Funktionsparametern führen kann (25). Ein positiver Effekt auf die Lebensqualität in der letzten Lebenswoche durch den Einsatz von Chemotherapie im Vorfeld wurde jedoch nicht nachgewiesen (26). Im Gegenteil existieren auch Daten, dass der (unreflektierte?) Einsatz von Chemotherapie im letzten Lebensmonat zu einer zunehmenden Häufigkeit von Reanimationshandlungen, mechanischer Beatmung und dem Versterben auf einer Intensivstation führt (27).

Die European Society of Clinical Oncology (ESMO) schlug kürzlich mit Hilfe eines Scoring-Systems eine Brücke zwischen lebenszeitbezogenen Effekten einerseits und Toxizität und Lebensqualität andererseits (28). 
In einem systematischen Review des Instituts für Qualität und Wirtschaftlichkeit im Gesundbeitswesen (IQWiG 2014) wurden in diesem Zusammenhang onkologische Therapiestudien zu aggressiven Tumorentitäten (Glioblastom inklusive anaplastisches Astrozytom, NSCLC Stadium $\geq I I I b$, Malignes Melanom Stadium IV, und Pankreaskarzinom) mit einer postulierten medianen Überlebenszeit von weniger als zwei Jabren mit Blick auf Studienendpunkte, Therapieziele und Terminologie untersucht. Von jeder Tumorentität wurden die aktuellsten $25 \mathrm{RCTs}$ bis zum Jahr 2012, d. h. insgesamt 100 Studien, untersucht. In 38 Studien wurden die Therapieqiele konkret benannt (davon $30 \times$ Lebenszeitverlängerung, $2 \times$ Symptomkontrolle, $6 \times$ beides). In nabezu allen Studien (98) wurde die Gesamtüberlebenszeit (OS) als Studienendpunkt benannt, in 45 Studien auch die progressionsfreie Überlebenszeit (PFS). Therapieziele und Studienendpunkte waren konsistent. Lebensqualitätsbezogene Ziele (patient reported outcomes, PROs) wurden in 36 Studien als sekundäre/tertiäre Studienendpunkte benannt; in 32 (84,2 $\%)$ dieser Studien wurden auch die verwendeten Lebensqualitätserfassungsinstrumente benannt. In 31 (86\%) der Studien wurden die entsprechenden Ergebnisse publiziert; in 21 (58\%) der Studien war die gesundheitsbezogene Lebensqualität (HR QoL) als Parameter benannt. Das Nutzen-/Schadensverhältnis wurde 88 Mal diskutiert; in 34 Studien wurde eine Überlegenheit, in 29 Studien eine Unterlegenheit der Intervention herausgelesen.

\subsection{Symptomlinderung - Toxizitätsvermeidung - Lebenszeit: Das Beispiel Q-Twist}

Den unmittelbaren Effekt von Tumortherapie auf die Symptomlast zu ermitteln setzt voraus, dass prätherapeutisch bereits erfassbare Symptome und Belastungen vorhanden sind, wie dies bei vielen Krebserkrankungen der Fall ist. Bei weniger aggressiven Verläufen ohne bereits vorhandene relevante Belastungen, insbesondere in der Erstlinien-Behandlungssituation, bedarf es anderer Modelle, um die in Frage kommende Tumortherapie unter Lebensqualitätsgesichtspunkten zu evaluieren.

Ein Modell, mit dem zwischen den Therapiezielen „Verbesserung der Lebensqualität“ und „Verlängerung der Lebenszeit“ abgewogen werden kann, stellt z. B. Q-TWIST dar (quality-adjusted time without symptoms or toxicity) (29, 30). Dieses Konzept bildet sowohl die Zeit bis zur neuerlichen Progression als auch die dafür in Kauf zu nehmende Toxizität ab, indem es z. B. die Dauer von unterschiedlichen Erkrankungsphasen aufsummiert, die geprägt sind von tumortherapiebedingter Toxizität, von Tumortherapie ohne Toxizität, von behandlungs- und symptomfreien Phasen und von einer Progression der Grunderkrankung (31). 


\subsection{Zusammenfassung und Ausblick}

Trotz der nur wenigen, primär auf Symptomkontrolle und Lebensqualitätsverbesserung ausgerichteten Tumortherapiestudien lassen sich eine Vielzahl von Hinweisen (z. B. aus Auswertungen sekundärer Studienendpunkte) dafür zusammentragen, dass sich eine behutsam und angemessen eingesetzte lokale, aber auch systemische Tumortherapie positiv auf das Befinden und die Belastungen von unheilbar erkrankten Krebspatienten auswirken kann. Für die palliativmedizinische Perspektive bedeutet dies, auch explizit onkologische Therapieoptionen in individueller und differenzierter Weise in das Behandlungskonzept einzubeziehen, so wie umgekehrt eine Vielzahl von Hinweisen existiert, (32,33,34,35) die die Sinnhaftigkeit und Notwendigkeit des frühzeitigen Einbezugs palliativmedizinischer Expertise in das onkologische Behandlungssetting belegt.

\subsection{Literatur}

(1) Wedding U, Vordermark D. Quality of life of elderly patients with cancerous diseases. Onkologe 21(6):514-517

(2) Waller A, Williams A, Groff S L, Bultz B D, Carlson L E. Screening for distress, the sixth vital sign: examining self-referral in people with cancer over a one-year period. Psychooncology 2013;22(2):388-395.

(3) Schachter M, Fins J J. Informed consent revisited: a doctrine in the service of cancer care. Oncologist 2008;13(10):1109-1113.

(4) Velikova G. Evaluating treatment strategies in chronic lymphocytic leukemia: use of quality-adjusted survival analysis. J Clin Epidemiol 2001;54(7):747754.

(5) Quinten C, Maringwa J, Gotay C C, Martinelli F, Coens C, Reeve B B, Flechtner H, Greimel E, King M, Osoba D, Cleeland C, Ringash J, SchmuckerVon Koch J, Taphoorn M J, Weis J, Bottomley A, Levy V, Porcher R. Patient selfreports of symptoms and clinician ratings as predictors of overall cancer survival. J Natl Cancer Inst 2011;03(24):1851-8.

(6) Fishman J, Ten Have T, Casarett D. Cancer and the media: how does the news report on treatment and outcomes? Arch Intern Med 2010;170(6):515-518.

(7) Vogelzang N J, Benowitz SI, Adams S, Aghajanian C, Chang S M, Dreyer Z E et al. Clinical cancer advances 2011: annual report on progress against can- 
cer from the American Society of Clinical Oncology. J Clin Oncol 2012;30(1):88109.

(8) Marshall E. Cancer research and the $\$ 90$ billion metaphor. Science 2011;331(6024):1540-1541.

(9) Winkler E, Reiter-Theil S, Lange-Rieß D, Schmahl-Menges N, Hiddemann W. Patient Involvement in Decisions to Limit Treatment: The Crucial Role of Agreement Between Physician and Patient. J Clin Oncol 2009;27:22252230 .

(10) Chu D, Kim S, et al. Patient attitudes towards chemotherapy and survival: a prospective observational study in advanced non-small cell lung cancer. Lung Cancer 2009;66:250-6.

(11) Dorman S, Hayes J. What do patients with brain metastases from nonsmall cell lung cancer want from their treatment? Palliative Medicine 2009;23:594600 .

(12) Bukowski R, Cella D, Gondek K, Escudier B; Sorafenib TARGETs Clinical Trial Group. Effects of sorafenib on symptoms and quality of life: results from a large randomized placebo-controlled study in renal cancer. Am J Clin On$\operatorname{col} 2007 ; 30(3): 220-7$.

(13) Cufer T, Vrdoljak E, Gaafar R, Erensoy I, Pemberton K; SIGN Study Group. Phase II, open-label, randomized study (SIGN) of single-agent gefitinib (IRESSA) or docetaxel as second-line therapy in patients with advanced (stage IIIb or IV) non-small-cell lung cancer. Anticancer Drugs 2006;17(4):401-9.

(14) Duvic M, Kuzel T M, Olsen E A, Martin A G, Foss F M, Kim Y H, Heald P W, Bacha P, Nichols J, Liepa A. Quality-of-life improvements in cutaneous T-cell lymphoma patients treated with denileukin diftitox (ONTAK). Clin Lymphoma. 2002 Mar;2(4):222-8.

(15) Osoba D, Slamon J, et al. Effects on quality of life of combined trastuzumab and chemotherapy in women with metastatic breast cancer. J Clin Oncol 2002;20(14):3106-3113.

(16) Loriot Y, Miller K, Sternberg C N, Fizazi K, De Bono JS, Chowdhury S, Higano C S, Noonberg S, Holmstrom S, Mansbach H, Perabo F G, Phung D, Ivanescu C, Skaltsa K, Beer T M, Tombal B. Effect of enzalutamide on healthrelated quality of life, pain, and skeletal-related events in asymptomatic and minimally symptomatic, chemotherapy-naive patients with metastatic castration- 
resistant prostate cancer (PREVAIL): results from a randomised, phase 3 trial. Lancet Oncol 2015;16(5):509-21.

(17) Haas A L, Nauck F, Alt-Epping B. Symptom control and quality of life as primary outcome parameters in clinical studies - a systematic review. Abstract, eingereicht Dt. Krebskongress 2016.

(18) IQWiG Institut für Qualität und Wirtschaftlichkeit im Gesundheitswesen Kuration vs. Palliation: Versuch einer Begriffsklärung. www.iqwig.de 155.04.2014.

(19) Schandelmaier S, Conen K, von Elm E, You J J, Blümle A, Tomonaga Y, Amstutz A, Briel M, Kasenda B; the DISCO study group. Planning and reporting of quality-of-life outcomes in cancer trials. Ann Oncol 2015;26(9):1966-1973.

(20) Glimelius B, Hoffman K, et al. Chemotherapy improves survival and quality of life in advanced pancreatic and biliary cancer. Ann Oncol 1996;7(6):593600.

(21) Glimelius B, Ekstrom K, et al. Randomized comparison between chemotherapy plus best supportive care in advanced gastric cancer. Ann Oncol 1995;8(2):163-8.

(22) Burris H, et al. Improvements in survival and clinical benefit with gemcitabine as first-line therapy for patients with advanced pancreas cancer: a randomized trial. J Clin Oncol 1997:15;2403-2413.

(23) Bernhard J, Dietrich D, Glimelius B, Bodokyd G, Scheithauer W, Herrmann R. Clinical Benefit Response in Pancreatic Cancer Trials Revisited. Oncol Res Treat 2014;37:42-48.

(24) Vansteenkiste J F, Vandenbroek J E, et al. Clinical benefit response in advanced non.small cell lung cancer: a multicenter prospective randomized phase III study in single agent gemcitabine versus cisplatin-videsine. Ann Oncol 2001;12(9):1221-1230.

(25) Alt-Epping B, Jung W, Nauck F. Symptomkontrollierende Effekte der Chemotherapie - Ergänzung palliativer Konzepte? Onkologe 2007;13:619-624.

(26) Prigerson H G, Bao Y, Shah M A, Paulk M E, LeBlanc T W, Schneider B J, Garrido M M, Reid M C, Berlin D A, Adelson K B, Neugut A I, Maciejewski P K. Chemotherapy Use, Performance Status, and Quality of Life at the End of 
Life. JAMA Oncol. doi:10.1001/jamaoncol.2015.2378. Published online July 23, 2015.

(27) Wright A A, Zhang B, Keating N L, Weeks J C, Prigerson H G. Associations between palliative chemotherapy and adult cancer patients' end of life care and place of death: prospective cohort study. BMJ 2014; 348: g1219 doi:

10.1136/bmj.g1219 (Published 4 March 2014).

(28) Cherny N, Sullivan R, Dafni U, Kerst JM, Sobrero A, Zielinski C, de Vries E G E, Piccart M J. A standardised, generic, validated approach to stratify the magnitude of clinical benefit that can be anticipated from anti-cancer therapies: the European Society for Medical Oncology Magnitude of Clinical Benefit Scale (ESMO-MCBS). Ann Oncol 2015;26:1547-1573.

(29) Gelber R D, Goldhirsch A. A new endpoint for the assessment of adjuvant therapy in postmenopausal women with operable breast cancer. J Clin Oncol 1986;4:1772-1779.

(30) Goldhirsch A, Gelber R D, Simes R J, Glasziou P, Coates A S. Costs and benefits of adjuvant therapy in breast cancer: a quality-adjusted survival analysis. J Clin Oncol 1989;7:36-44.

(31) Tate W R, Skrepnek G H. Quality-adjusted time without symptoms or toxicity (Q-TWiST): patient-reported outcome or mathematical model? A systematic review in cancer. Psychooncology 2015;24(3):253-61.

(32) Smith T J, Temin S, Alesi E R, Abernethy A P, Balboni T A, Basch E M et al. American Society of Clinical Oncology provisional clinical opinion: the integration of palliative care into standard oncology care. J Clin Oncol 2012;30(8):880 887.

(33) American Society of Clinical Oncology, European Society for Medical Oncology. ASCO-ESMO consensus statement on quality cancer care. Ann Oncol 2006;17(7):1063-1064.

(34) Holland J C, Andersen B, Breitbart W S, Compas B, Dudley M M, Fleishman S et al. Distress management. J Natl Compr Canc Netw 2010;8(4):448485.

(35) Temel J S, Greer J A, Muzikansky A, Gallagher E R, Admane S, Jackson $\mathrm{V}$ A et al. Early palliative care for patients with metastatic non-small-cell lung cancer. N Engl J Med 2010;363(8):733-742. 


\section{Zuerst einmal nicht schaden, dann aber Fürsorge und Selbstbestimmung gewichten}

PD Dr. med. Dr. phil. Eva C. Winkler, Dr. med. Bernd Oliver Maier

Nationales Centrum für Tumorerkrankungen, 69120 Heidelberg

St. Josefs-Hospital Wiesbaden, 65189 Wiesbaden

\subsection{Abstract}

Die Positionierung für oder gegen die Empfehlung einer tumorspezifischen Therapie bei Patienten mit fortgeschrittener Erkrankung wird im klinischen Alltag oft als herausfordernd empfunden und ist häufig Anlass für Meinungsverschiedenheiten und Spannungen in den Behandlungsteams. Eine angemessene Entscheidungsfindung sollte sich dabei an den medizinethischen Grundprinzipien orientieren, deren reflektierte Anwendung auch dazu beitragen kann, „sprachfähig“ zu werden bezüglich der Art und Weise, wie Therapieempfehlungen zustande kommen. In diesem Kapitel werden typische Szenarien diskutiert, die auf einen Bewertungskonflikt zwischen Fürsorgeüberlegungen und Selbstbestimmung des Patienten oder Unsicherheiten in der Interpretation von Nutzen und Schaden für den Patienten zurückzuführen sind.

\section{$9.2 \quad$ Einleitung}

Eines der ältesten handlungsleitenden medizinethischen Prinzipien ist die Schadensverhütungsregel „Primum nil nocere - zuerst einmal nicht schaden“. Diesen 
Rat soll der Hofarzt Scribonius Largus (50 n. Chr.) des Kaisers Tiberius Claudius Nero Drusus seinen ärztlichen Kollegen gegeben haben. Dieses Prinzip war auch als vertrauensbildende Maßnahme für den Ruf der Ärzte bei Hof gedacht, die bei prominenten Todesfällen schnell unter Verdacht der Giftmischerei gerieten. Aber schon in der Schriftensammlung des Corpus Hippocraticum im 5. Jahrhundert vor Christus hieß es: „Die Regeln zur Lebensweise werde ich zum Nutzen der Kranken einsetzen, nach Kräften und gemäß meinem Urteilsvermögen; vor Schaden und Unrecht werde ich sie bewahren“ (1). Bereits in dieser Ausführung wird deutlich, dass letztlich das Nichtschadensprinzip um das Fürsorgeprinzip ergänzungsbedürftig ist, da es in der Betreuung Kranker nicht primär um das Nichts-Tun, sondern um die Rechtfertigung des richtigen Verhältnisses von möglichem Nutzen und Schaden geht.

Ein Kernanliegen der Palliativmedizin ist gerade diese sorgfältige Abwägung von Nutzen und Schaden der Maßnahmen, die Patienten in der letzten Lebensphase zukommt. Eine solche Abwägung kann aber immer nur im Hinblick auf ein bestimmtes Therapieziel erfolgen und gerade dieses Ziel ändert sich zum Lebensende hin: von einer Behandlung, die primär auf den Gewinn an Lebenszeit durch tumorspezifische Therapie ausgerichtet war, hin zu einer Behandlung, die die Symptomkontrolle und bestmögliche psychosoziale Begleitung von Patient und Angehörigen in den Mittelpunkt stellt. Diese Änderung des Therapieziels verlangt vom Patienten ein hohes Maß an Krankheitseinsicht und realistischer Einschätzung seiner Situation und vom Onkologen eine Kommunikation über den gesamten Krankheitsverlauf, die dem Patienten realistische Erwartungen vermittelt, damit eine Entscheidung zur palliativen Zielsetzung gemeinsam mit dem Patienten getroffen werden kann (2). Nach einer Umfrage unter Onkologen werden gerade diese Gespräche zur Therapiezieländerung als die größte kommunikative Herausforderung empfunden - noch vor der Mitteilung einer unheilbaren Diagnose oder dem Progress der Erkrankung (3).

Die Situationen, in denen diese gemeinsame Entscheidungsfindung gerade nicht gelingt, es also zu Meinungsverschiedenheiten zwischen Behandlungsteam, dem Patienten und/oder den Angehörigen kommt, sind einer der häufigsten Anlässe für eine klinische Ethikberatung oder eine ethische Falldiskussion. Nach einer immer noch aktuellen Umfrage unter Ärztlichen Direktoren und Pflegedirektoren deutscher Universitätskliniken stellen Therapiebegrenzung und -abbruch, Aufklärung und Einwilligung sowie insbesondere Konflikte zwischen Fürsorgepflicht und Patientenselbstbestimmung die wichtigsten ethischen Herausforderungen im klinischen Alltag dar (4).

Die häufigsten ethischen Herausforderungen im klinischen Alltag:

- $\quad$ Entscheidung zum Abbruch oder Begrenzung einer Therapie

- $\quad$ Aufklärung und Einwilligung

- Konflikt zwischen Fürsorgepflicht und Patientenselbstbestimmung 
In Konflikt kommen die beiden Prinzipien Fürsorge und Selbstbestimmung, wenn ihre Befolgung unterschiedliche Handlungsweisen nahelegen. Hier sind im Wesentlichen zwei unterschiedliche Konstellationen denkbar: Der Patient lehnt eine nützliche Therapie ab, die ihm der Arzt nahelegt, oder der Patient wünscht eine Therapie, von der sich der behandelnde Arzt keinen Nutzen verspricht oder von der er sogar befürchtet, dass sie schaden könnte.

Eine Differenz auf der Bewertungsebene bedeutet, dass Ärzte und Patienten die medizinischen Informationen z. B. bezüglich des Nutzens oder der Belastung einer Behandlung oder der Bedeutung eines zu erreichenden Therapieziels unterschiedlich gewichten. Es ist wichtig, solche Bewertungsdifferenzen von Meinungsverschiedenheiten abzugrenzen, die nicht auf einer unterschiedlichen Bewertung bei gleicher Informationslage beruhen, sondern darauf zurückzuführen sind, dass der Patient von einer anderen Situation ausgeht, weil er wichtige Informationen noch nicht bekommen hat, er sie nicht verstanden hat oder zum Zeitpunkt der Beratung nicht wahrhaben möchte. Bei den Beispielen wird daher Wert gelegt auf die „Ursachenforschung“ für die unterschiedlichen Bewertungen.

\subsection{Der „starke Therapiewunsch“}

Fall 1: 67-jähriger Patient mit Bauchspeicheldrüsenkrebs in fortgeschrittenem Stadium mit Lebermetastasen in beiden Leberlappen (diffus hepatisch metastasiertes Pankreaskarzinom Stadium IV): Aktuell besteht der Nachweis der Größenzunahme der Tumorabsiedlungen in der Bildgebung und ein aussagekräftiger Anstieg des Tumormarkers CA 19-9, also ein eindeutiger Progress der Erkrankung. Der Patient hatte als tumorspezifische Therapie primär eine Kombinationschemotherapie mit FOLFIRINOX (5-FU, Oxaliplatin, Irinotecan) über drei Monate erhalten. Darunter kam es zu erheblichen Nebenwirkungen (Schweregrad 4 nach CTC (Common Toxicity Criteria nach NCI (National Cancer Institute)) $)^{5}$ mit einer lebensbedrohlichen Infektion wegen therapiebedingt geschwächtem Immunsystem (Sepsis in Neutropenie). Deshalb erfolgte zuletzt der Wechsel der tumorspezifischen Therapie auf die Kombinationschemotherapie Gemcitabine und nab-Paclitaxel bis zur jetzigen Kontrolle. Der Patient wird beschrieben als „sehr motiviert, mit ausgeprägtem Therapiewunsch“.

In dieser Situation stellt sich die Frage, was man dem Patienten „,mit ausgeprägtem Therapiewunsch" noch anbieten kann und darf, ohne ihm zu schaden. Vor allem aber gilt es herauszufinden, welche Gründe und Vorstellungen hinter dem Therapiewunsch stehen. Wie sieht der Patient seine Erkrankungssituation? Weiß er um seine Prognose und hat er verstanden, dass er bereits alle wirksamen Substanzen erhalten hat? Warum hat er einen ausgeprägten Therapiewunsch?

Zwei Drittel der Patienten mit infauster Prognose wünschen in der letzten Lebensphase eine palliative Behandlung, die auf Symptomkontrolle ausgerichtet ist. Ein Drittel wünscht jedoch, wie der Patient hier, mittels Maximaltherapie Lebens- 
zeit zu gewinnen (6). Die erste Frage, die geklärt werden muss, geht an den Arzt: Falls es der gut informierte Wunsch des Patienten ist, primär Lebenszeit zu gewinnen, ist das ein erreichbares Therapieziel? Der Arzt geht davon aus, dass es sehr unwahrscheinlich, aber nicht ausgeschlossen ist, dass der Patient durch die Umstellung auf eine Therapie mit Gemcitabine/Erlotinib - einer Chemotherapie mit einer neuen Substanz und einer, die der Patient bereits erhalten hat - etwas länger lebt, als wenn er eine rein symptomatische Therapie erhält. Der Patient war primär progredient auf das nebenwirkungsreiche Folfirinox-Protokoll und die besser verträgliche Therapie mit Gemcitabine/nab-Paclitaxel, sodass nicht zu erwarten ist, dass die Tumorerkrankung chemotherapiesensibel ist und durch den Einsatz einer weiteren Substanz wesentlich am Fortschreiten gehindert wird. Der Arzt argumentiert zudem, dass die Nebenwirkungen der nochmalig umgestellten Therapie mit Gemcitabine/Erlotinib gegenüber dem wahrscheinlich marginalen Nutzen beträchtlich sein können, da der Patient bei mangelnder Knochenmarkreserve auf die initiale Kombinationstherapie mit einem deutlichen Leukozytenabfall reagiert hat. Das birgt die Gefahr, dass die gewonnene Zeit mit der Behandlung von Therapienebenwirkungen, wie z. B. einer erneuten Infektion, vertan wird. Das Therapieziel ist also fraglich erreichbar und wahrscheinlich unter einem ungünstigen Nutzen/Belastungsverhältnis.

Hier stehen daher die Verpflichtungen des Arztes, seinen Patienten vor Schaden zu bewahren und seinen Willen zu achten, in Konflikt. In solchen Fällen ist es besonders wichtig, herauszufinden, worauf der Wunsch des Patienten nach einer Therapie mit ungünstigem Nutzen-Risiko-Verhältnis beruht. Hier sind im Wesentlichen zwei Konstellationen zu unterscheiden: Wünscht der Patient eine weitere Chemotherapie, weil er seine Situation nicht realistisch einschätzt oder hat er verstanden, dass es allenfalls um einen geringen Zeitgewinn mit möglicherweise erheblicher Belastung geht? Laut Studienlage weiß weniger als die Hälfte der Patienten im fortgeschrittenen Tumorstadium, dass ihre Behandlung keine kurative Intention mehr hat (7). In einer Studie mit Patienten mit Lungenkarzinomen konnte gezeigt werden, dass eine unrealistische Erwartung an die Therapieeffekte mit einer aggressiveren Behandlung einhergeht und dass die intensiver behandelten Patienten nicht notwendig länger leben $(8,9)$. Gründe für die unrealistische Erwartung der Patienten sind die mangelnde prognostische Aufklärung von Ärzteseite, aber auch Verdrängungsmechanismen im Umgang mit der schweren Krankheit. Diese sind durchaus nachvollziehbar und sollen nicht eine Zwangsaufklärung des Patienten nahelegen. Jedoch bestehen für den Fall, dass ein Patient entgegen der ärztlichen Empfehlung eine Therapie mit ungünstigem Nutzen-Belastungsverhältnis einfordert, hohe Anforderungen für eine realistische Einschätzung der Situation, da hier das Prinzip des Respekts vor der autonomen Entscheidung des Patienten stark gemacht wird. Diese beinhaltet aber notwendigerweise eine informierte Entscheidung. Hingegen kann ein Patient, der qua Verdrängung von seinem Recht auf Nichtwissen Gebrauch macht, nicht in eine solche Therapieentscheidung einbezogen werden, weil diese notwendigerweise einen Wirklichkeitsbezug voraussetzt. 
Die Überlegung, ob eine geringe Chance auf einen Gewinn an Lebenszeit einen Therapieversuch mit der Chemotherapie rechtfertigt oder ob die dann gewonnene Lebenszeit durch eine nebenwirkungsbedingte Verschlechterung des Allgemeinbefindens als erstrebenswert angesehen wird, beinhaltet eine Wertentscheidung.

Die Studienlage zeigt, dass sich die Bewertung eines erträglichen NutzenBelastung-Verhältnisses im Krankheitsverlauf eines Menschen häufig ändert: Schwerkranke Patienten sind im Vergleich zu gesunden Menschen viel eher bereit, intensive Therapien auch mit geringer Aussicht auf einen Nutzen auf sich zu nehmen (10). Diese Perspektivenverschiebung zu berücksichtigen ist wichtig, wenn Ärzte sich in die Lage ihrer Patienten versetzen. Wenn der Patient seine Situation realistisch einschätzt, sollte der Arzt seine Bewertung von Nutzen und Belastung und die Konsequenzen der verschiedenen Optionen im besten wie im schlechtesten Verlaufsfall mit dem Patienten besprechen. Wenn dieser sich dann nach gemeinsamer Überlegung in Abwägung der Vor- und Nachteile für eine Chemotherapie entscheidet, hat der Arzt gute Gründe, diesem Wunsch zu entsprechen.

\subsection{Was heißt „Nihil nocere“?}

Fall 2: 86-jährige Patientin mit Erstdiagnose eines aggressiven Lymphoms (diffus großzelliges B-NHL Stadium IIIA): Klinisch auffällig geworden waren tastbare Lymphknotenvergrößerungen am Hals, die zur stationären Einweisung mit der Bitte um Abklärung führten. Die Patientin wird aufgrund einer seit ca. sechs Jahren zu beobachtenden dementiellen Entwicklung durch ihren Sohn betreut. Spezifische Aussagen bzgl. ihrer Erwartungen an Therapie oder Therapiebegrenzung lassen sich nicht erheben. Sie lebt in einem Pflegeheim. Relevante Komorbidität besteht in Form einer substituierten Hypothyreose, einer medikamentös behandelten und darunter kompensierten Herzinsuffizienz und einer seit langem bekannten depressiven Stimmungslage.

Bei dieser Patientin besteht rein mit Blick auf die gerade diagnostizierte Lymphomerkrankung kein Zweifel bezüglich des Nutzens einer tumorspezifischen Therapie. Mit sechs bis acht Zyklen einer Kombinationschemotherapie (CHOP14 und Rituximab) leben nach zwei Jahren im Durchschnitt $80 \%$ der Patienten geheilt (11). Allerdings ist die Belastung durch die Therapie schon bei jüngeren Patienten nicht unerheblich, da Phasen der geschwächten Immunabwehr und eine damit verbundene Gefahr für schwere Infektionen zu erwarten sind. Bei älteren Patienten ist dieses Risiko aufgrund der bestehenden Komorbiditäten und altersphysiologischen Veränderungen zusätzlich gesteigert $(12,13)$. Soll der Arzt die Patientin in kurativer Intention behandeln? Ist das in ihrem Sinne? Wie würde sie die Belastungen der Therapie empfinden und bei eingeschränkter kognitiver Funktion verarbeiten?

Hier steht mit Blick auf die Belastung durch die Therapie die Klärung des Patientenwunschs tatsächlich vor den Fürsorgeüberlegungen an erster Stelle. Da die 
Patientin aufgrund ihrer Demenz und zusätzlich schweren Depression selbst nicht mehr entscheidungsfähig ist, muss der Arzt zunächst mit dem betreuenden Sohn besprechen, ob die Mutter sich dazu geäußert hat, ob sie in einer Situation, wie der, in der sie sich jetzt befindet, eine Behandlung mit dem Ziel der Heilung oder Lebensverlängerung gewollt hätte. Wenn sie das nicht schriftlich, z. B. in einer Patientenverfügung, festgehalten hat, muss der mutmaßliche Wille aus Äußerungen hierzu eruiert werden. Sollte auch ein mutmaßlicher Wille nicht rekonstruierbar sein, dann gilt es, danach zu entscheiden, was allgemein als eine vernünftige Abwägung von wertvollen Zielen, Nutzen und Schaden gelten könnte.

In diese Abwägung sollte eingehen, ob die derzeitige Lebenssituation der Patientin eine ist, die man durch eine medizinische Behandlung erhalten möchte. Wenn dies schon verneint wird, weil die Patientin unter ihrer dementiellen Erkrankung und Depression leidet, dann könnte man annehmen, dass sie einer Therapie nicht zustimmen würde. Wenn sie jedoch aktuell nicht leidet, dann wäre prinzipiell das Ziel gerechtfertigt, ihre sonst tödlich verlaufende Erkrankung zu behandeln. Es stellt sich dann jedoch die Frage, wie sie die Nebenwirkungen und Veränderungen erlebt, die die zweiwöchentliche Therapie mit sich bringt. Auch hier kann man gemeinsam mit dem Sohn zu dem Ergebnis kommen, dass die zu erwartende Verschlechterung ihres Allgemeinzustandes unter Therapie, die wiederholten Hospitalisierungen und der damit einhergehende Verlust ihres gewohnten Umfelds den Nutzen, den eine Lebensverlängerung bedeuten würde, aufwiegen. Hier wäre es also tatsächlich das Prinzip der Schadensvermeidung, welches eine Entscheidung gegen eine Therapie begründen würde.

\subsection{Kein palliativer „Fatalismus“}

Fall 3: 47-jähriger Patient mit kleinzelligem Lungenkarzinom rechts zentral im Stadium IV: Die Erstdiagnose wurde acht Monate vor der jetzigen Konsultation gestellt. Bekannt sind seit Diagnosestellung intrapulmonale Metastasen kontralateral, Lymphknotenfiliae mediastinal und eine hepatische Metastasierung. Daher wurde eine palliative systemische Chemotherapie empfohlen. Metabolisch auffällig war eine LDH $780 \mathrm{U} / \mathrm{ml}$. Die initiale systemische Therapie mit Carboplatin/Etoposid über sechs Zyklen brachte eine schnell rückläufige LDH und bildgebend objektivierbares Ansprechen im Sinne einer guten partiellen Remission nach RECIST. Daraufhin wurde eine prophylaktische Ganzhirnradiatio diskutiert, die ambulant eingeleitet wurde. Wegen zunehmender Wesensveränderung unter Radiatio wurde der Patient stationär aufgenommen. Dabei zeigte sich eine (korrigierte) Hyperkalzämie von $3.1 \mathrm{mmol} / 1$. Im Ultraschall des Abdomen sah man einen neuerlichen Progress der Lebermetastasen. Der Patient ist Architekt, vor der Erkrankung selbständig berufstätig, verheiratet und hat zwei Kinder, die 15 und 17 Jahre alt sind. Er lebt in einem eigenen Haus mit seiner Familie. 
In Anbetracht des massiven Tumorprogresses und der zusätzlichen neuropsychologischen Verschlechterung unter Tumortherapie scheint es auch bei diesem Patienten naheliegend, gleich in die Diskussion einzusteigen, wie intensiv weiter Diagnostik betrieben werden soll und ob man sich nicht besser auf ein palliatives Konzept mit einem Fokus auf die Symptomkontrolle umstellen sollte. So wichtig es ist, im Verlauf einer infausten Tumorerkrankung das Therapieziel (z. B. Lebenszeit versus Lebensqualität primär) und die Rechtfertigbarkeit belastender Therapien und Diagnostik zu überprüfen, so unverzichtbar ist es dennoch, differentialdiagnostisch mögliche andere Ursachen für die Verschlechterung des Allgemeinzustandes eines Patienten auszuschließen. Das bedeutet in diesem Fall, dass zunächst die Hyperkalzämie ausgeglichen werden sollte und eine ossäre Metastasierung als deren Ursache untersucht werden sollte. Die Wesensveränderung wäre dann reversibel. Anschließend ist die prognostisch ungünstige Situation mit dem dann neuropsychologisch wiederhergestellten Patienten zu erörtern. Dazu gehört tatsächlich die Frage nach dem Therapieziel und den Möglichkeiten, Lebenszeit bei vertretbarer Lebensqualität zu gewinnen.

\subsection{Das Spannungsfeld von Fürsorge und Selbstbestimmung des Patienten}

Fall 4: Eine 43-jährige Patientin mit aktuell ossär und hepatisch metastasiertem Mammakarzinom stellt sich mit progredienter Tumorerkrankung auf Veranlassung einer Freundin vor. Die Erstdiagnose war vor sechs Jahren. Die Patientin hat zwei kleine Kinder und ist alleinerziehend. Sie berichtet, dass sie nur „alternative“ Therapien in Anspruch nimmt. Bislang ist nur eine antihormonelle Therapie für die ersten zwei Jahre erfolgt, seitdem kam keine spezifische Tumortherapie zur Anwendung, obwohl anderslautende Empfehlungen an die Patientin herangetragen wurden.

Die chemotherapeutische Behandlung ist in einer viszeral-metastasierten Erkrankungssituation, bei der die Notwendigkeit einer raschen Remission besteht, eine von allen Fachgesellschaften empfohlener Therapiestandard, weil sie im Vergleich zur alleinigen Hormontherapie deutlich besser geeignet ist, das Gesamtüberleben zu verlängern. Wichtig ist es daher, in einem ersten Schritt herauszufinden, welche Gründe hinter der bisherigen Ablehnung der Chemotherapie stehen und ob die Patientin so aufgeklärt ist, dass sie die Vor- und Nachteile der beiden Möglichkeiten (Chemotherapie gegenüber Hormontherapie) und die Konsequenzen einschätzen kann. Nutzen und Risiken verständlich zu machen und so zu kommunizieren, dass sie für Patienten als Entscheidungsgrundlage dienen können, ist dabei keine triviale Aufgabe $(14,15)$. Es ist wichtig, die Befürchtungen und Erwartungen bezüglich der Chemotherapie zu erfragen. Häufig lassen sich so Ängste vor Nebenwirkungen nehmen oder ein Weg finden, damit umzugehen. 
Nachdem die Patientin informiert ist und nach eingehender Aufklärung für sich selbst entscheidet, dass sie die Nebenwirkungen der Chemotherapie schwerer gewichtet als den Gewinn an Lebenszeit, hätte der Arzt gute Gründe, dem Prinzip des Respekts vor der Autonomie der Patientin zu folgen und ihre selbstbestimmte Entscheidung zu respektieren. Denn das Therapieangebot, das aus seiner Sicht zum Wohlergehen der Patientin beiträgt, bedarf immer der Zustimmung des Patienten, damit es umgesetzt werden kann.

Der Respekt vor der informierten und selbstbestimmten Entscheidung fällt in unserem Beispiel auch deshalb schwer, weil die Patientin Verantwortung für zwei kleine Kinder hat und noch nicht klar ist, ob sich beide Seiten über die Informationsbasis verständigen können. Schwierig wird es, wenn die Vorstellungen von Krankheitsentstehung, daraus resultierenden Behandlungskonzepten oder wissensabsichernder Evidenz zwischen Patientin und Arzt weit auseinander liegen und Patienten beispielsweise Therapien mit erwiesenermaßen hoher Aussicht auf Heilung zugunsten von Ansätzen ohne nachgewiesenen Nutzen ablehnen. Aber auch hier greift das Prinzip der Selbstbestimmung. Der Patient kann auch Therapieangebote ablehnen, die ihm das Leben retten.

Gerade bei schweren oder chronischen Erkrankungen spielt die patienteneigene Erfahrung und Interpretation dessen, was ihm widerfährt, im Kontext seiner Biographie eine wichtige, teilweise stabilisierende, handlungsleitende und handlungsrechtfertigende Rolle. Arthur Kleinmann, Medizinanthropologe und -ethiker, hat zwischen „disease“ und ,illness" unterschieden, um die medizinische Krankheitstheorie von der subjektiven Erfahrung zu differenzieren und legt allen Klinikern Schlüsselfragen nahe, um nicht nur Heilung, sondern auch Fürsorge anzubieten (care as well as cure) (16).

Schlüsselfragen zur Anamnese der subjektiven Krankheitserklärung und -erfahrung:

„Was ist Ihr Problem?“

„Was denken Sie, ist die Ursache?“

„Welche Auswirkungen hat es auf Ihren Körper?“

„Was fürchten Sie am meisten daran und an der Behandlung?““

Das heißt, auch hier beginnt die gemeinsame Entscheidungsfindung auf der kommunikativen und informationellen Ebene. 


\subsection{Zusammenfassung}

Aus der Diskussion der verschiedenen Fälle lässt sich folgende erste Handreichung zum Umgang mit Fragen im Spannungsfeld zwischen dem Fürsorge- und Autonomieprinzip ableiten. Zunächst sollte geklärt werden, worin die Meinungsverschiedenheit begründet ist: Gibt es Unterschiede im Informationsstand und Verständnis oder tatsächlich in der Bewertung der Therapieoptionen oder der vertretbaren Ziele? Die Konstellationen unterscheiden sich, je nachdem, ob ärztlicherseits eine Therapie angeboten wird - hier spielt die Indikationsstellung eine wichtige Rolle. Indikationen lassen sich immer nur mit Blick auf ein gemeinsam definiertes Therapieziel (Kuration, Lebenszeitgewinn, Lebensqualitätsgewinn) stellen und dabei nach dem Härtegrad der Empfehlung abstufen. Dabei fußt die Empfehlungsstärke auf einer möglichst präzisen Einschätzung des Onkologen bezüglich der vorhersehbaren biologischen Dynamik der Krebserkrankung auf eine spezifische Therapieoption. Die Empfehlungsstärke kann dann entsprechend ausgeprägt sein von „dringend angeratener Therapie“ über „zu rechtfertigende Therapie“ bis hin zu „,kontraindizierter oder unzulässiger Therapie“. In den ersten beiden Fällen sollte der Arzt eine Therapie anbieten und gemeinsam mit dem Patienten entscheiden, ob die Risiken für diesen im Verhältnis zum Nutzen mit Blick auf das Therapieziel vertretbar erscheinen. Dabei hat der Patient natürlich das Recht, die Therapieangebote zu prüfen und selbstbestimmt zu entscheiden, ob er das Angebot annimmt. Eine mit Blick auf das Therapieziel kontraindizierte Behandlung darf der Arzt nicht anbieten. Hier ändert sich der Kommunikationsfokus: Es wird zur Aufgabe des Arztes, zu vermitteln, warum keine Therapie zum Einsatz kommen sollte.

\section{$9.8 \quad$ Literatur}

(1) Schubert C. Der hippokratische Eid: Medizin und Ethik von der Antike bis heute. Darmstadt: Wiss. Buchges.; 2005.

(2) Pfeil TA, Laryionava K, Reiter-Theil S, Hiddemann W, Winkler EC. What keeps oncologists from addressing palliative care early on with incurable cancer patients? An active stance seems key. Oncologist 2015;20(1):56-61.

(3) Baile WF, Buckman R, Lenzi R, Glober G, Beale EA, Kudelka AP. SPIKES-A six-step protocol for delivering bad news: application to the patient with cancer. Oncologist 2000;5(4):302-311.

(4) Vollmann J, Burchardi N, Weidtmann A. Klinische Ethikkomitees an deutschen Universitätskliniken. Eine Umfrage aller Ärztlichen Direktoren und Pflegedirektoren [Health care ethics committees in German university clinics. A survey of all medical directors and directors of nursing]. Deut Med Wochenschr 2004;129(22):1237-1242. 
(5) U.S. Department of Health and Human Services, National Institutes of Health, National Cancer Institute (Hg.). Common Terminology Criteria for Adverse Events (CTCAE). 2010;v4.03:1-194.

www.eortc.be/services/doc/ctc/CTCAE_4.03_2010-06-

14_QuickReference_5x7.pdf.

(6) Winkler EC, Reiter-Theil S, Lange-Riess D, Schmahl-Menges N, Hiddemann W. Patient involvement in decisions to limit treatment: the crucial role of agreement between physician and patient. J Clin Oncol 2009;27(13):2225-2230.

(7) Weeks JC, Catalano PJ, Cronin A, et al. Patients' expectations about effects of chemotherapy for advanced cancer. New Eng J Med 2012;367(17):16161625.

(8) Temel JS, Greer JA, Muzikansky A, et al. Early palliative care for patients with metastatic non-small-cell lung cancer. New Eng J Med 2010;363(8):733-742.

(9) Temel JS, Greer JA, Admane S, et al. Longitudinal perceptions of prognosis and goals of therapy in patients with metastatic non-small-cell lung cancer: results of a randomized study of early palliative care. J Clin Oncol 2011;29(17):2319-2326.

(10) Sahm S, Will R, Hommel G. What are cancer patients' preferences about treatment at the end of life, and who should start talking about it? A comparison with healthy people and medical staff. Support Care Cancer 2005;13(4):206-214.

(11) Cunningham D, Hawkes EA, Jack A, et al. Rituximab plus cyclophosphamide, doxorubicin, vincristine, and prednisolone in patients with newly diagnosed diffuse large B-cell non-Hodgkin lymphoma: a phase 3 comparison of dose intensification with 14-day versus 21-day cycles. Lancet. 2013;381(9880):18171826.

(12) Sokol KC, Knudsen JF, Li MM. Polypharmacy in older oncology patients and the need for an interdisciplinary approach to side-effect management. J Clin Pharm Ther 2007;32(2):169-175.

(13) Extermann M, Boler I, Reich RR, et al. Predicting the risk of chemotherapy toxicity in older patients: the Chemotherapy Risk Assessment Scale for HighAge Patients (CRASH) score. Cancer. 2012;118(13):3377-3386.

(14) Wegwarth O, Gigerenzer G. Nutzen und Risiken richtig verstehen. Dt Ärzteblatt 2011;108(11):A568-570. 
(15) Antes G, Gigerenzer G, eds. Bessere Ärzte, bessere Patienten, bessere Medizin: Aufbruch in ein transparentes Gesundheitswesen. Berlin: MedizinischWissenschaftl. Verl.-Ges.; 2013. Strüngmann Forum reports.

(16) Kleinman A. From Illness as Culture to Caregiving as Moral Experience. N Eng J Med 2013;368(15):1376-1377. 



\title{
10. Spezielle Supportivtherapie
}

\author{
Dr. med. Sabine Mousset, PD Dr. med. habil. Christoph Kabl
}

Agaplesion Markus Krankenhaus, 60431 Frankfurt am Main

Klinikum Magdeburg, 39130 Magdeburg

\section{$10.1 \quad$ Einleitung}

„Supportive Therapie umfasst alle unterstützenden Maßnahmen zur Vermeidung oder Behandlung von Nebenwirkungen der Tumorerkrankung oder -therapie. Diese können sich auf das Management von physischen, psychischen Symptomen oder auf Nebenwirkungen über den gesamten Behandlungsprozess und Krankheitsverlauf beziehen, beginnend von der Diagnose über die Tumortherapie bis hin zur Nachsorge.“ [www.s3supportiv.de]. Gerade im Kontext frühzeitiger palliativmedizinischer Mitbehandlung von Krebspatienten (d. h. auch unter onkologischen Tumortherapiebedingungen), besteht eine relevante inhaltliche und zeitliche Überschneidung palliativmedizinischer und supportivtherapeutischer Behandlungsansätze. Oftmals sind Hausärzte und Mitarbeitende in der spezialisierten Palliativversorgung diejenigen, die z. B. in der häuslichen Umgebung als erste wahrnehmen, dass sich bei einem Patienten unter Tumortherapie eine interventionsbedürftige tumortherapieassoziierte Nebenwirkung oder gar eine potentiell letale Komplikation abzeichnet. Daher sind Grundkenntnisse der Supportivtherapie und des onkologischen Komplikationsmanagements - neben einem raschen, akutmedizinischen Handeln und einer engstmöglichen Kommunikation mit dem behandelnden Onkologen - auch für die Palliativmedizin unabdinglich.

Im Folgenden wird eine Auswahl an Situationen, die vor allem aus der Perspektive einer aktuellen Tumortherapie besonders relevant sind, dargestellt. 


\subsection{Therapie von Infektionen}

Eine der schwerwiegenden Nebenwirkungen von Chemotherapie besteht in der Knochenmarktoxizität, welche eine Myelosuppression, d. h. einen Abfall aller drei Reihen der Blutbildung, bedingen kann. Durch den Abfall der weißen Blutkörperchen, insbesondere der neutrophilen Granulozyten, haben hämato-onkologische Patienten ein erhöhtes Risiko für Fieber, Infektionen, Sepsis und somit für eine tumortherapieassoziierte Sterblichkeit. Hierdurch ergeben sich einige Besonderheiten im Management von Infektionen, welche im Folgenden aufgeführt werden. Wird bei einem Patienten unter tumorspezifischer Therapie eine bestimmte Infektion nachgewiesen (z. B. Pneumonie, Clostridien-assoziierte Kolitis, Herpes zoster), so wird diese dokumentierte Infektion gemäß den allgemeinen Empfehlungen für nicht-onkologische Patienten behandelt.

\subsubsection{Neutropenes Fieber}

Als „,neutropenes Fieber“ bezeichnet man Fieber (Temp. $\geq 38.3{ }^{\circ} \mathrm{C}$ ) ohne klinischen Infektfokus bei Patienten mit Werten für die neutrophilen Granulozyten von $<500 / \mu l$. Das neutropene Fieber gilt bei hämato-onkologischen Patienten im kurativen Setting als Notfall und bedarf einer raschen Therapie mit Antibiotika; eine verzögerte Gabe von Antibiotika ist mit einen erhöhten Risiko des Versterbens an der Infektion verbunden. Nach einer ersten diagnostischen Abklärung (Laborwerte, Blut- und Urinkultur, evtl. Röntgen-Thorax) muss entschieden werden, ob der Patient ambulant oder stationär behandelt werden sollte. Dies geschieht anhand von Risiko-Scores, hier hat sich der Score der MASCC (Multinational Association for Supportive Care in Cancer) (1) bewährt. Wichtige klinische Kriterien sind die zu erwartende Länge der Neutropenie (in Kenntnis der vorangegangenen Chemotherapie), die Schwere der aktuellen Infektion (z. B. SepsisZeichen) und Begleiterkrankungen (z. B. COPD).

Nach der Risikoeinschätzung richtet sich auch die Entscheidung für ein Antibiotikaregime (orale versus intravenöse Therapie). In der Abbildung 1 findet sich ein Beispiel für einen Algorithmus, wie er an einer deutschen Universitätsklinik erarbeitet wurde. Erfüllt der Patient die Kriterien für eine stationäre Aufnahme, so muss unmittelbar eine intravenöse Therapie mit einem Breitbandantibiotikum (z. B. Imipenem oder Piperacillin/Tazobactam) begonnen werden.

Besteht eine Konstellation mit einer zu erwartenden Neutropenie von mehr als sieben Tagen und entfiebert der Patient nach 72-96 Stunden unter einem Breitbandantibiotikum nicht, so wird gemäß deutschen und internationalen Leitlinien eine Behandlung mit einem schimmelpilzwirksamen Antimykotikum (z. B. Caspofungin, Voriconazol oder liposomales Amphotericin B) empfohlen (1). Man spricht in diesem Fall von einer empirischen Therapie von Pilzinfektionen, da bei diesem Patientenkollektiv (zumeist Patienten mit akuten Leukämien oder nach allogener Stammzelltransplantation) Schimmelpilzinfektionen eine häufige Ursache 
von anhaltendem Fieber sind. Eine erneute diagnostische Abklärung mittels Computertomographie der Lunge ist in diesen Fällen notwendig, um nachträglich aufgetretene Infiltrate auszuschließen.

Auch wenn der Patient rasch entfiebert, sollte die antibiotische Therapie mindestens bis zum Anstieg der neutrophilen Granulozyten auf $>500 / \mu$ l (hämatopoetische Regeneration) und bis 48 Stunden nach Ende des Fieber fortgeführt werden. Bei einer anhaltenden Neutropenie wird die antibiotische Therapie bis sieben Tage nach der Entfieberung fortgeführt.

Neutropenes Fieber $=$ Hämatologischer Notfall:

- Klinische Untersuchung + Anamnese

- $\mathrm{BB}, \mathrm{CRP}, \mathrm{Kreatinin}$, Blutkultur, Urin-Stix

- Rö Thorax (nur bei resp. Symptomen)

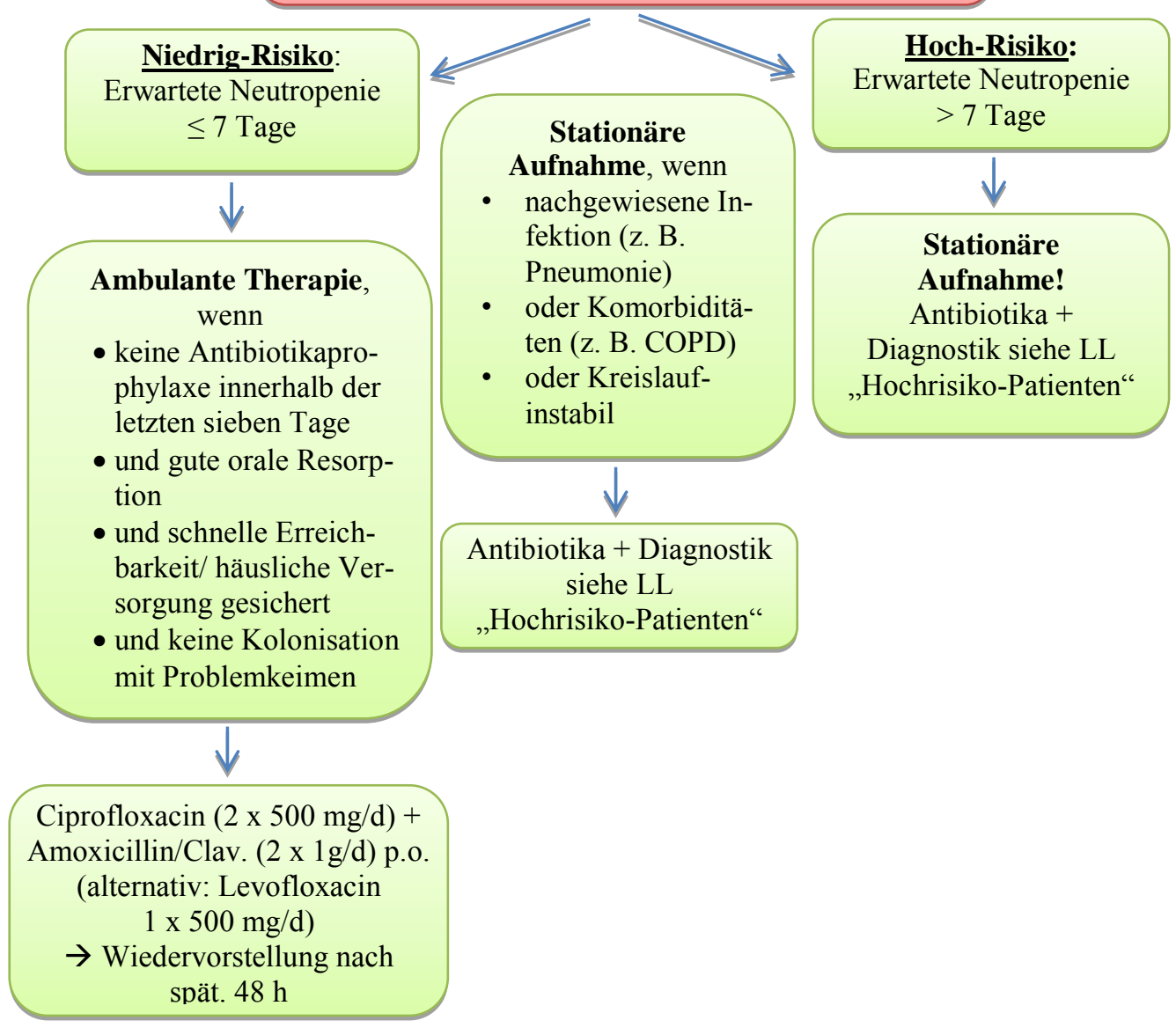

Abbildung 1: Algorithmus zur Risiko-Stratifikation bei neutropenem Fieber 


\subsubsection{Schimmelpilzinfektionen}

Bei Patienten mit hämatologischen Erkrankungen und einer anhaltenden Neutropenie von mehr als sieben Tagen steigt das Risiko, dass es zu einer Schimmelpilzinfektion kommt. Diese betrifft zumeist die Lunge oder die Nasennebenhöhlen und wird in der Regel durch Aspergillus Spezies bedingt. Um diese Infektionen zu diagnostizieren, bedarf es einer Bildgebung der Pilzinfiltrate mittels Computertomographie sowie einem histologischen oder kulturellen Nachweis aus einer Biopsie. Da eine Biopsie nicht immer leicht zu gewinnen ist und je nach klinischem Kontext dem Patient evtl. nicht zuzumuten ist, wurden neuere Verfahren (AntigenNachweis, PCR) entwickelt, welche den Nachweis von Schimmelpilz-Antigenen bzw. -DNA im Blut führen können (2).

Die Therapie einer Schimmelpilzinfektion mit einem Antimykotikum (z. B. Voriconazol i.v., liposomales Amphotericin B i.v.) wird meist intravenös begonnen, kann im weiteren Verlauf aber oralisiert (Voriconazol p.o., Posaconazol p.o.) werden. Die Dauer der Therapie sollte mindestens sechs Wochen betragen (3). Besteht z. B. im palliativen Setting einer akuten Leukämie oder eines MDS eine irreversible Neutropenie, so können Pilzinfektionen trotz adäquater Therapie unheilbar sein. Hier muss abgewogen werden, ob eine Fortsetzung der antimykotischen Therapie zur Symptomkontrolle sinnvoll ist oder ob diese in Anbetracht des Gesamtkontextes abgesetzt werden kann.

\subsubsection{Infektionen mit Hefepilzen}

Bei hämato-onkologischen Patienten kommen ebenso oberflächliche Hefepilzinfektionen (z. B. oraler Soor) und invasive Infektionen (z. B. Candida-Sepsis) vor. Oberflächliche Infektionen können lokal mit Amphotericin B Mundspüllösung behandelt werden. Bei immunsupprimierten Patienten empfiehlt sich jedoch eine kurze systemische Therapie mit niedrig dosiertem Fluconazol $(100 \mathrm{mg} / \mathrm{d}$ für sieben bis zehn Tage).

Invasive Infektionen mit Candida Spezies bedürfen einer differenzierten Diagnostik (Entnahme von Blutkulturen, Augenhintergrundspiegelung zum Ausschluss einer Endophtalmitis; Sonographie Abdomen zum Ausschluss eines Leber- und Milzbefalls) und eine längerdauernde Therapie von mindestens zwei bis sechs Wochen. Falls eine Erregergewinnung gelingt, sollte sich die antimykotische Therapie nach der jeweiligen Resistenzbestimmung richten (3). Bei mit Fluconazol vorbehandelten oder neutropenen Patienten sollte bis zum Erhalt der Resistenzbestimmung mit einem Echinocandin (Caspofungin, Anidulafungin oder Micafungin) behandelt werden. 


\subsection{Prophylaxe von Infektionen}

\subsubsection{Hygienemaßnahmen}

Patienten mit Neutrophilen-Werten $<500 / \mu l$ oder Leukozyten von $<1000 / \mu \mathrm{l}$ sollten im Krankenhaus eine Umkehrisolierung (Händedesinfektion, Mundschutz, Schutzkittel für die Besucher/Behandler) erhalten. Bei einer anhaltenden Neutropenie im palliativen Setting kann von diesen Maßnahmen nach Aufklärung des Patienten Abstand genommen werden. Auch im häuslichen Umfeld werden diese Maßnahmen nicht empfohlen.

Eine wichtige Bedeutung zur Vermeidung der Übertragung von Krankheitserregern kommt der Händedesinfektion zu. Hierüber sollten auch die Angehörigen aufgeklärt werden.

Für die Ernährung in der Phase der Neutropenie gelten ebenfalls besondere Empfehlungen, hierzu gibt die Leitlinie des Robert Koch-Instituts detaillierte Hinweise (4). Zusammengefasst sollten neutropene und immunsupprimierte Patienten darauf achten, kein rohes Fleisch oder rohen Fisch, keine rohen Eier, keine Rohmilchprodukte und keine offenen Salate zu sich zu nehmen, um nahrungsmittelassoziierte Erkrankungen zu vermeiden.

\subsubsection{Medikamentöse Prophylaxe}

Eine systemische antibiotische Prophylaxe während der Chemotherapie kann die Rate von febrilen Episoden und Infektionen reduzieren, hat aber nur einen geringen Einfluss auf die Sterblichkeit (Mortalität). Um Antibiotika-Resistenzen zu vermeiden, sollte eine antibiotische Prophylaxe nur bei Patienten mit hohem Infektionsrisiko durchgeführt werden (zu erwartende Neutropenie mehr als sieben Tage oder schwere Begleiterkrankungen) (5). Als Subtanzen kommen hier bevorzugt Chinolone zum Einsatz, z. B. Levofloxacin $500 \mathrm{mg} / \mathrm{d}$ oder Ciprofloxacin 2 x 500 $\mathrm{mg} / \mathrm{d}$.

Bei Patienten z. B. unter einer Lymphomtherapie sowie nach allogener oder autologer Stammzelltransplantation besteht zusätzlich zu den Phasen der Neutropenie häufig eine Lymphopenie. Ab einem Wert der CD4-Lymphozyten (Helferzellen) von $<200 / \mu l$ haben diese Patienten ein erhöhtes Risiko für schwere Herpesinfektionen und -reaktivierungen sowie für eine Pneumonie durch Pneumocystis jirovecii. Um diesen Infektionen vorzubeugen, erhalten lymphopene Patienten eine antivirale Prophylaxe (in der Regel mit Aciclovir, z. B. zwei bis drei Mal 400 mg/d) und eine Pneumocystis-Prophylaxe mit Cotrimoxazol/Trimethoprim (z.B. Cotrim forte drei Mal pro Woche) $(5,6)$. 


\subsubsection{Gabe von Myeloischen Wachstumsfaktoren zur Prophylaxe von Neutropenem Fieber}

Die Indikation zur Gabe von myeloischen Wachstumsfaktoren (Granulozytencolony stimulating factor, G-CSF) richtet sich nach dem zu erwartenden Risiko für eine febrile Neutropenie (7). Je nach Chemotherapie-Regime und Grunderkrankung sind Richtwerte für das Risiko einer febrilen Neutropenie bekannt. Ab einem Risiko von mehr als $20 \%$ wird der Einsatz von Granulozyten-stimulierenden Wachstumsfaktoren prophylaktisch empfohlen (7). Dies trifft z. B. für Chemotherapien zur Behandlung von Lymphomen, akuter lymphatischer Leukämie und bestimmten Chemotherapien zur Behandlung des Mammakarzinoms zu. An Präparaten stehen Filgrastim, Lenograstim, pegyliertes Filgrastim und Biosimilars (z. B. XM02) zu Verfügung, welche alle subkutan verabreicht werden.

Häufige Nebenwirkungen der Granulozyten-stimulierenden Wachstumsfaktoren sind Knochenschmerzen und grippeähnliche Symptome bis hin zu Fieber. Hierüber sollten die Patienten im Vorhinein aufgeklärt werden.

\subsubsection{Impfungen bei Krebspatienten}

Bei hämato-onkologischen Patienten sollte gemäß den Empfehlungen der STIKO an eine jährliche Impfung gegen Influenza und an eine Impfung gegen Pneumokokken (bevorzugt mit dem konjugierten Impfstoff PVC-13) gedacht werden. Der günstigste Zeitpunkt für eine Impfung liegt vor dem Beginn der Chemotherapie, da hier noch eine optimale Impfantwort zu erwarten ist. Ist dies nicht möglich, kann auch während der Chemotherapie geimpft werden, da ein partieller Impfschutz einen milderen Verlauf z. B. der saisonalen Influenza bedingen kann und keine ernsthaften Nebenwirkungen zu erwarten sind. Das Personal in medizinischen Einrichtungen sowie die Angehörigen von immunsupprimierten Patienten sollten ebenfalls jährlich gegen Influenza geimpft werden, um so einen „Schutzwall“" gegen Ansteckung um den Patienten zu bilden.

\section{$10.4 \quad$ Antiemese}

\subsubsection{Allgemeines}

Übelkeit und Erbrechen sind zwei Symptome, die häufig im Verlauf einer unheilbaren Erkrankung auftreten. Grundsätzlich kann man aufgrund der Ätiologie folgende Unterscheidungen treffen:

- Störungen im Bereich des gesamten Verdauungstrakts: vom Pharynx bis zum Rektum, einschließlich Leber, Pankreas und Gallenwegen, wie Entzündungen, mechanische Hindernisse oder toxische Reizungen 
- Zentrales Erbrechen: Reizung des Brechzentrums in der dorsolateralen Formatio reticularis bzw. der Chemorezeptor-Triggerzone (CTZ) in der Area postrema des IV. Ventrikels durch Zytostatika (oder Morphin)

- Psychogenes Erbrechen: Konditionierung von Brechzentrum und CTZ $\rightarrow$ antizipatorisches Erbrechen

Differentialdiagnostisch sind die Ursachen von Übelkeit und Erbrechen sowohl im Magen-Darm-Trakt (Mukositis, Soorbefall, Ulcera, Tumor, Opioide), auf ZNSEbene (erhöhter Hirndruck, Meningeosis), psychogen (Stress, Angst) als auch metabolisch medikamentös zu suchen. Gerade die medikamentöse Ursache von Übelkeit und Erbrechen sollte bei onkologischen Patienten immer in Betracht gezogen werden, da hier neben dem in der Palliativmedizin verbreiteten Einsatz von Antikonvulsiva oder Opioiden auch die spezifische antitumoröse Therapie mit Zytostatika als Ursache in Betracht kommt.

Bei der Therapie mit Zytostatika nimmt man je nach dem zeitlichen Auftreten der Übelkeit folgende Unterscheidungen vor:

Antizipatorisches Erbrechen: Emesis als konditionierte Erfahrung früherer Therapien. Einsetzen vor Therapiebeginn, spricht auf Antiemetika nur bedingt an, in der Regel durch Psychopharmaka zu beeinflussen, selten ganz zu beherrschen. Deshalb schon bei der ersten Chemotherapie optimale Antiemese, um Patienten vor „schlechten Erfahrungen“ zu bewahren!

Akutes Erbrechen: Abhängig von der emetogenen Potenz des Zytostatikums sowie von der Dosis und Konstitution des Patienten. Frauen neigen häufiger zu Erbrechen als Männer, junge Patienten mehr als ältere, und nach langjährigem höherem Alkoholkonsum kann der Brechreiz fast vollständig fehlen. Setzt innerhalb 24 Stunden nach Applikation ein und hält in der Regel nicht länger als 48 Stunden an.

Verzögertes Erbrechen: Häufig nach Cisplatin, setzt nach über 24 Stunden ein und hält mehrere Tage an. Entsprechend der Wahrscheinlichkeit und Häufigkeit des Auftretens von Übelkeit und Erbrechen werden Zytostatika entsprechend ihrer emetogenen Potenz eingeteilt (siehe Tabelle 1).

Tabelle 1: Emetogene Potenz der wichtigsten Zytostatika, Antikörper und molekularen Inhibitoren

\begin{tabular}{|l|l||}
\hline $\begin{array}{l}\text { Sehr schwache } \\
\text { Emetogenität } \\
(<\mathbf{1 0} \mathbf{0})\end{array}$ & $\begin{array}{l}\text { Bevacizumab, Bleomycin, Busulfan, Chlorambucil, Chlorodeoxyadeno- } \\
\text { sin, Cladribin, Erlotinib, Fludarabin, Gefitinib, Hydroxyurea, } \\
\text { Lenalidomid, Melphalan, Mercaptopurin, MTX }\left(<100 \mathrm{mg} / \mathrm{m}^{2}\right), \text { Pen- } \\
\text { tostatin, Rituximab, Sorafenib, Thioguanin, Vincristin, Vinblastin, } \\
\text { Vinorelbin i.v. }\end{array}$ \\
\hline $\begin{array}{l}\text { Schwache } \\
\text { Emetogenität }\end{array}$ & $\begin{array}{l}\text { Asparaginase, Bendamustin, Bortezomib, Capecitabin, Catumaxomab, } \\
\text { Cetuximab, Cytarabin }(<1 \mathrm{~g} / \mathrm{m} 2), \text { Decitabin, liposomales Doxorubi- }\end{array}$ \\
\hline
\end{tabular}




\begin{tabular}{|c|c|}
\hline$(10-30 \%)$ & $\begin{array}{l}\text { cin, Etoposid, 5-Fluorouracil, Gemcitabin, Lenalidomid, Mitomycin, } \\
\text { Mitoxantron, MTX }\left(>100 \mathrm{mg} / \mathrm{m}^{2}\right) \text {, Panitumumab, Pemetrexed, } \\
\text { Sunitinib, Taxane, Temsirolimus, Thalidomid, Topotecan }\end{array}$ \\
\hline $\begin{array}{l}\text { Mittlere } \\
\text { Emetogenität } \\
(30-90 \%)\end{array}$ & $\begin{array}{l}\text { Anthrazykline (Mono-Tx), Alemtuzumab, Azacytidin, Carboplatin, } \\
\text { Clofarabin, Cyclophosphamid }\left(<1500 \mathrm{mg} / \mathrm{m}^{2}\right) \text {, Cytarabin }\left(>1 \mathrm{~g} / \mathrm{m}^{2}\right) \text {, } \\
\text { Ifosfamid, Imatinib, Irinotecan, Oxaliplatin, Temozolomid, Trabecte- } \\
\text { din, Treosulfan, Vinorelbin p.o. }\end{array}$ \\
\hline $\begin{array}{l}\text { Hohe } \\
\text { Emetogenität } \\
(>90 \%)\end{array}$ & $\begin{array}{l}\text { Anthrazykline (in Kombination mit anderen Zytostatika, z. B. AC, } \\
\text { FEC, TAC, VAIA), Cisplatin, Carmustin (BCNU), Cyclophosphamid } \\
\left.\text { (> } 1500 \mathrm{mg} / \mathrm{m}^{2}\right) \text {, Dacarbazin (DTIC), Dactinomycin, Pentostatin, } \\
\text { Procarbazin, Streptozotocin, jede HD-Tx }\end{array}$ \\
\hline
\end{tabular}

\subsubsection{Diagnostik}

Da Übelkeit und Erbrechen Symptome sind, die die Lebensqualität erheblich beeinflussen und verschlechtern, sollte immer versucht werden, mit einer adäquaten Diagnostik die Ursache abzuklären. Hierbei spielt die Anamneseerhebung eine zentrale Rolle (insbesondere die Frage nach einer stattgehabten Zytostatikatherapie, s. o.). Die Frage nach der Häufigkeit, der auslösenden Ursache und einer möglichen Assoziation zur Einnahme von Medikamenten ist ebenso wichtig wie die Frage nach dem Geruch, dem Aussehen und der Farbe von Erbrochenem. Die körperliche Untersuchung sollte die Inspektion des Mund- und Rachenraumes zum Ausschluss einer Mukositis bzw. eines Soorbefalls ebenso umfassen wie die Untersuchung des Abdomens zum Ausschluss von Aszites, Stuhlverhaltes, Tumors, Vergrößerung der Leber. Unterstützend kann hierbei als bildgebende Maßnahme eine Ultraschalluntersuchung des Bauchraumes vorgenommen werden. Als weitere apparative Untersuchung macht sich manchmal bei gastroösophagealem Reflux, Gastritis oder Magenatonie eine Gastroskopie erforderlich. Zum Ausschluss von metabolischen Ursachen oder Medikamentenintoxikationen sollte eine Laboruntersuchung mit den entsprechenden Parametern erfolgen.

\subsubsection{Therapie}

Grundsätzliche sollten reversible Ursachen wie z. B. Schmerzen, Obstipation oder Hirndruck behandelt werden. Des Weiteren sollte eine gründliche Medikamentenanamnese durchgeführt werden und Medikamente, die nicht unbedingt notwendig sind und potentiell emetogen sind, weggelassen werden. Sollte beides nicht den gewünschten Erfolg bringen, ist eine reine Symptomkontrolle indiziert. Dabei ist es wichtig zu betonen, dass häufig eine Beeinflussung der Frequenz des Erbrechens ausreichend ist. Die meisten Patienten tolerieren es sehr gut ein bis zweimal am Tag zu erbrechen. Es können verschiedene Wirkgruppe der Antiemetika unterteilt werden. Grundsätzlich wirken die Antiemetika über eine Blockade verschiede- 
ner Neurotransmitter. Die Rezeptoren dieser Neurotransmitter sind sowohl im Gastrointestinaltrakt als auch im vierten Ventrikel im Hirnstamm lokalisiert. Die Wahl des Emetikums ist abhängig von der Ursache des Erbrechens. Eine Übersicht über die unterschiedlichen Substanzgruppen mit den entsprechenden Dosierungen und Applikationsintervallen ist in folgender Tabelle aufgeführt.

Tabelle 2: Antiemetika entsprechend der verschiedenen Substanzgruppen und Dosierungen

\begin{tabular}{|c|c|c|c|}
\hline Substanzgruppe & Wirkstoff & Dosis (mg) & Intervall (h) \\
\hline Antihistaminika & Dimenhydrinat & $100-200$ & 8 \\
\hline Neuroleptika & $\begin{array}{l}\text { Haloperidol } \\
\text { Levomepromazin }\end{array}$ & $\begin{array}{l}0,3-0,5 \\
3\end{array}$ & $\begin{array}{l}8-12 \\
8\end{array}$ \\
\hline Anticholinergika & Scopolamin & $0,2-0,4$ s.c. & 8 \\
\hline Prokinetika & Metoclopramid & 10 & $4-5$ \\
\hline 5-HT3-Antagonisten & Ondansetron & $4-8$ & $8-12$ \\
\hline Glycokorticoide & Dexamethason & $4-8$ & $8-24$ \\
\hline Cannabinoide & Drobabinol & $2,5-5$ & $6-8$ \\
\hline Benzodiazipine & Lorazepam & $0,5-2$ & $8-12$ \\
\hline
\end{tabular}

Die Applikation des Antiemetikums sollte nach einem festen Zeitschema erfolgen. Eine kurzfristige Kontrolle der Wirksamkeit muss erfolgen, damit bei Nichtwirksamkeit entweder die Dosis angepasst oder ein Medikament mit einer anderen Rezeptoraffinität eingesetzt werden kann. Oft werden zwei Medikamente mit unterschiedlicher Rezeptoraffinität benötigt. Grundsätzlich ist als Applikationsweg immer die enterale Aufnahme zu wählen. Bei rezidivierendem Erbrechen sollte auf einen parenteralen oder rektalen Weg ausgewichen werden.

Des Weiteren sollte neben der medikamentösen Therapie auf nichtmedikamentöse Maßnahmen geachtet werden. Hierbei spielen vor allem die Umgebung (Gerüche) und die Art und Weise der Zubereitung von Mahlzeiten eine große Rolle.

Wichtig ist auch die Prophylaxe und Therapie des Zytostatika-indizierten Erbrechens. Ziel der Therapie ist der Zustand ohne Übelkeit während der Chemotherapie, welcher mit einer konsequenten Therapie bei ca. 60-80\% aller Patienten $\mathrm{zu}$ erreichen ist. Die antiemetische Therapie richtet sich nach der emetogenen Potenz der verwendeten Zytostatika (s. o.) und der subjektiven Empfindlichkeit des Patienten. Jeder Patient mit Nausea/Erbrechen wird beim nächsten Zyklus mit der Therapie der höheren Gruppe behandelt (siehe Tabelle 3). Bei den sehr schwach emetogenen Zytostatika ist in der Regel keine Therapie notwendig. 
Tabelle 3: Antiemetische Prophylaxe entsprechend des emetogenen Risikos der Zytostatika

\begin{tabular}{|c|c|c|c|}
\hline Risikogruppe & Emesisrisiko & Akutes Erbrechen & Verzögertes Erbrechen \\
\hline Minimal & $<10 \%$ & $\begin{array}{l}\text { keine präventiven Maßnah- } \\
\text { men }\end{array}$ & $\begin{array}{l}\text { keine präventiven Maß- } \\
\text { nahmen }\end{array}$ \\
\hline Niedrig & $10-30 \%$ & $\begin{array}{l}\text { Dexamethason o. Dopami- } \\
\text { nantagonist }\end{array}$ & $\begin{array}{l}\text { keine präventiven Maß- } \\
\text { nahmen }\end{array}$ \\
\hline Moderat & $30-90 \%$ & $\begin{array}{l}\text { Tag 1: } 5 \text { - } \mathrm{HT}_{3} \text {-Antagonist }+ \\
\text { Dexamethason }\end{array}$ & $\begin{array}{l}\text { Tag } 2+3 \text { : Dexamethason } \\
\text { o. } 5 \text {-HT' } \mathrm{H}_{3} \text {-Antagonist, (evtl. } \\
+\mathrm{NK}_{1} \text {-Antagonist) }\end{array}$ \\
\hline Hoch & $>90 \%$ & $\begin{array}{l}\text { Tag 1: } 5 \text { - } \mathrm{HT}_{3} \text {-Antagonist }+ \\
\text { Dexamethason } \\
+\mathrm{NK}_{1} \text {-Antagonist (i.v. oder } \\
\text { p.o.) } \pm \text { Lorazepam }\end{array}$ & $\begin{array}{l}\text { Tag } 2+3 \text { : Dexamethason } \\
\text { (evtl. auch Tag 4) } \\
+ \text { NK } 1 \text {-Antagonist (p.o.) } \\
\text { (nicht nötig, wenn Tag } 1 \\
\text { i.v.) } \pm \text { Lorazepam }\end{array}$ \\
\hline
\end{tabular}

\subsection{Anämie}

\subsubsection{Allgemeines}

Eine Anämie ist definiert als ein Abfall des Hämoglobinwertes im Blut unter 12 $\mathrm{g} / \mathrm{dl}$ bzw. 7,5 mmol/l und ist ein häufiges Begleitsymptom bei Patienten in einer Terminalphase von chronischen Erkrankungen. Es kommen verschiedene Ursachen dafür in Frage: Eisenmangel bei chronischer Blutung, infektionsbedingte Veränderungen, Hämolyse, Knochenmarkschädigung bei zytotoxischer Therapie oder Metastasierung. Je nach Dynamik der Entwicklung können die Anämiesymptome variieren. Grundsätzlich kann man sagen, dass eine sich langsam entwickelnde Anämie aufgrund einer Adaptation wenige Symptome hervorruft. Im Gegensatz dazu wird eine sich schnell entwickelnde Anämie, z. B. in Folge einer akuten Blutung, relativ schnell Symptome verursachen.

\subsubsection{Symptome}

Die Symptome sind Folge eines erhöhten Herzzeitvolumens und der Gewebehypoxie. Die Ausprägung der Symptome ist einerseits von der Schwere der Anämie, andererseits von der Geschwindigkeit der Entstehung abhängig. Bei langsam entstandenen Anämieformen ist die Kreislaufsymptomatik weniger dramatisch. Das klinische Bild der chronischen Anämie wird bestimmt durch Allgemeinsymptome wie Müdigkeit, Tinnitus, Schwäche, Schwindel, Leistungsabfall, Herzklopfen, ra- 
scher Pulsanstieg bei Belastung, Schlafstörungen, Konzentrationsstörungen und Kopfschmerzen. Die Blässe der Haut stellt kein zuverlässiges Kriterium dar, da diese auch von der gefäßbedingten Durchblutung und der Pigmentierung abhängt. Ein zuverlässigeres Anämiezeichen ist dagegen die Blässe der Konjunktiven, die Beurteilung der Handinnenflächen und der Nagelphalangen. Bei rascher Ausbildung einer Anämie treten Symptome des Herzkreislaufsystems wie z. B. Kurzatmigkeit, Blutdruckabfall, Herzjagen in den Vordergrund.

\subsubsection{Diagnostik}

Entsprechend der zugrundeliegenden Ursache der Anämie ergeben sich unterschiedliche Behandlungsmöglichkeiten. Um diese auszuschöpfen, sollte eine differenzierte Diagnostik erfolgen, die sich allerdings nach dem Ausmaß der Symptome, der Invasivität und der therapeutischen Konsequenz richten muss. Ist aufgrund des klinischen Zustands eine weiterführende Diagnostik unzumutbar, sollte man sich auf eine reine Beschwerdelinderung beschränken. Grundsätzlich muss man differentialdiagnostisch folgende Ursachen einer Anämie bedenken: Blutungen (akut, chronisch), chronische Infektionen, Mangelernährung, Hämolyse, Knochenmarkkarzinose. Neben der ausführlichen Anamnese (Medikamente) sind als initiale obligate Laboruntersuchungen das Blutbild, Erythrozytenindices und ein Hämoccult-Test empfehlenswert. Als weiterführende Laboruntersuchungen sollten je nach klinischer Verdachtsdiagnose ein Differentialblutbild, Retikulozyten, Ferritin, Vitamin B12, Folsäure, LDH, Haptoglobin, Bilirubin und ein Coombs-Test durchgeführt werden. Die Indikationsstellung zur weiterführenden, insbesondere apparativen Diagnostik, muss unter Würdigung der Gesamtsituation und der therapeutischen Konsequenz getroffen werden.

\subsubsection{Therapie}

Die Therapie einer Anämie richtet sich nach den Symptomen und nicht nach den Laborwerten. Grundsätzlich gilt: Eine Anämie ohne Symptomatik, unabhängig vom Ausmaß, stellt keine Therapieindikation dar. Ist in den Untersuchungen eine grundsätzlich therapierbare Ursache ermittelt worden, kann die Möglichkeit der Kausaltherapie erwogen werden. An erster Stelle stehen hier beispielsweise interventionelle Behandlungsverfahren zur Blutungsstillung, der Einsatz von Steroiden bei hämolytischer Anämie oder eine antineoplastische Therapie bei Knochenmarkkarzinose. Neben einer Kausaltherapie besteht in Abhängigkeit der Symptomatik die Substitution in Form von Bluttransfusionen bzw. die Stimulation der Erythropoese durch Zytokine (Erythropoetin) im Vordergrund. Gerade die Bluttransfusion hat einen Stellenwert bei der raschen Linderung von Anämiesymptomen, sollte aber immer im Kontext der Gesamtsituation, sowohl der persönlichen als auch der erkrankungsbedingten, gesehen werden. Auch die Option, auf eine spezifische Anämietherapie zu verzichten, muss berücksichtigt werden. 


\subsection{Prophylaktische Transfusion von Thrombozyten}

Bereits in den 1960er Jahren konnte bei Patienten mit akuter Leukämie gezeigt werden, dass ein Wert der Thrombozyten (Blutplättchen) von unter 20.000/ $\mu$ mit einer erhöhten Blutungsgefahr einhergeht. So wurde bei hämato-okologischen Patienten, welche unter einer Chemotherapie einen Abfall der Thrombozyten zu verzeichnen haben, die prophylaktische Transfusion von Thrombozytenkonzentraten Standard (1).

In den letzten Jahren wurden neue Studien publiziert und unterschiedliche Grenzwerte je nach Patientenkollektiv neu definiert. So wird bei Patienten mit akuter Leukämie ein Grenzwert der Thrombozyten von 10.000/ $\mu$ l, ab welchem prophylaktisch transfundiert wird, als sicher angesehen. Allerdings lassen sich auch trotz prophylaktischer Thrombozytengaben schwere Blutungen bei Patienten mit akuter Leukämie nicht vollständig vermeiden.

Bei klinisch stabilen Patienten mit chronischen Thrombozytopenien (z. B. beim Myelodysplastischen Syndrom (MDS) oder der Aplastischen Anämie) sollten Thromboyztenkonzentrate erst bei Unterschreiten eines Thrombozytenwertes von $5.000 / \mu$ l prophylaktisch gegeben werden.

Im palliativen Setting lässt sich im Rahmen der Therapiezieländerung und der Vermeidung von häufigen Klinikbesuchen eine therapeutische Strategie vertreten. Beim therapeutischen Ansatz werden, im Gegensatz zum prophylaktischen Ansatz, Thrombozytenkonzentrate nur verabreicht, wenn geringgradige Blutungen (mehr als nur Petechien) auftreten. Hierdurch lassen sich häufige Transfusionen vermeiden, da in der Regel schwerwiegende Blutungen bei Patienten mit chronischer Thrombozytopenie nur dann auftreten, wenn weitere Risikofaktoren (z. B. Schleimhautläsionen, Behandlung mit Thrombozytenfunktionshemmern) hinzukommen. Hierüber sollten die Patienten informiert werden. Ein weiterer Aspekt ist der, dass häufige Thrombozytentransfusionen zur Bildung von Antikörpern gegen humane Leukozytenantigene (HLA) oder Plättchenantigene (HPA) führen können. Diese Antikörper können die transfundierten Thrombozyten rasch abbauen und somit Thrombozytentransfusionen wirkungslos werden lassen. Hier besteht im Falle von Blutungen nur noch die Möglichkeit der Gabe von kompatiblen Thrombozytenkonzentraten von Einzelspendern, welche logistisch sehr aufwendig ist (8).

\subsection{Medikamentöse Behandlung von Knochenmetastasen}

Zur Behandlung von Knochenmetastasen stehen zwei Medikamentenklassen zur Verfügung, welche die Osteoklasten hemmen und somit einen vermehrten Abbau der Knochenmatrix unterbinden. Zum einen gibt es die Bisphosphonate, Analoge des Pyrophosphates, welche direkt die Osteoklasten inhibieren. Zum anderen steht seit wenigen Jahren der monoklonale Antikörper gegen den RANK-Liganden Denosumab zur Verfügung, welcher ebenfalls eine Inhibition der Osteoklasten- 
Aktivität verursacht. Die am häufigsten eingesetzten Substanzen, ihre Dosierung und ihre Zulassung können der Tabelle 4 entnommen werden.

Beide Substanzklassen werden bei Patienten mit Knochenmetastasen durch solide Tumoren mit dem Ziel eingesetzt, skelettbezogene Komplikationen zu vermeiden. Hierzu zählen pathologische Frakturen, die Notwendigkeit einer Bestrahlung der Knochenmetastasen, die Notwendigkeit einer operativen Therapie, die Rückenmarkkompression sowie eine Hyperkalzämie (9).

Eine häufige Nebenwirkung beider Substanzklassen ist die Hypokalzämie, sodass begleitend zur Therapie eine ausreichende Supplementierung mit Vitamin D und Calcium sichergestellt werden sollte. Des Weiteren besteht die Gefahr einer Osteonekrose des Kieferknochens, insbesondere bei längerfristiger Anwendung der Substanzen und vorhandenen Wundherden im Zahnbereich. Deshalb ist eine ausführliche zahnärztliche Untersuchung und konsequente Sanierung des Gebisses vor Beginn einer Therapie mit Bisphosphonaten oder Denosumab unabdingbar.

Sowohl Bisphosphonate als auch der RANK-Ligand Inhibitor können eine deutliche Reduktion der skelettbezogenen Ereignisse bei Patienten mit Knochenmetastasen von soliden Tumoren und beim Multiplen Myelom erreichen. Eine Verlängerung der Überlebenszeit konnte bisher nicht gezeigt werden. Jedoch findet sich unter beiden Substanzklassen eine deutliche Reduktion der Knochenschmerzen. Deshalb sollte bei Patienten im palliativen Setting auch nach Beendigung oder Pausieren einer tumorspezifischen Therapie die Indikation zur Gabe von knochenstabilisierenden Substanzen großzügig gestellt werden, um Lebensqualität zu erhalten. Eine Therapiedauer von 2-3 Jahren ist in der Regel ausreichend, anschließend sollte eine „Erhaltungstherapie“ in größeren Abständen fortgeführt werden.

Unter einer hormonablativen Therapie z. B. mit GnRH-Analoga beim Prostatakarzinom aber auch bei der Therapie mit Aromatase-Inhibitoren beim Mammakarzinom tritt häufig eine therapieassoziierte Osteoporose auf. Zur Behandlung dieser Komplikation sind ebenfalls bestimmte Präparate zugelassen, in der Regel in einer niedrigeren Dosierung als zur Behandlung von Knochenmetastasen (Beispiele finden sich in Tabelle 4).

Tabelle 4: Beispiele der Indikation und Zulassung von Bisphosphonaten und Denosumab (modifiziert nach Coleman 2014)

\begin{tabular}{|l|l|l|}
\hline Indikation & Substanz & Zulassung in der EU \\
\hline $\begin{array}{l}\text { Vermeidung von skelettbe- } \\
\text { zogenen Komplikationen bei } \\
\text { Knochenmetastasen }\end{array}$ & $\begin{array}{l}\text { Zolendronat 4 mg i.v. alle } \\
\text { 3-4 Wochen }\end{array}$ & $\begin{array}{l}\text { Alle soliden Tumoren und } \\
\text { Multiples Myelom }\end{array}$ \\
\hline & $\begin{array}{l}\text { Pamidronat } 90 \mathrm{mg} \text { i.v. } \\
\text { alle 3-4 Wochen }\end{array}$ & $\begin{array}{l}\text { Brustkrebs und Multiples } \\
\text { Myelom }\end{array}$ \\
\hline & $\begin{array}{l}\text { Ibandronat 6 mg i.v. alle } \\
\text { 3-4 Wochen }\end{array}$ & Brustkrebs \\
\hline
\end{tabular}




\begin{tabular}{|l|l|l|}
\hline & $\begin{array}{l}\text { Ibandronat } 50 \mathrm{mg} \text { p.o. } \\
\text { täglich }\end{array}$ & Brustkrebs \\
\hline $\begin{array}{l}\text { Denusomab } 120 \mathrm{mg} \text { s.c. } \\
\text { alle 4 Wochen }\end{array}$ & Alle soliden Tumoren \\
\hline $\begin{array}{l}\text { Prävention von therapieas- } \\
\text { soziierter Osteoporose }\end{array}$ & $\begin{array}{l}\text { Denusomab } 60 \mathrm{mg} \text { s.c. } \\
\text { alle 6 Monate }\end{array}$ & $\begin{array}{l}\text { Prostata- und Brustkrebs } \\
\text { unter hormonablativer } \\
\text { Therapie }\end{array}$ \\
\hline & $\begin{array}{l}\text { Ibandronat } 3 \mathrm{mg} \text { i.v. alle } \\
\text { 3 Monate }\end{array}$ & $\begin{array}{l}\text { Nur für postmenopausale } \\
\text { Osteoporose zugelassen }\end{array}$ \\
\hline
\end{tabular}

\section{$10.8 \quad$ Literatur}

(1) Freifeld AG, Bow EJ, Sepkowitz KA, Boeckh MJ, Ito JI, Mullen CA, et al. Clinical practice guideline for the use of antimicrobial agents in neutropenic patients with cancer: 2010 update by the infectious diseases society of america. Clin Infect Dis. [Practice Guideline Research Support, Non-U.S. Gov't]. 2011 Feb 15;52(4):e56-93.

(2) Ruhnke M, Bohme A, Buchheidt D, Cornely O, Donhuijsen K, Einsele $\mathrm{H}$, et al. Diagnosis of invasive fungal infections in hematology and oncology-guidelines from the Infectious Diseases Working Party in Haematology and Oncology of the German Society for Haematology and Oncology (AGIHO). Ann Oncol. [Practice Guideline Review]. 2012 Apr;23(4):823-33.

(3) Mousset S, Buchheidt D, Heinz W, Ruhnke M, Cornely OA, Egerer G, et al. Treatment of invasive fungal infections in cancer patients-updated recommendations of the Infectious Diseases Working Party (AGIHO) of the German Society of Hematology and Oncology (DGHO). Ann Hematol. [Consensus Development Conference Practice Guideline]. 2014 Jan;93(1):13-32.

(4) Kommission für Krankenhaushygiene und Infektionsprävention beim Robert Koch-Institut. Anforderungen an die Hygiene bei der medizinischen Versorgung immunsupprimierter Patienten. Bundesgesundheitsblatt. 2010;53:357-88.

(5) Neumann S, Krause SW, Maschmeyer G, Schiel X, von Lilienfeld-Toal M. Primary prophylaxis of bacterial infections and Pneumocystis jirovecii pneumonia in patients with hematological malignancies and solid tumors : guidelines of the Infectious Diseases Working Party (AGIHO) of the German Society of Hematology and Oncology (DGHO). Ann Hematol. [Practice Guideline Review]. 2013 Apr;92(4):433-42. 
(6) Sandherr M, Einsele H, Hebart H, Kahl C, Kern W, Kiehl M, et al. Antiviral prophylaxis in patients with haematological malignancies and solid tumours: Guidelines of the Infectious Diseases Working Party (AGIHO) of the German Society for Hematology and Oncology (DGHO). Ann Oncol. [Practice Guideline]. $2006 \mathrm{Jul} ; 17(7): 1051-9$.

(7) Vehreschild JJ, Bohme A, Cornely OA, Kahl C, Karthaus M, Kreuzer $\mathrm{KA}$, et al. Prophylaxis of infectious complications with colony-stimulating factors in adult cancer patients undergoing chemotherapy-evidence-based guidelines from the Infectious Diseases Working Party AGIHO of the German Society for Haematology and Medical Oncology (DGHO). Ann Oncol. [Research Support, Non-U.S. Gov't]. 2014 Sep;25(9):1709-18.

(8) Wandt H, Schafer-Eckart K, Greinacher A. Platelet transfusion in hematology, oncology and surgery. Dtsch Arztebl Int. 2014 Nov 28;111(48):809-15.

(9) Coleman R, Body JJ, Aapro M, Hadji P, Herrstedt J. Bone health in cancer patients: ESMO Clinical Practice Guidelines. Ann Oncol. [Practice Guideline]. 2014 Sep;25 Suppl 3:iii124-37.

Für eine deutsche Zusammenfassung der Leitlinien der DGHO siehe auch: www.dgho-onkopedia.de 



\section{Die Rolle der onkologischen Fachkrankenpflege}

Bärbel Heise

Universitätsmedizin Göttingen, 37075 Göttingen

\subsection{Einführung in das Berufsbild}

Die Pflege von onkologischen Patienten und die Mitbetreuung ihrer Angehörigen ist eine besondere Herausforderung. Bedingt durch sich permanent verändernde Tumortherapien, die allgemeine Zunahme von Krebserkrankungen und die Verbesserung der Überlebenschancen gehen die Anforderungen an das onkologische Pflegepersonal oft weit über die in der dreijährigen Ausbildung erworbenen Kompetenzen hinaus.

Daher wurden Anfang der neunziger Jahre die ersten Fachweiterbildungen für onkologische Pflegekräfte angeboten, die sich berufsbegleitend über eine Dauer von zwei Jahren erstrecken und mehrfach aktualisiert und überarbeitet worden sind.

Die Bundesarbeitsgemeinschaft der Leitungen der Weiterbildungsstätten für die Fachkrankenpflege in der Onkologie (BAGL) hat dabei schon 2004 folgendes Aufgaben- und Kompetenzprofil verfasst. 
Dieses beinhaltet:

- fachpraktisches Handeln, wie z. B. die direkte Unterstützung von Patient und Familie in allen Erkrankungsphasen, systematische Problemerfassung und Pflegeevaluation

- Anleitung und Beratung, z. B. über Nebenwirkungen und deren Management (ergänzend zum ärztlichen Gespräch), mögliche Unterstützungsangebote der Einrichtung

- Gestaltung von Beziehungen, Wahrnehmung von Zustand und Bedürfnissen der Patienten und ihrer Angehörigen

- Einsatz für den Patienten, manchmal als Vermittler zu den anderen Berufsgruppen

- Koordination und Organisation

- Mitwirkung bei der Forschung

- berufs- und gesellschaftspolitische Aktivität, z. B. eigene Weiterbildung, Schulung von Kollegen, Mitarbeit in Berufsverbänden (1)

Im Rahmen dieses Kapitels soll speziell auf die pflegerischen Möglichkeiten beim Nebenwirkungsmanagement eingegangen werden, um praxisorientierte Hilfestellung im Arbeitsalltag anzubieten.

\subsection{Pflegerische Handlungsmöglichkeiten am Beispiel häufiger Nebenwirkungen}

\subsubsection{Orale Mukositis}

Unter oraler Mukositis versteht man eine durch Radio- und/oder Chemotherapie bedingte Entzündung der Mundschleimhaut, die für den Patienten eine große Belastung darstellt. Nicht nur Nahrungs- und Flüssigkeitsaufnahme werden beeinträchtigt; der Mund ist das wichtigste Kommunikationsorgan und daher können Mundgeruch, kosmetische Beeinträchtigungen und Schmerzen auch zu sozialer Isolation führen.

Zum Thema „Mukositis“ gibt es einige sehr unterschiedliche Veröffentlichungen. Im Rahmen der Arbeitsgruppe „Netzwerk onkologische Pflege“ an der Universitätsmedizin Göttingen wurden daraus folgende Pflegeempfehlung zur Prophylaxe und Therapie zusammengestellt: 


\section{Zielsetrung:}

- Vermeidung bzw. Reduzierung einer Mukositis

- effiziente Schmerzlinderung

- rasche Abheilung

- Vermeidung einer Superinfektion

- Erhaltung des Ernährungszustandes

Risiken:

- Chemotherapie

- Bestrahlung

- Infektionen mit Bakterien, Viren und Pilzen

- Immunsuppression

- Behandlung mit Corticoiden und Antibiotika

- Mangelernährung/Vitaminmangel

- mangelnde Mundhygiene

- chronische Darmerkrankungen

Begutachtung/Verlaufskontrolle:

Eine gezielte Befragung und eine Mundinspektion sollten bei stationären Patienten täglich, bei ambulanten Patienten bei jedem Besuch stattfinden. Diese sind in der Akte/Kurve zu dokumentieren. Bei auftretenden Problemen ist eine Schweregradeinteilung, z. B. nach CTC, hilfreich.

\section{Prophylaxen:}

- Feuchthalten der Mundschleimhaut, z. B. durch Mundspülungen wie Salbeilösung, Kochsalzlösungen oder kohlensäurehaltiges Mineralwasser, Kauen von zuckerfreien Kaugummis, Lutschen von Eiswürfeln oder gefrorenen Ananasstückchen. Die Auswahl an Mundspüllösungen ist groß und sollte nach den individuellen Bedürfnissen des Patienten hinsichtlich Geschmacks, Kosten, Handling und bevorzugter Methode (pharmazeutisch, komplementär) ausgewählt werden, da es bisher keine in Studien nachgewiesene Effektivität gibt (2).

- Vermeidung von scharfen, sauren, zu heißen und sehr harten Speisen

- Benutzung einer weichen Zahnbürste 


\section{Therapiemöglichkeiten:}

- Intensivierung der Mundspülungen, Spüllösungen mit Lokalanästhetikaanteil (Stomatitislösung), evtl. Gabe von Antimykotika

- Schmerzlinderung lokal, z. B., mit Dynexan ${ }^{\circledR}-G e l$, Anästhesin ${ }^{\circledR}-$ Lutschtabletten oder Xylocain Gel viskös ${ }^{\circledR}$ (Vorsicht: Gefahr von Verschlucken)

- $\quad$ systemische Schmerztherapie nach ärztlicher Anordnung

- notfalls parenterale Ernährung und i.v.-Gabe von Schmerzmitteln

Wichtig ist die kontinuierliche Unterstützung und Motivation des Patienten, trotz vielleicht ausbleibenden Erfolgs weiterhin konsequente Mundpflege zu betreiben. Spätestens mit dem Wiederanstieg der Leukozyten tritt eine Besserung ein.

\subsection{2 Übelkeit und Erbrechen}

Übelkeit und Erbrechen gehören zu den Schutzreflexen des Menschen und sind ein natürlicher Mechanismus des Körpers, um sich vor Giftstoffen zu schützen. Übelkeit soll die Aufnahme von schädlichen Stoffen verhindern, Erbrechen die bereits aufgenommenen Stoffe entfernen. Diese Symptome können auch unabhängig voneinander auftreten.

Man unterscheidet beim chemotherapieinduzierten Erbrechen zwischen akutem (innerhalb von 24 Stunden nach Therapiebeginn), verzögertem (ein bis fünf Tage nach Therapiestart) und antizipatorischem Erbrechen (vor bzw. bei Therapiestart, erlernter Schutzreflex nach negativen Therapieerfahrungen), siehe auch Kapitel Supportive Therapie. Auch Strahlentherapie kann abhängig vom Bestrahlungsfeld zu Übelkeit und Erbrechen führen.

Diese Nebenwirkungen der Therapie werden von vielen Patienten gefürchtet, obwohl sie durch die deutlich verbesserten Antiemetika nicht mehr ein so großes Problem darstellen. Das Gefühl von Kontrollverlust, aber auch Scham und Ekel (teilweise auch bei Angehörigen und Pflegenden) sind oft schwer zu ertragen. Angehörigen, die ihre Fürsorge gerne durch das Mitbringen von Essen zeigen („Liebe geht durch den Magen"), wird diese Möglichkeit genommen.

Im Beratungsgespräch sollte man versuchen, diese belastende Situation anzusprechen und gemeinsam nach möglichen Unterstützungsmöglichkeiten zu suchen. Dabei ist wichtig, den Patienten zu verdeutlichen, dass die Medikamente, die sie prophylaktisch gegen Übelkeit und Erbrechen erhalten, regelmäßig nach Vorschrift eingenommen werden müssen, um Übelkeit möglichst erst gar nicht entstehen zu lassen. Außerdem sollte auf eine ausreichende Reservemedikation geachtet werden, besonders im ambulanten Bereich, denn eine optimale antiemetische Therapie verhindert schlechte Erfahrungen, Angst vor der nächsten Therapie und somit die Gefahr von antizipatorischer Übelkeit. 
Zusätzlich zur medikamentösen Therapie können folgende Tipps empfohlen werden:

\section{Ernährung:}

- kleine, appetitlich angerichtete Mahlzeiten (v. a. keine großen Mahlzeiten unmittelbar vor und während der Chemotherapie, aber auch nicht nüchtern sein)

- langsam essen

- geruchsarme, lauwarme, trockene, leichte Speisen wie Zwieback, Knäckebrot, Toast, Kartoffeln (stark gewürzte, fettreiche und sehr süße Gerichte eher meiden)

- Saures wie z. B. Zitronenbonbons

- Ingwertee (wirkt antiemetisch)

Gerüche vermindern:

- gut lüften, eine hohe Raumtemperatur vermeiden

- Parfum/Zigarettenrauch vermeiden

- Vorsicht mit Blumen

Entspannungsmethoden:

- Atemtherapie, Fantasiereisen, Musiktherapie oder Aromatherapie Ablenkung:

- z. B. Musik hören, Fernsehen, Gespräche über andere Themen als Übelkeit

\subsubsection{Ernährungsprobleme}

Außer unter Übelkeit und Erbrechen leiden viele Patienten unter Appetitlosigkeit, verändertem Geschmacks- und Geruchsempfinden und Mundtrockenheit oder zähem Speichel. Dies führt häufig zu Gewichtsverlust, besonders, wenn Schluckstörungen oder Diarrhoen hinzukommen.

Es ist wichtig, dies zu erkennen, bevor ein massiver Gewichtsverlust bei den Patienten eintritt. Hierfür gibt es einige relativ einfache Screeningbögen (SGA (Subject Global Assessmant), MNA (Mini Nutritional Assessment), MUST (Malnutrition Universal Screening Tool), NRS 2002 (Nutritional Risk Screening), Innsbrucker Ernährungs-Score), die man z. B. beim Erstkontakt und im weiteren The- 
rapieverlauf einsetzen kann. Bei Auffälligkeiten sollte man, falls möglich, eine Ernährungsberatung hinzuzuziehen.

Ähnlich wie bei Übelkeit und Erbrechen können hier kleine Tipps hilfreich sein:

Appetitlosigkeit:

- viele kleine Mahlzeiten, kleine Portionen auf großen Tellern appetitlich anrichten, farbliche Kontraste setzen, schöne Tischdekoration

- immer essen, wenn Appetit vorhanden ist, d. h. ständiges Angebot durch gute Vorratshaltung mit Lieblingssnacks o. ä., kurze Zubereitungszeiten

- starke Essensgerüche vermeiden, evtl. geruchsarme Speisen (Nudeln, Reis oder Kaltes) bevorzugen

- alkoholischer Aperitif, falls ärztlich erlaubt, oder ein kleines Glas Obstoder Gemüsesaft vor dem Essen (z. B. Tomatensaft)

- Bitterstoffe wirken appetitanregend: Tonic Water, Grapefruitsaft (Vorsicht vor Medikamentenwechselwirkungen), Tees mit Bitterstoffen z. B. Wermutkraut, Galgantwurzel, Tausendgüldenkraut, Artischockenblätter, Schafgarbe, Enzianwurzel, Hopfenzapfen, Koriander, auch in Mischungen mit Kamille/Pfefferminze

- auch leichte Bewegung fördert den Appetit

- evtl. Ablenkung beim Essen

Geschmacksveränderungen:

Die Geschmacksschwelle für bitter ist oft herabgesetzt, die für süß erhöht, viele Patienten klagen über einen Geschmack nach Pappe oder einen metallischen Geschmack.

- bei fadem Geschmack mit Gewürzen, frischen Kräutern, Knoblauch oder Zwiebeln experimentieren

- bei metallischem Geschmack Kunststoffbesteck versuchen

- bei Abneigungen gegen Fleisch/Fisch süße Marinaden z. B. aus Obstsäften oder Sojasauce

- allgemein andere Zubereitungsarten ausprobieren und versuchen, neue Vorlieben zu entdecken

- unterschiedliche „Bisserlebnisse“ (flüssig, knackig, weich, körnig) als Ausgleich zum Geschmacksverlust anbieten

- motivieren, nicht so schnell aufzugeben 


\section{Mundtrockenbeit (Xerostomie):}

- gute Mundpflege

- ausreichende Flüssigkeitszufuhr, wasserhaltige Nahrungsmittel bevorzugen

- häufig, auch nur schluckweise, trinken; kalte Getränke halten die Mundschleimhaut länger feucht

- Bonbons und Kaugummi regen die Speicheldrüsen an, auch kleine Zitronen-, Kiwi- oder Ananasstückchen sind zum Lutschen geeignet, sofern die Säure vertragen wird

- Eiswürfel z. B. aus Tonic Water, Fruchtsaft, Joghurt, Kräuterteemischung wirken lindernd

- Getränke in ein Zerstäuberfläschchen füllen und in den Mund sprühen

- $\quad$ evtl. spezielles Mundspray (künstlicher Speichel) verschreiben lassen

\section{Zäher Speichel:}

- ausreichende Flüssigkeitszufuhr (1,5-2 l) verflüssigt Schleim; kohlensäurehaltige Getränke können beim Schleimlösen unterstützen und so auch das Geschmacksempfinden verbessern

- $\quad$ ein paar Tropfen Zitronensaft ins Getränk geben

- falls Milchprodukte einen schleimigen Film auf der Mundschleimhaut hinterlassen, den Mund hinterher spülen

- Lebensmittel meiden, die lange gekaut werden müssen (z. B. trockenes Brot)

- evtl. inhalieren

\section{Schluckstörungen:}

- breiige Kost ohne Einlagen (Pürierstab)

- Essen sollte cremig und gleitfähig sein: Zugabe von Milch, Sahne, Crème fraîche, Öl

- Puddingsuppen, feinmehliges Brot ohne Kruste mit streichfähigem Belag probieren, weich gegartes Gemüse, gegartes Obst ohne Schale, Hackfleisch, etc.

- $\quad$ evtl. Einsatz von Babynahrung

- Getränke ggf. andicken (Speisestärke, Verdickungsmittel aus der Apotheke, auf Amylaseresistenz achten)

- für Dysphagiepatienten gibt es auch spezielle Trinknahrungen und hochkalorischen Pudding 
Möglichkeiten zur Gewichtszunahme bzw. -stabilisierung:

a) Anreicherung der normalen Ernährung:

- Verzehr fettreicher Lebensmittel (doppelt so hohe Kaloriendichte im Vergleich zu Proteinen und Kohlenhydraten)

- Anreicherung von Suppen, Saucen und Milchspeisen mit Sahne, Butter, Eigelb, Crème fraîche

- griffbereite kleine Snacks zum Knabbern zwischendurch (z. B. Nüsse)

- bei Milchprodukten die hochprozentigen Sorten wählen

b) Einsatz von Nährstoffkonzentraten:

- Kohlenhydratkonzentrate, z. B. Maltodextrin von verschiedenen Anbietern. Ein Esslöffel enthält ca. $40 \mathrm{kcal}$ und kann ohne Auswirkungen auf Geschmack und Konsistenz in Getränke, Suppen oder Saucen gegeben werden.

- Fettemulsionen, z. B. Fresubin shot, Calogen, Liquigen. Diese Emulsionen sind mit 4,5-5 kcal/ml sehr energiereich und ihre Dosierung sollte in Rücksprache mit dem Arzt oder Diätassistenten festgelegt werden. Die neutralen Sorten können zum Anreichern von Speisen verwendet werden.

- Eiweißkonzentrate, z. B. Fresubin Protein Powder. Auch diese können in Speisen eingerührt werden und enthalten etwa $1 \mathrm{kcal}$ pro Milliliter der Zubereitung.

Nährstoffkonzentrate sind nicht verordnungsfähig!

c) Einsatz von Trinknahrung:

- Trinknahrung ist verordnungsfähig, wenn zur alleinigen Ernährung geeignet (vollbilanziert)

- Akzeptanz oft schwierig, daher nur kleine Portionen anbieten (anfangs $200 \mathrm{ml}$ in drei Portionen aufteilen), leicht gekühlt servieren oder als Anreicherung in normalen Speisen (neutrale Sorten)

- zwischen den Mahlzeiten trinken 


\subsubsection{Hautreaktionen}

\subsubsection{Hautreaktionen durch Chemotherapie}

Hautveränderungen unter Chemotherapie treten relativ häufig auf, sind aber meist harmlos und verschwinden in der Regel wieder, wenn auch oft erst nach längerer Zeit. Nicht vergessen sollte man aber den oft stigmatisierenden Effekt und die damit verbundene Beeinträchtigung der Lebensqualität.

Folgende Veränderungen können auftreten (3):

- Hyperpigmentation

- Erythem, Exantheme

- allergische Reaktionen

- Nagelveränderungen: durch Verlangsamung des Wachstums entstehen pigmentierte Linien, diffuse Pigmentflecken oder Vertiefungen. Auch Brüchigkeit, Ablösung des Nagelbettes und Verlust des Nagels (Oncholyse) sind möglich. Bei Nagelfalz- und Nagelbettentzündungen (Paronychie) helfen antiseptische Bäder oder Salben. Prophylaktisch sollte auf eine schonende Nagelpflege geachtet werden (kein Zurückschieben der Nagelhaut, Nägel kurz und gerade abschneiden und evtl. Schutzlack verwenden)

- Photosensibilisierung: direkte Sonneneinstrahlung meiden, bedeckende Kleidung bzw. Creme mit hohem Lichtschutzfaktor für exponierte Stellen wählen

- Hand-Fuß-Syndrom (palmoplantare Erythrodysästhesie): beginnt mit einer leichten Rötung der Haut, übergehend in ein meist schmerzhaftes Erythem mit Schwellung und anschließender Abschuppung der Haut. Uridinhaltige Salbe, kühle Kompressen und evtl. dünne Baumwollhandschuhe bzw. -söckchen können hilfreich sein, häufig sind auch Schmerzmittel erforderlich. Unbedingt mechanische Belastung vermeiden. Die mögliche Wirkung von antioxidantienhaltigen Salben wird noch untersucht.

- Xerose: eine zunehmende Hauttrockenheit, die oft mit juckenden Ekzemen einhergeht und zu Rhagaden an Fingerkuppen und Fersen führen kann.

- Fissuren/Rhagaden: die Vulnerabilität der Haut kann durch die Therapie stark erhöht sein. Entstandene Fissuren und Rhagaden sollten frühzeitig mit Dexpanthenol-Verbänden (über Nacht), tetracyclinhaltigen Salben o- 
der Hydrokolloidverbänden versorgt werden. Bei Bedarf können sie auch mithilfe von Cyanoacrylatkleber verschlossen werden.

\subsubsection{Hautreaktionen bei „targeted therapies“}

Diese moderneren Therapieansätze (Tyrosinkinaseinhibitoren bzw. Gabe von EGFR-Antikörpern) sind besonders häufig mit schweren kutanen Nebenwirkungen verbunden und können die Patienten in ihrer Lebensqualität stärker beeinträchtigen als die zugrunde liegende Tumorerkrankung.

\section{a) EGFR-Antikörper-induzierte Hautreaktionen}

Bekanntester Wirkstoff ist das Cetuximab. Die dadurch auftretenden Hautreaktionen weisen variable klinische Bilder auf, die zudem in einer zeitlichen Dynamik auftreten. In der frühen Phase (zweite bis dritte Therapiewoche) tritt häufig im Gesicht und am oberen Körperstamm ein akneiformes Exanthem auf, manchmal ist auch die Kopfhaut betroffen. In der späten Phase (nach vier oder mehr Therapiewochen) kann sich dann eine generalisierte Hauttrockenheit entwickeln (Xerosis, s. u.). Eine weitere Komplikation der späten Phase ist die Paronychie.

Evidenzbasierte Leitlinien zur Prophylaxe und Therapie dieser Hautreaktionen existieren bisher nicht, da es nur wenige Studienergebnisse gibt (Stand 2/2013). Der Hersteller von Cetuximab empfiehlt jedoch anhand der vorliegenden Ergebnisse, dem aktuellen Stand der Literatur sowie eigenen klinischen Erfahrungen seiner Autoren folgende Vorgehensweise: Zur Prophylaxe ab Behandlungsbeginn kann neben den unten folgenden allgemeinen Maßnahmen der Einsatz von oralen Tetrazyklinen erwogen werden, auch gibt es positive Erfahrungen mit Vitamin-K1haltiger Creme. Spätestens bei Auftreten von Hautreaktionen sollte mit oraler Antibiotika-Gabe begonnen werden, hinzu kommt die Behandlung mit lokalen Antibiotika (z. B. Erythromycin, Metronidazol), bei stärkeren Reaktionen auch lokale Kortikosteroide. Bei Befall der Kopfhaut sollte auch diese mitbehandelt werden. In der späten Phase empfiehlt sich die Verwendung von Duschölen und von harnstoffhaltigen Pflegeprodukten, bzw. Fettsalbe bei starker Hauttrockenheit. Beim Auftreten von Ekzemen können je nach Ausprägung schwache bis stärkere Glucocorticoid-Cremes eingesetzt werden. Leichte Paronychen können mit antiseptischen Bädern oder Salben behandelt werden (4).

b) Hautreaktionen bei Tyrosinkinasehemmern

Die Hautreaktionen ähneln denen der EGFR-Antikörper, sind aber meist nicht so stark ausgeprägt. Zusätzlich erwähnenswert ist die Veränderung der Gesichtsbehaarung (Tarceva $\left.{ }^{\circledR}\right)$, eine Gelbfärbung der Haut und mögliche Haarverfärbung bzw. Depigmentierung bei den Multikinase-Inhibitoren (z. B. Sutent ${ }^{\circledR}$, Votrient $\left.{ }^{\circledR}\right)$. 
11.2.4.3 Allgemeine Maßnahmen zur Prävention kutaner Nebenwirkungen

Reduktion von mechanischer Belastung:

- lockere Kleidung, nicht einengendes Schuhwerk

- Schutz von Händen und Füßen durch leichte Baumwollhandschuhe/ -söckchen

- hohe Druck- und Scherkräfte vermeiden (knien, wandern, applaudieren,...)

- Haut nicht trockenrubbeln, sondern tupfen

Reduktion von thermischer Belastung:

- nur lauwarm duschen

- nicht heiß föhnen

- Saunagänge meiden

Reduktion von chemischer Belastung:

- Verwendung rückfettender, pH-neutraler und parfümfreier Waschlotionen, sowie rückfettender, ureahaltiger Pflegeprodukte

- keine alkoholhaltigen Lotionen benutzen

- kein direkter Kontakt zu Putzmitteln etc.

- Reduktion der Sonnenexposition

\subsubsection{Fatigue}

Fatigue, die von Außenstehenden am meisten unterschätzte Nebenwirkung von Krebserkrankungen und -therapien, bedeutet übersetzt so viel wie „Müdigkeit“ oder „Mattigkeit“. Dieser Ausdruck bezeichnet in der medizinischen Fachsprache eine oft völlige körperliche und seelische Erschöpfung, die weit über ein normales $\mathrm{Maß}$ hinausgeht und in keinem Verhältnis zu den vorhergegangenen Aktivitäten steht. Das Ruhebedürfnis der Betroffenen ist massiv erhöht, sie haben keine Energiereserven mehr und auch ausreichend Schlaf schafft keine Linderung.

Schätzungen zufolge leiden zwischen 60-90\% aller Tumorpatienten zumindest zeitweise unter dieser Begleiterscheinung ihrer Erkrankung und Therapie; während und auch oft noch nach der Behandlung. Die Intensität der Betroffenheit hängt von der Art und Dauer der Krebsbehandlung sowie dem Alter des Patienten ab. Im Allgemeinen tritt eine Normalisierung spätestens drei Monate nach Therapieende ein, bei einigen Patienten bleibt das Krankheitsbild aber weiter bestehen und wird dann als ,chronische Fatigue“ bezeichnet. 


\section{Mögliche Ursachen:}

- die Tumorerkrankung selbst

- Folgen der Therapie (OP, Beeinträchtigung der Blutbildung durch Chemotherapie und Bestrahlung, Immuntherapie)

- Mangelernährung, Dehydration, Elektrolytverschiebungen (durch Übelkeit, Erbrechen, Appetitverlust, Durchfall, Tumorstoffwechsel)

- Hormonmangel (Schilddrüse, Nebennieren, Geschlechtshormone)

- Begleiterkrankungen, chronische Infekte und Organschäden

- $\quad$ psychische Faktoren (Angst, Stress, Depressionen)

- Schlafstörungen

- Schmerzen

- Nebenwirkungen von Medikamenten

- Muskelabbau durch Mangel an körperlichem Training

Symptome/Definition:

Laut WHO liegt Fatigue dann vor, wenn von folgenden Symptomen mindestens sechs auftreten:

- Müdigkeit/Energiemangel/erhöhtes Bedürfnis, sich auszuruhen

- Gefühl der Gliederschwere und allgemeiner Schwäche

- Schwierigkeiten bei der Bewältigung des Alltags

- besonders langanhaltende Erschöpfung/Unwohlsein nach Anstrengungen

- Konzentrationsstörungen

- Störungen des Kurzzeitgedächtnisses

- Gestörtes Schlafmuster (Schlaflosigkeit/übermäßiges Schlafbedürfnis)

- Empfinden des Schlafs als wenig erholsam

- Motivationsmangel, auch bei den normalen Alltagsaktivitäten

- Gefühl, sich zu jeder Aktivität zwingen zu müssen

- ausgeprägte emotionale Reaktion auf die empfundene Erschöpfung (Reizbarkeit, Frustration, Niedergeschlagenheit) 
Diese Symptome entwickeln und verstärken sich häufig in einem „Teufelskreis“:

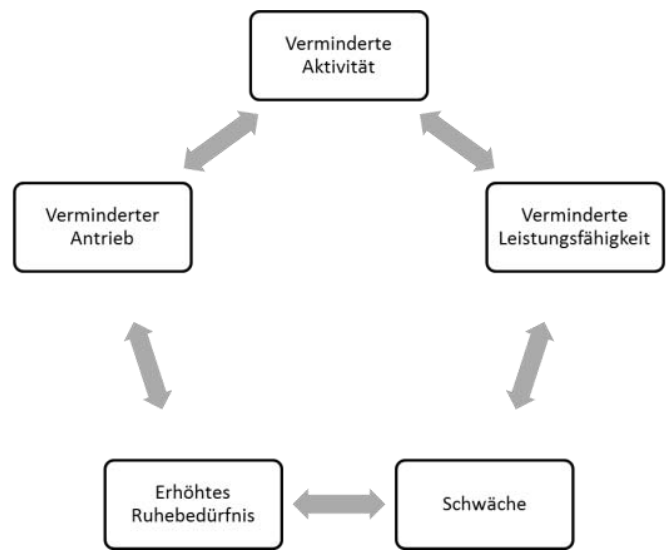

Zur Erfassung von Fatigue gibt es verschiedene Fragebögen. Dennoch gilt der Patient als „Experte seiner Müdigkeit“, da Müdigkeit ebenso wie Schmerz nicht oder nur schwer objektiv messbar ist. Aufgrund der Multikausalität der Erkrankung sollte die Einschätzung der Fatigue auf mehreren Ebenen erfolgen, und zwar auf der körperlichen („Leistungsfähigkeit“), der emotionalen („Niedergeschlagenheit, Antriebsschwäche“) und der mental-kognitiven („Konzentrationsschwierigkeiten"). Häufig wird auch die Frage nach der Dauer der Beschwerden einbezogen. Im Klinikalltag genügt aber meistens die Erfassung der Müdigkeit im Gespräch.

\section{Maßnabmen:}

Die vielen möglichen Ursachen der Fatigue bedingen auch eine möglichst multiprofessionelle Behandlung und Betreuung. Neben medikamentösen Maßnahmen, mit denen Ursachen wie Anämie, Vitamin- oder Hormonmangel und Schmerzen kontrolliert werden können, hat auch die physiotherapeutische, psychoonkologische und pflegerische Betreuung einen hohen Stellenwert. Vor allem die Beratung und Information zu Strategien im Umgang mit Fatigue ist wichtig für Betroffene und Angehörige, um den Teufelskreis an einer Stelle aufbrechen zu können.

Folgende Inhalte können dabei vermittelt werden:

\section{Energie- und kräftesparende Maßnahmen:}

Auch wenn man Energie nicht ansparen kann, sollte man sich seine Kräfte einteilen. Eine Unterforderung führt zum Abbau von Kraft, genau wie eine Überforderung zur völligen Erschöpfung führt. Das Führen eines Energietagebuchs kann Betroffenen helfen, ihre Situation immer wieder zu reflektieren und in kleinen 
Schritten zu verbessern. Dabei werden an jedem Tag die durchgeführten Tätigkeiten mit dem Energieaufwand und dem Erschöpfungszustand in Beziehung gebracht, um am nächsten Tag zu beurteilen, ob man sich über- oder unterfordert hat und wie man weiter vorgehen möchte (5).

Im Gespräch mit dem Patienten und den Angehörigen sollte man auch folgende mögliche Verhaltensänderungen ansprechen:

- Prioritäten setzen, Unwichtiges delegieren

- nicht zu viel auf einmal machen, Pausen einlegen

- Vereinfachungen von täglichen Verrichtungen

- wichtige Aktivitäten auf Tageszeiten legen, zu denen man sich leistungsfähiger fühlt

- Wechsel von Ruhe und Aktivität

Energieerbaltende Maßnahmen:

- erholsamer Schlaf

- nur kleine Nickerchen tagsüber

- ausgewogene Ernährung

ablenkende Aktivitäten/Krankheitsverarbeitung:

- Kraft und Zeit auch für Tätigkeiten einplanen, die Spaß machen und einen persönlichen Wert haben,

- Gespräche mit Familie/Freunden, evtl. in Selbsthilfegruppen oder mit professioneller Unterstützung

energiesteigernde Maßnabmen:

Hierzu gehört eine gute Ausgewogenheit zwischen Aktivität und Ruhe. Wie bereits vorgeschlagen, kann das Führen eines Energietagebuchs helfe, dies umzusetzen. Zusätzlich kann ein aufbauendes Ausdauertraining nach ärztlicher Rücksprache und unter physiotherapeutischer Anleitung erfolgen. Die Deutsche Fatigue Gesellschaft hat dazu eine Broschüre mit einem speziellen Trainingsprogramm für Patienten herausgegeben („Fitness trotz Fatigue“) (6). Laut Studien ist Aktivität die am besten belegte Strategie gegen Fatigue.

Fatigue im fortgeschrittenen Krankheitsstadium ist ein Bestandteil des Sterbeprozesses und sollte akzeptiert werden. In Übereinstimmung mit den Wünschen des Patienten könnte statt aktivierender Pflegemaßnahmen mehr die kompensierende Pflege in den Vordergrund rücken. Durch Übernahme von Tätigkeiten, die der Patient eigentlich (unter Anstrengung) noch selbst durchführen könnte, kann er diese Energie für andere, ihm wichtigere Dinge, nutzen. 


\subsection{Literatur}

(1) Bäumer R, Maiwald A. Thiemes onkologische Pflege. Thieme; Stuttgart 2008

(2) Wylegalla C, König P, Kirchhofer B, Uschok A, Saum G. Prävention und Management der oralen Mukositis. In: Forum Onkologische Pflege 3/2013, $48-60$

(3) Margulies A, Fellinger K, Kroner Th, Gaisser A. Onkologische Krankenpflege, 5. Auflage, Springer; Heidelberg 2010

(4) Gutzmer R, Wollenberg A, Ugurel S, Homey B, Ganser A, Kapp A. Kutane Nebenwirkungen von neuen medikamentösen Tumortherapien. Dt Ärzteblatt 109(8): 133-40

(5) Deutsche Krebshilfe. Die blauen Ratgeber: Fatigue Nr. 51 Stand 5/2011 http://www.krebshilfe.de/metanavigation/presse/archiv-meldungen/archivmeldungen-einzelansicht/browse/3/article/fatigue-chronische-muedigkeit-beikrebs/1167.html. Zugriff am: 28.09.2015

(6) Deutsche Fatigue Gesellschaft. Fitness trotz Fatigue.

http://www.deutsche-fatigue-

gesellschaft.de/oeffentlich/daten/fitness_trotz_fatigue.pdf. Zugriff am 28.09.2015

\section{Weitere Quellen:}

Reese A, Pech P. Tyrosinkinasehemmer zur oralen Tumortherapie, Fortbildungstelegramm Pharmazie 2013;7(4), S 127-144, www.uni-duesseldorf.de. Zugriff am: 04.07.2015

Sehouli J, Lichtenegger W. Update 2006/07 Innovative Therapien in der gynäkologischen Onkologie, adamos Wissenschaftsverlag; Hamburg 2006 



\section{Psychoonkologie}

Dipl.-Psych. Dipl.-Biol. Stefan Zettl

Schwerpunktpraxis für Psychoonkologie, 69126 Heidelberg

\subsection{Einleitung}

In den letzten Jahren hat sich ein schrittweiser Wandel in der Onkologie vollzogen. Er bewirkt eine reduzierte Mortalität mit vielfach verlängerten Überlebenszeiten: 80 \% der Patienten leben länger als vier Jahre nach der Diagnosestellung. Gleichzeitig hat sich das Spektrum von palliativmedizinischen Behandlungsmöglichkeiten vergrößert; es beinhaltet komplexe und lang andauernde multimodale Behandlungen, die in der Regel durch multiprofessionelle Behandlungsteams durchgeführt werden. Viele Patienten leben auch mit einer chronisch metastasierten Erkrankung bei zum Teil sehr guter Lebensqualität - aber sie werden auch mit neuen Herausforderungen für ihr Coping konfrontiert. Köhler (2015) äußerte dazu: „Medizinische Innovation rettet und verlängert Menschenleben. Aber sie sagt nicht, wie wir mit diesem geretteten Leben umgehen müssen." 
Die Entwicklung von Leitlinien in der Palliativmedizin (AWMF 2015) soll die Behandlung von Patienten mit einer nicht heilbaren Krebserkrankung und ihren Angehörigen verbessern, indem...

- die den Bedürfnissen der Betroffenen und ihren Angehörigen entsprechende palliativmedizinische Versorgungsstruktur rechtzeitig angeboten wird

- die Gespräche mit Patienten und Angehörigen angemessen geführt und die Therapieziele gemeinsam festgelegt werden

- häufige Symptome nach dem aktuellen Stand der Wissenschaft und der klinischen Expertise behandelt werden

- die Betreuung in der Sterbephase angemessen und optimal erfolgt

Psychoonkologische Aspekte spielen im Rahmen der interdisziplinären Behandlungskonzepte eine zentrale Rolle. Primäres Ziel ist es, die Lebensqualität von Menschen mit einer lebensbedrohenden Erkrankung und deren Angehörigen zu erhalten oder zu verbessern. Dies erfolgt durch psychosoziale Interventionen im physischen, psychischen, sozialen und spirituellen Bereich, die in den folgenden Abschnitten näher beschrieben werden. Dabei wird auch immer wieder Bezug auf die Leitlinienprogramme „Palliativmedizin für Patienten mit einer nicht heilbaren Krebserkrankung (2015)“ sowie das Leitlinienprogramm „Psychoonkologische Diagnostik, Beratung und Behandlung von erwachsenen Krebspatienten (2014)“ genommen.

\subsection{Der Sturz aus der Wirklichkeit}

Die Konfrontation mit einer unheilbaren Krebserkrankung löst bei den Betroffenen und ihren Angehörigen in besonderer Weise Angst und Verunsicherung aus. Gerdes (1984) spricht von einem "Sturz aus der Wirklichkeit", der durch die Befundmitteilung ausgelöst wird. 25-40 \% aller Krebspatienten benötigen professionelle psychoonkologische Unterstützung (Tschuschke 2005). Goleman (1997) bemerkt dazu kritisch: „Problematisch wird es, wenn das medizinische Personal sich zwar um den körperlichen Zustand des Patienten kümmert, aber über seine emotionalen Reaktionen binweggeht. Diese mangelnde Beachtung der emotionalen Realität lässt die wachsende wissenschaftliche Erkenntnis außer Acht, dass die emotionalen Zustände sowobl für die Krankheitsanfälligkeit als auch für die Genesung von erbeblicher Bedeutung sein können" (S. 210 f.). 


\subsection{Der Verlust von Kontrolle}

Menschen haben lebenslang das Bedürfnis, über sich und ihr Leben selbst entscheiden zu können, „die Kontrolle zи haben. "Erfahrungen wie der Verlust von nahen Angehörigen durch Scheidung oder Tod, der Verlust des Arbeitsplatzes usw. sind deshalb mit Angst verbunden. Auch die Konfrontation mit einer unheilbaren Erkrankung stellt einen solchen Kontrollverlust dar, wie es ein Patient beschreibt: „Ich hatte das Gefühl, dass mir keiner konkret sagen kann oder will, wie die konkreten Zukunftsperspektiven in meinem Fall aussehen. Ich war zum ersten Mal gezwungen, mich mit der Tatsache auseinander zu setzen, dass es etwas in meinem Leben gab, das ich nicht unter Kontrolle hatte. Diese Erkenntnis löste Angst und Unsicherheit in mir aus. "

Die Vermittlung von möglichst vielen Entscheidungs- und Handlungsmöglichkeiten im Rahmen der medizinischen Behandlung („Patient Empowerment “), stellt daher einen wichtigen Ansatz zur Reduzierung krankheitsbezogener Ängste dar.

\subsection{Befundmitteilung}

Das Überbringen schlechter Nachrichten stellt für den behandelnden Arzt bei aller Routine immer wieder eine neue Herausforderung dar. Die Schwierigkeiten bei der Befundmitteilung haben in den letzten Jahren zu einer Vielzahl von Versuchen geführt, durch Verhaltensanweisungen und Trainings mehr professionelle Kompetenz zu entwickeln. Beispielhaft für diese Ansätze steht das SPIKES-Protokoll (Baile et al. 2000), das den Aufklärungsprozess in sechs Abschnitte untergliedert und ein stufenweises Vorgehen empfiehlt:

\begin{tabular}{|c|c|c|}
\hline & Setting & $\begin{array}{l}\text { einen ruhigen, ungestörten Gesprächsrahmen gestal- } \\
\text { ten }\end{array}$ \\
\hline & Perception & Kenntnisstand des Patienten erfragen \\
\hline & Invitation & $\begin{array}{l}\text { Einladung durch den Patienten zur Aufklärung und } \\
\text { Informationsweitergabe einholen }\end{array}$ \\
\hline & Knowledge & Wissensvermittlung \\
\hline & $\begin{array}{l}\text { Exploration } \\
\text { of Emotions }\end{array}$ & Emotionen ansprechen und mit Empathie reagieren \\
\hline & $\begin{array}{l}\text { Strategy } \\
\text { and Summary }\end{array}$ & $\begin{array}{l}\text { Entwicklung eines Behandlungsplans und Zusam- } \\
\text { menfassung }\end{array}$ \\
\hline
\end{tabular}


Antrainierte gesprächstechnische Verhaltensregeln (z. B. „Stay with the feelings!" geben zu Beginn mehr Sicherheit, werden allerdings den existenziellen Erfordernissen einer Aufklärungssituation - gerade in der Palliativmedizin - nur bedingt gerecht. Gottschlich (2007) äußert dazu kritisch: „So als würden ein paar bingeworfene freundliche Phrasen schon den Anspruch gelingender Arzt-Patient-Kommunikation erfilllen. Damit wird das eigentliche Problem einer gestörten Arzt-Patienten-Beziehung auf unzulässige Weise banalisiert. ... Kommunikation, die sich mehr an vorgefertigten Regeln als am anderen und der mit ihm geteilten Situation orientiert, wird ibrem eigentlichen Anspruch nicht gerecht" (S. 66 f.).

\subsection{Reaktionen auf die Aufklärung}

Nur wenige Patienten wirken in der Aufklärungssituation vollkommen aufgewühlt und verzweifelt. Die Diagnosemitteilung löst bei vielen zunächst zu einen schockartigen Zustand aus, der von einer mehr oder weniger ausgeprägten Abwehr der begleitenden Emotionen gekennzeichnet ist (,freezing "). Dadurch werden aber auch die kognitiven Fähigkeiten mehr oder weniger eingeschränkt, d. h. darauf folgende Informationen werden möglicherweise nur noch eingeschränkt oder gar nicht mehr aufgenommen und verarbeitet. Nachbefragungen nach Diagnosemitteilung zeigen, dass deren Inhalte von vielen Patienten entweder nur teilweise oder gar nicht wahrgenommen oder verfälscht erinnert werden. So nahmen in einer Befragung von Patienten mit metastasiertem, nicht-kleinzelligem Bronchialkarzinom zu Behandlungsbeginn $32 \%$ der Befragten an, dass die Krebserkrankung heilbar sei. $69 \%$ gingen davon aus, dass die Krankheitssymptome durch die Therapie völlig beseitigt werden können (Temel 2011). Bei diesem unzutreffenden Informationsstand können die Betroffenen keine bewussten und verantwortlichen Entscheidungen treffen.

Es erscheint daher sinnvoll, neben einer schrittweisen und wiederholten Aufklärung wenn möglich einen Familienangehörigen oder eine andere Person des Vertrauens in das Gespräch mit einzubeziehen („Vier Ohren bören mehr als zwei" Die Schockstarre kann sich im weiteren Verlauf verändern und z. B. in Verzweiflung und Suizidgedanken umschlagen. Die Art der Reaktion hängt von der jeweiligen Diagnose, der Persönlichkeit, den Krankheitsvorerfahrungen und der aktuellen Lebenssituation $\mathrm{ab}$.

\subsection{Angst}

Die Konfrontation mit einer schwerwiegenden und unheilbaren Erkrankung löst bei den Betroffenen und deren Angehörigen in der Regel heftige Ängste aus gleichgültig, ob es im Einzelfall aus medizinischer Sicht angezeigt erscheint oder nicht. 12-30 \% der Krebspatienten entwickeln deshalb Angstsymptome in einem klinisch relevanten Ausmaß, bis zu $40 \%$ weisen klinisch relevante depressive 
Symptome auf (Angenendt et al. 2007). Dies gilt insbesondere bei einem Fortschreiten der Erkrankung und einer palliativen Behandlungssituation. Das Ausmaß an Angst ist allerdings unterschiedlich ausgeprägt. Dabei spielen lebensgeschichtliche Erfahrungen, Vorerfahrungen mit Krankheiten und die aktuelle Lebenssituation eine bedeutsame Rolle.

Neben der Panikstörung (ICD-10 F 41.0) werden generalisierte Angststörungen (ICD-10 F 41.1) sowie Angst und depressive Störung (ICD-10 F 41.2) beobachtet; diese können jedoch auch schon prämorbid bestanden haben. Am häufigsten treten Reaktionen auf schwere Belastungen und Anpassungsstörungen (ICD-10 F 43) auf. Stehen die Angstsymptome in direktem zeitlichem Zusammenhang mit organischen Ursachenfaktoren mit Auswirkungen auf das zentralen Nervensystem (z. B. ZNS-Tumoren) oder auch unerwünschten Nebenwirkungen von Medikamenten, handelt es sich differentialdiagnostisch um eine organisch bedingte Angststörung (ICD-10 F 06.4). Diese Störung bildet sich in der Regel nach Behandlung der zugrunde liegenden organischen Ursache zurück.

\subsection{Angstinhalte}

Unheilbare Erkrankungen bedrohen das seelische Gleichgewicht und lösen eine Vielzahl von Ängsten aus, die ausgehalten und verarbeitet werden müssen. Betroffene berichten über Ängste vor

- den fehlenden kurativen Behandlungsmöglichkeiten

- mit der Krankheit und Behandlung verbundenen Empfindungen von Hilflosigkeit und Kontrollverlust

- Abhängigkeit und Gefühlen des Ausgeliefert-Seins

- belastenden diagnostischen und therapeutischen Eingriffen und möglichen Nebenwirkungen

- qualvollen Schmerzen

- vorübergehenden, bleibenden oder zunehmenden Verlusten von Körperfunktionen, z. B. motorischen Einschränkungen

- vorübergehenden oder bleibenden Körperbildveränderungen, z. B. verstümmelnde operative Eingriffe

- negativen Auswirkungen auf Partnerschaft und Familie

- vorübergehender Einschränkung oder dauerhaftem Verlust der Arbeitsfähigkeit

- finanziellen Belastungen, sozialer Ausgrenzung

- Sterben und Tod 
Vorerfahrungen in der Familie oder im näheren Freundeskreis beeinflussen Inhalte und das Ausmaß der Ängste. Ebenso färben eigene vorhergehende Krankheitserfahrungen die Hoffnungen und Befürchtungen in der aktuellen Situation ein: So hofft der Patient z. B. entweder auf eine gute ärztliche und pflegerische Betreuung oder er ist bereits voller Angst oder Misstrauen. Ebenso wird die bewusst empfundene Angst durch mögliche (Fehl-)Informationen und Vorurteile über die eigene Erkrankung verstärkt (z. B. „Wabrscheinlich habe ich nur noch ein paar Wochen, aber es sagt mir keiner!" $)$. In gleicher Weise können dramatisierende Schilderungen von Mitpatienten oder dem sozialen Umfeld Ängste auslösen. Die Ängste werden dabei in der Regel nicht ununterbrochen wahrgenommen, aber in Form von wiederkehrenden und sich nahezu zwanghaft aufdrängenden Gedanken (Intrusionen).

\section{8 „Angst essen Seele auf“}

Der Titel des gleichnamigen Films von Rainer Werner Fassbinder aus dem Jahr 1974 beschreibt die destruktive Wirkung überschießender oder chronifizierter Ängste. Ab wann das Ausmaß an Angst als ,nicht mehr angemessen“ oder „dysfunktional" bewertet werden kann, hängt vom jeweiligen Einzelfall und dem subjektiven Erleben des Patienten ab - es gibt keine klare Grenze zwischen „normal" und „anormal“. Eine Reihe von Risikofaktoren kann allerdings die Entwicklung überschießender Ängste erschweren:

Krankheitsbezogene Faktoren

- schwerwiegende körperliche Symptome, z. B. zunehmende Atemnot

- nebenwirkungsreiche Therapieverfahren

- unzureichende somatische Behandlungsmöglichkeiten, z. B. bei Tumorschmerzen

- Fatigue

Komorbidität

- seelische Erkrankungen, z. B. Panikstörung, Agoraphobie, Depression

- regelmäßige Einnahme von Psychopharmaka

- Alkohol- und/oder Medikamentenabusus

- körperliche Begleiterkrankungen, z. B. kann eine Hyperthyreose Panikattacken auslösen

- Nebenwirkungen von Medikamenten, z. B. Kortikosteroide, L-Thyroxin 
Soziale Situation

- Beziehungskonflikte

- familiäre Auseinandersetzungen

- wirtschaftliche Probleme, z. B. Arbeitslosigkeit, Armut

- soziale Isolation

Es sind aber nicht nur die Patienten, sondern auch deren Partner und Familien, die durch die Diagnosemitteilung in Angst versetzt werden. So weist in Studien fast die Hälfte aller Partner von Krebspatienten erhöhte Angstwerte auf (Bergelt et al. 2009). Im Rahmen der Behandlungsplanung sollten Ängste frühestmöglich identifiziert und Möglichkeiten einer Prävention oder Therapie mit eingeplant werden.

\section{9 Überhaupt keine Angst?}

Manche Patienten berichten darüber, dass sie trotz Voranschreiten der Erkrankung kaum oder überhaupt keine Angst spüren. Ein Patient schildert dieses Erleben mit den Worten: „Ich weiß, dass sich mein Aræt Zeit genommen hat, um mir das Rezidiv und die notwendige Behandlung ausführlich zu erklären. Aber irgendetwas verschloss sich in mir. Ich habe ihm zwar zugehört, aber irgendwie drangen seine Worte zu mir nicht durch. Gespürt habe ich überhaupt nichts. "

Diese „Gefühllosigkeit“ ist in den meisten Fällen auf den Einsatz seelischer Abwehrmechanismen zurückzuführen, die eine Überflutung des Ichs durch Ängste verhindern sollen. Dies geschieht automatisiert und unterliegt nicht der Kontrolle des Bewusstseins. In manchen Fällen steht dann nicht das bewusste Erleben von Angst im Vordergrund, sondern es werden eher körperliche Beschwerden wie motorische Unruhe, Beklemmungsgefühle, Herzrasen, Schwitzen oder Einschlafund Durchschlafstörungen geschildert. Die Angst wird in diesen Fällen also nur körperlich erfahren. Die relative Angstfreiheit kann aber auch Ausdruck einer gelungenen Auseinandersetzung mit der eigenen Erkrankung und dem bevorstehenden Sterbeprozess sein.

Auch bei präfinalen Patienten können solche Abwehrmechanismen wirksam werden und die realistische Wahrnehmung der Situation bis zum letzten Moment behindern. Ziel dabei ist immer der Schutz vor einer Angstüberflutung. Es ist wichtig, diese schützende Funktion der Abwehrmechanismen zu sehen und nicht in bester Absicht zu versuchen, den Patienten mit der Realität zu konfrontieren. Jeder Patient benötigt sein eigenes Tempo, um sich seiner Krankheitsrealität innerlich anzunähern. 


\subsection{Diagnostik und Behandlung der Angst}

Angstsymptome können durch ein Screeningverfahren (z. B. Hospital Anxiety and Depression Scale HADS-D, Patient Health Questionnaire PHQ-D) erfasst werden. Sie ersetzen jedoch nicht das persönliche Gespräch zwischen Arzt und Patient. Da sich die Befindlichkeit eines Patienten im Verlauf einer Krebserkrankung und deren Behandlung immer wieder verändern kann, sollte diese Diagnostik in regelmäBigen Abständen erfolgen.

Die Behandlung von überschießenden Ängsten kann sowohl mit psychotherapeutischen Ansätzen als auch medikamentös erfolgen. Als niedrigschwellige Intervention sind Entspannungs- und achtsamkeitsbasierte Verfahren (z. B. Carlson u. Speca 2013) geeignet, die es dem Patienten ermöglichen, die aufkeimenden Affekte selbst zu regulieren. Bei der nicht-medikamentösen Behandlung von Angstsymptomen können sowohl verhaltenstherapeutische als auch tiefenpsychologisch fundierte Verfahren eingesetzt werden.

Bei einer medikamentösen Anxiolyse stehen sowohl schnell wirksame Benzodiazepine (z. B. Lorazepam) als auch Antidepressiva (z. B. Mirtazapin ${ }^{\circledR}, C i-$ talopram $\AA$, Escitalopram ${ }^{\circledR}$ oder Venlafaxin $\AA$ zur Verfügung. Bei den Benzodiazepinen ist auf das Abhängigkeitspotential zu achten, eine Behandlungsdauer über mehr als 14 Tage ist zu vermeiden. Bei weit fortgeschrittener Erkrankung, z. B. bei angstgetriggerter Hyperventilation oder akuter Dyspnoe, treten diese Überlegungen allerdings in den Hintergrund, da es um einen schnellen Wirkungseintritt in einer für den Patienten bedrohlichen Situation geht. Für einen längerfristigen Einsatz erscheinen Antidepressiva eher geeignet, die anxiolytische Wirkung setzt allerdings häufig erst verzögert nach einer Stimmungsaufhellung ein. Im Bedarfsfall sollte deswegen zu Behandlungsbeginn ein Benzodiazepinpräparat zum Einsatz kommen.

\subsection{Depression}

Die Entwicklung einer vorübergehenden depressiv getönten Stimmungslage oder von Trauergefühlen im Kontext einer schwerwiegenden körperlichen Erkrankung stellt eine normale und angemessene menschliche Reaktion auf das Geschehen dar. Darin ist aber auch einer der Hauptgründe dafür zu sehen, dass depressiven Störungen bei Krebspatienten häufig nicht erkannt und adäquat behandelt werden.

Wenn es sich nicht mehr um vorübergehende Gefühlsschwankungen handelt, die Lebensqualität durch depressive Symptome erheblich beeinträchtigt wird und z. B. die Adhärenz bedroht wird, spricht man von einer depressiven Störung. Die Symptomatik ist weit gefächert und zeigt sich in Elementen wie depressiver Grundstimmung mit Freudlosigkeit und psychischer Einengung, Antriebsminderung bis hin zur Apathie (häufiges „Morgentief“"), Hemmung von Denken und Wollen und somatischen Beschwerden (z. B. Einschlaf- und Durchschlafstörungen). 
Depressive Symptome entsprechend ICD-10 (F 32) treten bei Krebspatienten in Deutschland durchschnittlich bei 6,0\% (adjustierte Punktprävalenz für deutsche Studien; international 8,2 \%) auf. Je nach Schweregrad werden leichte (F 32.0), mittelgradige (F 32.1) und schwere depressive Episoden ohne (F 32.2) und mit psychotischen Symptomen (F 32.3) unterschieden. Auch hier kann die depressive Episode bereits prämorbid bestanden haben. Wird das Vorliegen einer Depression vermutet, orientiert sich die klinische Diagnose an der Schwere, der Dauer der depressiven Symptome und dem Grad der Beeinträchtigung entsprechend den Kriterien der ICD-10. Weitere differentialdiagnostische Hinweise ergeben sich z. B. durch die Art, wie sich der Patient mitteilt, nonverbalen Signalen wie Körperhaltung, Gestik und Mimik. Je mehr die affektive Kommunikation beeinträchtigt und je weniger der Patient im Gespräch erreichbar erscheint und je mehr der Untersucher selbst Gefühle einer lähmenden Schwere und Hilflosigkeit erlebt, umso schwerer ist die depressive Episode einzuordnen.

Hoffnungslosigkeit und Antriebshemmung sind auch dafür verantwortlich, dass viele Patienten von sich aus nicht ihr subjektives Erleben schildern. Depressive Symptome müssen daher aktiv erfragt und/oder durch ein Screeningverfahren (z. B. Hospital Anxiety and Depression Scale HADS-D, Patient Health Questionnaire PHQ-D) erfasst werden. Manchmal wird auch die Erhebung einer Fremdanamnese erforderlich. Da sich die Befindlichkeit eines Patienten im Verlauf einer Krebserkrankung und deren Behandlung immer wieder verändert, sollte diese Diagnostik in regelmäßigen Abständen wiederholt werden.

Eine Depression geht mit einer erhöhten Suizidalität einher. Im Vergleich zur Allgemeinbevölkerung ist die Suizidrate bei Krebspatienten um das Zweifache erhöht (Anguiano et al. 2012). Die S3-Leitlinie „Psychoonkologische Diagnostik, Beratung und Behandlung von erwachsenen Krebspatienten (2014)“ führt anhand von 33 ausgewerteten Studien zur Suizidalität bei meist fortgeschritten an Krebs erkrankten Patienten an, dass bei durchschnittlich 14,7 \% der Patienten Suizidgedanken auftraten (Spannweite 0,8-32,6 \%). Die Häufigkeit von Suizidversuchen lag bei durchschnittlich 5,6 \% (Spannweite 0-22,6 \%). Im Vergleich zu Frauen haben an Krebs erkrankte Männer ein 6,2-fach erhöhtes Risiko für einen Suizid (Pessin et al. 2012). Das Vorliegen von Suizidphantasien ist jedoch nicht immer ein Hinweis auf eine akut bestehende Suizidalität, sondern häufig Ausdruck des Wunsches nach einer Kontrolle in einer bedrohlich erlebten Situation („Ich muss nicht alles aushalten! ‘).

Mögliche Selbsttötungsgedanken oder konkrete -pläne müssen einfühlsam und respektvoll erfragt werden, da sich der Betroffene sonst eher verschließt. Die Leitlinie „Palliativmedizin für Patienten mit einer nicht heilbaren Krebserkrankung (2015)“ schlägt dazu folgende Fragen vor: 
- „Haben Sie in letzter Zeit daran denken müssen, nicht mehr leben zu wollen?"“

- „Häufig?“

- „Haben Sie auch daran denken müssen, ohne es zu wollen?

D. h. mit anderen Worten:

Haben sich Suizidgedanken aufgedrängt?“

- „Konnten Sie diese Gedanken beiseiteschieben?“

- „Haben Sie konkrete Ideen, wie Sie es tun würden?“

- „Haben Sie Vorbereitungen getroffen?“

- „Umgekehrt: Gibt es etwas, was Sie davon abhält?“

- „Haben Sie schon mit jemandem über Ihre Suizidgedanken gesprochen?“

- „Haben Sie jemals einen Suizidversuch unternommen?“

- „Hat sich in Ihrer Familie oder Ihrem Freundes- und Bekanntenkreis schon jemand das Leben genommen?" (S. 115)

Bei der Dysthymie (ICD-10 F 34.1) handelt es sich um eine chronisch (mindestens zwei Jahre) verlaufende depressive Verstimmung, die nach Schweregrad und Dauer der einzelnen Episoden nicht die Kriterien für eine leichte oder mittelgradige rezidivierende depressive Störung erfüllt. Die Dysthymie weist bei Krebspatienten eine durchschnittliche Punktprävalenz von 10,8 \% auf.

Von einer depressiven Episode ist die Anpassungsstörung (ICD-10 F 43.2) abzugrenzen. Bei ihr ist der depressive Zustand weniger stark ausgeprägt und nur vorübergehend - in der Regel hält er nicht länger als einen Monat an. Bei den Anpassungsstörungen erfüllt die depressive Verstimmung die Kriterien für eine leichte oder mittelgradige depressive Episode nie oder nur sehr selten.

Stehen die depressiven Symptome in direktem zeitlichem Zusammenhang mit organischen Ursachenfaktoren mit Auswirkungen auf das zentrale Nervensystem (z. B. ZNS-Tumore, Hyperkalzämie, Hypothyreose) oder auch unerwünschten Nebenwirkungen von Medikamenten, handelt es sich differentialdiagnostisch um eine organisch bedingte depressive Störung (ICD-10 F 06.3). Diese Störung bildet sich in der Regel nach Behandlung der zugrunde liegenden organischen Ursache zurück. Von einer depressiven Störung sind weiterhin das Fatigue, das hypoaktive Delir, die Demenz und das Parkinsonoid differenzialdiagnostisch abzugrenzen.

Die wichtigsten Risikofaktoren für die Entstehung einer Depression im Kontext einer palliativmedizinischen Behandlung sind Depressionen in der Eigen- oder Familienanamnese, gleichzeitig bestehende Belastungen (z. B. Arbeitslosigkeit), fehlende soziale Unterstützung, jüngeres Alter, schlechte Symptomkontrolle (ins- 
bes. Fatigue, Tumorschmerzen), schlechter körperlicher Funktionsstatus und körperliche Beeinträchtigungen.

Wenn sich ein erhöhtes Risiko zur Entwicklung einer Depression abzeichnet oder bereits depressive Symptome ausgebildet haben, sind ein Facharzt für Psychiatrie und Psychotherapie, ein Facharzt für Psychosomatische Medizin und Psychotherapie und/oder ein psychologischer/ärztlicher Psychotherapeut hinzuzuziehen. Es stehen grundsätzlich vier Behandlungsstrategien zur Verfügung, die sich u. a. an den Schweregraden orientieren:

- aktiv-abwartende Begleitung

- medikamentöse Behandlung

- psychotherapeutische Behandlung

- Kombinationstherapie

Entsprechend den S3-Leitlinien zur Behandlung der unipolaren Depression (AWMF 2012) sollten Antidepressiva nicht generell zur Erstbehandlung bei leichten depressiven Episoden eingesetzt werden, sondern allenfalls unter besonders kritischer Abwägung des Nutzen-Risiko-Verhältnisses. Zur Behandlung akuter leichter bis mittelschwerer depressiver Episoden wird eine Psychotherapie angeboten. Zur Behandlung einer akuten mittelgradigen depressiven Episode wird eine medikamentöse Therapie (Antidepressivum) empfohlen. Bei akuten schweren depressiven Episoden soll eine Kombinationsbehandlung mit medikamentöser Therapie und Psychotherapie angeboten werden. Bei der nicht-medikamentösen Behandlung von Depressionen werden verhaltenstherapeutische oder tiefenpsychologisch fundierte Verfahren eingesetzt. Ergänzend können andere Verfahren (z. B. Kreativtherapien, Achtsamkeitsbasierte Verfahren) angewendet werden. Eine Behandlung der Depression bei Patienten mit einer nicht heilbaren Krebserkrankung soll auch bei kurzer Lebensprognose von wenigen Wochen erfolgen. In der Sterbephase soll die Therapie mit Antidepressiva beendet werden.

\subsection{Holding Function}

Krankheitsbezogene Ängste und depressive Symptome im Kontext einer Krebserkrankung lösen häufig den regressiv getönten Wunsch nach der konkreten Präsenz und Steuerung durch eine haltgebende Person (,,holding function ") aus: „W Was ist bloß mit den Ärzten los? W arum begreifen sie nicht die Bedeutung ibrer schieren Gegenwart? Warum können sie nicht erkennen, dass gerade der Augenblick, in dem sie sonst nichts mehr zu bieten haben, der Augenblick ist, in dem man sie am nötigsten hat?" (Yalom 2000, S. 31). Die Behandelnden können Patienten und Angehörige dabei unterstützen, die unausweichlich auftauchenden bedrohlichen Gefühle von Angst, Ohnmacht und Kon- 
trollverlust auszuhalten und mit ihnen in einer adäquaten Weise umzugehen (z. B. nicht zu flüchten, oder eine notwendige und medizinisch sinnvoll erscheinende Behandlung zu verweigern usw.). Die damit verbundene Förderung von Selbstwirksamkeit beeinflusst ganz entscheidend, ob und wie sich eine Person einer Herausforderung bzw. einer schwierigen Aufgabe stellt - dies gilt erst recht in der Palliativsituation.

\subsection{Auseinandersetzung mit Sterben und Tod}

In unserer Kultur existieren kaum positiv getönte Bilder von Sterben und Tod; im Alltag denken die meisten Menschen kaum darüber nach, dass sie einmal sterben werden. „Der moderne Mensch redet nicht gerne über das Sterben. ... Wir sagen zwar, dass es neulich auf irgendeiner Veranstaltung sterbenslangweilig war. Am Abend davor haben wir uns noch totgelacht. Und wenn es um extensives Feiern, Arbeiten oder Durchbalten geht, sind viele absolut nicht totzukriegen. Vor allem aber ist unsere Gesellschaft nicht totzukriegen darin, so ₹u tun, als gäbe es für immer ein Morgen " (zu Salm 2013, S. 9). Dazu trägt bei, dass Patienten heute häufig nicht mehr zu Hause, sondern in Institutionen wie Krankenhäusern, Heimen oder Hospizen sterben. Bestatter versorgen den Leichnam, der unmittelbare Kontakt mit dem Toten ist oft nicht mehr möglich. Friedhöfe liegen nicht mehr mitten im Ort, sondern weit außerhalb. Dadurch werden aber Sterben und Tod für den Einzelnen immer weniger „begreifbar“ und es verstärkt sich die Furcht vor dem unausweichlichen Ende des Lebens (Yalom 2008).

Für viele Patienten wird dies aber durch ihre Erkrankung unausweichliche psychische Realität - unabhängig von der jeweiligen spezifischen Erkrankung, deren Behandlungsmöglichkeiten und zeitlichen Prognose. Ein möglichst offener Umgang mit den Themen Sterben und Tod erscheint daher in der Palliativsituation besonders notwendig. Umfassende Hilfestellungen zur Gesprächsführung finden sich bei Yalom (2008).

Ein positiver Zugang zur Religiosität kann ebenso die Auseinandersetzung mit der eigenen Sterblichkeit erleichtern. Die Zugehörigkeit zu einer Glaubensgemeinschaft fördert soziale Unterstützung; Religiosität (Glauben) vermag Sinnorientierung, positives Selbstwertgefühl, internale Kontrollüberzeugungen, Optimismus, Dankbarkeit und Vergebungsbereitschaft zu fördern (Grom 2007). Durch diese Pufferwirkung werden auch Depressivität und Ängstlichkeit reduziert sowie die Lebensqualität verbessert. Zur palliativmedizinischen Teamarbeit gehört deshalb auch die Zusammenarbeit mit Klinikseelsorgern und anderen kirchlichen Mitarbeitern. 


\subsection{Spiritualität und Sinnsuche}

Sinnsuche und Spiritualität beinhalten die Frage nach der Sinnhaftigkeit des eigenen Lebens oder der aktuellen Lebenssituation. Von Nietzsche ist der Satz überliefert: „Wer ein Wofür im Leben hat, der kann fast jedes Wie ertragen. "Und der Psychologe Viktor Frankl (1992) äußerte im Zusammenhang mit seinen Erfahrungen im Konzentrationslager ,... eröffnet sich auch noch in den schwierigsten Situationen und noch bis zur letaten Minute des Lebens eine Fülle von Möglichkeiten, das Leben sinnvoll zu gestalten " (S. 110). Das Erfassen spiritueller Bedürfnisse und Ressourcen und sinnbasierte Interventionen stellen daher einen weiteren Aspekt psychoonkologischer Interventionen dar. Einen Gesprächsleitfaden bietet das SPIR-Modell von Frick (2009). Es umfasst Fragen zu

- $\quad$ spirituellen und Glaubensüberzeugungen (S)

- Platz und Einfluss, den diese Überzeugungen im Leben des Patienten einnehmen $(\mathrm{P})$

- seiner Integration in eine spirituelle, religiöse oder kirchliche Gemeinschaft (I)

- der Rolle des Arztes/der Pflegenden: Wie sollen sie mit den spirituellen Bedürfnisse und Ressourcen des Patienten umgehen? (R)

Beispielhafte Fragen zu spirituellen und Glaubensüberzeugungen (S)

- Würden Sie sich im weitesten Sinne als gläubigen (religiösen/spirituellen) Menschen betrachten?

- In wen oder was setzen Sie Ihre Hoffnung?

- Woraus schöpfen Sie Kraft?

- Gibt es etwas, das Ihrem Leben einen Sinn verleiht?

- Welche Glaubensüberzeugungen sind für Sie wichtig? 
Beispielhafte Fragen zu Platz und Einfluss spiritueller Überzeugungen (P)

- Sind die Überzeugungen, von denen Sie gesprochen haben, wichtig für Ihr Leben und Ihre gegenwärtige Situation?

- Welchen Einfluss haben diese Überzeugungen darauf, wie Sie mit sich selbst umgehen und in welchem Maß Sie auf Ihre Gesundheit achten?

- Wie haben Ihre spirituellen und Glaubensüberzeugungen Ihr Verhalten während dieser Erkrankung beeinflusst?

- Welche Rolle spielen Ihre Überzeugungen dabei, dass Sie wieder gesund werden?

Beispielhafte Fragen zu spirituellen und/oder religiösen Gruppen (I)

- Gehören Sie zu einer spirituellen oder religiösen Gemeinschaft?

- Bedeutet dies seine Unterstützung für Sie?

- Gibt es eine Person oder eine Gruppe von Menschen, die Ihnen wirklich viel bedeuten und die wichtig für Sie sind?

Beispielhafte Fragen zur Rolle des Arztes/Pflegenden (R)

- Wie soll ich als Arzt/Pflegender mit diesen Fragen umgehen?

- Wer ist Ihr wichtigster Gesprächspartner in Bezug auf spirituelle und Glaubensüberzeugungen?

- Welche Rolle sollen diese Überzeugungen in der ärztlichen Behandlung spielen?

- Spirituelle und Glaubensfragen sind für Krank- und Gesundsein ein wichtiger Bereich. Haben Sie den Eindruck, dass wir über Ihre Überzeugungen so gesprochen haben, wie Sie es sich wünschen?

- Möchten Sie etwas hinzufügen?

\subsection{Nicht an Krebs erkrankt, aber betroffen: die Angehörigen}

Eine gelingende Partnerschaft stellt eine bedeutsame Ressource dar, die es Menschen ermöglicht, krankheitsbedingte Belastungen zu kompensieren. Diese inzwischen durch zahlreiche Studien empirisch gesicherte Erkenntnis ist keineswegs neu; so kommentierte bereits Paracelsus (1493-1541): „Die beste Medizin für den Menschen ist der Menscb. "Dieser positiven Betrachtungsweise von Beziehungen steht 
jedoch entgegen, dass Partner und Angehörige nicht nur eine wichtige tragende Rolle für den Patienten übernehmen. Schwerwiegende Erkrankungen wie Krebs sind nicht nur im medizinischen Verständnis eine „systemische Erkrankung“, sondern sie führen ebenso zu Belastungen des sozialen Systems des Erkrankten insbesondere dessen Partner und Familienangehörigen. Zahlreiche Untersuchungen weisen übereinstimmend darauf hin, dass Angehörige durch eine Tumorerkrankung und deren Behandlung ebenso belastet erscheinen wie die Patienten: „Krebskrankheiten ,metastasieren" auch in familiäre Beziehungen und sind somit eher selten Einzelschicksal, sondern meist ein Familienereignis. "(Kappauf u. Gallmeier, 1995, S. 145).

\subsection{Supportives dyadisches Coping}

Kohäsion, Stabilität sowie die Veränderbarkeit und Anpassungsfähigkeit einer Partnerschaft sind wichtige Determinanten für eine erfolgreiche Krankheitsverarbeitung. Unter supportivem dyadischen Coping wird die Möglichkeit von Paaren verstanden, diese Belastungen gemeinsam zu bewältigen oder bei Stress, der nur einen Partner betrifft, angemessene Unterstützung zur Bewältigung zu geben (supportives dyadisches Coping). In vielen Partnerschaften entwickelt sich jedoch in der Folge ein wechselseitiges „Schonklima“, in dem jeder versucht, den Anderen nicht zusätzlich zu belasten. In einer Untersuchung von Faller (1998) geben $87 \%$ der Patienten an, dass sie oft ihre Empfindungen für sich behalten und vor Familienmitgliedern verbergen. Eine fehlende unverstellte Kommunikation über Ängste, Sorgen, Wünsche und Bedürfnisse kann jedoch unbeabsichtigt zu gravierenden wechselseitigen Fehleinschätzungen führen. Unter self-perceived burden versteht man die Besorgnis von Patienten bezüglich der Auswirkungen der eigenen Krankheit und Pflegebedürftigkeit auf ihre Angehörigen, d. h. diesen zur Last zu fallen. Diese führt zu Schuldgefühlen, Kummer, Verantwortungsdruck, vermindertem Selbstwertgefühl sowie potentiell zu Suizidwünschen (McPherson 2007).

Eine gemeinsame Bewältigung wird weiter erschwert, wenn

- die Partner schon vor dem Ausbruch der Erkrankung auf vorhergehende Krisen mit einer mehr oder weniger ausgeprägten Sprachlosigkeit reagiert haben

- bereits vor der Erkrankung deutliche Konflikte zwischen den Partnern vorlagen oder von diesen verleugnet wurden

- fixierte Rollenerwartungen in der Partnerschaft vorherrschen

- sich die Partner wechselseitig zu schonen versuchen 
- der Partner eine gut gemeinte, aber eher überfürsorgliche Haltung einnimmt und es dadurch dem Erkrankten schwer macht, eigene Aktivitäten zu entwickeln

- Belastungen nicht ausgesprochen werden und es dadurch zu wechselseitigen Fehleinschätzungen kommt; hier besteht die Gefahr, dass sich die Beteiligten überfordern

- sich der Partner wegen der Erkrankung des Anderen alle positiv getönten Aktivitäten versagt (,Wie kann ich es mir gut gehen lassen, wenn der Andere leidet?")

Partner und Familienangehörige können auch in einem Einzelgespräch durch zirkuläres Fragen mit einbezogen werden, obwohl sie nicht anwesend sind. Ein Beispiel für ein „Paargespräch ohne Partner“: „Wenn Ibr Mann / Ibre Frau jetz̧t hier wäre: was würde er zu dem Problem sagen?" Grundsätzlich sollte der Patient immer aktiv dazu eingeladen werden, zu allen ärztlichen Gesprächen den Partner mitzubringen (,Vier Ohren bören einfach mehr als zwei!' '). Manche Paare benötigen eine Ermutigung dazu, sich trotz oder gerade wegen der Erkrankung zu öffnen und sich dadurch möglicherweise gegenseitig auch etwas „zuzumuten“. Aber nur dann hat das Paar eine Chance, sich wechselseitig effektiv zu unterstützen. Zudem verlangen sich Partner oft eine unrealistische Stärke und Belastbarkeit ab; in diesen Fällen geht es darum, dass sie ihrer eigenen Person, ihren Wünschen, Ängsten und Sorgen mehr Platz einräumen. Hilfreich erscheinen in vielen Fällen das Einführen von ritualisierten, regelmäßig (z. B. einmal wöchentlich) stattfindenden gemeinsamen Gesprächen des Paares und damit verbunden eine regelmäßige wechselseitige Rückmeldung: Was läuft gut, was erscheint eher schwierig?

Von Zimmermann und Heinrichs (2008) wurde ein kognitiv-behaviorales Therapieprogramm entwickelt, das für Paare konzipiert ist, bei denen die Frau mit einer gynäkologischen Malignomerkrankung konfrontiert ist, das aber auch auf andere Krebserkrankungen übertragbar erscheint. Paaren, die trotz dieser Angebote in ihren Bewältigungsmöglichkeiten überfordert erscheinen oder bei denen dysfunktionale Interaktionszirkel dominieren, sollte eine gezielte psychoonkologische Unterstützung vermittelt werden - insbesondere auch dann, wenn gemeinsame Kinder mit betroffen sind. Ein nach Postleitzahlen geordnetes Verzeichnis qualifiziert ausgebildeter und von der Deutschen Krebsgesellschaft zertifizierter Psychoonkologen findet sich unter www.dapo-ev.de. Hilfestellungen können auch ambulante Krebsberatungsstellen sowie die Mitarbeiter von Ehe-, Familien- und Lebensberatungsstellen geben, deren Anschriften über die Webseite www.efl.de abgerufen werden können. 


\subsection{Literatur}

(1) Angenendt, G., Schütze-Kreilkampm U., Tschuschke, V. (2007): Praxis der Psychoonkologie: Psychoedukation, Beratung und Therapie. Stuttgart: Hippokrates

(2) Anguiano L, Mayer DK, Piven ML, Rosenstein D. A literature review of suicide in cancer patients. Cancer Nursing 2012;35(4):E14-26.

(3) AWMF. Leitlinienprogramm Onkologie (Deutsche Krebsgesellschaft, Deutsche Krebshilfe): Palliativmedizin für Patienten mit einer nicht heilbaren Krebserkrankung. Langversion 1.0, 2015;AWMF-Registernummer: 128/001OL. http:/ / leitlinienprogrammonkologie.de/Palliativmedizin.80.0.html (Zugriff am: 21.06.2015)

(4) AWMF. Leitlinienprogramm Onkologie (Deutsche Krebsgesellschaft, Deutsche Krebshilfe): Psychoonkologische Diagnostik, Beratung und Behandlung von erwachsenen Krebspatienten. Langversion 1.1, 2014;AWMF-Registernummer: 032/051OL. http://leitlinienprogrammonkologie. de/Leitlinien.7.0.html (Zugriff am: 21.06.2015)

(5) AWMF. S3-Leitlinie/Nationale Versorgungsleitlinie Unipolare Depression (DGPPN, BÄK, KBV, AWMF, AkdÄ, BPtK, BApK, DAGSHG, DEGAM, DGPM, DGPs, DGRW). Langversion 1.3, Januar 2012;AWMF-Registernummer: nvl-005. http:/ / www.depression.versorgungsleitlinien.de (Zugriff am: 21.06.2015)

(6) Baile WF, Buckman R, Lenzi R, Glober G, Beale EA, Kudelka AP. SPIKES-A six-step protocol for delivering bad news: application to the patient with cancer. Oncologist 2000;5:302-311.

(7) Bandura A. (1997): Self-Efficacy: The Experience of Control. New York: Freeman

(8) Bergelt C, Lehmann C, Welk H-J, Barth J, Gaspar M, Ghalehie S, Günzel K, Kauffmann, C, Kiehne U, Rotsch M, Schmidt R, Steimann M, Koch U. Geschlechtsspezifische psychische Belastungen und Lebensqualität bei Partnern von Krebspatienten in der onkologischen Rehabilitation. In: Koch U, Weis J (Hrsg.) Psychoonkologie. Göttingen: Hogrefe: 2009;80-93.

(9) Carlson LE, Speca M. (2013): Krebs bewältigen mit Achtsamkeit. Bern: Huber 
(10) Faller, H. (1998): Krankheitsverarbeitung bei Krebskranken. Göttingen: Verlag f. Angewandte Psychologie

(11) Frankl V (1992): Trotzdem Ja zum Leben sagen. Ein Psychologe erlebt das Konzentrationslager. München: dtv

(12) Frick E. Spiritualität: Religion und Glauben. In: Dorfmüller M, Dietzfelbinger H (Hrsg) Psychoonkologie. München: Urban \& Fischer: 2009:78.

(13) Gerdes N. Der Sturz aus der normalen Wirklichkeit. In: Deutsche Arbeitsgemeinschaft für Psychoonkologie (Hrsg.) Ergebnisbericht der 2. Jahrestagung der Deutschen Arbeitsgemeinschaft für Psychoonkologie, Bad Herrenalb: 1984.

(14) Gottschlich M. (2007): Medizin und Mitgefühl. Die heilsame Kraft empathischer Kommunikation. Wien: Böhlau Verlag

(15) Grom B. (2007): Religionspsychologie. München: Kösel

(16) Kappauf, H., Gallmeier W.M. (1995): Nach der Diagnose Krebs - Leben ist eine Alternative. Freiburg: Herder

(17) Köhler A. Vortrag beim Kongress des Bundesverbandes Managed Care, zit. nach Deutsches Ärzteblatt, PP, Heft 3, März 2015;101.

(18) Leitlinien AMWF „Palliativmedizin für Patienten mit einer nicht heilbaren Krebserkrankung (2015), s.S. 114

(19) McPherson, CJ. Feeling like a burden: exploring the perspectives of patients at the end of life. Social Science \& Medicine 2007;(64):417-427.

(20) Pessin H, Amakawa I, Breitbart WS. Suicide. In: Holland JC et al. (Eds.) Psycho-Oncology, $2^{\text {nd }}$ ed., New York: Oxford University Press 2010;319-323.

(21) Temel MD, Jennifer S. Longitudinal Perceptions of Prognosis and Goals of Therapy in Patients with Metastatic Non-Small-Cell Lung Cancer: Results of a Randomized Study of Early Palliative Care. JCO Jun 10 2011; 2319-2326; DOI:10.1200/JCO.2010.32.4459.

(22) Tschuschke V. (2005): Psychoonkologie. Psychologische Aspekte der Entstehung und Bewältigung von Krebs. Stuttgart: Schattauer

(23) Yalom I. (2008): In die Sonne schauen. Wie man die Angst vor dem Tod überwindet. München: btb 
(24) Yalom I. (2000): Die Reise mit Paula. München: btb Goldmann

(25) Zimmermann T, Heinrichs N. (2008): Seite an Seite. Eine Krebserkrankung gemeinsam bewältigen. Göttingen: Hogrefe

(26) zu Salm C.(2013): Dieser Mensch war ich. München: Goldmann 



\title{
13. Das Schnittstellenproblem
}

\author{
Dr. med. Marianne Kloke, Dr. med Manuela Sauren
}

Kliniken Essen-Mitte, 45136 Essen

Universitätsklinikum Köln, 50937 Köln

\subsection{Einleitung}

Fortschritte in den tumorspezifischen Therapien haben zu einer deutlichen Verlängerung der Überlebenszeit von Krebspatienten selbst in der metastasierten Situation geführt. In der Folge hat der Anteil der Patienten mit palliativmedizinischem und -pflegerischem Behandlungsbedarf deutlich zugenommen. Bereits 2003 wurde in der EU Recommendation 24 betont, dass Palliative Care nicht gleichbedeutend mit End-of-Life-Care sei, sondern allen Patienten, die einer Palliativbetreuung bedürfen, zur Verfügung stehen müsse (1). Diese Herangehensweise erlangte erst durch die 2010 publizierte Arbeit von J. Temel nachhaltigen Einfluss auf die Betreuung von Krebspatienten. Zur Charakterisierung des Miteinanders von Onkologie und Palliative Care wurde der Begriff der shared responsibility verwandt (2). Nur durch freien und niederschwelligen Zugang zu situationsgerechter Palliativversorgung unabhängig von der Länge der prospektiven Lebenserwartung und dem jeweiligen Behandlungsort kann dem Recht des Patienten auf optimale Linderung von Schmerzen und anderen Problemen, seien sie physischer, psychischer, sozialer oder spiritueller Natur, besonders in komplexen Situationen entsprochen werden (3). Dies ermöglicht die frühe und kontinuierliche Integration von Palliative Care in ein umfassendes Konzept zur Behandlung des Tumorkranken. Somit stellt die Gestaltung dieser Schnittstelle mit Blick auf den Wunsch der Menschen mit einer unheilbaren Er- 
krankung nach Kontinuität und Verlässlichkeit eine zentrale Herausforderung für beide Fachgebiete mit ihren jeweils spezifischen Herangehensweisen sowie eigenständigem Wissen und Können dar. Die Strukturmodelle müssen eine gemeinsame Verantwortlichkeit von palliativmedizinisch, hausärztlich und onkologisch tätigen Ärzten, Pflegenden und therapeutischen Berufen ermöglichen, um dem hohen Bedürfnis des Patienten nach Kontinuität und Verlässlichkeit in der Behandlung gerecht zu werden.

\subsection{Strukturmodelle}

Hierzu wurden unterschiedliche Strukturmodelle beschrieben, deren Effizienz und Übertragbarkeit in das deutsche Gesundheitssystem wenig wissenschaftlich untersucht wurde $(4,5,6)$. Das dem Erkrankungsverlauf angepasste Modell ist das traditionell praktizierte: PC findet erst in weit fortgeschrittenen Stadien oder in Form von End-of-life Care Eingang in das Behandlungskonzept. Dass bei einem solchen Vorgehen palliativer Unterstützungsbedarf nicht erkannt und konsekutiv Leiden auch nicht angemessen gelindert wird, ist hoch wahrscheinlich. Wenn die so ,austherapierten" Patienten dann einer spezialisierten Palliativmedizin überstellt werden, ist offenkundig, dass wichtige Prinzipien wie die „Kontinuität der medizinischen Betreuung“ und das „Nicht-Verlassen des Patienten“ in diesem Konzept nur schwer beachtet werden können. Im sogenannten onkozentrischen Modell ist der Onkologe umfassend verantwortlich auch für die palliative Versorgung, spezialisierte Palliativversorgung wird allenfalls konsiliarisch eingefordert. Gewichtige Vorteile sind die Sicherung der Kontinuität der Betreuung sowie die Option einer zeitnahen Palliation. Eine Voraussetzung für das Gelingen dieses Modells wäre eine nicht erhebliche Aufstockung der Zeit, die dem onkologischen Team für den Patienten und seine Angehörigen zur Verfügung steht. Bezweifelt werden darf auch, dass eine Fachperson zugleich auf dem aktuellen Wissens- und Könnensstand zweier komplexer Fachgebiete zugleich sein kann. Dies impliziert die Gefahr, dass Unterdiagnose zu Untertherapie führt. Erfahrungen haben gezeigt, dass innerhalb dieses Modells häufig deutliche Defizite in der Multiprofessionalität des Vorgehens bestehen.

Innerhalb des sogenannten pallizentrischen Modells gibt es drei verschiedene Konzepte. Das Zunveisungsmodell sensibilisiert Onkologen, die den kooperierenden Palliativspezialisten frühzeitig einbeziehen. Hier rückt PC in die Nähe von End-oflife Care. Im Einheitsmodell haben einige Mitglieder des onkologischen Teams eine zusätzliche Palliativausbildung. Hier sind eine zeitnahe und zumeist qualifizierte Betreuung ebenso gewährleistet wie die Kontinuität der Betreuung. Das Defizit dieses Konzeptes ist die fehlende Verfügbarkeit einer spezialisierten Palliativmedizin. Dieses ist durch Integration einer solchen in das Team der Onkologie möglich. Dieses würde dann dem von J. Temel evaluierten Betreuungsmodell (sogenanntes Zwei-Köpfe-Prinzip) entsprechen. Sein absoluter Vorteil besteht in der kontinuierli- 
chen Verfügbarkeit der höchsten Kompetenz beider Fachgebiete zu jedem Zeitpunkt. Dieses somit als ideal anzusehende Modell ist sehr personal- und damit auch kostenintensiv, was seine Umsetzbarkeit erheblich einschränkt.

Die jüngst publizierte S3-Leitlinie Palliativmedizin des Leitlinienprogrammes Onkologie stellt die konsentierte Forderung auf, dass der Evidenz entsprechend die Integration spezialisierter Palliativteams in die Behandlung onkologischer Patienten in Abhängigkeit von der Phase der Krebserkrankung (Nicht-Heilbarkeit) erfolgen und im Verlauf der Belastung bzw. dem Bedarf und den Bedürfnissen der Patienten und ihrer Angehörigen angepasst werden sollte (7). Alle Patienten mit einer Krebserkrankung sollen unabhängig vom Krankheitsstadium Zugang zu Informationen über Palliativversorgung haben (8).

\subsection{Das Recht des Patienten auf eine umfassende Betreuung}

\subsubsection{Information}

Die meisten Krebspatienten und ihre Behandler fokussieren ihre Aufmerksamkeit auf innovative Therapieansätze, die vorrangig eine Verlängerung der Lebenszeit zum Ziel haben. Informationen zur palliativen Versorgung werden häufig als „noch nicht aktuell“ beiseitegeschoben. Palliativmedizinisch relevante Informationen zu einem Zeitpunkt der Therapie zu geben, in dem das Fehlen einer kurativen Chance zwar deutlich, jedoch die Hoffnung auf einen bedeutsamen Zugewinn an Lebenszeit durch spezifische Therapien das Denken und Fühlen der Patienten und ihrer Angehörigen bestimmt, gestaltet sich oft schwierig und bedarf einer empathischen Kommunikation durch den Onkologen. Hieraus ergibt sich eine erste Empfehlung: Der Information Betroffener, Angehöriger und des medizinischen Fachpersonals über Ziele und Chancen der Integration von Palliativversorgung in ein umfassendes onkologisches Therapiekonzept kommt eine Schlüsselfunktion für die Verbesserung der Versorgung von Tumorpatienten zu (9).

\subsubsection{Assessment}

Die Erfassung der mit der Krebserkrankung verbundenen Probleme, seien sie physischer, psychischer, sozialer oder auch spiritueller Natur, ist wesentlich für eine angemessene und umfassende Betreuung in allen Phasen der Erkrankung. Dieses in freier, ausführlicher Kommunikation zu gewährleisten, stellt im klinischen Alltag eine Herausforderung dar und erfolgt idealerweise systematisch. Darüber hinaus halten Patienten und Angehörige das onkologische Team oft nicht für den richtigen Adressaten, wenn es um andere als körperliche Symptome geht. Hieraus ergibt sich eine zweite Empfehlung: Ein umfassendes Assessment physischer, 
psychischer, sozialer oder auch spiritueller Probleme mittels geeigneter und validierter Selbsterfassungsinstrumente sollte zu Beginn einer Behandlung und danach in angemessenen Abständen erfolgen. Handlungsempfehlungen und -pfade zum Umgang mit einmal erkannten (palliativen) Problemen und Bedürfnissen sollten verfügbar sein.

\subsubsection{Interdisziplinäre Kommunikation}

Die Mehrzahl der systemischen Tumortherapien erfolgt heute ambulant. Eine vollstationäre Behandlung findet zumeist nur bei hoch toxischen oder aufwändigen Therapien, bei problematischer Komorbidität oder bei Komplikationen statt. Die besonderen Bedingungen tumorspezifischer Therapien (getaktete Therapieschemata mit regelmäßigen, oft engmaschigen Wiedervorstellungen beim Onkologen, kontinuierliche Therapie oft über viele Monate bis mehrere Jahre) können dazu führen, dass die Rolle des Hausarztes auf administrative Aufgaben reduziert wird (z. B. Blutbildkontrolle, Laborkontrollen, Ausstellen von Transport- und Einweisungsscheinen). In langjährigen Verläufen besteht somit die Gefahr der Entfremdung von Patient und Hausarzt. Dieser kommt oft erst in der Sterbephase wieder in die Rolle als medizinischer Begleiter. Somit mag eine dritte Empfehlung lauten:

Die zeitlich, formal und inhaltlich strukturierte Kommunikation zwischen palliativ, hausärztlich und onkologisch tätigen Ärzten, Pflegenden und Vertretern therapeutischer Berufe ist Schlüssel zur Betreuungskontinuität für Betroffene über alle Phasen der Erkrankung hinweg. Die Übernahme einer gemeinsamen Verantwortung setzt klare Absprachen und eine unvoreingenommene Analyse der Probleme und Bedürfnisse des Patienten und seiner Angehörigen voraus. Die routinemäßige Verwendung von Assessmentinstrumenten zu Screening und Dokumentation von relevanten Befunden und des Befindens kann dabei für alle beteiligten Berufsgruppen sinnvoll und hilfreich sein. Die Beteiligung von Palliativmedizinern an Tumorboards ist ebenso wie die von Onkologen an palliativmedizinischen Fallkonferenzen wünschenswert.

\subsubsection{Interdisziplinäre Fort- und Weiterbildung}

Nahezu monatlich erweitern die Zulassung neuer Krebsmedikamente oder die Etablierung neuer Therapieverfahren die onkologischen Behandlungsmöglichkeiten. Auch in der Palliativmedizin gibt es erhebliche Fortschritte. Beide Gebiete verstehen sich als eigenständige Fachgebiete und verfügen somit über jeweils spezifisches Wissen, Können und Fähigkeiten. Defizite in dem Wissen um die fachlichen Optionen des jeweils anderen Faches begünstigen Über-, Unter- und Fehltherapien. Hieraus ergibt sich eine vierte Empfehlung:

Onkologisch tätige Ärzte, Pflegende und Vertreter therapeutischer Berufe sollten über ein Basiswissen in Palliativmedizin, Tätige im Bereich der Palliativversor- 
gung über ein Basiswissen in Onkologie verfügen. Dieses bedarf der regelmäßigen Fort- und Weiterbildung.

\subsubsection{Sektorenübergreifende vernetzte Versorgung}

Die Über-/Zuweisung zu einer Palliativstation, einem stationären Hospiz oder auch zur Weiterbetreuung im Rahmen der Allgemeinen oder Spezialisierten Ambulanten Palliativversorgung erfolgt vorrangig nach der Verfügbarkeit der palliativen Versorgungstrukturen und dem Informiertheitsgrad des Zuweisers und der jeweils Beteiligten. Somit kommt der Qualität regionaler Netze oder auch der lokalen Infrastruktur (Großstadt versus ländliche Region) größere Bedeutung als erkrankungsbedingten Faktoren zu. Auch der Einfluss gesetzgeberischer Vorgaben und regionaler Besonderheiten darf nicht unterschätzt werden. Die Entwicklung eines für alle Regionen und Patienten sowie Angehörigen gültigen einheitlichen Struktur-, Organisations- und Personalkonzeptes an der ausgesprochenen Vielfalt der gegebenen Bedingungen erscheint unrealistisch. Hieraus wird eine fünfte Empfehlung abgeleitet:

Es sollten Minimalanforderungen für eine flächendeckende Verfügbarkeit einer angemessenen und an den aktuellen Problemen und Bedürfnissen des Patienten und seiner Angehörigen orientierten Palliativversorgung formuliert werden. Dies bedeutet im Gegenzug, dass sich verschiedene, lokal unterschiedliche BestPractice-Modelle entwickeln können, die sich aber hinsichtlich ihrer Effizienz gleichen Ziel- und Bewertungskriterien stellen müssen.

\subsection{Mindestanforderungen für eine Schnittstellengestaltung}

Mindestanforderungen für eine Schnittstellengestaltung ergeben sich somit auf struktureller und organisatorischer sowie auf personeller Ebene (10, 11, 12, 13). Organisation und Struktur müssen eine Zugangsgerechtigkeit gleichermaßen zu Palliativmedizin und Onkologie ermöglichen und zugleich Garant für eine Kontinuität der Versorgung durch alle Phasen der palliativen Erkrankung sein. Unverzichtbare Elemente zur Erreichung dieser Ziele sind:

1. Information des Patienten und seiner Angehörigen über die Möglichkeiten und die lokale Verfügbarkeit einer Palliativversorgung und Hospizbegleitung bei Eintritt in die palliative Therapiesituation

2. Niederschwelliger Zugang und sichere Verfügbarkeit palliativmedizinischer Kompetenz auf qualifiziertem Niveau rund um die Uhr für jeden Krebspatienten (14). Das bedeutet z. B.: 
a. Einrichtung von Palliativstationen in der von den Fachgesellschaften vorgegebenen Dichte

b. Bereitstellung von palliativmedizinischen Notfallbetten

c. Etablierung von Palliativmedizinischen Diensten in Krankenhäusern mit einer zumindest 24-stündigen telefonischen Erreichbarkeit

d. Stärkung der Strukturen der Allgemeinen und Spezialisierten Palliativversorgung

3. Verfügbarkeit hospizlicher ambulanter und stationärer Begleitung für jeden Betroffenen, der sie in Anspruch nehmen möchte

4. Etablierung von Routinen wie klinischen Pfaden und Standards, die die Bedürfnisse von Patienten mit einer Krebserkrankung und ihrer Angehörigen systematisch erfassen und die individuell unterschiedliche, rechtzeitige Einbeziehung von Palliativversorgung gewährleisten.

5. Option der Durchführung von ethischen Konsilen/Einzelfallbesprechungen bei schwierigen Therapie- und Entscheidungssituationen (z. B. Durchführung einer tumorspezifischen Therapie bei nicht oder eingeschränkt entscheidungsfähigen Menschen, Therapiezieländerungen bei schwierigen Komplikationen wie z. B. Dialyseabbruch, Beendung einer maschinellen Beatmung, Verzicht auf die Gabe von Blutprodukten)

6. Strukturierte Kooperation von onkologischen (Schwerpunkt-)praxen/ ambulanten onkologischen Versorgungszentren mit Institutionen der Palliativ- und Hospizversorgung (z. B. Ambulanten Palliativpflegediensten, niedergelassenen Palliativärzten, Palliative Care Teams der Spezialisierten Ambulanten Palliativversorgung, ambulanten Hospizgruppen, stationären Hospizen und regionalen Palliativnetzen), Beispiele der Realisation einer solchen sind:

a. Fallbesprechungen

b. Tumor- und Palliativkonferenzen, an denen die jeweils andere Fachrichtung teilnimmt

c. Entwicklung von gemeinsamen Standards und Abläufen innerhalb eines Versorgungsbereiches sowie Verfügbarkeit relevanter Behandlungsdaten sektoren- und berufsgruppenübergreifend

d. Etablierung neuer Versorgungsmodelle wie z. B. palliativen Tageskliniken, palliativen (Pflege-)visiten, Patientenscouts 
7. Mitwirkung/Mitgliedschaft in einem regionalen Palliativnetz für onkologische Hauptfach- oder Schwerpunktabteilungen sowie für onkologische Praxen und ambulante Versorgungszentren zur Weiterentwicklung von Palliative Care und der Schaffung eines öffentlichen Bewusstseins für die Notwendigkeit des Miteinanders von Onkologie und Palliativmedizin

Die personellen Maßnahmen sichern in erster Linie die Qualität der integrierten palliativen/onkologischen Betreuung, dienen aber ebenso der Vernetzung und garantieren somit die Nachhaltigkeit der strukturellen und organisatorischen Maßnahmen.

1. Integration von palliativen Inhalten in die onkologische und von onkologischen in die palliative Ausbildung. Überprüfung dieses Wissens und Könnens in den jeweiligen Fachprüfungen.

2. Kontinuierliche, nachzuweisende Fortbildung der onkologisch und palliativmedizinisch tätigen Ärzte und Pflegenden über die spezifischen Optionen des jeweils anderen Fachgebietes und Anerkennung der Grenzen der jeweiligen Fachkompetenz auch nach Abschluss der Fachweiterbildung

3. Strukturierter Erwerb weitergehender Qualifikationen
a. im Erkennen und Bearbeiten ethischer Konflikte
b. im Arbeiten im Multiprofessionellem Team
c. in der Kommunikation mit Patienten, An- und Zugehörigen sowie Teammitgliedern und ehrenamtlichen Hospizmitarbeitern
d. in der Sterbe- und Trauerbegleitung

\subsection{Fazit und Ausblick}

Analyse, Erprobung und wissenschaftliche Begleitung maßgeschneiderter regionaler Versorgungs- und Strukturkonzepte bleiben eine dauernde Herausforderung. Es sollten jedoch Mindeststandards erfüllt werden, um dem Anspruch einer umfassenden Betreuung von Menschen mit Krebserkrankungen gerecht zu werden. Das Recht auf eine (spezialisierte) Palliativversorgung muss aktiv gelebt und nicht nur verbal eingefordert werden. Dies gelingt nur durch ein koordiniertes Miteinander von Onkologen, Hausärzten und Palliativmedizinern. Hier erscheint die Orientierung an Best-Practice-Modellen sinnvoll $(15,16)$. Sie ermöglichen eine den jeweiligen Bedingungen angepasste Struktur zur Gestaltung der oft schwierigen 
Schnittstellen zur Wahrung von Kontinuität und Zuverlässigkeit für den Patienten und seine Zugehörigen.

\subsection{Literatur}

(1) Bakitas M, Tosteson TD, Zhigang L, et al, Early Versus Delayed Initiation of Concurrent Palliative Oncology Care: Patient Outcomes in the ENABLE III Randomized Controlled Trial J Clin Onc 2015;33:1438-1445.

(2) Deutsche Gesellschaft für Palliativmedizin, Deutscher Hospiz- und Palliativverband, Bundesärztekammer. Charta zur Betreuung schwerkranker und sterbender Menschen (2011). www.charta-zur-betreuung-sterbender.de (Zugriff am: 27.09.2015)

(3) Council of Europe. Empfehlung des Ministerkomitees des Europarats an die Mitgliedstaaten zur Organisation von Palliative Care vom 12.November 2003. http://www.dgpalliativmedizin.de/allgemein/europa.html (Zugriff am: 27.09.2015)

(4) European Association for Palliative Care (EAPC). White Paper on Standards and Norms for Hospice and Palliative Care in Europe: part I Eur J Pall Care 2009;16:278-289.

(5) Ferris FD, Bruera E, Cherny N, Cumming Ch, et al. Palliative Cancer Care a Decade Later: Accomplishments, the Need, Next Steps - From the American Society of Clinical Oncology JCO 2009;27.18:3052-3058.

(6) Gade G, Venohr I, et al. Impact of an Inpatient Palliative Care Team: A Randomized Controlled Trial J Pall Med 2008;11(2):180-190.

(7) Gaertner J, Wolf J, Frechen S, Klein U, Scheicht D, Hellmich M, Toepelt K, Glossmann P, Ostgathe C, Hallek M. Recommending early integration of palliative care - does it work? Support Care Cancer 2012;20(3):507-513.

(8) Bundesregierung Deutschland. Entwurf eines Gesetzes zur Verbesserung der Hospiz- und Palliativversorgung in Deutschland, 2015.

http://www.bmg.bund.de/fileadmin/dateien/Downloads/Gesetze_und_Verordn ungen/GuV/H/Kabinettvorlage_HPG_18-15032.pdf

(9) Hui D, Kim Y, Park K, Zhang Y, Strasser F, Cherny N, Kaasa S, Davis MP, Bruera E. Integration of Oncology and Palliative Care: A Systematic Review. The Oncologist 2015;20(1):77-83. 
(10) Leitlinienprogramm Onkologie (Deutsche Krebsgesellschaft, Deutsche Krebshilfe, AWMF): Palliativmedizin für Patienten mit einer nicht heilbaren Krebserkrankung, Kapitel Versorgungsstrukturen, Langversion 1.0, 2015, AWMFRegisternummer: 128/001OL, http:/ / leitlinienprogrammonkologie.de/Palliativmedizin.80.0.html (Zugriff am: 27.09.2015)

(11) Deutsche Gesellschaft für Hämatologie und Medizinische Onkologie. Frühzeitige Integration palliativmedizinischer Versorgung in die onkologische Therapie. Gemeinsame Stellungnahme von DGHO und AG Interdisziplinäre Onkologie in der Palliativmedizin der DGP, 2015.

http://www.dgho.de/informationen/stellungnahmen/patientenversorgung/Stellu ngnahme_DGP_DGHO.pdf

(12) Partridge AH, Seah DS, King T, et al. Developing a service model that integrates palliative care throughout cancer care: the time is now. J Clin Oncol 32 2014;(29):3330-3336.

(13) Peppercorn JM, Smith TJ, Helft PR, et al. American Society of Clinical Oncology statement: toward individualized care for patients with advanced caner JCO 2011;27.18:3052-3058.

(14) Smith T, Temin S, Alesi ER, et al. American Society of Clinical Oncology Provisional Clinical Opinion: The Integration of Palliative Care into Standard Oncology Care JCO 2012;30.8:880-887.

(15) Temel JS, Greer JA, Admane S. Longitudinal perceptions of prognosis and goals of therapy in patients with metastatic non-small-cell lung cancer: results of a randomized study of early palliative care J Clin Oncol 10 2011;29(17):2319-26.

(16) Hui D, Elsayem A, De La Cruz M et al (2010) Availability and Integration of Palliative Care at US Cancer Centers JAMA.;303(11):1054-1061. 



\section{Perspektiven in der Onkologie}

Prof. Dr. med. Florian Lordick

Universitäres Krebszentrum Leipzig (UCCL), 04103 Leipzig

\subsection{Zusammenfassung}

Die zunehmende Kenntnis der Tumorbiologie ermöglichte zwei maßgebliche Entwicklungen in der Onkologie. Auf der Grundlage genetischer Analysen werden zielgerichtete, tumorspezifische Medikamente zum Einsatz gebracht. Da die genetischen Veränderungen zum Teil ganz charakteristisch für die individuelle Erkrankung sind, wird dieser Behandlungsansatz auch „personalisiert“ genannt. Außerdem gelingt es mittels neuer Technologien in immer mehr Fällen, das körpereigene Immunsystem gegen maligne Erkrankungen zu aktivieren. Die Immun- und zellulären Therapien stehen am Anfang einer vielversprechenden Entwicklung. Als dritte Revolution in der Onkologie der Gegenwart könnte man den Nachweis der Wirksamkeit einer frühen Integration palliativmedizinischer Behandlungsangebote in die onkologische Allgemeinversorgung bezeichnen.

\subsection{Stand des Wissens}

In den westlichen Zivilisationen erreichen Menschen heute ein höheres Lebensalter als in vorausgehenden Generationen. Weniger Menschen versterben in jungen Jahren an Infektionen, Herz-Kreislauf-Erkrankungen oder an den Folgen von Unfällen, Katastrophen oder Kriegen. Das sind wesentliche Gründe, warum immer 
mehr Menschen an Krebs erkranken. Hinzu kommen Zivilisations- und Umweltfaktoren wie Übergewicht, Bewegungsmangel, Alkohol- und Tabakkonsum oder Ultraviolett-Strahlung, deren krebsfördernde Auswirkungen weitgehend unstrittig sind und denen Menschen heute immer stärker ausgesetzt sind.

Krebserkrankungen sind zu einem dominierenden Gesundheitsproblem unserer Zeit geworden. Auch wenn mehr als die Hälfte der diagnostizierten Krebserkrankungen nicht zum Tode führen, bleibt die Prognose jenseits von Frühstadien der Erkrankungen oft problematisch (1). Insofern stehen wir vor großen Herausforderungen.

- Lässt sich das Gesundheitsbewusstsein in der Bevölkerung modifizieren, sodass krebsverursachendes Verhalten reduziert und sinnvolle Vorsorgemaßnahmen wahrgenommen werden?

- $\quad$ Lassen sich Qualitätssicherungsmaßnahmen in der Krebsmedizin implementieren, die letztlich zu besseren Behandlungsergebnissen und Überlebenschancen führen?

- Kann eine multidisziplinäre und multiprofessionelle Krebsmedizin flächendeckend und auf hohem Niveau angeboten werden?

Über diese Fragen hinaus sind spezifische Behandlungsstrategien zu entwickeln, die schlussendlich zu einer effektiveren und an den Bedürfnissen des Individuums orientierten Behandlung führen sollen. Dazu zählen

- die personalisierte Therapie auf Grundlage von Biomarkern,

- $\quad$ eine Aktivierung des körpereigenen Immunsystems gegen eine Krebserkrankung und

- $\quad$ die frühzeitige Berücksichtigung palliativmedizinischer Gesichtspunkte im Gesamtbehandlungsplan.

\subsection{Personalisierte Krebstherapie - die molekulare Ära}

Der Wunsch einer personalisierten Therapie ist wahrscheinlich so alt wie die abendländische Medizin selbst: Krankheiten scheinen so unterschiedlich zu sein wie die Menschen selbst. Je genauer wir die Charakteristika einer Erkrankung verstehen, desto besser sind die Chancen, eine für den einzelnen Patienten wirksame Behandlung anzuwenden. Je spezifischer wir behandeln, desto eher ersparen wir Nebenwirkungen durch Therapien ohne Nutzen. Mit dem Vorwurf, ungerechtfertigte Belastungen hervorzurufen, sieht sich die Onkologie in besonderem Maße konfrontiert, da praktisch alle onkologischen Therapien mit einem ungewöhnlich starken Ausmaß an Risiken, Nebenwirkungen und Belastungen assoziiert sind. Mit der Dechiffrierung des menschlichen Genoms und den damit verbundenen Möglichkeiten, molekulare Veränderungen auf zellulärem Niveau zu charakterisie- 
ren, begann ein rasanter Zuwachs an Wissen über genetisch determinierte Tumoreigenschaften. Dabei sind hauptsächlich sogenannte somatische Genveränderungen gemeint. Diese sind im Vergleich zu den genetisch veranlagten Keimbahnveränderungen nicht von einer Generation auf die nächste vererbbar. Sie werden aus unterschiedlichen Gründen - im Laufe des Lebens erworben und werden maßgeblich mit der Entstehung von Krebserkrankungen in Zusammenhang gesehen.

Somatisch erworbene Genveränderungen können Mutationen oder Genamplifikationen sein. Sie sind bei einer Vielzahl von Krebserkrankungen nachweisbar. Die meisten Tumorerkrankungen weisen hunderte bis tausende unterschiedlicher genetischer Veränderungen auf (2). Seit der Entdeckung der sogenannten Onkogene und Tumorsuppressorgene galt die bis heute anerkannte Hypothese, dass wahrscheinlich eine begrenzte Zahl von Genen in der Lage ist, eine normale Zelle in eine Krebszelle zu verwandeln. Dieses Konzept ist in der Regel gemeint, wenn von „gene addiction“ (Genabhängigkeit) und von „genetic drivers“ (Genveränderungen, die eine bestimmte Erkrankung antreiben) die Rede ist. Aktuell wurden ca. 140 Gene identifiziert, die das Krebswachstum in besonderer Weise vorantreiben, wenn sie mutiert oder anderweitig verändert und damit aktiviert oder deaktiviert sind. Die Identifikation relevanter Genveränderungen und onkogener Signalwege hat die Entwicklung zielgerichteter Medikamente enorm beflügelt.

So können heute Krebserkrankungen, bei denen spezifische Genveränderungen gefunden werden, effektiv mit zielgerichteten Medikamenten behandelt werden, die zuvor mit konventionellen Krebsmedikamenten als praktisch unbehandelbar galten. Praxisrelevante Beispiele sind die bcr/abl translozierte chronische myeloische Leukämie (CML) oder das in ca. 50-60 \% der Fälle im BRAF-Gen mutierte maligne Melanom oder das im EGFR-Gen (epidermaler Wachstumsfakor-Rezeptor) mutierte oder EML4/ALK-translozierte Lungenkarzinom $(3,4,5,6)$. Die genannten Beispiele machen überaus deutlich, dass eine spezifische Behandlung, welche - bildlich gesprochen - gegen die Achillesferse der Erkrankung gerichtet ist, zu dramatisch besseren Behandlungsergebnissen führt. So war z. B. die CML vor 15 Jahren medikamentös kaum behandelbar. Eine langfristige Kontrolle über die Erkrankung war nur mit Hilfe einer knochenmarkszerstörenden Chemo- oder Strahlentherapie mit nachfolgender Blutstammzelltransplantation von einem fremden Knochenmarkspender möglich. Heute hingegen können die meisten Patienten, die an einer CML erkrankt sind, mit Hilfe spezifisch gegen das veränderte Genprodukt gerichteten Inhibitoren (u. a. Imatinib, Dasatinib oder Nilotinib) in eine zum Teil langanhaltende Kontrolle der Erkrankung gebracht werden. Es ist noch nicht klar, ob einzelne Patienten mit CML durch die Gabe dieser Inhibitoren sogar geheilt werden könnten.

Ein noch ungelöstes Grundproblem ist die Fähigkeit von Krebszellen, auch gegen die initial wirksamsten Inhibitoren nach variabler Zeit Resistenzen zu entwickeln. Hier hat die Entwicklung krebsspezifischer Therapien noch ein großes Aufgabenfeld vor sich. Denn Resistenzentstehung von Krebserkrankungen ist eine 
dynamische Entwicklung und weder in ihrer Geschwindigkeit noch in ihrer Ausprägung exakt vorhersagbar. Medikamente, die spezifische Resistenzen überwinden, sind erst vereinzelt in Erprobung, und nur wenige Beispiele scheinen sich in der Praxis zu bewähren.

Eine weitere Herausforderung ist die Beherrschung von therapiebedingten Belastungen und Nebenwirkungen. Es soll nicht übersehen werden, dass auch die Medikamente neuerer Generation häufig mit einem erheblichen und für den Patienten belastenden Spektrum an Nebenwirkungen einhergehen. Zum Teil handelt es sich um qualitativ ganz andere Toxizitäten als jene, die durch klassische Chemotherapien hervorgerufen werden (7).

Es lässt sich zusammenfassen, dass genetische Untersuchungen von Tumorerkrankungen heute eine genauere Charakterisierung der Tumoreigenschaften zulassen und damit eine auf den individuellen Tumor zugeschnittene Behandlung ermöglichen. Zu berücksichtigen sind andere, zum Teil auch belastende Nebenwirkungen der neuen Medikamente. Solche molekular stratifizierten Therapien sind zielgenauer; sie sind wirksamer und haben gegenüber der unspezifischen Chemotherapie zudem den Vorteil einer besseren Symptomkontrolle und Lebensqualität (8).

\subsection{Immuntherapie}

Hippokrates ist den meisten Menschen vor allem durch seine grundlegenden Formulierungen zur ärztlichen Ethik bekannt. Seine Schriften geben jedoch auch Einblick in Grundprinzipien der medizinischen Wissenschaft seiner Zeit. Eine Grundaussage gewinnt heute, in den Zeiten moderner Tumorimmunologie, besondere Aktualität: „Die wirksamste Medizin ist die natürliche Heilkraft, die im Inneren eines jeden von uns liegt.“ (Hippokrates von Kos, 460 bis etwa 377 v. Christus, griechischer Arzt)

Arzneimittel, die jene „Heilkraft, die im Inneren von uns liegt“, stärken, stimulieren oder freisetzen, wurden bereits zahlreich entwickelt. Aber erst in jüngster Zeit kann von maßgeblichen Erfolgen gesprochen werden. Es geht vor allem um die Stimulation krebsbekämpfender T-Lymphozyten. T-Lymphozyten sind ein wichtiger Bestandteil des zellulären Immunsystems, mit dem jeder gesunde Mensch ausgestattet ist und der eine Abwehr gegen fremdes Gewebe, Erreger, Parasiten und im Prinzip auch gegen entartete Krebszellen ermöglicht.

Doch Krebs vermag sich durch eine Vielzahl von Mechanismen dem Zugriff des Immunsystems geschickt zu entziehen. In der naturwissenschaftlichen Fachsprache wird dieser Vorgang „Immuntoleranz“ genannt (9). Dass Krebs grundsätzlich einer Kontrolle durch Immunzellen unterworfen sein könnte, ist seit Längerem bekannt. Vor knapp zehn Jahren erreichte eine Publikation hohe Aufmerksamkeit, die andeutete, dass Dickdarmkrebserkrankungen, die mit einer Aktivierung von Immunzellen im Bereich des Tumors und an seiner Invasionsfront ein- 
hergehen, eine deutlich bessere Prognose haben als Erkrankungen ohne immunaktivierende Eigenschaften (10). Mit zunehmendem Verständnis, über welche Signale Krebs dem menschlichen Immunsystem Toleranz signalisiert und eine effektive Immunantwort unterbindet, konnten in den vergangenen Jahren neue Medikamente entwickelt und zum Teil bereits zugelassen werden. Sie mindern jene Immuntoleranz oder schalten sie ab. Die Medikamente der aktuellen Generation richten sich gegen Rezeptoren auf T-Lymphozyten, über welche Immuntoleranz durch Botenmoleküle der Krebszellen vermittelt wird. Die Botenmoleküle täuschen dem Immunsystem gewissermaßen vor, dass die Krebserkrankung nicht fremd ist und nicht attackiert werden soll. Zu den Rezeptoren auf Seiten der T-Zellen zählen CTLA-4 (cytotoxic T-lymphocyte-associated Protein 4), auch benannt als CD152 (cluster of differentiation 152) und Programmed cell death protein 1, auch bekannt als PD-1 oder CD279 (cluster of differentiation 279). Mit Hemmstoffen dieser TZellrezeptoren wie Ipilimumab (anti-CTLA-4) oder Nivolumab und Pembrolizumab (anti-PD-1) wurden in jüngster Zeit geradezu dramatische Wirkeffekte gegen Erkrankungen wie das maligne Melanom oder das Lungenkarzinom beobachtet $(11,12,13)$. Auch Wirkstoffe gegen die entsprechenden Botenstoffe oder Liganden wie z. B. den PD-1-Liganden (PD-L1) erweisen sich als wirksam (14). Dieses völlig neue und fast schon revolutionär wirksam zu bezeichnende Behandlungsprinzip in der Onkologie wird Immun-Checkpoint-Blockade (deutsch: Immun-KontrollpunktBlockade) genannt.

Ein anderes interessantes und vielversprechendes Behandlungsprinzip am Horizont ist die genetische Modulierung von T-Zellen außerhalb des Körpers und Rückgabe von T-Zellen, die gegen den Krebs aktiv werden. Diese Therapie wird zelluläre Immuntherapie genannt. Die genetisch modifizierten T-Zellen heißen CART (chimäre Antigen-Rezeptor-T-Zellen) (15,16).

Wie funktioniert die T-Zell-Transfer-Behandlung?

- Immunzellen des Patienten (T Zellen) werden aus dem Körper entfernt und genetisch modifiziert oder im Labor reprogrammiert.

- Diese Modifikation oder Reprogrammierung erlaubt den T-Zellen, die körpereigenen Krebszellen anzugreifen und zu zerstören. Die modifizierten T-Zellen (CTL019 Zellen) werden im Labor herangezüchtet und dann in den Patienten rückinfundiert.

- Wenn die modifizierten oder reprogrammierten T-Zellen die malignen Zellen erkennen und an sie binden, werden sie aktiviert und können sie abtöten. 
Zusammenfassend stellen die neuen immuntherapeutischen Medikamente und Strategien die vielversprechendste Entwicklung in der Krebsbehandlung des vergangenen Jahrzehnts dar. Es ist zu hoffen, dass bei einer Vielzahl von Erkrankungen wirksame immunologische Behandlungswege etabliert werden können.

\subsection{Palliativmedizin in der Onkologie}

Trotz bahnbrechender Entwicklungen in der Onkologie werden wir uns darauf einstellen müssen, dass auch in Zukunft zahlreiche Krebserkrankungen nicht effektiv und langanhaltend genug behandelt werden können und zum Tode des Patienten führen. Deshalb sind und bleiben die Weiterentwicklungen in der supportiven und palliativen Medizin für Patienten und deren Angehörige von so maßgeblicher Bedeutung. Es ist eine der wichtigsten Erkenntnisse in der Onkologie des vergangenen Jahrzehnts, dass eine frühzeitige Integration palliativer Behandlung in den onkologischen Behandlungsalltag zu einer Verbesserung der Symptomkontrolle, einer besseren Lebensqualität und wahrscheinlich sogar zu einem verbesserten Gesamtüberleben beiträgt (17). Es bleibt zu hoffen, dass infrastrukturell die Möglichkeiten geschaffen werden und genügend Ressourcen bereitgestellt werden, dass auch die palliative Perspektive, man möchte es fast eine Revolution in der Onkologie nennen, ihren Weg fortsetzen kann.

\subsection{Literatur}

(1) De Angelis R, Sant M, Coleman M P, et al. Cancer survival in Europe 1999-2007 by country and age: results of EUROCARE-5-a population-based study. Lancet Oncol 2014 Jan;15(1):23-34.

(2) Vogelstein B, Papadopoulos N, Velculescu V E, et al. Cancer genome landscapes. Science 2013;339:1546-58.

(3) Druker B J, Talpaz M, Resta D J, et al. Efficacy 1. and safety of a specific inhibitor of the BCR-ABL tyrosine kinase in chronic myeloid leukemia. N Engl J Med 2001;344:1031-7.

(4) Chapman PB, Hauschild A, Robert C, et al. Improved survival with vemurafenib in melanoma with BRAF V600E mutation. N Engl J Med 2011;364:2507-16.

(5) Lynch T J, Bell D W, Sordella R, et al. Activating mutations in the epidermal growth factor receptor underlying responsiveness of non-small-cell lung cancer to gefitinib. N Engl J Med 2004;350:2129-39. 
(6) Kwak E L, Bang Y J, Camidge D R, et al. Anaplastic lymphoma kinase inhibition in non-small-cell lung cancer. N Engl J Med 2010;363:1693-703.

(7) Niraula S, Seruga B, Ocana A, et al. The Price We Pay for Progress: A Meta-Analysis of Harms of Newly Approved Anticancer Drugs. J Clin Oncol 2012;30:3012-9.

(8) Solomon B J, Mok T, Kim D W, et al. First-line crizotinib versus chemotherapy in ALK-positive lung cancer. N Engl J Med. 2014 Dec 4;371(23):2167-77.

(9) Hanahan D, Weinberg R A. Hallmarks of cancer: the next generation. Cell. 2011 Mar 4;144(5):646-74.

(10) Galon J, Costes A, Sanchez-Cabo F, et al. Type, density, and location of immune cells within human colorectal tumors predict clinical outcome. Science. 2006 Sep 29;313(5795):1960-4.

(11) Hodi F S, O'Day S J, McDermott D F, et al. Improved survival with ipilimumab in patients with metastatic melanoma. N Engl J Med. 2010 Aug 19;363(8):711-23.

(12) Robert C, Long G V, Brady B, et al. Nivolumab in Previously Untreated Melanoma without BRAF Mutation. N Engl J Med. 2014 Nov 16. [Epub ahead of print]

(13) Topalian S L, Hodi F S, Brahmer J R, Gettinger S N, Smith D C, McDermott D F, Powderly J D, Carvajal R D, Sosman J A, Atkins M B, Leming P D, Spigel D R, Antonia S J, Horn L, Drake C G, Pardoll D M, Chen L, Sharfman W H, Anders R A, Taube J M, McMiller T L, Xu H, Korman A J, Jure-Kunkel M, Agrawal S, McDonald D, Kollia G D, Gupta A, Wigginton J M, Sznol M. Safety, activity, and immune correlates of anti-PD-1 antibody in cancer. $\mathrm{N}$ Engl J Med. 2012 Jun 28;366(26):2443-54.

(14) Brahmer J R, Tykodi S S, Chow L Q, et al. Safety and activity of antiPD-L1 antibody in patients with advanced cancer. N Engl J Med. 2012 Jun 28;366(26):2455-65.

(15) Maude S L, Frey N, Shaw P A, et al. Chimeric antigen receptor T cells for sustained remissions in leukemia. N Engl J Med. 2014 Oct 16;371(16):1507-17.

(16) Ledford H. Cancer treatment: The killer within. Nature. 2014 Apr 3;508(7494):24-6. 
(17) Temel J S, Greer J A, Muzikansky A, et al. Early palliative care for patients with metastatic non-small-cell lung cancer. N Engl J Med. 2010 Aug 19;363(8):733- 


\section{Autorenverzeichnis}

PD Dr. med. Bernd Alt-Epping

Universitätsmedizin Göttingen

Georg-August-Universität Göttingen

Robert-Koch-Str. 40

D-37075 Göttingen

E-Mail: bernd.alt-epping@med.uni-goettingen.de

+49-551-39170550

Prof. Dr. med. Stefan Delorme

Deutsches Krebsforschungszentrum

Im Neuenheimer Feld 280

D-69120 Heidelberg

E-Mail: s.delorme@dkfz.de

$+49-6221-422564$

Prof. Dr. med. Norbert Frickhofen

HELIOS Dr. Horst Schmidt Kliniken Wiesbaden

Klinik für Hämatologie, Onkologie und Palliativmedizin

Ludwig-Erhard-Str. 100

D-65199 Wiesbaden

E-Mail: norbert.frickhofen@helios-kliniken.de 
Dr. med. Stefan Fuxius

Onkologische Schwerpunktpraxis Heidelberg

Kurfürsten Anlage 34

D-69115 Heidelberg

E-Mail: stefanfuxius@gmx.de

$+49-6221-714990$

Prof. Dr. med. Uwe Haberkorn

Radiologische Universitätsklinik

Nuklearmedizin

Universität Heidelberg

Im Neuenheimer Feld 400

D-69120 Heidelberg

E-Mail: Uwe_Haberkorn@med.uni-heidelberg.de

$+49-6221-567731$

Prof. Dr. rer. medic. Uwe Haverkamp

Universitätsklinikum Münster

Klinik für Strahlentherapie - Radioonkologie

Albert-Schweitzer-Campus 1

D-48149 Münster

E-Mail: uwe.haverkamp@ukmuenster.de

$+49-251-8347384$

Bärbel Heise

Klinik für Hämatologie und Medizinische Onkologie

Universitätsmedizin Göttingen

Georg-August-Universität Göttingen

Robert-Koch-Str. 40

D-37075 Göttingen

$+49-551-394488$

PD Dr. med. habil. Christoph Kahl

Klinikum Magdeburg

Hämatologie / Onkologie

Birkenallee 34

D-39130 Magdeburg

E-Mail: christoph.kahl@klinikum-magdeburg.de

$+49-391-7915601$ 
Dr. med. Mathias Kleiß

Rotes Kreuz Krankenhaus Kassel

Klinik für interdisziplinäre Onkologie

Hansteinstraße 29

D-34121 Kassel

E-Mail: kleiss@rkh-kassel.de

+49-561-3086-74101

Dr. med. Marianne Kloke

Kliniken Essen-Mitte

Klinik für Palliativmedizin und

Institut für Palliative Care

Henricistr. 92

D-45136 Essen

E-Mail: M.Kloke@kliniken-essen-mitte.de

+49-201-17424302

Prof. Dr. med. Florian Lordick

Universitäres Krebszentrum Leipzig

Universitätsklinikum Leipzig

Liebigstr. 20

D-04103 Leipzig

E-Mail: direktion.ucc1@medizin.uni-leipzig.de

+49-341-9712560

Dr. med. Bernd Oliver Maier

St. Josefs-Hospital Wiesbaden

Palliativmedizin und Onkologie

Beethovenstraße 20

D-65189 Wiesbaden

E-Mail: bomaier@joho.de

+49-611-1773830

Dr. med. Sabine Mousset

Agaplesion Markus Krankenhaus

Interdisziplinäres Zentrum für Palliativmedizin

Wilhelm-Epstein-Str. 4

D-60431 Frankfurt am Main

E-Mail: sabine.mousset@fdk.info

+49-69-95334618 
PD Dr. med. Birgitt van Oorschot

UniversitätsklinikumWürzburg

Interdisziplinäres Zentrum Palliativmedizin

Josef-Schneider-Str. 11

D-97080 Würzburg

E-Mail: Oorschot-b@ukw.de

+49-931-20128857

Prof. Dr. med. Franz-Josef Prott

RNS Gemeinschaftspraxis Wiesbaden. Radiologie, Strahlentherapie

Beethovenstraße 20

D-65189 Wiesbaden

prof.prott@rns-wiesbaden.de

+49-611-565891500

Prof. Dr. med. habil. Konrad K. Richter FRACS

Consultant General Surgeon and Surgical Oncologist

Clinical Associate Professor University of Otago

Associate Dean Southland

Southland Hospital Invercargill, New Zealand

E-Mail: konradklaus.richter@gmail.com

Dr. med. Manuela Sauren

Uniklinik Köln

Medizinisches Versorgungszentrum

Kerpener Str. 62

D-50937 Köln

E-Mail: manuela.sauren@uk-koeln.de

+49-221-478-97449

PD Dr. med. Ulrich Wedding

Universitätsklinikum Jena

Klinik für Innere Medizin II, Abteilung Palliativmedizin

Erlanger Allee 101

D-07747 Jena

E-Mail: ulrich.wedding@med.uni-jena.de

+49-3641-9392201 
PD Dr. med. Dr. phil. Eva C. Winkler

Universitätsklinikum Heidelberg

Nationales Centrum für Tumorerkrankungen

Im Neuenheimer Feld 460

D-69120 Heidelberg

E-Mail: eva.winkler@med.uni-heidelberg.de

+49-6221-56-36049

Dipl.-Psych. Dipl.-Biol. Stefan Zettl

Schwerpunktpraxis für Psychoonkologie

Bliesweg 10

D-69126 Heidelberg

E-Mail: s.zett1@t-online.de

+49-6221-372746 
ber $90 \%$ der in der spezialisierten Palliativversorgung betreuten Patienten leiden an einer Krebserkrankung. Sowohl der Impuls einer frühzeitigen, bedürfnisorientierten palliativmedizinischen Mitbehandlung als auch die erheblichen Weiterentwicklungen einer (zunehmend molekular definierten) Onkologie erfordern, dass auch die in der Palliativversorgung Tätigen ein Grundverständnis von Tumorbiologie, von modernen onkologischen Therapiekonzepten und von supportivtherapeutischen Möglichkeiten haben. Dieses Buch möchte dieses Grundverständnis von Krebs und onkologischer Behandlung in einer auch für NichtOnkologen verständlichen Form vermitteln und richtet sich vor allem an jene, die in der palliativmedizinischen Betreuung krebskranker Menschen involviert sind: Palliativärzte, Palliativpflegende, aber auch Haus- und Fachärzte, Physiotherapeuten, Seelsorger, Psychotherapeuten und viele mehr. Es will kein Lehrbuch der Onkologie ersetzen, sondern eine praxisorientierte, therapie- und versorgungsrelevante Hilfestellung im (palliativ-)medizinischen Arbeitsalltag sein - dort, wo es um eine umfassende Unterstützung von Krebspatienten geht.

Das Buch ist ein Projekt der „AG Interdisziplinäre Onkologie“ der Deutschen Gesellschaft für Palliativmedizin (DGP). 